\title{
DESENVOLVIMENTO DE UMA METODOLOGIA DE FABRICAÇÃO DE TRANSISTORES DE FILMES FINOS ORGÂNICOS
}

\author{
Dissertação apresentada à Escola \\ Politécnica da Universidade de \\ São Paulo para obtenção do \\ Título de Mestre em Engenharia
}

São Paulo 


\title{
DESENVOLVIMENTO DE UMA METODOLOGIA DE FABRICAÇÃO DE TRANSISTORES DE FILMES FINOS ORGÂNICOS
}

\author{
Dissertação apresentada à Escola \\ Politécnica da Universidade de \\ São Paulo para obtenção do \\ Título de Mestre em Engenharia \\ Área de Concentração: \\ Engenharia Elétrica \\ Orientador:
}

Prof. Dr. Fernando Josepetti Fonseca

São Paulo 
Este exemplar foi revisado e alterado em relação à versão original, sob responsabilidade única do autor e com a anuência de seu orientador.

São Paulo, 19 de março de 2010.

Assinatura do autor mave Rulato Carlhew

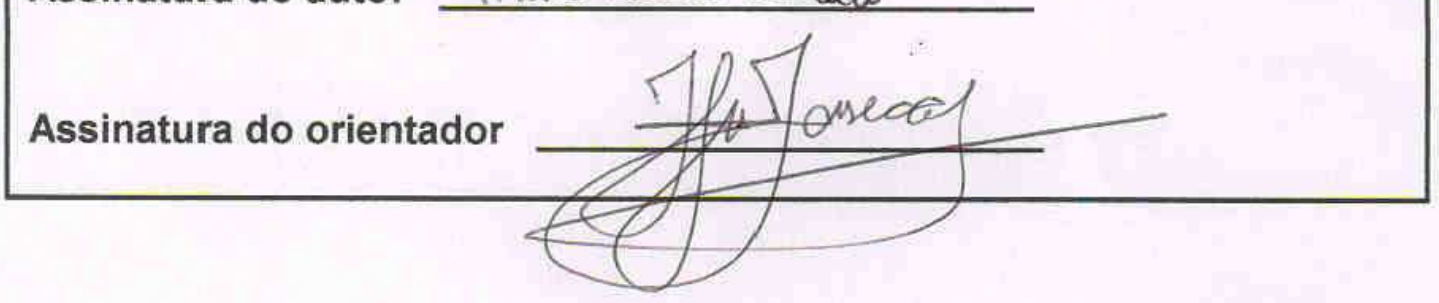

FICHA CATALOGRÁFICA

Cavallari, Marco Roberto

Desenvolvimento de uma metodologia de fabricação de transistores de filmes finos orgânicos / M.R. Cavallari. -- ed.rev. -- São Paulo, 2010.

$129 \mathrm{p}$.

Dissertação (Mestrado) - Escola Politécnica da Universidade de São Paulo. Departamento de Engenharia de Sistemas Eletrônicos.

1. semicondutores 2. Transistores 3. Células solares 4. Processos de fabricação I. Universidade de São Paulo. Escola Politécnica. Departamento de Engenharia de Sistemas Eletrônicos II. $t$. 
Aos meus leitores, que este trabalho lhes seja de grande auxílio em suas buscas. 


\section{AGRADECIMENTOS}

Em primeiro lugar, agradeço ao Prof. Dr. Fernando Josepetti Fonseca, meu orientador neste trabalho, pela oportunidade de realizar uma parte das atividades científicas na Fondazione Bruno Kessler em Trento, Itália, e pelas diversas colaborações que mantém com grupos de pesquisa nacionais e internacionais responsáveis pelo enriquecimento científico do trabalho aqui apresentado. Agradeço a oportunidade de fazer parte do Grupo de Eletrônica Molecular (GEM) do Departamento de Engenharia de Sistemas Eletrônicos (PSI, Escola Politécnica da Universidade de São Paulo).

Aos Prof. Dr. Lorenzo Pavesi, co-diretor do Master in Nano and Micro Electromechanical Systems (NEMS/MEMS) da FBK/Università degli Studi di Trento, Dr. Mario Zen, co-diretor do Master NEMS/MEMS, Tatsiana Yatskevich, assistente do Laboratorio di Nanoscienze do Departamento de Física da Università degli Studi di Trento e secretária do Master, Dr. Paolo Gregori, vice-presidente do Technology Transfer Office (FBK), Dr. Pierluigi Bellutti, chefe do Micro Technologies Laboratory (MTLab-FBK), e Dr. Georg Pucker, chefe do grupo Advanced Photonics and Photovoltaics $(A P P-F B K)$, pelo suporte dado à atividade em células solares. Assim como aos Doutores Yoann Jestin e Christine Marie Cuppoletti dentro do grupo APP. Aos funcionários do MTLab: Maurizio Boscardin, coordenador do Micro Fabrication Lab (MFLab) e representando aqui a sala limpa e seus funcionários; Vittorio Zanini, coordenator do Microsystems Integration Lab (MILab) e responsável pela fabricação das máscaras mecânicas; enfim, Amos Collini, coordenador do Testing Lab (TLab), responsável por programas em LabVIEWTM e montagens para caracterização de dispositivos orgânicos.

Aos colaboradores Dra. Katia F. Albertin e Carlos A. S. Ramos pela deposição de óxido de nitreto de silício por PECVD e óxido de silício térmico, respectivamente. Aos colaboradores Mestrando Cleber A. de Amorim e Prof. Dr. Sérgio Mergulhão do 
Laboratório de Semicondutores do Departamento de Física da Universidade Federal de São Carlos, pela caracterização da mobilidade em semicondutores orgânicos.

Aos Professores Roberto M. Faria (Instituto de Física de São Carlos, USP), Dario Natali e Marco Sampietro (Politecnico di Milano, Itália) pelas interessantes discussões ao decorrer de seus cursos em eletrônica orgânica. Ao Prof. Luiz F. R. Pereira pelo apoio científico dado ao GEM-EPUSP e a sua palestra realizada em 2008 no LME-EPUSP.

Agradeço à contribuição direta do Prof. Dr. Adnei Melges de Andrade - Instituto de Eletrotécnica e Energia, USP - devido a seu conhecimento prévio em dispositivos eletrônicos tais como células solares e transistores de filmes finos, assim como sua contribuição prestada ao grupo GEM como um todo e à formação e estabelecimento do laboratório de microeletrônica (LME-EPUSP).

Aos colegas do GEM Gerson dos Santos, Emerson R. Santos, Elvo Burini Jr, Leonardo Paterno, Guilherme Braga, John Paul H. Lima, Helena Gimaiel, Alexandre Nardes, Nadja Wiziack, Camila Gregorut, Sergio Ozaki, Diego Aparecido, Alex Chen e Daniela Diodato, pelo companheirismo e colaboração no trabalho científico cotidiano.

Ao Prof. Dr. Roberto K. Onmori pela contribuição com seu trabalho de doutorado, essencial para a implementação de transistores orgânicos na Escola Politécnica, e participação em discussões científicas no tema.

Aos técnicos da sala limpa e da sala de medidas do LME-EPUSP pelo auxílio na fabricação e caracterização dos transistores de filmes finos orgânicos.

À Fundação de Amparo a Pesquisa do Estado de São Paulo (Processo FAPESP $\mathrm{n}^{\mathrm{o}}$ 2007/06064-0) e ao CNPq pelo suporte financeiro à atividade desenvolvida no Brasil e à $F B K$ e a companhia multinacional Diatec (colaboradora do grupo $A P P$ ) pelo suporte financeiro à atividade desenvolvida na Itália.

Enfim, deixo estas últimas linhas para agradecer a meus queridos pais, Pedro Lopes Cavallari e Ivone Mainente Cavallari, meu irmão Victor Hugo Cavallari, minha irmã Thais Adriana Cavallari e minha companheira Camila M. Longo Machado. Obrigado por acreditar em minhas capacidades, reconhecer a minha dedicação e estar ao meu lado em todos os momentos. 


\section{RESUMO}

Neste trabalho, é apresentada uma metodologia de fabricação de transistores de filmes finos orgânicos. Foram fabricadas células solares de heterojunção de poli(3hexiltiofeno) (P3HT) e [6,6]-fenil-C61-butirato de metila (PCBM) por apresentarem máxima conversão de potência $(P C E)$ de cerca $5 \%$. Partindo de rendimentos de $10^{-6}$ até atingir $1,7 \%$, são mostradas as dificuldades no processamento de filmes orgânicos e na caracterização destes dispositivos. Destacam-se dentre outros, a importância da geometria dos eletrodos, da preparação da solução de blendas orgânicas e dos cuidados na utilização de substratos flexíveis (e.g. polietileno tereftalato - PET). A estrutura empregada é composta por vidro, óxido de índio dopado com estanho (ITO), poli(3,4etilenodioxitiofeno) complexado com poli(ácido estireno-sulfônico) (PEDOT:PSS), P3HT:PCBM, fluoreto de lítio $(\mathrm{LiF})$ e alumínio. PET coberto por $\operatorname{In}_{2} \mathrm{O}_{3} / \mathrm{Au} / \mathrm{Ag}$ em substituição ao vidro-ITO é utilizado devido à busca da indústria eletrônica por materiais alternativos de baixo custo. Estrutura semelhante é empregada para caracterização da mobilidade dos portadores de carga em filmes orgânicos. Técnicas tais como Time of Flight (ToF), Charge Extraction in Linearly Increasing Voltage (CELIV), além da interpretação de curvas estacionárias de densidade de corrente por tensão $(J x V)$ foram empregadas para estudo de derivados de poli(para-fenileno vinileno) (PPV). Foram obtidas mobilidades de $10^{-8}-10^{-6} \mathrm{~cm}^{2} /$ Vs para modelos de corrente limitada por carga espacial (SCLC) com armadilhas rasas e profundas. Mobilidades de efeito de campo caracterizadas em TFTs bottom gate bottom contact com porta comum são pelo menos duas ordens de grandeza superiores às obtidas através das técnicas anteriormente citadas. Foram utilizados diversos substratos (e.g. silício monocristalino e vidro-ITO), dielétricos (e.g. oxinitreto de silício $\left(\mathrm{SiO}_{\mathrm{x}} \mathrm{N}_{\mathrm{y}}\right)$ por $P E C V D$ e $\mathrm{SiO}_{2}$ térmico), tratamentos de superfície (e.g. vapor de hexametildissilazana - HMDS), semicondutores (derivados de PPV, P3HT, pentaceno) e eletrodos (e.g. camada de aderência de titânio). Definiu-se assim uma metodologia de seleção de novos semicondutores orgânicos para a indústria eletrônica. 


\section{ABSTRACT}

In this work, it is presented a methodology for organic thin-film transistor (OTFT) fabrication. Poly(3-hexylthyophene) (P3HT):[6,6]-phenyl-C61-butyric acidmethyl ester (PCBM) bulk heterojunction solar cells were studied for their maximum power conversion efficiency $(P C E)$ around $5 \%$. Efficiencies evolution in time from $10^{-6}$ to $1.7 \%$ show the difficulties involved in organic thin-film processing and device characterization. It is of remarkable importance the electrodes geometry, the organic blend solution preparation and the extra-care while processing on flexible substrates (e.g. polyethylene terephthalate - PET). Devices are composed of indium tin oxide covered glass, poly(3,4-ethylenedioxythiophene) doped with poly(styrene sulfonic acid) (PEDOT:PSS), P3HT:PCBM active layer, lithium fluoride (LiF) and aluminum. PET covered with $\mathrm{In}_{2} \mathrm{O}_{3} / \mathrm{Au} / \mathrm{Ag}$ substituting glass-ITO was employed due to the electronic industry research for low cost alternative materials. Similar structure is used for charge carrier mobility characterization. Techniques such as Time of Flight (ToF), Charge Extraction in Linearly Increasing Voltage (CELIV), and charge transport modeling of current density $v s$. voltage $(J x V)$ stationary curves were applied on semiconductors like poly(para-phenylene vinylene) (PPV) derivatives. Mobilities around $10^{-8}-10^{-6} \mathrm{~cm}^{2} / \mathrm{Vs}$ for space charge limited current (SCLC) with shallow and deep traps were obtained. Field effect mobilities characterized in bottom gate bottom contact TFTs with common gate are at least two orders higher than previous values. During this work, it was tested different substrates (e.g. monocrystalline silicon and glass-ITO), insulators (e.g. PECVD silicon oxynitride and thermal $\mathrm{SiO}_{2}$ ), surface treatments (e.g. hexamethyldisilazane vapor), semiconductors (PPV derivatives, P3HT, pentacene) and electrodes (e.g. titanium adhesion layer). It was defined that way a methodology of new semiconducting material selection for the electronic industry. 


\section{SUMÁRIO}

\section{LISTA DE FIGURAS}

LISTA DE TABELAS

LISTA DE ABREVIATURAS E SIGLAS

LISTA DE SÍMBOLOS

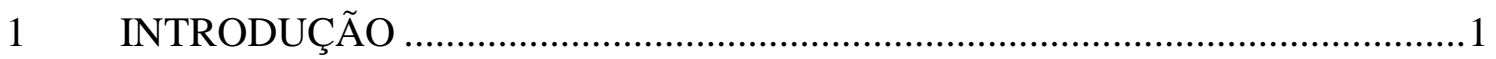

1.1 Materiais orgânicos para a eletrônica: de isolantes a condutores ........................1

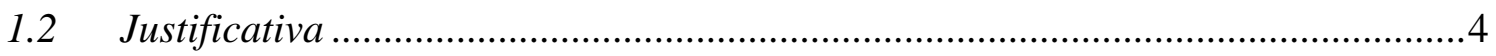

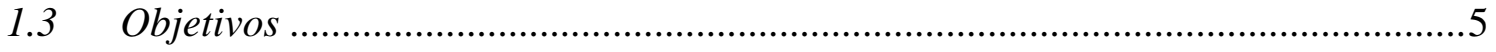

2 REVISÃO BIBLIOGRÁFICA ………………...........................................

2.1 Técnicas de caracterização da mobilidade dos portadores de carga .....................7

2.1.1 Tempo de Vôo com excitação óptica (Time of Flight, ToF) ....................................7

2.1.2 Charge Extraction in Linearly Increasing Voltage (CELIV) ..................................8

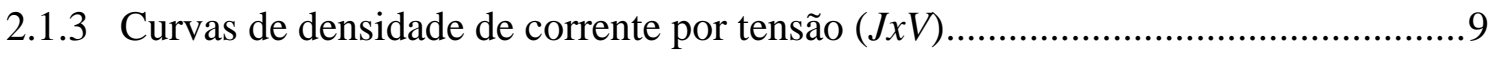

2.2 Células solares orgânicas de heterojunção ........................................................11

2.2.1 Princípios fundamentais e principais parâmetros.......................................................11

2.2.2 Estratégias para aumentar a eficiência na conversão de potência.............................18

2.3 Transistores de filmes finos orgânicos..............................................................24

2.3.1 Técnicas de formação de filmes orgânicos ............................................................26

2.3.2 Modelagem das curvas características dos OTFTs ................................................2

2.3.3 Mobilidade de efeito de campo no FET ……………………...........................36

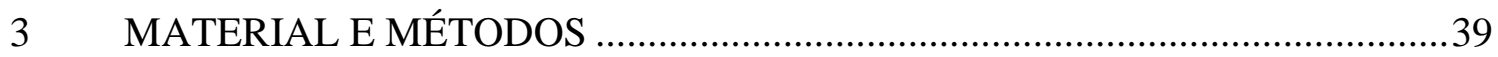

3.1 Estudo dos processos de fabricação de dispositivos orgânicos através de células

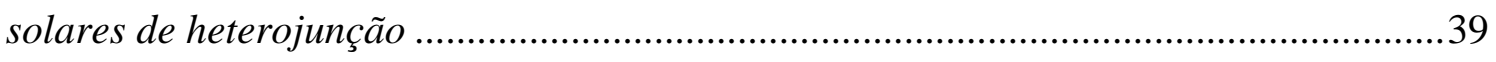

3.1.1 Fabricação de células solares orgânicas ...................................................................

3.1.2 Caracterização dos dispositivos orgânicos fabricados .............................................41 
3.1.3 Extração dos principais parâmetros

3.2 Determinação da mobilidade de portadores em semicondutores orgânicos comerciais

3.3 Estudo dos processos envolvidos na fabricação de TFTs orgânicos e sua aplicação

3.3.1 Fabricação de TFTs orgânicos

3.3.2 Caracterização dos transistores orgânicos fabricados

3.3.3 Extração dos principais parâmetros e análise dos resultados .53

4 RESULTADOS .55

4.1 Células Solares Orgânicas. .55

4.1.1 Definição dos eletrodos .55

4.1.2 Tempo de secagem do PEDOT:PSS .57

4.1.3 Primeiros estudos em substratos flexíveis: corrosão, limpeza e tempos de secagem .58

4.1.4 Efeitos de tratamentos térmicos ao substrato de PET-CT. 60

4.1.5 Recozimento final (Post-Production Thermal Treatment) 61

4.1.6 Preparação da solução de P3HT:PCBM em diclorobenzeno .63

4.1.7 Panorama geral da evolução na eficiência de conversão de potência $(P C E)$.......64

4.2 As diferentes técnicas para caracterização da mobilidade e aplicação em semicondutores comerciais .66

4.2.1 Tempo de Vôo com excitação óptica (Time of Flight, ToF) 66

4.2.2 Charge Extraction in Linearly Increasing Voltage (CELIV) .69

4.2.3 Curvas de densidade de corrente por tensão $(J x V)$. 71

4.3 Transistores de Filmes Finos de MDMO-PPV .73

4.3.1 Dielétricos e substratos estudados através de mobilidade constante .73

4.3.2 Mobilidade dependente da tensão de porta $-\mu=f\left(V_{\mathrm{GS}}\right)$ .80

4.4 TFTs de MEH-PPV.

4.5 TFTs de P3HT.... .87

4.6 TFTs de pentaceno .89

5 DISCUSSÃO .96 
5.1 Estudo da fabricação de dispositivos orgânicos através de células solares ........96

5.2 Aplicação de oxinitreto de silício $\left(\mathrm{SiO}_{x} \mathrm{~N}_{y}\right)$ e eletrodos de ITO em transistores de filmes finos orgânicos .100

5.3 Definição de uma metodologia de seleção de novos semicondutores para

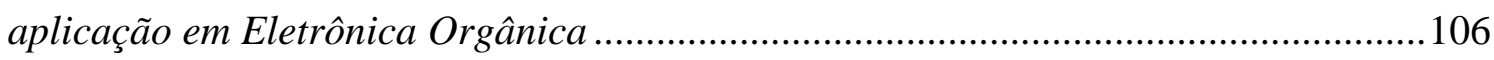

5.3.1 Tempo de Vôo com excitação óptica (Time of Flight, ToF).............................106

5.3.2 Charge Extraction in Linearly Increasing Voltage (CELIV) ............................108

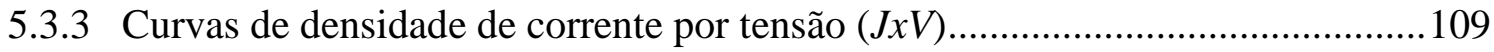

5.3.4 Transistores de Filmes Finos Orgânicos ..........................................................110

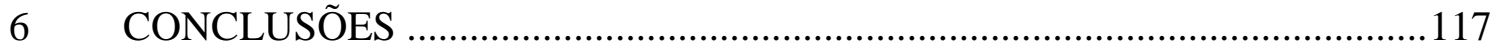

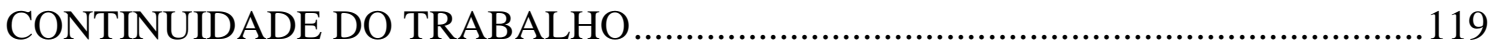

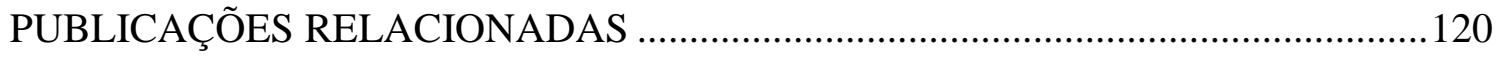

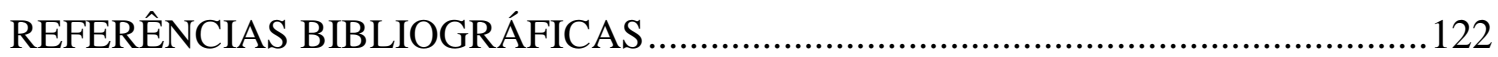




\section{LISTA DE FIGURAS}

Figura 1.1 - (a) Hibridização sp² do carbono na molécula de etileno; (b) Diagrama de bandas para os semicondutores orgânicos com alternância entre ligações simples e duplas; Estes materiais podem ser divididos em pequenas moléculas (e.g. (c) pentaceno, (d) fulereno) e polímeros (e.g. (e) poliacetileno, (f) politiofeno)

Figura 1.2 - Indústrias que despontam no mercado de dispositivos orgânicos: Konarka (células solares), PlasticLogic, Samsung, Sony (TV de OLEDs), PolyId (etiquetas de RFID). 4

Figura 2.1 - (a) Densidade de corrente do diodo versus potencial entre seus eletrodos $(J x V)$ deslocada para baixo quando iluminada por $100 \mathrm{~mW} / \mathrm{cm}^{2}$ de luz solar (AM1,5G).

(b) Gráfico destacando na região fotovoltaica o ponto de máxima potência elétrica ( $V_{\mathrm{mp}}$, $\left.J_{\mathrm{mp}}\right)$. Este corresponde ao máximo de conversão de energia solar em energia elétrica (adaptado da referência [37]). (c) Representação por circuito equivalente de uma célula solar orgânica (adaptado da referência [38]). 13

Figura 2.2 - Ilustração esquemática de uma célula solar: a luz solar atravessa o substrato de vidro sendo absorvida na camada ativa; a corrente elétrica gerada é fornecida a uma resistência conectada entre o ânodo de ITO e ao cátodo de Al 16

Figura 2.3 - Esquema ilustrativo da geração de corrente em uma célula solar de heterojunção de polímero:fulereno. Detalhes dos processos a) a f) e os mecanismos de perda 1) a 3) são apresentados no texto. Adaptado da referência [45].

Figura 2.4 - (a) Fluxo de fótons do sol (AM1,5G) em função do comprimento de onda. A integral da curva é representada em vermelho como o percentual de fótons do total irradiado e a densidade de corrente máxima que seria obtida a partir da absorção destes fótons. (b) Alinhamento dos níveis de energia em uma heterojunção de polímero de pequeno bandgap ( $L B G)$ e PCBM. O intervalo aceitável de energia para o HOMO do doador está sombreado. Adaptado da referência [48]. 
Figura 2.5 - (a) Representação esquemática da distribuição espacial do quadrado do campo elétrico irradiado $|\mathrm{E}|^{2}$ internamente à célula solar com e sem espaçador óptico. (b) Ilustração da estrutura do dispositivo e dos processos envolvidos na preparação da camada de $\mathrm{TiO}_{\mathrm{x}}$. $\mathrm{O}$ diagrama de energia da célula fotovoltaica é mostrado abaixo. Adaptado da referência [55]

Figura 2.6 - (a) Estrutura do dispositivo (direita) e imagem de seção transversal obtida por microscopia eletrônica de transmissão (esquerda) da célula polimérica tandem. Barras de escala: $100 \mathrm{~nm}$ (imagem inferior) e $20 \mathrm{~nm}$ (imagem superior). (b) Diagrama de níveis de energia mostrando os níveis HOMO e LUMO de cada componente. (c) Espectro IPCE das células individuais e da tandem com iluminação bias. (d) Característica $J x V$ das células individuais e da tandem sob iluminação AM1,5G de um simulador solar calibrado a $100 \mathrm{~mW} / \mathrm{cm}^{2}$. Adaptado da referência [56].

Figura 2.7 - Esquema com transistores de filmes finos orgânicos bottom-gate (a) topcontact (staggered) ou (b) bottom-contact (coplanar). Diagrama esquemático de estruturas de OTFT top-gate (c) bottom-contact e (d) top-contact. Adaptado da referência [65]..... .26

Figura 2.8 - Perfil dos diversos tipos de transistores $M O S$ e sua respectiva simbologia: (a) e (b) p-MOSFET tipo enriquecimento; (c) e (d) p-MOSFET tipo depleção. Adaptado da referência [79] .28

Figura 2.9 - Principais regimes de operação do p-OTFT: (a) linear e (b) saturação. .......30 Figura 2.10 - Curvas características de TFTs de pentaceno: (a) $I_{\mathrm{D}} v s . V_{\mathrm{DS}}$ de um dispositivo em substrato de policarbonato (adaptado da referência [77]); (b) $I_{\mathrm{D}}{ }^{1 / 2} v s . V_{\mathrm{GS}}$ e $\log _{10}\left(I_{\mathrm{D}}\right)$ vs. $V_{\mathrm{GS}}$ de um TFT com isolante $\operatorname{Mylar}^{\mathrm{TM}}(900 \mathrm{~nm})$ substituindo o substrato (adaptado da referência [78]). .32

Figura 2.11 - Comparação entre as trans-características $\log _{10}\left(I_{\mathrm{D}}\right) v s$. $V_{\mathrm{GS}}$ de um TFT de MDMO-PPV com porta não litografada (linhas tracejadas) e litografada (linhas sólidas). Adaptado da referência [82] .33 
Figura 2.12 - Regioregularidade em poli(3-hexiltiofenos). Adaptado da referência [71].

Figura 3.1 - (a) Estrutura da célula solar orgânica de heterojunção. (b) Materiais orgânicos empregados nas células solares fabricadas.

Figura 3.2 - (a) Instalação da FBK em Trento; (b) Planta da sala limpa situada no subsolo.

Figura 3.3 - (a) Esquema ilustrativo das diversas etapas de fabricação dos dispositivos fotovoltaicos.

Figura 3.4 - (a) Sistema de caracterização de células solares utilizando o simulador solar ABET Sun 2000. (b) As conexões aos eletrodos foram realizadas através de conectores do tipo "jacaré” em um sistema a quatro pontas. (c) Interface LabVIEW"M utilizada para medições com o simulador solar do TLab-FBK

Figura 3.5 - Sistema de caracterização de células solares alternativo para estudos preliminares com um micromanipulador e uma lâmpada de xenônio.

Figura 3.6 - Gráfico ilustrativo de como extrair os principais parâmetros de uma célula solar a partir de suas curvas $J x V$ e $P x V$.

Figura 3.7 - Equipamentos utilizados na UFSCar para caracterização de filmes finos. 47

Figura 3.8 - Estrutura modelo para fabricação do OTFT

Figura 3.9 - Esquema ilustrativo de como calcular o ângulo de contato $\theta$ de uma gota d'água sobre um dielétrico de porta. Adaptado da referência [102]. .50

Figura 3.10 - Capacitores MOS: (a) micrografo ótico dos dispositivos; (b) sistema de caracterização.

Figura 3.11 - Máscaras utilizadas para definição de eletrodos de fonte e dreno: (a) interdigitados em amostra de $1 \times 1$ pol $^{2}$ de MDMO-PPV sobre $\mathrm{p}+\mathrm{Si}_{-}-\mathrm{SiO}_{\mathrm{x}} \mathrm{N}_{\mathrm{y}}(268 \mathrm{~nm})$; (b) eletrodos paralelos em amostra de $1 \times 1 \mathrm{~cm}^{2}$ de MEH-PPV sobre $\mathrm{p}+\mathrm{Si}_{-}-\mathrm{SiO}_{2}(274 \mathrm{~nm})$ tratado com HMDS. 
Figura 3.12 - Sistema de caracterização de OTFTs: (a) micromanipulador e analisador de parâmetros; (b) contato de porta $(G)$ através do suporte metálico; (c) contatos de fonte $(S)$ e dreno $(D)$ através de micropontas de ouro

Figura 3.13 - Gráfico ilustrativo do método empregado para calcular a mobilidade $\left(\mu_{h}\right)$ na saturação, a tensão de limiar $\left(V_{T}\right)$, a inclinação de sublimiar $(S)$ e a modulação de corrente $\left(I_{O N / O F F}\right)$. Curva extraída para TFT de MDMO-PPV em substrato de p+$\mathrm{Si} / \mathrm{SiO}_{\mathrm{x}} \mathrm{N}_{\mathrm{y}}(279 \mathrm{~nm})$

Figura 4.1 - (a) Curva da corrente vs. tensão elétrica de CSO em vidro com contato circular de Al; (b) Substituindo a máscara mecânica do cátodo por outra de formato retangular, o $P C E$ foi aumentado 280 vezes (dimensões da amostra comparáveis às de uma moeda de $1 €)$.

Figura 4.2 - Máscara mecânica desenvolvida com o Laboratório de Integração de Microsistemas (MILab-FBK) para deposição do cátodo. .57

Figura 4.3 - Pontos claros na superfície do Al observados após o tratamento térmico final de amostras em vidro. Acredita-se que estas regiões brilhantes eram devidas a bolhas de solvente remanescentes de uma secagem incompleta .58

Figura 4.4 - Underetching do eletrodo de $\mathrm{In}_{2} \mathrm{O}_{3} / \mathrm{Au} / \mathrm{Ag}$ em substrato flexível de PET. .60 Figura 4.5 - Resistência de folha monitorada no tempo para quatro resistores diferentes em um mesmo substrato de PET para diferentes patamares de temperatura (intervalo: da temperatura ambiente até $200{ }^{\circ} \mathrm{C}$ ). $\mathrm{O}$ material condutor é um multicamada $\mathrm{In}_{2} \mathrm{O}_{3} / \mathrm{Au} / \mathrm{Ag}$ da Delta Tech.

Figura 4.6 - Degradação no tempo de células solares de heterojunção de rr-P3HT:PCBM em substratos de (a) vidro e (b) PET

Figura 4.7 - Comparação entre células solares na mesma amostra tratadas diferentemente após a deposição do cátodo: $120{ }^{\circ} \mathrm{C}$ por 10 min com (legenda $\mathrm{A}+\mathrm{V}$ ) e sem (A) a aplicação de uma tensão de 1,5 V entre os eletrodos das células. 
Figura 4.8 - Evolução de PCE no tempo de CSOs de P3HT:PCBM em substratos de vidro (símbolos fechados) e PET (símbolos abertos). Os dados são apresentados antes (diamantes) e após (pirâmides) o recozimento final.

Figura 4.9 - Densidade de corrente versus potencial para uma célula solar flexível e de alta eficiência no escuro até sob iluminação de $101,3 \mathrm{~mW} / \mathrm{cm}^{2}$ de luz branca: (a) região fotovoltaica; (b) varredura completa de -1 a $1 \mathrm{~V}$ do logaritmo da densidade de corrente.

Figura 4.10 - Espectrofotometria de filmes finos de derivados de PPV: (a) espectro de absorção; (b) transmitância calculada a partir do coeficiente de atenuação $(\alpha)$ obtido da curva de $O D v s . \lambda$

Figura 4.11 - Transientes de corrente ToF dispersivos em amostra de MDMO-PPV extraídos à partir da tensão em um resistor série.

Figura 4.12 - Gráficos da (a) tempo de trânsito $\left(t_{\text {tr }}\right)$ e (b) mobilidade $(\mu)$ de elétrons e lacunas obtidos para diversas espessuras do polímero MDMO-PPV em amostras de ITO/MDMO-PPV/Al. .68

Figura 4.13 - (a) Mobilidade $(\mu)$ e tempo de trânsito $\left(t_{\mathrm{tr}}\right)$ de lacunas obtidos para $460 \mathrm{~nm}$ de MEH-PPV. (b) Diagrama de energia das estruturas empregadas para estudo da mobilidade por ToF.

Figura 4.14 - Transientes de corrente photo-CELIV em amostras de (a) MDMO-PPV e (b) MEH-PPV extraídos à partir da tensão em um resistor série.

Figura 4.15 - Mobilidade de lacunas $(\mu)$ e condutividade $(\sigma)$ calculadas considerando o material polimérico com distribuição exponencial de armadilhas. 70

Figura 4.16 - Condução SCLC com um nível energético de armadilhas rasas para MDMO-PPV. .71

Figura 4.17 - Condução SCLC com distribuição exponencial de armadilhas profundas para MDMO-PPV.

Figura 4.18 - Gráfico de corrente por tensão para ITO/PEDOT:PSS/MEH-PPV/Al. ....73 
Figura 4.19 - Espectroscopia FTIR para filmes de $\mathrm{SiO}_{2}$ térmico e $\mathrm{SiO}_{\mathrm{x}} \mathrm{N}_{\mathrm{y}}$ por PECVD.75 Figura $4.20-I_{\mathrm{D}} v s . V_{\mathrm{DS}}$ e $I_{\mathrm{D}} v s . V_{\mathrm{GS}}$ para $T F T s$ de MDMO-PPV sobre (a) $\mathrm{p}+-\mathrm{Si} / \mathrm{SiO}_{2}$, (b)

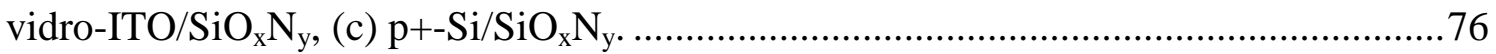

Figura 4.21 - Ausência de saturação em OTFTs de MDMO-PPV em vidro-ITO/ $\mathrm{SiO}_{\mathrm{x}} \mathrm{N}_{\mathrm{y}}$.

Figura 4.22 - Variação de $\mu_{\mathrm{h}}$ com a espessura de $\mathrm{SiO}_{2}$ e $\mathrm{SiO}_{\mathrm{x}} \mathrm{N}_{\mathrm{y}}$ (Dimensões do canal: $\left.\mathrm{W}_{\mathrm{M}}=1.1 \mathrm{~mm} \mathrm{e} \mathrm{L}_{\mathrm{M}}=10 \mu \mathrm{m}\right)$. .78

Figura 4.23 - Variação de $\mu_{\mathrm{h}}$ com o comprimento do canal para OTFTs de MDMO-PPV com (a) $\mathrm{SiO}_{2}$ e (b) $\mathrm{SiO}_{\mathrm{x}} \mathrm{N}_{\mathrm{y}}$ em substrato de p+-Si. .78

Figura 4.24 - Inclinação de sublimiar versus comprimento do canal para OTFTs de MDMO-PPV com $\mathrm{SiO}_{2}$ e $\mathrm{SiO}_{\mathrm{x}} \mathrm{N}_{\mathrm{y}}$ em substrato de p+-Si.

Figura 4.25 - Imagens das gotas d'água sobre $\mathrm{SiO}_{2}$ após diferentes tratamentos: (a) limpeza em solventes orgânicos; (b) 10 min de plasma de $\mathrm{O}_{2}$; e (c) 30 min de exposição ao vapor de HMDS

Figura 4.26 - Resultados obtidos para TFTs de MDMO-PPV em $\mathrm{SiO}_{\mathrm{x}} \mathrm{N}_{\mathrm{y}}$ com $W_{\mathrm{M}}=1,1$ $\mathrm{mm}$ e $L_{\mathrm{M}}=10 \mu \mathrm{m}$ operando em regime de saturação $\left(V_{\mathrm{DS}}=-40 \mathrm{~V}\right.$ ): (a) dados experimentais de $I_{\mathrm{D}}$ vs. $V_{\mathrm{GS}}$ para $\mathrm{p}+-\mathrm{Si}_{\mathrm{SiO}} \mathrm{Si}_{\mathrm{y}}(279 \mathrm{~nm})$ e aproximação por dois métodos diferentes. (b) Dependência da mobilidade com $V_{\text {OV }}$ para dispositivos em p+-Si (quadrados), e ITO (pirâmides). Parâmetros da Tabela 4.6.

Figura 4.27 - Mobilidade de lacunas em função do campo elétrico longitudinal médio em TFTs de MDMO-PPV sobre ambos os dielétricos. A linha tracejada são aproximações segundo a Equação (26).

Figura 4.28 - Curvas características de um TFT de MEH-PPV sobre p+-Si/ $\mathrm{SiO}_{2}$ .84 Figura 4.29 - Mobilidade de lacunas em função do campo elétrico longitudinal médio em TFTs de MEH-PPV sobre p+-Si/SiO 2 . A linha tracejada é a curva aproximada segundo a Equação (26). 
Figura 4.30 - Dependência da mobilidade com a tensão de overdrive para TFTs de MEH-PPV sobre p+-Si/SiO ${ }_{2}$ em saturação (parâmetros extraídos da Tabela 4.11)........87

Figura 4.31 - Curvas características de um TFT de P3HT sobre $\mathrm{p}+-\mathrm{Si} / \mathrm{SiO}_{2} \ldots \ldots \ldots \ldots \ldots . . . . . . .88$

Figura 4.32 - Mobilidade de lacunas em função do campo elétrico longitudinal médio em TFTs de P3HT sobre p+-Si/SiO 2 . A linha tracejada é a curva aproximada segundo a Equação (26).

Figura 4.33 - Curvas características de um TFT de pentaceno sobre p+-Si/ $\mathrm{SiO}_{2}$. .........90

Figura 4.34 - Estudo por linha de transmissão da resistência série $\left(R_{\mathrm{S}}\right)$ em TFTs de pentaceno sobre p+-Si/SiO 2 : (a) mobilidade de lacunas $\left(\mu_{h}\right)$ sem considerar efeitos de resistência séries vs. comprimento de canal (L); (b) resistência total em regime linear multiplicada pela largura do canal $\left(R_{\mathrm{ON}} W\right)$ vs. $L$; (c) condutância de folha do canal

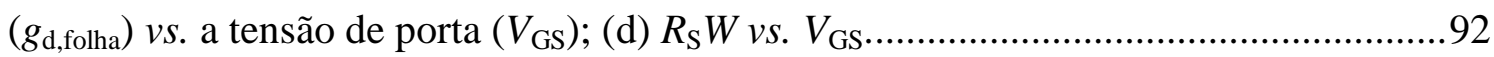

Figura 4.35 - Aplicação do método diferencial considerando $\mathrm{R}_{\mathrm{S}}$ constante em TFTs de pentaceno sobre p+-Si/SiO 2 : (a) $z$ vs. $V_{\mathrm{GS}}$; (b) $w$ vs. $V_{\mathrm{GS}}$; (c) $R_{\mathrm{S}} v s . V_{\mathrm{GS}}$ 95 


\section{LISTA DE TABELAS}

Tabela 3.1 - Materiais orgânicos cuja mobilidade de seus portadores foi investigada neste trabalho.

Tabela 3.2 - Dimensões do canal segundo as máscaras fotolitográficas utilizadas

Tabela 4.1 - Melhores resultados em cada tipo de substrato a 1 sol AM1,5G com ABET Sun 2000.

Tabela 4.2 - Principais parâmetros extraídos de capacitores MOS empregando $\mathrm{SiO}_{2}$ e $\mathrm{SiO}_{\mathrm{x}} \mathrm{N}_{\mathrm{y}}$

Tabela 4.3 - Principais parâmetros extraídos a partir de $I_{\mathrm{D}} v s$. $V_{\mathrm{GS}}$ em regime de saturação para MDMO-PPV dissolvido em clorofórmio e depositado em ambos os dielétricos e substratos. As dimensões do canal são $W_{\mathrm{M}}=1,1 \mathrm{~mm}$ e $L_{\mathrm{M}}=5 \mu \mathrm{m}$.

Tabela 4.4 - Principais parâmetros extraídos a partir de $I_{\mathrm{D}}$ vs. $V_{\mathrm{GS}}$ em regime de saturação para MDMO-PPV depositado a partir de clorofórmio e tolueno em ambos os dielétricos. As dimensões do canal são $W_{\mathrm{M}}=1,1 \mathrm{~mm}$ e $L_{\mathrm{M}}=5 \mu \mathrm{m}$. A carga acumulada é $(3,4 \pm 0,1)$ sobre $\mathrm{SiO}_{2}$ e $(10,3 \pm 1,4) \times 10^{12}$ cargas $/ \mathrm{cm}^{2}$ com $\mathrm{SiO}_{\mathrm{x}} \mathrm{N}_{\mathrm{y}}$

Tabela 4.5 - Principais parâmetros extraídos a partir de $I_{\mathrm{D}} v s$. $V_{\mathrm{GS}}$ em regime de saturação para MDMO-PPV dissolvido em clorofórmio e depositado sobre eletrodos com e sem filme de titânio $(20 \mathrm{~nm})$. As dimensões do canal são $W_{\mathrm{M}}=1,1 \mathrm{~mm}$ e $L_{\mathrm{M}}=20$ $\mu \mathrm{m}$.

Tabela 4.6 - Parâmetros extraídos de TFTs para $\mu=f\left(V_{\mathrm{GS}}\right)$ em regime de saturação de MDMO-PPV dissolvido em clorofórmio e depositado em ambos os dielétricos e substratos. As dimensões do canal são $W_{\mathrm{M}}=1,1 \mathrm{~mm}$ e $L_{\mathrm{M}}=5 \mu \mathrm{m}$. ...

Tabela 4.7 - Dependência Poole-Frenkel da mobilidade com o campo elétrico longitudinal em TFTs de MDMO-PPV depositado sobre ambos os dielétricos. 
Tabela 4.8 - Principais parâmetros extraídos a partir de $I_{\mathrm{D}} v s$. $V_{\mathrm{GS}}$ em regime linear para MEH-PPV depositado sobre $\mathrm{p}+-\mathrm{Si} / \mathrm{SiO}_{2}$. A largura do canal $\left(W_{\mathrm{M}}\right)$ é $1,1 \mathrm{~mm} \ldots \ldots \ldots \ldots \ldots . . . . . . . .84$ Tabela 4.9 - Principais parâmetros extraídos a partir de $I_{\mathrm{D}} v s$. $V_{\mathrm{GS}}$ em regime de saturação para MEH-PPV depositado sobre p+-Si/SiO ${ }_{2}$. A largura do canal $\left(W_{\mathrm{M}}\right)$ é 1,1 $\mathrm{mm}$.

Tabela 4.10 - Dependência Poole-Frenkel da mobilidade com o campo elétrico longitudinal em TFTs de MEH-PPV depositado sobre $\mathrm{p}+-\mathrm{Si} / \mathrm{SiO}_{2}$. A largura do canal $\left(W_{\mathrm{M}}\right)$ é $1,1 \mathrm{~mm}$. .86

Tabela 4.11 - Parâmetros extraídos de TFTs para $\mu=f\left(V_{\mathrm{GS}}\right)$ em regime de saturação de MEH-PPV depositado sobre p+-Si/SiO ${ }_{2}$. A largura do canal $\left(W_{\mathrm{M}}\right)$ é $1,1 \mathrm{~mm}$ .86

Tabela 4.12 - Principais parâmetros extraídos a partir de $I_{\mathrm{D}} v s$. $V_{\mathrm{GS}}$ em regime linear para P3HT depositado sobre p+-Si/SiO 2 . A largura do canal $\left(W_{\mathrm{M}}\right)$ é $1,1 \mathrm{~mm}$ .88

Tabela 4.13 - Principais parâmetros extraídos a partir de $I_{\mathrm{D}} v s$. $V_{\mathrm{GS}}$ em regime de saturação para P3HT depositado sobre $\mathrm{p}+-\mathrm{Si} / \mathrm{SiO}_{2}$. A largura do canal $\left(W_{\mathrm{M}}\right)$ é $1,1 \mathrm{~mm} .88$

Tabela 4.14 - Principais parâmetros extraídos a partir de $I_{\mathrm{D}} v s$. $V_{\mathrm{GS}}$ em regime linear para pentaceno evaporado sobre $\mathrm{p}+-\mathrm{Si} / \mathrm{SiO}_{2}$. A largura do canal $\left(W_{\mathrm{M}}\right)$ é $1,1 \mathrm{~mm}$

Tabela 4.15 - Principais parâmetros extraídos a partir de $I_{\mathrm{D}} v s$. $V_{\mathrm{GS}}$ em regime de saturação para pentaceno evaporado sobre $\mathrm{p}+-\mathrm{Si} / \mathrm{SiO}_{2}$. A largura do canal $\left(W_{\mathrm{M}}\right)$ é 1,1 mm em eletrodos paralelos e $20,9 \mathrm{~mm}$ em eletrodos interdigitados.

Tabela 4.16 - Parâmetros extraídos de TFTs para $\mu=f\left(V_{\mathrm{GS}}\right)$ em regime de saturação de pentaceno depositado sobre $\mathrm{p}+-\mathrm{Si} / \mathrm{SiO}_{2}$. A largura do canal $\left(W_{\mathrm{M}}\right)$ é $1,1 \mathrm{~mm}$. 


\section{LISTA DE ABREVIATURAS E SIGLAS}

CELIV - Charge Extraction by Linearly Increasing Voltage

CSO - Célula solar orgânica

CT - Condutor transparente

D $\quad$ - Eletrodo de dreno (ou drain) do FET

DCB - Diclorobenzeno

DOS - Distribution of States (distribuição de estados)

EO - Eletrônica Orgânica

EPUSP - Escola Politécnica da Universidade de São Paulo

FBK - Fondazione Bruno Kessler

FET - Field-Effect Transistor (transistor de efeito de campo)

$G \quad$ - Eletrodo de porta (ou gate) do FET

HMDS - Hexametildissilazana

HOMO - Highest Occupied Molecular Orbital (orbital molecular ocupado de maior energia)

IEEE - Institute of Electrical and Electronics Engineers

ITO - Óxido de índio dopado com estanho

$J x V \quad-$ Curvas de corrente por tensão

LED - Light-Emitting Diode (diodo eletroluminescente)

LUMO - Lowest Unoccupied Molecular Orbital (orbital molecular desocupado de menor energia)

MDMO-PPV - Poli(2-metoxi-5-(3',7'-dimetiloctiloxi)-1,4'-fenileno vinileno)

MEH-PPV - Poli(2-metoxi-5-(2-etil-hexiloxi)-1,4-fenileno vinileno)

OTFT - Organic Thin Film Transistor (Transistor orgânico de filmes finos)

P3HT - Poli(3-hexiltiofeno)

PCBM - [6,6]-fenil-C61-butirato de metila 
PEDOT:PSS - Poli(3,4-etilenodioxitiofeno) complexado com poli(ácido estireno-sulfônico)

PET - Polietileno tereftalato

$S \quad$ - Eletrodo de fonte (ou source) do FET

SAM - Self-Assembled Monolayer (monocamada automontada)

SCLC - Space charge limited current (corrente limitada por carga espacial)

ToF - Time of Flight (Tempo de vôo) 


\section{LISTA DE SÍMBOLOS}

$\varepsilon_{0} \quad-$ Permissividade elétrica do vácuo $(\mathrm{F} / \mathrm{cm})$

$\gamma \quad-$ Expoente adimensional no modelo diferencial

$\eta \quad$ - Expoente no modelo Poole-Frenkel $\left(\mathrm{cm}^{1 / 2} / \mathrm{V}^{1 / 2}\right)$

$\kappa \quad-$ Constante dielétrica relativa do dielétrico de porta

$\lambda \quad-$ Comprimento de onda $(\mathrm{nm})$

$\mu \quad-$ Mobilidade dos portadores de carga $\left(\mathrm{cm}^{2} / \mathrm{Vs}\right)$

$\mu_{0} \quad-$ Mobilidade a campo elétrico nulo $\left(\mathrm{cm}^{2} / \mathrm{Vs}\right)$

$\mu_{\mathrm{e}} \quad-$ Mobilidade dos portadores de carga negativa ou elétrons $\left(\mathrm{cm}^{2} / \mathrm{Vs}\right)$

$\mu_{\mathrm{h}} \quad$ - Mobilidade dos portadores de carga positiva ou lacunas $\left(\mathrm{cm}^{2} / \mathrm{Vs}\right)$

$c \quad-$ Velocidade da luz $(\mathrm{m} / \mathrm{s})$

$C_{\mathrm{i}} \quad$ - Capacitância do dielétrico de porta por unidade de área $\left(\mathrm{F} / \mathrm{cm}^{2}\right)$

$h \quad-$ Constante de Planck (J.s)

$E_{\mathrm{g}} \quad-$ Bandgap de semicondutor $(\mathrm{eV})$

FF $\quad$ - Fator de preenchimento $(\%)$

$g_{\text {d }} \quad-$ Condutância do $\operatorname{OTFT}(1 / \Omega)$

$g_{\text {d,folha }}-$ Condutância de folha do OTFT em regime linear $(\square / \Omega)$

$g_{\mathrm{m}} \quad-$ Transcondutância do OTFT $(1 / \Omega)$

$I_{\mathrm{D}} \quad-$ Corrente entre dreno e fonte (A)

IPCE - Incident photon to current efficiency ou eficiência quântica externa (\%)

$J_{\mathrm{mp}} \quad$ - Densidade de corrente no ponto de máxima potência $\left(\mathrm{A} / \mathrm{cm}^{2}\right)$

$J_{\mathrm{ph}} \quad$ - Densidade de corrente elétrica fotogerada $\left(\mathrm{A} / \mathrm{cm}^{2}\right)$

$J_{\mathrm{SC}} \quad$ - Densidade de corrente de curto-circuito $\left(\mathrm{A} / \mathrm{cm}^{2}\right)$

$k-$ Constante no modelo diferencial $\left(\mathrm{cm}^{2} / \mathrm{V}^{1-\gamma} \mathrm{s}\right)$

$k_{\mathrm{B}} \quad-$ Constante de Boltzmann $(\mathrm{J} / \mathrm{K})$

$L \quad$ - Comprimento do canal $(\mu \mathrm{m})$

$L_{\mathrm{M}} \quad$ - Comprimento do canal na máscara litográfica $(\mu \mathrm{m})$ 


$$
\begin{array}{ll}
P C E & - \text { Rendimento ou eficiência na conversão de potência }(\%) \\
R_{\mathrm{ON}} & - \text { Resistência do TFT em regime linear }(\Omega) \\
R_{\mathrm{S}} & - \text { Resistência série }(\Omega) \\
R_{\mathrm{SH}} & - \text { Resistência paralela ou shunt }(\Omega) \\
T & - \text { Temperatura }(\mathrm{K}) \\
V_{\mathrm{DS}} & - \text { Tensão entre dreno e fonte }(\mathrm{V}) \\
V_{\mathrm{GS}} & - \text { Tensão entre porta e fonte }(\mathrm{V}) \\
V_{\mathrm{mp}} & - \text { Tensão no ponto de máxima potência }(\mathrm{V}) \\
V_{\mathrm{OC}} & - \text { Tensão de circuito aberto }(\mathrm{V}) \\
W & - \text { Largura do canal }(\mu \mathrm{m}) \\
x_{\mathrm{i}} & - \text { Espessura do dielétrico de porta }(\mathrm{nm})
\end{array}
$$




\section{INTRODUÇÃO}

\subsection{Materiais orgânicos para a eletrônica: de isolantes a condutores}

Materiais orgânicos que possuem potencial aplicação em produtos eletrônicos são pequenas moléculas (e.g. oligômeros) ou polímeros cuja estrutura é composta principalmente de carbono. O elemento carbono possui 6 elétrons com distribuição em camadas $1 \mathrm{~s}^{2} 2 \mathrm{~s}^{2} 2 \mathrm{p}^{2}$, ou seja, apresenta quatro elétrons na última camada e eletronegatividade mediana (tendência a partilhar elétrons e não capturar ou ceder, i.e. ligar-se covalentemente). A hibridização $\mathrm{sp}^{2}$ é característica dos semicondutores orgânicos. Este estado é representado na Figura 1.1.a para a molécula de etileno (ou eteno). Nesta molécula, cada átomo de carbono se encontra hibridizado desta maneira: realiza ligações $\sigma$ no plano definido pelos átomos de carbono e hidrogênio com elétrons fortemente localizados entre os núcleos dos átomos; porém efetua também ligações $\pi$ fora do plano e de caráter altamente deslocalizado.

As moléculas $\pi$-conjugadas são caracterizadas pela alternância entre ligações simples e duplas, sendo que alguns exemplos podem ser vistos na Figura 1.1.c-f. As ligações realizadas através da sobreposição dos orbitais atômicos $p_{\mathrm{z}}$ (i.e. fora do plano) criam orbitais moleculares ligantes $(\pi)$ e anti-ligantes $\left(\pi^{*}\right)$. Os elétrons do orbital ligante possuem menor energia e, por este motivo, o orbital é conhecido como HOMO (do inglês, Highest Occupied Molecular Orbital). Dado que as ligações $\pi$ são tipicamente mais fracas, estes elétrons são facilmente excitáveis ao nível superior, ficando assim livres para se mover ao longo da molécula, desfrutando da sobreposição dos orbitais $p_{\mathrm{z}}$ com os átomos vizinhos (deslocalização dos orbitais $\pi$ ). Este nível energético superior é conhecido como LUMO (do inglês Lowest Unoccupied Molecular Orbital). Quando a diferença energética entre os níveis $H O M O$ e $L U M O$ é muito maior que a energia térmica ( $k_{\mathrm{B}} T$, onde $k_{\mathrm{B}}$ é a constante de Boltzmann e $T$ a temperatura), há a aparição da faixa proibida (i.e. bandgap) e é possível comparar o HOMO à banda de valência e o 
LUMO à de condução de um semicondutor ou isolante. Tais definições foram retomadas da referência [1], assim como a Figura 1.1.b que ilustra o diagrama de energia destes materiais para os elétrons de maior energia.

(a)

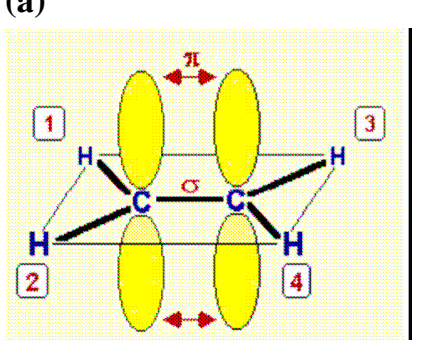

(e)

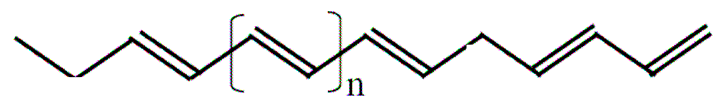

(b)
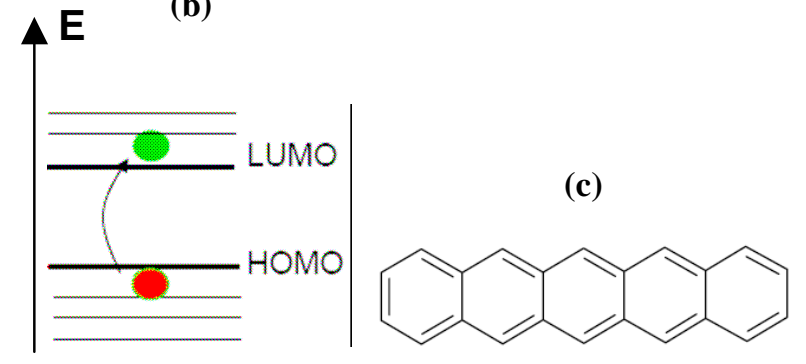

(d)

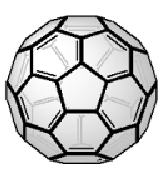

(f)

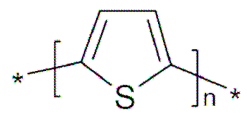

Figura 1.1 - (a) Hibridização $\mathrm{sp}^{2}$ do carbono na molécula de etileno; (b) Diagrama de bandas para os semicondutores orgânicos com alternância entre ligações simples e duplas; Estes materiais podem ser divididos em pequenas moléculas (e.g. (c) pentaceno, (d) fulereno) e polímeros (e.g. (e) poliacetileno, (f) politiofeno).

Polímeros conjugados apresentam condutividades elétricas que tanto podem ser típicas de isolantes como de supercondutores, de acordo com modificações químicas ou natureza e grau de dopagem, oferecendo ainda vantagens por serem leves, flexíveis e resistentes à corrosão. Estes materiais utilizados na Eletrônica Orgânica (EO) diferem dos convencionais por possuírem estrutura eletrônica deslocalizada que pode acomodar portadores de carga como elétrons e lacunas. A idéia de utilizar polímeros pelas suas propriedades condutoras só apareceu em 1977 com as descobertas de Shirakawa et al. [2], em que trans-poliacetileno (ver Figura 1.1.b) dopado com iodo exibiu condutividade de $10^{3} \mathrm{~S} / \mathrm{cm}$. Esta descoberta levou Heeger, McDiarmid e Shirakawa a ganharem o prêmio Nobel de Química em 2000. Desde então, o interesse em sintetizar outros polímeros orgânicos que apresentem esta propriedade tem aumentado, e outros polímeros com estrutura de elétrons- $\pi$ (e.g. polianilina (PAni), polipirrol (PPy), 
politiofeno (PT), polifurano (PFu), poli(p-fenileno) e policarbazol [3, 4]) têm sido sintetizados e testados em dispositivos eletrônicos.

Dada a importância das propriedades físicas destes materiais, uma grande variedade de técnicas vem sendo amplamente utilizada para determiná-las, tais como eletroquímica, óptica, espectroscopia de ressonância paramagnética eletrônica, microscopia eletrônica de varredura (MEV), microscópio de força atômica (MFA), cromatografia de permeação em gel $(G P C)[5,6]$. Os dados experimentais assim obtidos para estes parâmetros possuem um papel fundamental na utilização destes materiais em aplicações com finalidade tecnológica e comercial, assim como no desenvolvimento de novos materiais orgânicos para a indústria de semicondutores [7].

A condução elétrica em materiais orgânicos ocorre através de defeitos nãolineares/topológicos (sólitons/pôlarons) gerados durante a polimerização ou como consequiência da dopagem. O transporte de carga, por sua vez, pode ser limitado pela injeção de portadores devido à altura da barreira de potencial nas interfaces. Quando o campo elétrico é muito alto ou a altura das barreiras é baixa, o transporte é dominado pela carga acumulada no semicondutor orgânico devido às limitações de transporte (carga espacial) [8]. O maior limitante da eficiência neste caso é a mobilidade efetiva dos portadores de carga nos materiais orgânicos e, por este motivo, torna-se um dos parâmetros mais importantes na busca por novos materiais. A mobilidade é a razão entre a velocidade dos portadores e o campo elétrico aplicado e, em comparação aos semicondutores inorgânicos utilizados na indústria [9], normalmente é baixa $\left(\sim 10^{-5}-10^{-2}\right.$ $\left.\mathrm{cm}^{2} / \mathrm{Vs}\right)$.

Dispositivos eletrônicos orgânicos são, na sua forma mais simples, camadas orgânicas dispostas entre dois eletrodos em uma estrutura vertical ou sanduíche de camadas. Exemplos típicos são dispositivos emissores de luz ( $L E D$, do inglês LightEmitting Diodes) [10], dispositivos fotovoltaicos [11] e transistores de efeito de campo (FET, do inglês Field-Effect Transistor) [12]. Obviamente dispositivos passivos como resistores [13], capacitores [14] e diodos [15] também podem ser constituídos. Algumas características elétricas específicas dos materiais orgânicos podem ser utilizadas para construção de dispositivos sem análogo aos semicondutores inorgânicos convencionais. 
Como exemplo, podem ser citados memórias moleculares [16], osciladores monocamada [17], janelas inteligentes [18], músculos artificiais [19] e biossensores [20].

Dispositivos orgânicos chamaram a atenção não somente da comunidade científica, mas também de indústrias interessadas em dominar este futuro mercado (ver Figura 1.2). Maior televisor $O L E D$ da atualidade, o último modelo de destaque da Samsung apresentado em outubro de 2008 tem 40 polegadas, resolução de 1920×1080 pixels, contraste de 1.000.000:1, gama de cores de 107\% NTSC e luminosidade média de $200 \mathrm{~cd} / \mathrm{m}^{2}$.
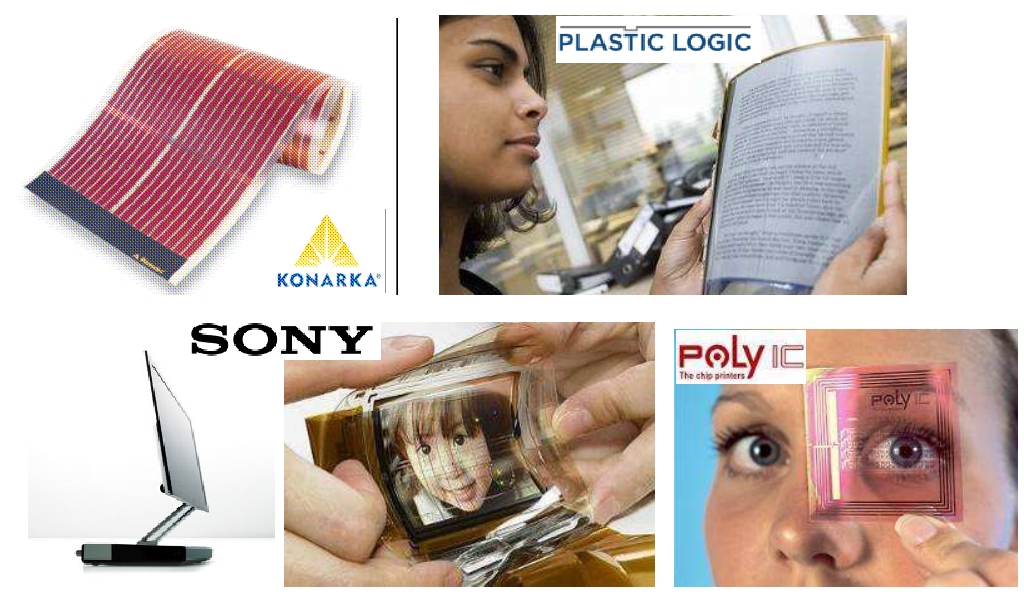

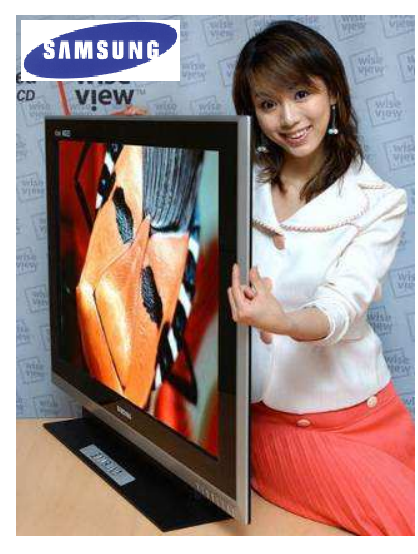

Figura 1.2 - Indústrias que despontam no mercado de dispositivos orgânicos: Konarka (células solares), PlasticLogic, Samsung, Sony (TV de OLEDs), PolyId (etiquetas de RFID).

\subsection{Justificativa}

Sistemas eletrônicos orgânicos oferecem a vantagem de poderem ser flexíveis e leves, além de cobrir grandes superfícies a um custo extremamente baixo [21]. Transistores de filmes finos orgânicos podem ser utilizados para vários fins, tais como circuitos complementares (e.g. inversores e osciladores em anel), biossensores e memórias [20, 16]. As aplicações mais interessantes para estes dispositivos são em circuitos integrados flexíveis totalmente orgânicos e transparentes para a indústria de 
painéis luminosos [21, 22]. As técnicas de fabricação são variadas, mas há uma tendência de se desenvolverem cada vez mais circuitos integrados por impressão direta dos vários componentes do sistema, dispensando técnicas tradicionais tais como oxidação térmica e fotolitografia [22]. Num futuro próximo, devido à compatibilidade dos semicondutores orgânicos com biomoléculas e células vivas, espera-se integrar as áreas de biomédicas e tecnologia da informação através da cibernética avançada [20].

Um dos elementos mais importantes para o desenvolvimento e afirmação destes dispositivos orgânicos é o comportamento dos portadores de carga das camadas orgânicas. Mobilidades superiores às do silício amorfo hidrogenado foram obtidas para pentaceno [23] e fulerenos [24] (e.g. $\left.\mu \sim 6 \mathrm{~cm}^{2} / \mathrm{Vs}\right)$, mas estes valores ainda são inferiores aos obtidos em transistores de silício monocristalino (e.g. $\left.\mu \sim 10^{2} \mathrm{~cm}^{2} / \mathrm{Vs}\right)$ [9]. Novos materiais orgânicos com mobilidades cada vez mais elevadas surgem continuamente, prometendo facilidades de utilização e aplicação em geometrias cada vez menores. Por este mesmo motivo, são necessários métodos simples e rápidos de caracterização destes materiais, entre os quais a determinação da mobilidade é um dos mais importantes. Neste contexto, o escopo deste projeto é desenvolver uma metodologia de fabricação de transistores orgânicos, que leve em consideração a determinação da mobilidade dos portadores como etapa para a escolha dos materiais semicondutores, incorporando novos processos de fabricação de dispositivos e visando a inserção destes em diversas aplicações cotidianas.

\subsection{Objetivos}

Desenvolvimento de uma metodologia de fabricação de transistores de filmes finos orgânicos (OTFTs) através das seguintes etapas:

(i) Produção e caracterização de células solares de alta eficiência (e.g. P3HT:PCBM) visando o estudo da estrutura vertical de transporte de carga e das técnicas de fabricação em Eletrônica Orgânica;

(ii) Aplicação de técnicas de extração da mobilidade em filmes semicondutores orgânicos; 
(iii) Fabricação e caracterização de transistores orgânicos a partir dos materiais previamente analisados.

A fabricação de células solares orgânicas de heterojunção é necessária ao aprendizado dos processos de fabricação em microeletrônica orgânica e familiarização com a estrutura vertical utilizada na maior parte dos dispositivos desta área. Tal estrutura é aplicável aos estudos da mobilidade dos portadores de carga em semicondutores orgânicos.

Formação de recursos humanos em Eletrônica Orgânica, incluindo o aprendizado relacionado aos diversos equipamentos utilizados no mundo da microeletrônica, sejam eles de fabricação ou caracterização de dispositivos.

Aperfeiçoamento da fabricação de TFTs com camadas orgânicas, assim como de competências relacionais e técnico-científicas. 


\section{REVISÃO BIBLIOGRÁFICA}

A mobilidade dos portadores de carga pode ser estudada em estruturas simples através de técnicas que empreguem transiente de corrente ou corrente estacionária (ver Seção 2.1), ou diretamente no dispositivo final, como no caso dos FETs. Este último terá sua modelagem e técnicas de processamento apresentadas em detalhes na Seção 2.3. As células solares orgânicas de heterojunção serão apresentadas na Seção 2.2. Estes dispositivos possuem estrutura vertical (i.e. empilhamento de camadas com diferentes propriedades elétricas) semelhante às amostras empregadas nas técnicas para medição de mobilidade, empregando técnicas de fabricação que podem ser utilizadas em microeletrônica orgânica na fabricação de transistores de filmes finos.

\subsection{Técnicas de caracterização da mobilidade dos portadores de carga}

Existem diversas técnicas para estudo da mobilidade dos portadores de carga em filmes orgânicos, tais como Time of Flight (ToF), Dark Injection Space-Charge-Limited Current (DI-SCLC) [25], Charge Extraction in Linearly Increasing Voltage (CELIV), espectroscopia de admitância [26], além da interpretação de curvas estacionárias de densidade de corrente por tensão $(J x V)$. As técnicas mais relevantes a este trabalho serão apresentadas em maiores detalhes a seguir.

\subsubsection{Tempo de Vôo com excitação óptica (Time of Flight, ToF)}

As duas técnicas mais utilizadas para determinar a mobilidade dos portadores de carga são a modelagem do transporte de carga através de curvas $J x V$, além de medidas de tempo de vôo (ToF) [27]. De forma resumida, o ToF consiste em gerar pares de elétron-lacuna por um estímulo externo, separá-los através de um campo aplicado ao material e, enquanto um tipo de portador recombina no eletrodo estimulado, os 
portadores de carga oposta derivam através da amostra, criando uma corrente que será função do tempo e permita identificar o tempo de trânsito. Isto permite extrair a mobilidade tanto dos portadores de carga positiva quanto de carga negativa em materiais semicondutores. Aplica-se para tal escopo a equação:

$\mu=\frac{v}{E}=\frac{d^{2}}{V \cdot t_{t r}}$

onde $v$ é a velocidade do portador de carga, $E$ o campo elétrico, $V$ o potencial e $t_{\text {tr }} \mathrm{O}$ tempo que o portador demora para percorrer a distância $d$ entre os eletrodos. ToF é empregado sempre que possível por permitir a análise do transporte de carga e de mobilidades da ordem de $10^{-8}$ a $1 \mathrm{~cm}^{2} /$ Vs em filmes espessos (i.e. > $1 \mu \mathrm{m}$ ) de semicondutores orgânicos [28] e inorgânicos amorfos [29].

\subsubsection{Charge Extraction in Linearly Increasing Voltage (CELIV)}

A técnica CELIV, proposta por Juška et al. em 1999 [30], surge justamente como uma alternativa ao $T o F$, devido a dificuldades na aplicação desta última a estruturas heterogêneas e de alta condutividade tais como as de silício microcristalino ( $\mu \mathrm{c}-\mathrm{Si}: \mathrm{H})$. CELIV se mostrou eficiente no estudo das propriedades elétricas de Si:H microcristalino, assim como de polímeros conjugados (e.g. P3HT) [31]. Sua maior vantagem está em sua aplicação a filmes finos, implicando em um menor desperdício de material e possibilidade de deposição de filmes semelhantes aos aplicados em dispositivos. Os contatos devem ser bloqueantes para ambos os portadores, no entanto, uma desvantagem se comparada ao ToF está na impossibilidade de extrair a mobilidade dos portadores minoritários. O leitor interessado em maiores detalhes sobre a técnica pode consultar a referência [30].

As fórmulas aplicadas para o cálculo da mobilidade das lacunas $(\mu)$ e da condutividade $(\sigma)$ são, respectivamente: 
$\mu=\frac{2 d^{2}}{2 A t_{\max }^{2}[1+0,36(\Delta J / J(0))]}$

e

$\sigma=\frac{3 \kappa \varepsilon_{0} \Delta J}{2 t_{\max } J(0)}$

onde $A$ é a taxa de aumento da tensão, $t_{\max }$ o tempo de obtenção do pico de corrente $\Delta j$, $j(0)$ o corrente de deslocamento da capacitância, $\kappa$ a constante dielétrica relativa, $\varepsilon_{0}$ a permissividade elétrica do vácuo.

\subsubsection{Curvas de densidade de corrente por tensão (JxV)}

Dependendo do modelo adotado de condução de corrente estacionária nestes materiais, pode ser extraído um valor de mobilidade a partir das curvas $J x V$ para comparação com valores obtidos por outras técnicas. De forma simplificada, os modelos se dividem em limitado por mecanismos de injeção ou de volume. Emissão termiônica, Richardson-Schottky e Fowler-Nordheim são modelos de injeção utilizados no caso de contatos retificantes, porém não fornecem informações sobre a distribuição e concentração de armadilhas no material assim como sobre a mobilidade dos portadores de carga. Este não é o caso quando a corrente é limitada pelo semicondutor: os principais são a lei de Ohm e de correntes limitadas por carga espacial (SCLC) podendo ou não apresentar o efeito Poole-Frenkel. Normalmente, estes modelos são de difícil observação por requererem a fabricação de contatos injetores ôhmicos [13]. Arkhipov et al. propõem um modelo mais complexo que os citados, baseado na probabilidade de injeção a partir do nível de Fermi do contato metálico para uma distribuição de estados localizados $(D O S)$ no semicondutor, levando em conta mecanismos de transporte por hopping entre estados energéticos localizados [32]. Maiores detalhes sobre estes e outros modelos de transporte de carga podem ser encontrados em [33, 34, 35]. Os modelos 
adotados neste trabalho e que permitem o estudo da mobilidade dos portadores serão detalhados a seguir.

Em níveis baixos de injeção, i.e. quando a densidade de portadores gerados termicamente $\left(p_{0}\right)$ dentro da amostra é maior que a densidade de portadores injetados, a condução ôhmica é predominante. Esta é caracterizada pela relação linear entre corrente e tensão:

$J=q \mu p_{0} \frac{V}{d}$

onde $q$ é a carga elementar, $\mu$ a mobilidade dos portadores de carga, $p_{0}$ a densidade de portadores livres termicamente gerados, $V$ diferença de potencial aplicada aos eletrodos e $d$ a espessura da camada semicondutora. Considerando um semicondutor sem armadilhas, quando os portadores injetados são capazes de percorrer um caminho que una os dois eletrodos através do semicondutor e sua concentração é superior à $p_{0}$, ocorre o início da corrente $S C L C$. A expressão da corrente é dada pela Lei de Child:

$$
J=\frac{9}{8} \varepsilon_{r} \varepsilon_{0} \mu \frac{V^{2}}{d^{3}}
$$

$\mathrm{Na}$ presença de armadilhas rasas (i.e. níveis de energia localizados entre nível quasiFermi das lacunas e o $H O M O$ do polímero), a mobilidade é modulada por um fator $\theta$ em (5). Se as armadilhas estão confinadas em um único nível energético de concentração $H$, a tensão de preenchimento destas armadilhas (ou trap filling limited voltage, $V_{T F L}$ ) é calculada através de:

$$
V_{T F L}=\frac{q H d^{2}}{2 \varepsilon_{r} \varepsilon_{0}}
$$


$\mathrm{Na}$ presença de uma distribuição exponencial em energia das armadilhas, i.e. $h(E)=\left(H / k T_{c}\right) \exp \left(E / k T_{c}\right)$, a Lei de Child se torna:

$$
J=e^{1-l} \mu N_{v}\left(\frac{2 l+1}{l+1}\right)^{l+1}\left(\frac{l}{l+1} \frac{\varepsilon_{r} \varepsilon_{0}}{H}\right)^{l} \frac{V^{l+1}}{d^{2 l+1}}
$$

onde $N_{v}$ é a densidade efetiva de estados na banda de valência (aqui estimada em $1,10 \times 10^{18} \mathrm{~cm}^{-3}$ ) e $l$ está relacionada com a temperatura característica $T_{c}$ da distribuição de armadilhas através de $l=T_{c} / T$, em que $T$ é a temperatura. Igualando as Equações (4) e (7), a tensão aplicada $V_{\Omega}$ necessária para passar de um regime ao outro é:

$$
V_{\Omega}=\frac{q d^{2} H}{\varepsilon_{r} \varepsilon_{0}}\left(\frac{p_{0}}{N_{v}}\right)^{1 / l}\left(\frac{l+1}{l}\right)\left(\frac{l+1}{2 l+1}\right)^{(l+1) / l}
$$

Quando todas as armadilhas são preenchidas, uma transição entre $S C L C$ com e sem armadilhas acontece. Igualando agora as Equações (5) e (7), a tensão necessária $V_{T F L}$ se torna:

$V_{T F L}=\frac{q d^{2}}{\varepsilon_{r} \varepsilon_{0}}\left[\frac{9}{8} \frac{H^{l}}{N_{v}}\left(\frac{l+1}{l}\right)^{l}\left(\frac{l+1}{2 l+1}\right)^{l+1}\right]^{1 /(l-1)}$

\subsection{Células solares orgânicas de heterojunção}

\subsubsection{Princípios fundamentais e principais parâmetros}

Uma célula solar é um diodo que sob iluminação tem sua curva de densidade de corrente $v s$. tensão elétrica $(J x V)$ deslocada para baixo por um valor de densidade de corrente constante $\left(J_{\mathrm{ph}}\right)$ proporcional à intensidade da luz irradiada. O quarto quadrante 
deste gráfico é a região de interesse, i.e. região em que a tensão é positiva e a densidade de corrente é negativa, pois potência é fornecida pelo dispositivo. Se conectada a um sistema representado por uma resistência de carga, forneceria potência elétrica ao mesmo, oriunda da conversão da energia solar em energia elétrica (Figura 2.1.a). Conhecido como efeito fotovoltaico, foi descoberto em 1839 por Edmund Becquerel [36]. Devido ao deslocamento da densidade de corrente de $J_{\mathrm{ph}}$, alguns parâmetros aparecem tais como:

- densidade de corrente de curto-circuito $\left(J_{\mathrm{SC}}\right)$ : a uma diferença de potencial nula entre os eletrodos, a densidade de corrente não é mais nula e seu valor passa a ser chamado de densidade de corrente de curto-circuito. Em outras palavras, esta representa a densidade de corrente obtida curto-circuitando-se os contatos de uma célula solar sob iluminação.

- tensão de circuito aberto $\left(V_{\mathrm{OC}}\right)$ : a uma densidade de corrente nula circulando, a diferença de potencial entre os eletrodos da célula não é mais zero e seu valor é chamado de tensão de circuito aberto. Em outras palavras, representa a tensão medida entre os contatos em condições de circuito aberto e irradiada.

No quarto quadrante (ver Figura 2.1.b), é possível extrair o ponto de máxima densidade de potência elétrica gerada (dada pelo produto entre tensão e densidade de corrente da célula solar, $V . J)$ e calcular a eficiência na conversão de potência $(P C E$, do inglês Power Conversion Efficiency). O rendimento ou $P C E$ é a razão entre $(V . J)_{\max }=$ $V_{\mathrm{mp}} \cdot J_{\mathrm{mp}}$ e a densidade de potência de luz irradiada [37].

Um diagrama de circuito equivalente é apresentado na Figura 2.1.c. O modelo comumente adotado é representado pela equação do diodo Shockley [38]:

$$
J=J_{p h}-\frac{V+J \cdot R_{S}}{R_{S H}}-J_{S}\left[\exp \left\{\frac{q}{n \cdot k_{B} \cdot T}\left(V-J \cdot R_{S}\right)\right\}-1\right]
$$


onde $J$ é a densidade de corrente da célula solar, $V$ a tensão entre os terminais da célula, $J_{\mathrm{S}}$ e $n$ são respectivamente a densidade de corrente de saturação e o fator de idealidade do diodo interno, $k_{\mathrm{B}}$ é a constante de Boltzmann, $T$ a temperatura, $J_{\mathrm{ph}}$ a densidade de corrente oriunda da iluminação da célula, $R_{\mathrm{S}}$ é a resistência elétrica parasitária série e $R_{\mathrm{SH}}$ é a resistência elétrica parasitária paralela. $R_{\mathrm{S}}$ representa a resistência elétrica interna de geradores, cabos e contatos (e.g. entre microponta de ouro e cátodo da célula solar), enquanto que $R_{\mathrm{SH}}$ representa uma corrente de fuga através da célula solar.

(a)

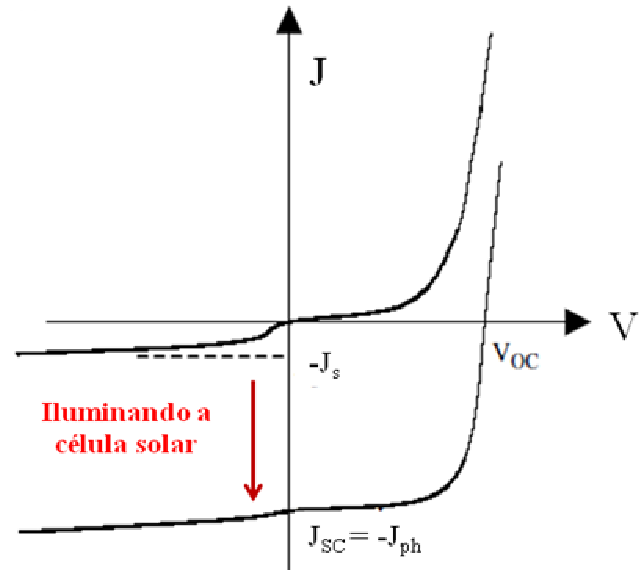

(b)

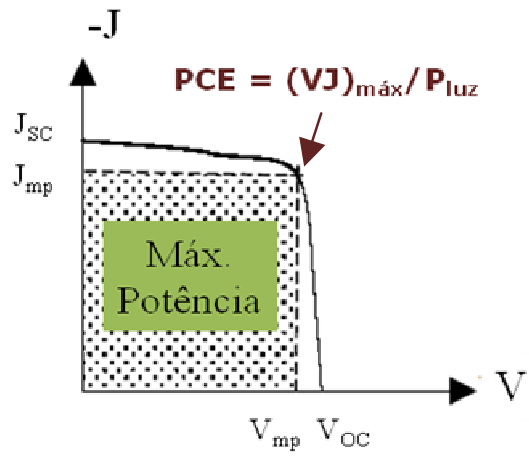

(c)

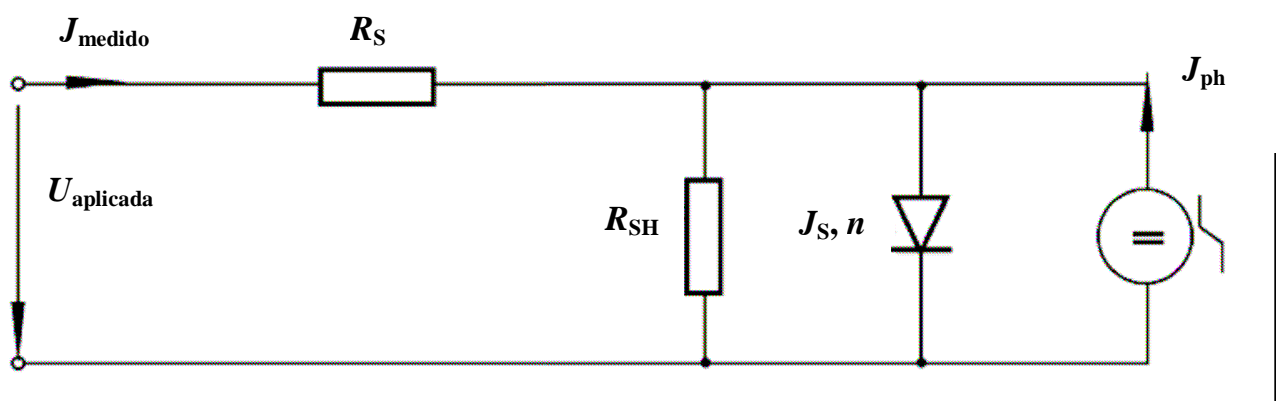

Figura 2.1 - (a) Densidade de corrente do diodo versus potencial entre seus eletrodos $(\mathrm{Jx} V)$ deslocada para baixo quando iluminada por $100 \mathrm{~mW} / \mathrm{cm}^{2}$ de luz solar (AM1,5G). (b) Gráfico destacando na região fotovoltaica o ponto de máxima potência elétrica $\left(V_{\mathrm{mp}}, J_{\mathrm{mp}}\right)$. Este corresponde ao máximo de conversão de energia solar em energia elétrica (adaptado da referência [37]). (c) Representação por circuito equivalente de uma célula solar orgânica (adaptado da referência [38]). 
Outro fator de desempenho de uma célula solar é a eficiência quântica externa (IPCE, do inglês incident photon-to-current conversion efficiency) dada por:

$$
I P C E=\frac{n_{e}}{n_{p h}}=\frac{J}{P_{l u z}} \cdot \frac{h c}{\lambda q}=S R \cdot \frac{1240}{\lambda(n m)}
$$

Esta indica qual é o percentual de fótons incidentes da fonte luminosa $\left(n_{\mathrm{ph}}\right)$ convertidos em cargas elétricas que alimentam o circuito externo $\left(n_{\mathrm{e}}\right)$. Na Equação (11), $J$ representa a densidade de corrente extraída dos eletrodos da célula solar, $P_{\text {luz }}$ a densidade de potência da luz incidente, $h$ a constante de Planck, $c$ a velocidade da luz, $\lambda$ o comprimento de onda, $q$ a carga elementar do elétron. A razão entre $J$ e $P_{\text {luz }}$ é conhecida como responsividade espectral (SR, do inglês Spectral Responsivity). Esta fórmula é aplicada a um comprimento de onda específico, sendo necessário um monocromador ou fonte de radiação monocromática para a realização desta medição.

A principal tecnologia empregada atualmente data de 1954, ano em que a primeira célula solar de silício monocristalino foi fabricada [39]. Apesar do rendimento de $6 \%$ alcançado, observou-se durante os anos seguintes apenas um ligeiro crescimento na produção de energia por células fotovoltaicas, pois o seu alto custo impediu sua exploração em geração de energia. Nos anos 70, após a primeira crise do petróleo, começou a procura por novos meios de geração de energia, e as pesquisas em células solares ganharam destaque e assim permanecendo até os dias de hoje. No entanto, a fabricação destas células solares convencionais de primeira geração e também as de segunda (e.g. silício policristalino) é custosa e complexa, envolve temperaturas elevadas (400-1400 ${ }^{\circ} \mathrm{C}$ ), processamento em vácuo e diversos passos litográficos [40]. O investimento necessário para a criação de uma linha de produção ainda não é competitivo para aplicações em áreas urbanas.

Em 2010, uma questão persiste sobre o futuro da energia renovável solar: é possível produzir dispositivos fotovoltaicos reduzindo o custo dos materiais e até mesmo de processamento tornando-os competitivos com as tecnologias atuais tais como hidroelétrica, termoelétrica e nuclear? Isto é de fato possível, porém novos materiais e 
uma tecnologia inovadora devem ser desenvolvidos para substituir o silício e outros materiais inorgânicos (e.g. germânio, arseneto de gálio, telureto de cádmio, sais de sulfetos, ligas de cobre-índio-gálio-disseleneto) em células solares. Uma candidata a esta tarefa é a célula solar orgânica de heterojunção [41].

Esse dispositivo é principalmente constituído de um substrato (e.g. vidro, polímero) coberto por um condutor transparente (CT) como ânodo (e.g. óxido de índio dopado com estanho - ITO, do inglês indium tin oxide), várias camadas orgânicas (e.g. poli(3,4-etilenodioxitiofeno) complexado com poli(ácido estireno-sulfônico) PEDOT:PSS - e um compósito orgânico semicondutor) e um cátodo metálico (e.g. alumínio). A camada semicondutora é composta por dois materiais com propriedades eletrônicas diferentes que representam a junção p-n em diodos inorgânicos (ver Figura 2.2). Estes dispositivos surgiram nos anos 90 como competidores potenciais quando derivados do PPV foram depositados com fulereno $\left(\mathrm{C}_{60}\right)$. $\mathrm{Yu}$ et al. atingiram um rendimento de 2,9\% com uma célula solar de poli(2-metoxi-5-(2-etil-hexiloxi)-1,4fenileno vinileno) (MEH-PPV):[6,6]-fenil-C61-butirato de metila (PCBM) sob iluminação de $20 \mathrm{~mW} / \mathrm{cm}^{2}$ [42]. O segredo do sucesso está na elevada eficiência do processo conhecido como "transferência eletrônica fotoinduzida" em compósitos de polímeros condutores doadores de elétrons ( $D$, do inglês donor) e derivados do fulereno como receptores de elétrons ( $A$, do inglês acceptor). Visto que o intervalo de tempo para a transferência de carga fotoinduzida é inferior ao picossegundo, $10^{3}$ vezes mais rápida que o decaimento radiativo e não-radiativo de cargas foto-excitadas, a eficiência quântica de separação de carga do doador ao receptor é próxima à unidade $(\lambda \approx 510 \mathrm{~nm})$ [43]. O segundo fator importante está na construção de uma rede interpenetrada de fases do doador (e.g. MEH-PPV) e do receptor (e.g. $\mathrm{C}_{60}$ ) por todo o volume do semicondutor. Através do controle da morfologia, pode-se atingir uma elevada área interfacial doadorreceptor $(D-A)$. Supondo que qualquer ponto do compósito semicondutor esteja a poucos nanômetros da interface $D-A$, tal material é conhecido como "bulk heterojunction $D-A$ " [42]. Tal arranjo espacial da rede $D-A$ polímero:fulereno é semelhante a um espaguete com almôndegas. 
Na década de 2000, excelentes resultados foram apresentados por Padinger et al. com o desenvolvimento de um tratamento térmico final a células solares de poli(3hexiltiofeno) (P3HT) e PCBM [44]. Comparado aos $29 \%$ de IPCE alcançados por Yu et al., esta fornecia um valor superior a $70 \%$ e $P C E$ de $3,5 \%$ sob $80 \mathrm{~mW} / \mathrm{cm}^{2}$. O tratamento térmico a $75{ }^{\circ} \mathrm{C}$ por 4 min com aplicação simultânea de uma tensão externa maior que a tensão de circuito aberto (no caso deles 2,7 V) é realizado após a deposição do cátodo. $\mathrm{O}$ aumento de $P C E$ de 0,4 a 3,5 \% observado entre dispositivos não tratados e tratados, respectivamente, é principalmente devido ao aumento na mobilidade dos portadores de carga e no fator de preenchimento. Mesmo que o rendimento de células solares poliméricas esteja distante dos obtidos com silício monocristalino ( $\mathrm{ca} .28 \%$ ), a possibilidade de processar estes dispositivos em sistemas roll-to-roll (multi-rolos) que reduzam os custos de um fator de $1 / 4$ continua motivando a pesquisa nesta área [41].

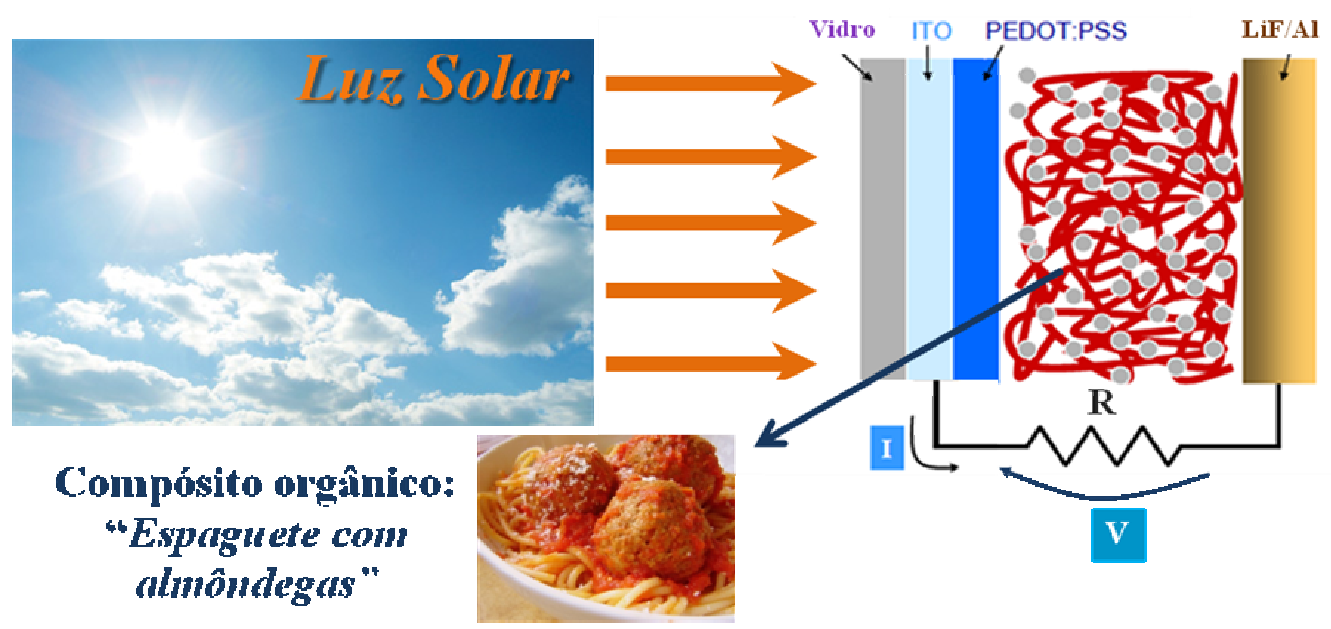

Figura 2.2 - Ilustração esquemática de uma célula solar: a luz solar atravessa o substrato de vidro sendo absorvida na camada ativa; a corrente elétrica gerada é fornecida a uma resistência conectada entre o ânodo de ITO e ao cátodo de Al.

Em termos de mecanismos de conversão de energia (ver Figura 2.3), a célula solar ideal absorve a totalidade dos fótons incidentes (a); gera um par elétron-lacuna neutro (ou exciton) para cada fóton absorvido (b); permite a este par alcançar uma junção de semicondutores com diferentes afinidades eletrônicas dentro de seu tempo de 
vida (c), até o desaparecimento do par devido à separação das cargas (elétron no receptor e lacuna no doador) (d); transporta cada carga individualmente pelo volume do semicondutor até o respectivo eletrodo (e); coleta cada carga no respectivo eletrodo (f), com eletricidade gerada pela recombinação destas cargas em um circuito externo conectado aos eletrodos. No entanto, há diversos mecanismos de perda: fótons não absorvidos na camada ativa (1); o decaimento do exciton gerando, por exemplo, luminescência (2); recombinação das cargas separadas de um mesmo exciton (processo conhecido como germinate recombination) (3); recombinação bimolecular de cargas originárias de excitons diferentes (4). O mecanismo (2) é de extrema importância e implica que excitons sejam formados a uma distância menor ou igual a seu comprimento de difusão (geralmente menor que $20 \mathrm{~nm}$ ), definindo assim o limite superior de separação de fase entre o polímero semicondutor e o fulereno receptor [45]. Diferente dos semicondutores inorgânicos, a energia de ligação de um exciton é tipicamente alta, da ordem ou maior que $500 \mathrm{meV}$; tal energia é vinte vezes superior à energia térmica à temperatura ambiente, $k_{\mathrm{B}} T(300 \mathrm{~K})=26 \mathrm{meV}$ [46]. A tensão $V_{\mathrm{OC}}$ em uma célula solar de heterojunção é dada pela diferença entre os níveis de energia de transporte de elétrons (ou $L U M O$ ) no receptor e de transporte de lacunas (ou HOMO) no doador.

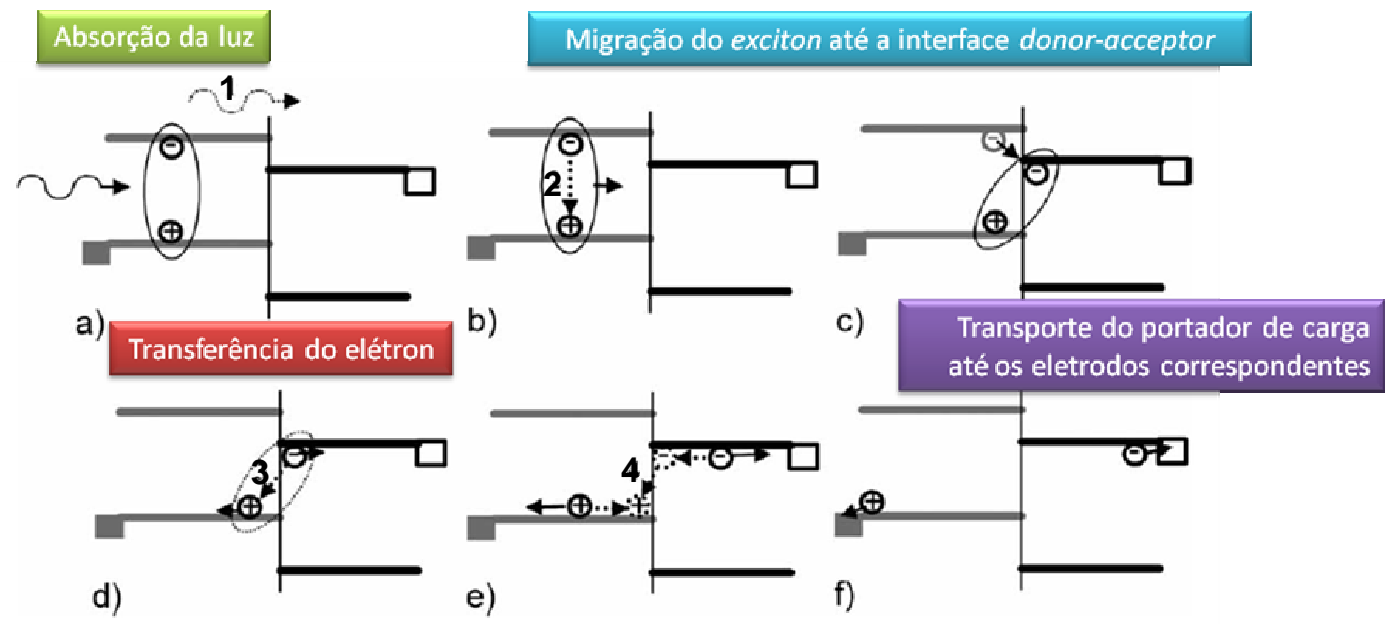

Figura 2.3 - Esquema ilustrativo da geração de corrente em uma célula solar de heterojunção de polímero:fulereno. Detalhes dos processos a) a f) e os mecanismos de perda 1) a 3) são apresentados no texto. Adaptado da referência [45]. 


\subsubsection{Estratégias para aumentar a eficiência na conversão de potência}

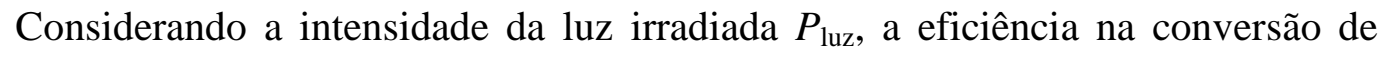
potência $(P C E)$ é dada por:

$P C E=\frac{V_{m p} \cdot J_{m p}}{P_{l u z}}=\frac{F F \cdot V_{O C} \cdot J_{S C}}{P_{l u z}}$

onde $V_{\mathrm{OC}}$ é a tensão de circuito aberto, $J_{\mathrm{SC}}$ a densidade de corrente de curto-circuito e $\left(V_{\mathrm{mp}}, J_{\mathrm{mp}}\right)$ as coordenadas do ponto de máxima densidade de potência elétrica. $\mathrm{O}$ parâmetro restante, $F F$, é conhecido como fator de preenchimento ou fill factor e definido como sendo:

$F F=\frac{V_{m p} \cdot J_{m p}}{V_{O C} \cdot J_{S C}}$

idealmente próximo à unidade. Uma das táticas possíveis para maximizar a eficiência energética da célula é aumentar $J_{\mathrm{SC}}$, através da captura do maior número de fótons possível pela camada ativa. A atenuação de um feixe luminoso ao atravessar um semicondutor é geralmente descrita pela lei de Lambert-Beer:

$\phi(x)=\phi_{0} \cdot \exp (-\alpha x)$

onde $\phi(x)$ é o fluxo luminoso a uma distância $x$ da superfície e dentro do material, $\phi_{0}$ é o fluxo incidente, $\alpha$ o coeficiente de absorção (fortemente dependente do comprimento de onda). Devido ao elevado coeficiente de absorção ( $c a .10^{5} \mathrm{~cm}^{-1}$ ), polímeros conjugados absorvem luz de forma mais eficaz que semicondutores inorgânicos cristalinos no máximo de absorção de seu espectro. Conseqüentemente, levando-se em 
conta os fótons refletidos no eletrodo posterior, bastam poucas centenas de nanômetros de material ativo semicondutor polimérico para absorver toda a luz incidente com comprimento de onda igual ao máximo de absorção. Comparativamente, células solares inorgânicas de silício monocristalino de bandgap indireto necessitam de centenas de micrômetros para absorver a mesma quantidade de radiação.

No entanto, dado que as bandas de absorção dos semicondutores orgânicos são estreitas se comparadas às dos inorgânicos, conforme será visto adiante, o desempenho de células solares poliméricas passa a ser pobre. O bandgap $\left(E_{\mathrm{g}}\right)$ de um semicondutor, como visto na Seção 1.1, é definido como a diferença energética entre o término da banda de valência (ou HOMO) e o começo da banda de condução (ou $L U M O$ ). Somente fótons de energia superior ou igual à do bandgap podem ser absorvidos pelo semicondutor:

$$
E_{\text {photon }}=h f=\frac{h c}{\lambda} \geq E_{g}
$$

onde $h$ é a constante de Planck, $f$ a freqüência do fóton, $c$ a velocidade da luz e $\lambda$ o comprimento de onda do fóton. Uma célula solar orgânica cobre somente uma pequena parcela do espectro solar. Por exemplo, um bandgap de $1,1 \mathrm{eV}$ é necessário para varrer $77 \%$ do fluxo de fótons do sol em condições $\mathrm{AM} 1,5 \mathrm{G}$, enquanto que a maior parte dos polímeros semicondutores processáveis em solução (e.g. PPVs, P3HT) tem bandgap maior que 1,9 eV, cobrindo somente $30 \%$ do espectro de emissão solar (ver Figura 2.4.a). O espectro AM1,5G corresponde à radiação solar com o sol a um ângulo $\theta=45^{\circ}$ acima do horizonte; $\mathrm{AM}$ denota a massa de $\mathrm{ar}=1 / \cos \theta ; \mathrm{G}$ se refere a global e considera a pequena contribuição de luz difusa à luz incidente direta [46, 47]. Além disso, devido à baixa mobilidade dos portadores de cargas nestes materiais, a espessura da camada ativa é limitada a cerca $100 \mathrm{~nm}$, que por sua vez implica na absorção de somente $c a$. $60 \%$ da luz incidente no máximo de absorção do material semicondutor (sem reflexão no eletrodo de alumínio) [48]. 


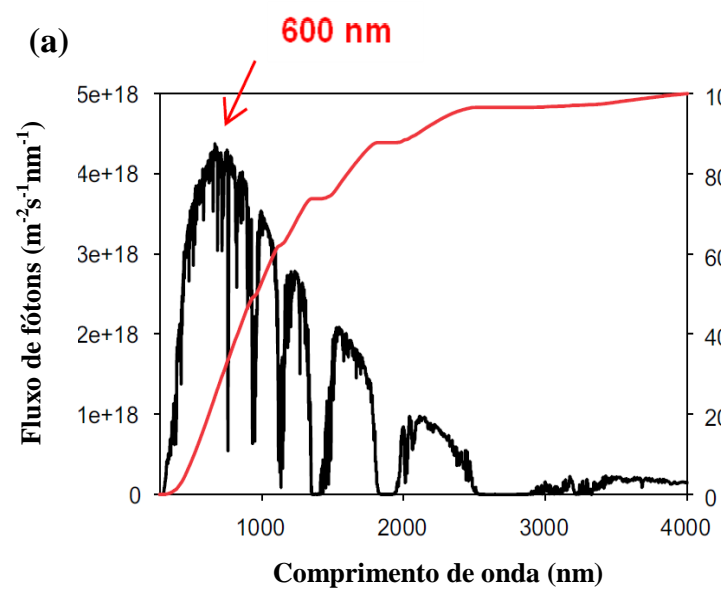

(b)
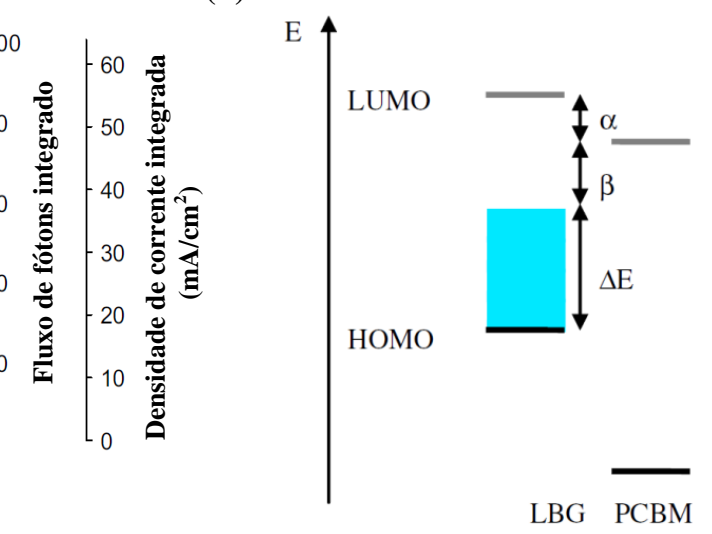

Figura 2.4 - (a) Fluxo de fótons do sol (AM1,5G) em função do comprimento de onda. A integral da curva é representada em vermelho como o percentual de fótons do total irradiado e a densidade de corrente máxima que seria obtida a partir da absorção destes fótons. (b) Alinhamento dos níveis de energia em uma heterojunção de polímero de pequeno bandgap ( $L B G)$ e PCBM. O intervalo aceitável de energia para o HOMO do doador está sombreado. Adaptado da referência [48].

Lembrando que o fotovoltaico orgânico é composto por dois materiais semicondutores de propriedades eletrônicas diferentes conhecidos por doador e receptor, conclui-se que os níveis energéticos $H O M O$ e $L U M O$ nestes materiais é de elevada importância na tentativa de aumentar o rendimento através do controle de $V_{\mathrm{OC}}$ e de uma eficiente separação de cargas na junção $D-A$. Na Figura 2.4.b, pode-se observar o diagrama energético de uma célula solar de heterojunção. A energia $\alpha$ representa a diferença entre o $L U M O$ do polímero e o LUMO do PCBM (poderia ser outro material receptor). A variável $\alpha$ expressa o quão menor é o $L U M O$ do receptor PCBM em relação ao $L U M O$ do doador, devendo ser suficientemente grande para garantir uma separação de carga eficaz. A energia $\beta$ representa o menor valor aceitável de $V_{\mathrm{OC}}$. Até este ponto, a escolha de $\alpha$ e $\beta$ é certamente arbitrária, dado que se deseja uma separação de carga eficaz e um alto valor de $V_{\mathrm{OC}}$; materiais com bandgap maior ou igual a $2 \mathrm{eV}$ preenchem facilmente estas condições. Agora, levando-se em conta que um bandgap elevado implica em menor absorção de fótons, conclui-se que há uma faixa de energia em que o nível HOMO do doador pode variar satisfazendo os critérios de $\alpha$ e $\beta$ (na Figura, 
simbolizado por $\Delta E$ ). Conhecendo o bandgap do polímero e os níveis de energia aceitáveis de $\alpha$ e $\beta$, é possível estimar o intervalo de energia aceitável para o HOMO do doador: $\Delta E=E_{\mathrm{g}}-\alpha-\beta$. Se o bandgap diminui, os valores de $\alpha$ e $\beta$ junto com a posição do $H O M O$ do doador se tornam cruciais para o funcionamento eficiente da célula e provavelmente impossível em muitos casos em que o material receptor não pode ser variado.

Visto que o atual estado da arte emprega derivados de fulereno, o intervalo de energia aceitável não varia arbitrariamente já que o $L U M O$ do receptor está fixado. Este aspecto é de alta relevância e há uma real necessidade por novos receptores com HOMO e LUMO significativamente diferente dos fulerenos. Outra estrutura alotrópica do carbono, os nanotubos podem ser uma alternativa e vêm sendo testados complexados com MDMO-PPV [49], material que já apresenta atualmente alta eficiência em células solares com fulerenos (ca. $3 \%$ ) [50]. Uma extensa lista de referências com novos materiais (e.g. copolímeros de tiofenos, carbazóis e fluorenos, polímeros complexados com metais, corantes dispersados em compósitos orgânicos) é apresentada em [11, 51].

Uma alternativa ao uso de materiais com HOMO e LUMO diferentes está no aumento da eficiência através do desenvolvimento de processos que influenciem $J_{\mathrm{SC}}$ (como visto no começo desta Seção) e $F F$. O tratamento térmico ou recozimento pósdeposição do cátodo (conhecido na literatura como post-production thermal treatment) é uma das ferramentas mais conhecidas para melhorar o desempenho. Através de um estudo detalhado da mudança no $P C E$ com a temperatura e o tempo de tratamento, Ma et al. atingiram $5 \%$ a $150{ }^{\circ} \mathrm{C}$ por $30 \mathrm{~min}$ com dispositivos de P3HT:PCBM processados em substrato de vidro [52]. Os autores demonstraram elevada estabilidade do dispositivo contra altas temperaturas, ou seja, um grande passo a sua comercialização. Outros grupos que buscaram aperfeiçoar a nanomorfologia do filme semicondutor através do controle de seu processamento (e.g. condições de deposição por spin coating, tempo e atmosfera de secagem do solvente, recozimento final) são listados em [53, 54].

Kim et al., por sua vez, utilizaram outra estratégia: a deposição de um espaçador óptico por spin coating [55]. A idéia vem da célula solar mais simples - o dispositivo homojunção -, na qual um único material é alterado tal que um lado seja do tipo p e o 
outro do tipo n, de tal forma que a junção p-n esteja localizada no ponto de máxima absorção da luz irradiada. Células fotovoltaicas à base de polímeros são por convenção dispositivos de filmes finos fabricados na configuração condutor-isolante-condutor como já mostrado na Figura 2.2.a e retomado na Figura 2.5.a. A camada conhecida como bulk heterojunction para absorção dos fótons e separação das cargas tem uma espessura de aproximadamente $100 \mathrm{~nm}$ entre dois eletrodos seletivos para um tipo de carga; um eletrodo bicamada transparente de PEDOT:PSS sobre óxido condutor (e.g. ITO) para coletar as lacunas e um metal de baixa função trabalho (e.g. Al) para coletar elétrons.

(a)

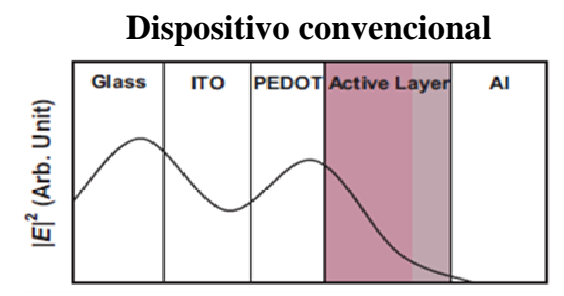

Dispositivo com espaçador ótico

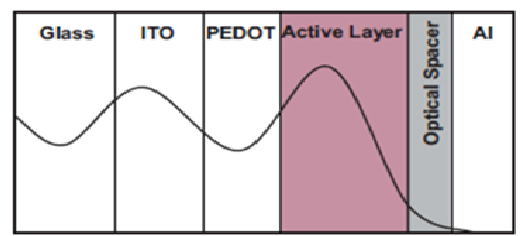

(b)
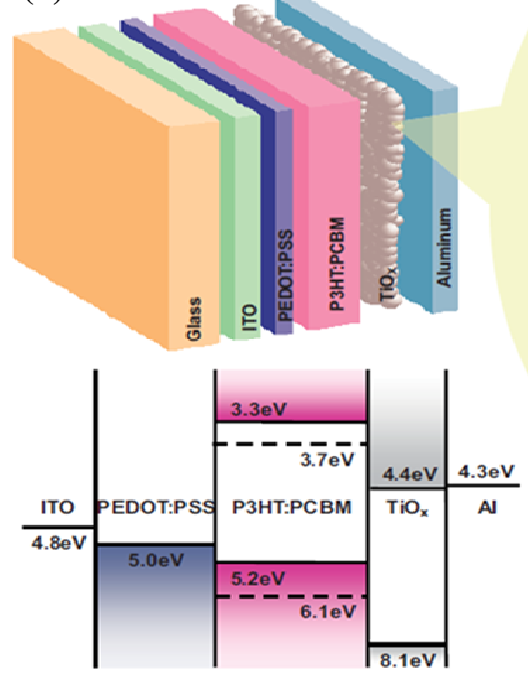

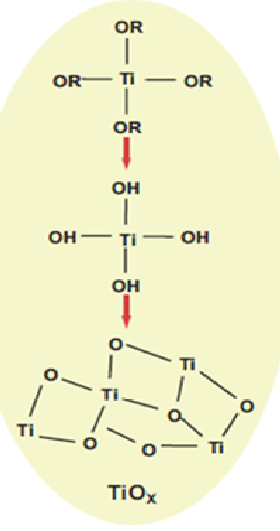

Figura 2.5 - (a) Representação esquemática da distribuição espacial do quadrado do campo elétrico irradiado $|\mathrm{E}|^{2}$ internamente à célula solar com e sem espaçador óptico. (b) Ilustração da estrutura do dispositivo e dos processos envolvidos na preparação da camada de $\mathrm{TiO}_{\mathrm{x}}$. $\mathrm{O}$ diagrama de energia da célula fotovoltaica é mostrado abaixo. Adaptado da referência [55].

Por causa de interferência óptica entre a luz incidente (pelo lado do ITO) e refletida no eletrodo posterior, a intensidade da luz é zero no eletrodo metálico; a Figura 2.5.a mostra uma representação esquemática da distribuição espacial do quadrado do campo elétrico da radiação. Portanto, dependendo da espessura da camada ativa, uma 
fração considerável da mesma pode estar em uma região de baixa absorção na qual a fotogeração de portadores é reduzida. Um simples aumento da espessura da camada ativa não resolveria o problema, pois o aumento da resistência interna reduz enormemente o rendimento devido às baixas mobilidades envolvidas. Uma alternativa é alterar a arquitetura do dispositivo através da introdução de um espaçador óptico entre o material ativo e o $\mathrm{Al}$ com o intuito de redistribuir a intensidade do campo elétrico no dispositivo, assim como esquematizado na Figura 2.5.a. Dióxido de titânio $\left(\mathrm{TiO}_{\mathrm{x}}\right)$, um candidato promissor já utilizado em outras células tais como as de corantes (ou dyesensitized cells), foi obtido neste estudo por um processo sol-gel para posterior deposição por spin coating sobre a camada semicondutora (Figura 2.5.b).

Outra possibilidade é a fabricação de células solares tandem, nas quais duas ou mais células solares com diferentes espectros de absorção são conectadas para varrer ainda mais o espectro solar. Kim et al. fabricaram tal célula com todas as camadas processadas em fase líquida e utilizando-se de heterojunção composta por semicondutores poliméricos e derivados do fulereno: poli[2,6-(4,4-bis-(2-etil-hexil)-4Hciclopenta[2,1-b;3,4-b']ditiofeno)-alt-4,7-(2,1,3-benzotiadiazol)] (PCPDTBT): PCBM e P3HT:[6,6]-fenil-C71-butirato de metila $\left(\mathrm{PC}_{70} \mathrm{BM}\right)[56]$. $\mathrm{TiO}_{\mathrm{x}}$ transparente foi utilizado para permitir a fabricação de células empilhadas umas sobre as outras e conectá-las eletricamente (ver Figura 2.6.a). A camada de $\mathrm{TiO}_{\mathrm{x}}$ serve de transportadora e coletora de elétrons da primeira célula, além de suporte para a fabricação da segunda célula do dispositivo tandem. A estrutura utilizada é invertida, i.e. o compósito do polímero de pequeno bandgap PCPDTBT se encontra na célula anterior e o polímero de maior bandgap $\mathrm{P} 3 \mathrm{HT}$ na célula posterior. Rendimento de mais de $6 \%$ foi alcançado à $200 \mathrm{~mW} / \mathrm{cm}^{2}$. Outros detalhes sobre as células fabricadas individualmente e no tandem são relatados na Figura 2.6. 

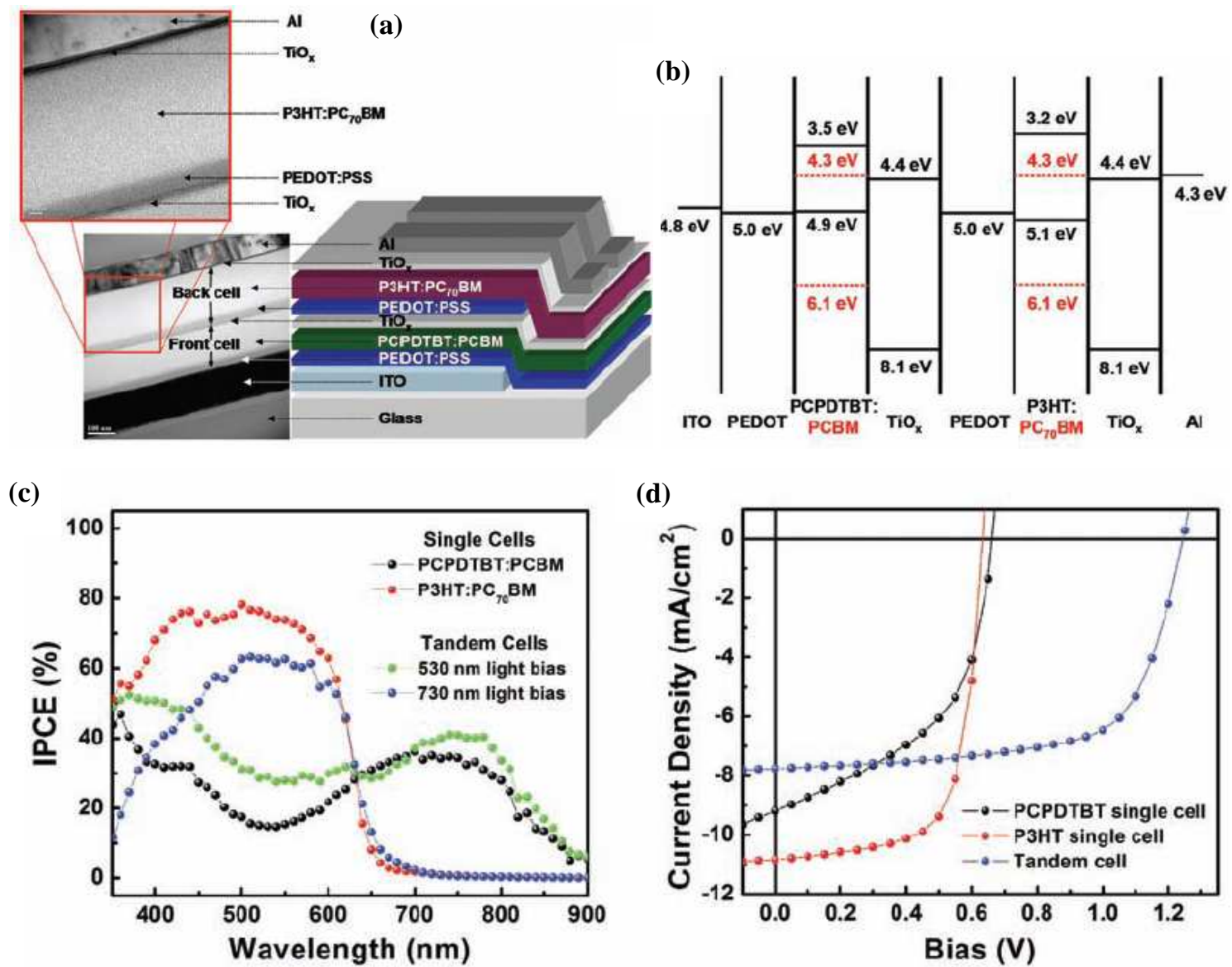

(d)

Figura 2.6 - (a) Estrutura do dispositivo (direita) e imagem de seção transversal obtida por microscopia eletrônica de transmissão (esquerda) da célula polimérica tandem. Barras de escala: $100 \mathrm{~nm}$ (imagem inferior) e $20 \mathrm{~nm}$ (imagem superior). (b) Diagrama de níveis de energia mostrando os níveis HOMO e LUMO de cada componente. (c) Espectro IPCE das células individuais e da tandem com iluminação bias. (d) Característica $J x V$ das células individuais e da tandem sob iluminação AM1,5G de um simulador solar calibrado a $100 \mathrm{~mW} / \mathrm{cm}^{2}$. Adaptado da referência [56].

\subsection{Transistores de filmes finos orgânicos}

A tecnologia em eletrônica tem evoluído rapidamente durante as últimas décadas e a tendência é que os dispositivos utilizados na vida moderna sejam cada vez mais rápidos e menores. Atualmente, quase todos os dispositivos eletrônicos são baseados em silício semicondutor, cuja geometria tradicional dos Transistores de Efeito de Campo 
(FET) utiliza substratos de silício coberto por dióxido de silício $\left(\mathrm{SiO}_{2}\right)$ obtido por crescimento térmico. Idealizado e patenteado por Lilienfeld em 1930 [57], porém fabricado pela primeira vez em 1960 nos laboratórios Bell por D. Kahng e M. Atalla [58], o transistor FET vêm sendo miniaturizado e integrado com milhões de outros transistores para implementação de circuitos de alta complexidade e sofisticação. No entanto, para uma maior integração e conseqüentemente menor tamanho conforme prediz a lei de Moore [59], há a possibilidade de superaquecimento e interferência (cross-talk) entre os componentes, afetando o desempenho global. Assim, uma solução para superar tal limitação é a utilização de novos materiais e tecnologias de fabricação para executar as mesmas funções comumente executadas por semicondutores convencionais.

Os Transistores de Filmes Finos Orgânicos (OTFT, do inglês Organic Thin Film Transistors) são um tipo de FET construído através de camadas orgânicas depositadas sobre substratos de baixo custo como vidros e plásticos. Estes materiais orgânicos podem ser depositados através de processos variados até em superfícies flexíveis, através de técnicas de fabricação a baixo custo interessantes à indústria eletrônica. OTFTs oferecem grande número de aplicações como: mostradores flexíveis [21], etiquetas de identificação por rádio freqüência [60], memórias [61], eletrônica têxtil [62], sensores químicos, biológicos e de pressão [20, 63, 64]. Além disso, há demanda por componentes pequenos, portáteis e baratos, principalmente com aplicações em diagnósticos médicos, monitoramento de alimentos, detecção de armas químicas e biológicas e para confecção de línguas e narizes eletrônicos. A geometria atualmente adotada em laboratórios de pesquisa é a bottom-gate (ver Figura 2.7.a-b) com a utilização de substratos de silício altamente dopado coberto por $\mathrm{SiO}_{2}$ térmico de alta qualidade, facilmente encontrados no mercado [65].

Recentemente, foi mostrado que dielétricos orgânicos são promissores para a construção de OTFTs, pois (i) podem ser processados através de soluções, (ii) produzem filmes finos em substratos de vidro transparente e de plástico, (iii) são adequados para a construção de OTFTs fotossensíveis na área da optoeletrônica devido à transparência óptica destes filmes, e (iv) podendo possuir uma constante dielétrica elevada de até 18 
[66, 67]. Uma oportunidade imediata de uso de camadas dielétricas orgânicas aparece em OTFTs top-gate (Figura 2.7.c-d), visto que o processo de deposição destes dielétricos orgânicos não danifica as camadas semicondutoras inferiores.

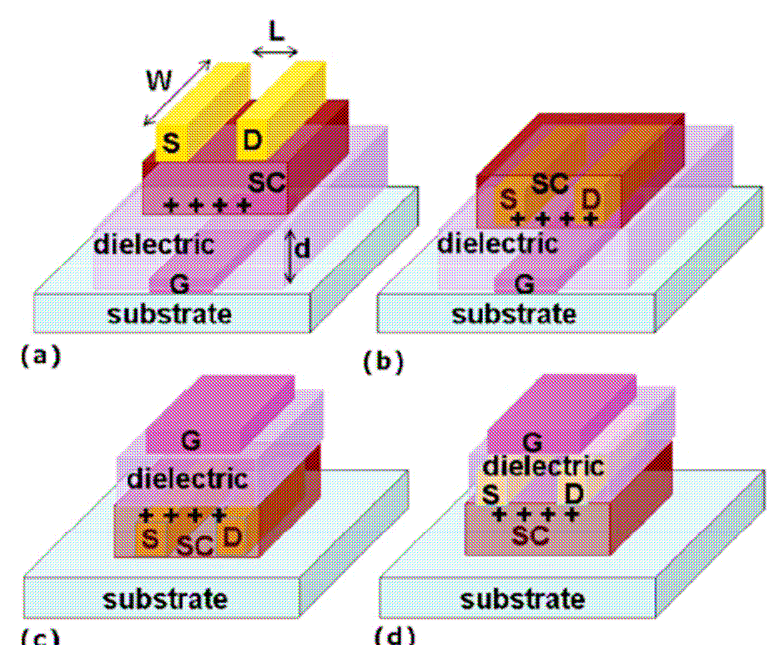

Figura 2.7 - Esquema com transistores de filmes finos orgânicos bottom-gate (a) topcontact (staggered) ou (b) bottom-contact (coplanar). Diagrama esquemático de estruturas de OTFT top-gate (c) bottom-contact e (d) top-contact. Adaptado da referência [65].

Os processos envolvidos na fabricação destas estruturas, assim como a modelagem do dispositivo final e a mobilidade no FET serão apresentados a seguir.

\subsubsection{Técnicas de formação de filmes orgânicos}

Polimerização eletroquímica foi a primeira técnica de formação de uma camada semicondutora empregada na fabricação de OTFTs. Consiste na reação de polimerização realizada diretamente sobre os eletrodos, posteriormente utilizados como contatos de fonte e dreno $[68,69]$.

Spin coating é talvez a técnica de deposição de filmes poliméricos mais utilizada em pesquisa por ser de baixo custo e permitir a produção de filmes homogêneos sobre 
grandes superfícies com controle perfeito sobre a espessura [70]. A aplicação da solução é realizada sobre a amostra rotacionando, sendo a freqüência de rotação e o tempo de processamento os principais parâmetros. Alternativamente, casting de materiais orgânicos é uma técnica de deposição por fase aquosa que consiste na aplicação direta da solução em um substrato imóvel. Devido ao maior tempo necessário para secagem da camada depositada, permite ao material em solução um tempo maior para se organizar e, portanto, atingir maior cristalinidade. Por outro lado, não permite um elevado controle sobre o valor da espessura da camada (geralmente, $>1 \mu \mathrm{m}$ ) e sua homogeneidade [71].

Evaporação em vácuo, por sua vez, é desejável para pequenas moléculas, devido à impossibilidade de se obter soluções de alta viscosidade destes materiais para deposição por spin coating. Fornece um controle preciso da espessura e pureza do filme, além de um elevado grau de ordenação para baixas taxas de deposição [72].

Uma alternativa para deposição de filmes finos de pequenas moléculas ou polímeros conjugados é a automontagem ou Electrostatic Self-Assembly (ESA), que utiliza duas espécies iônicas para formar bicamadas sucessivas de filmes finos [73]. Ideal para filmes nanométricos, destaca-se por ser de baixo custo e simples, ocorrer à temperatura ambiente e permitir um controle preciso da estrutura e da espessura do filme.

Técnicas de deposição por impressão estão em maior desenvolvimento na atualidade, sendo capazes de produzir circuitos de forma rápida e a baixo custo. As principais são por jato de tinta (inkjet) [22], screen printing [74], roll-to-roll [75] e microcontato [76], capazes de fornecerem resolução de até $2 \mu \mathrm{m}$. Estas tecnologias de fabricação têm evoluído muito nos últimos anos, mas mostram que há a necessidade de aprimoramento das técnicas para obtenção de interfaces de melhor qualidade e maiores mobilidades de portadores. Dentre os compostos orgânicos aplicados em EO, devido à grande quantidade de técnicas de deposição e baixo custo de processamento, os materiais baseados em polímeros $\pi$-conjugados aparecem como os mais promissores para aplicação em circuitos flexíveis, multifunção e econômicos.

\subsubsection{Modelagem das curvas características dos OTFTs}


A maior parte dos transistores de filmes finos orgânicos encontrados na literatura possui a estrutura de um transistor de efeito de campo (FET), cuja condução ocorre no canal entre os eletrodos de fonte e dreno e é controlada pela tensão de porta, sendo a corrente de porta igual a zero [77, 78]. A escolha pela estrutura Metal-IsolanteSemicondutor (MIS) se deve à ampla utilização de transistores MOSFET (a tecnologia metal-oxide-semiconductor FET mostrada na Figura 2.8 atualmente domina o mercado antes pertencente ao bipolar de junção - TBJ) e por ser a estrutura mais empregada em TFTs de silício amorfo [79].

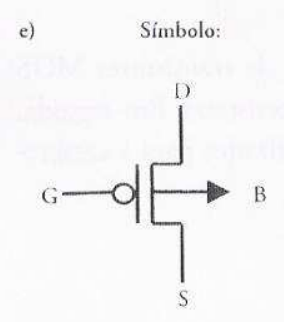

(c)

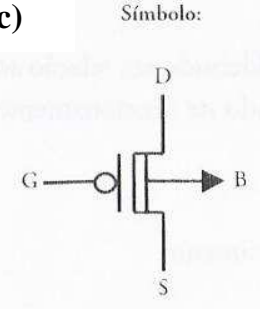

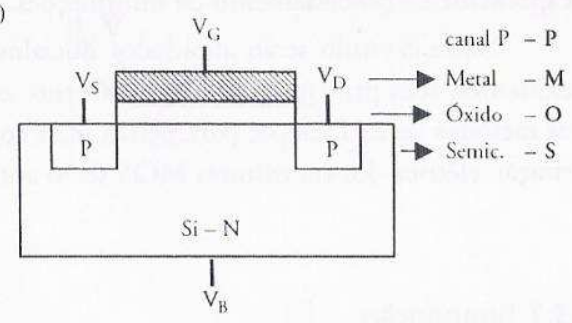

(d)

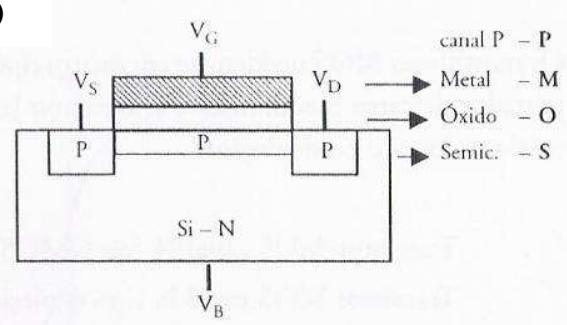

Figura 2.8 - Perfil dos diversos tipos de transistores MOS e sua respectiva simbologia: (a) e (b) p-MOSFET tipo enriquecimento; (c) e (d) p-MOSFET tipo depleção. Adaptado da referência [79].

A estrutura central do dispositivo é o capacitor $M I S$, em que o eletrodo de porta controla a densidade de cargas no canal do transistor e, portanto, sua condutância. A densidade de cargas acumuladas em regime linear [80] pode ser descrita por:

$n_{Q}=\frac{C_{i}\left(V_{G S}-V_{T}\right)}{q}$ 
onde $q$ é a carga elementar e a capacitância por área:

$$
\mathrm{C}_{\mathrm{i}}=\frac{\kappa \varepsilon_{0}}{x_{i}}
$$

onde $\kappa$ é a constante dielétrica relativa, $\varepsilon_{0}$ a permissividade elétrica do vácuo e $x_{\mathrm{i}}$ a espessura do filme dielétrico. Diferentemente dos FETs tradicionais de enriquecimento e depleção mostrados na Figura 2.8, OTFTs funcionam por acumulação de cargas no canal. Embora semelhante ao tipo depleção, o semicondutor na interface com o dielétrico não necessita ser dopado para formação do canal, i.e. a camada semicondutora é somente de um tipo. Além disso, em estudos preliminares do dispositivo, considera-se a mobilidade constante. Transistores geralmente do tipo $\mathrm{p}$, para uma tensão nula entre porta e fonte $\left(V_{\mathrm{GS}}=0\right)$, já existe um canal formado que permitiria a passagem de uma corrente significativa entre fonte e dreno para $V_{\mathrm{DS}}$ diferente de zero (Figura 2.9.a). Logo, define-se para este tipo de transistor, uma tensão de limiar $\left(V_{\mathrm{T}}\right)$ positiva responsável por diminuir a concentração de lacunas na interface dielétrico/semicondutor e cortar a passagem de corrente no transistor. No entanto, em muitos p-TFTs orgânicos, a condutância é significativa mesmo para $V_{\mathrm{GS}}>50 \mathrm{~V}$ [71].

Dado que a concentração de cargas disponíveis para transporte no canal é função da diferença de tensão entre os terminais do capacitor $M I S$, o que aconteceria se a tensão de fonte fosse mantida constante e nula enquanto que a tensão de dreno fosse cada vez mais negativa (lembre-se que em um $p$-TFT as tensões de operação são negativas)? Observa-se neste caso uma distribuição de cargas não homogênea no canal e, quando $V_{\mathrm{GS}}-V_{\mathrm{DS}}>V_{\mathrm{T}}$, a concentração de lacunas é mínima perto do eletrodo de dreno, levando à competição entre dois fenômenos que ocorrem em paralelo: $i$ ) uma tensão de dreno cada vez mais negativa implicaria no aumento da corrente circulando entre os eletrodos de fonte e dreno; ii) estrangulamento do canal ao redor do dreno devido à baixa concentração de lacunas, tenderia a limitar a corrente no canal (fenômeno 
conhecido como pinch-off). Tal situação leva, na verdade, a saturação da corrente que, teoricamente, se manteria constante (Figura 2.9.b).
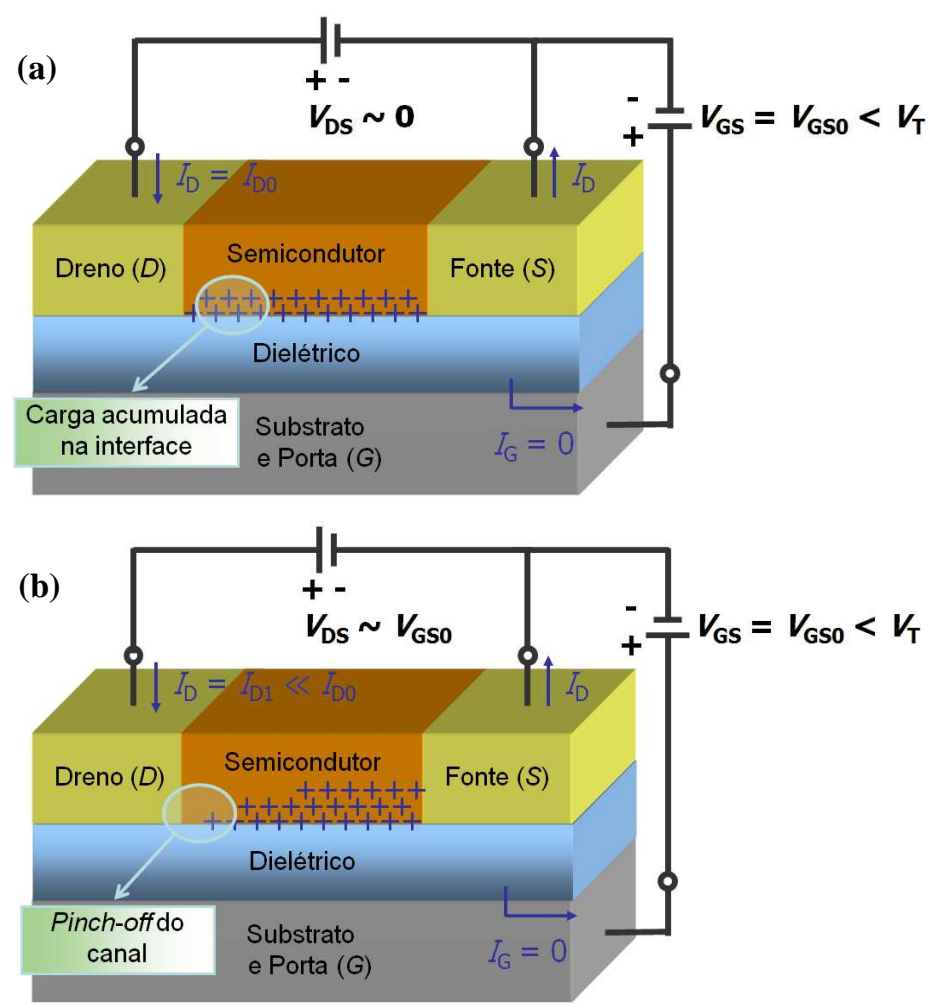

Figura 2.9 - Principais regimes de operação do p-OTFT: (a) linear e (b) saturação.

As curvas características de transistores p-OTFT são mostradas na Figura 2.10. A partir das curvas de $I_{\mathrm{D}} v s$. $V_{\mathrm{DS}}$, como descrito anteriormente, é possível observar que o dispositivo apresenta duas regiões distintas de operação: linear e saturação (ver Figura 2.10.a). A separação entre os dois regimes pode ser estabelecida por uma relação envolvendo as tensões $V_{\mathrm{DS}}$ e $V_{\mathrm{GS}}$ aplicadas, além da tensão de limiar ( $\left.V_{\mathrm{T}}\right)$ do dispositivo. Quando $\left|V_{\mathrm{DS}}\right|<\left|V_{\mathrm{GS}}-V_{\mathrm{T}}\right|$ para um dado $V_{G S}$ constante, o OTFT opera na região linear e a corrente de dreno pode ser descrita pela seguinte equação:

$$
I_{D}=\mu C_{i} \frac{W}{L} V_{D S}\left[\left(V_{G S}-V_{T}\right)-\frac{V_{D S}}{2}\right]
$$


onde $\mu$ é a mobilidade dos portadores, $W$ a largura do canal e $L$ o comprimento do canal. Observa-se que para baixas tensões de dreno, i.e. $V_{\mathrm{DS}} \ll 2\left(V_{\mathrm{GS}}-V_{\mathrm{T}}\right)$, a corrente apresenta comportamento linear (ou ôhmico) em função de $V_{\mathrm{DS}}$ :

$I_{D} \approx \mu C_{i} \frac{W}{L}\left(V_{G S}-V_{T}\right) V_{D S}$

Pode-se definir então a condutância do canal como sendo:

$g_{d}=\left.\frac{\partial I_{D}}{\partial V_{D S}}\right|_{V_{D S} \approx 0} \approx \mu C_{i} \frac{W}{L}\left(V_{G S}-V_{T}\right)$

Portanto, um aumento na tensão de porta implica no aumento da condutância do canal, além do adiamento do início da saturação de $I_{\mathrm{D}}$ (que ocorre para $\left|V_{\mathrm{DS}}\right|=\mid V_{\mathrm{GS}}-$ $\left.V_{\mathrm{T}} \mid\right)$.

Considerando agora $\left|V_{\mathrm{DS}}\right|>\left|V_{\mathrm{GS}}-V_{\mathrm{T}}\right|$ para um dado $V_{\mathrm{GS}}$ constante, o OTFT opera na região de saturação e a corrente de dreno não depende mais de $V_{\mathrm{DS}}$, podendo ser descrita pela seguinte equação:

$I_{D}=\frac{1}{2} \mu C_{i} \frac{W}{L}\left(V_{G S}-V_{T}\right)^{2}$

O mesmo modelo pode ser aplicado a $n$-OTFTs, levando-se em conta que as tensões de operação são positivas tanto para $V_{\mathrm{DS}}$ quanto para $V_{\mathrm{GS}}$. Assim como em $p$ TFTs, a tensão de limiar ( $\left.V_{\mathrm{T}}\right)$ é oposta a de trabalho (portanto, negativa) e o aumento de condutividade do canal é dado por acumulação de cargas negativas (ou elétrons) na interface semicondutor/dielétrico.

Analisando as curvas $I_{\mathrm{D}} v s$. $V_{\mathrm{GS}}$, é possível definir mais dois regimes de operação (ver Figura 2.10.b): um terceiro regime de operação onde o transistor está cortado pois $V_{\mathrm{GS}}<V_{\mathrm{ON}}$ (tensão característica para um dado transistor) e a corrente $I_{\mathrm{D}}=I_{\mathrm{OFF}} \approx 0$; um 
quarto regime de operação definido como regime sublimiar onde a corrente cresce exponencialmente com um aumento de $V_{\mathrm{GS}}$. Para este último, é possível definir a inclinação de sublimiar $(S)$, parâmetro que diz o incremento de tensão necessário para aumentar a corrente de dreno em uma década. Deseja-se que $S$ seja o menor possível, assim como a tensão de limiar, para que menores tensões de operação sejam atingidas. A partir da corrente de operação $\left(I_{\mathrm{ON}}\right)$ definida para um par $V_{\mathrm{DS}}$ e $V_{\mathrm{GS}}$ desejados, pode-se calcular a modulação de corrente que é a dada pela relação entre $I_{\mathrm{ON}}$ e $I_{\mathrm{OFF}}$. Na Figura 2.10.b, pode-se observar que o TFT é do tipo enriquecimento, pois $V_{\mathrm{T}}<0$. A transição entre depleção e enriquecimento em TFTs de um mesmo semicondutor pode ocorrer de acordo com o tratamento de superfície aplicado ao dielétrico em contato com o semicondutor [81].

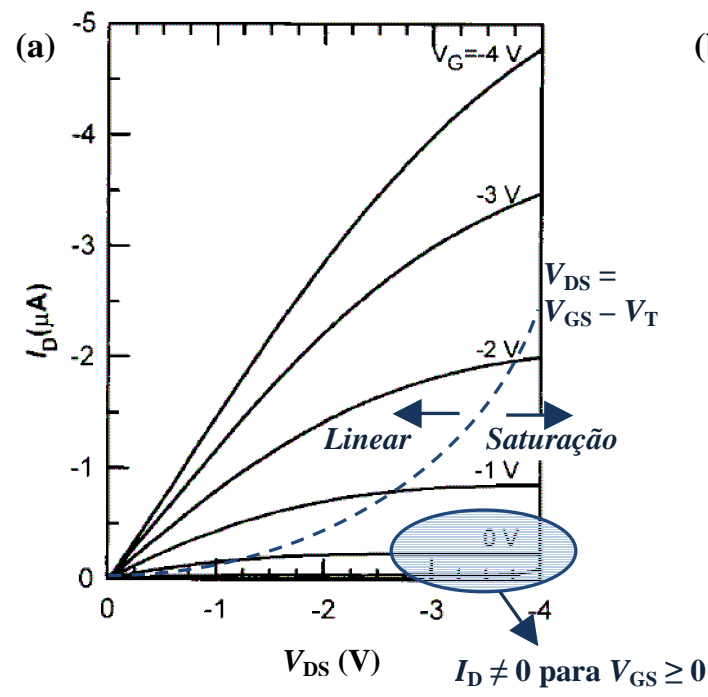

(b)

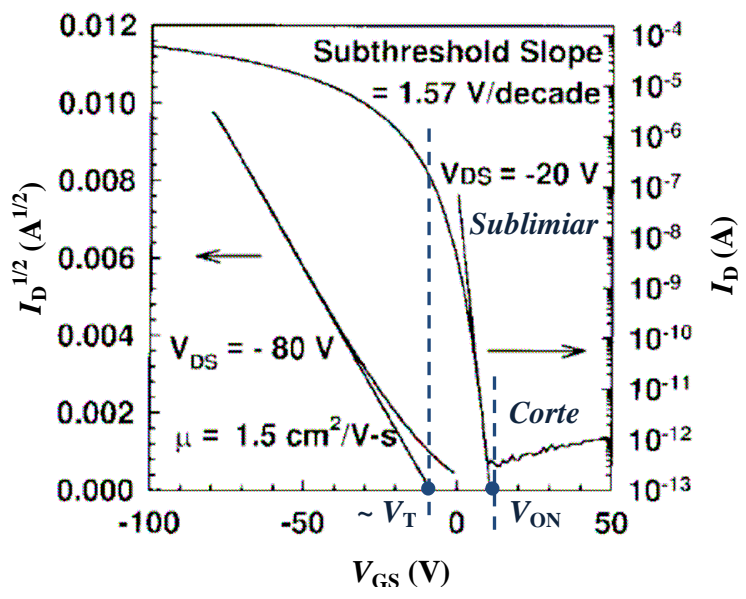

Figura 2.10 - Curvas características de TFTs de pentaceno: (a) $I_{D} v s$. $V_{D S}$ de um dispositivo em substrato de policarbonato (adaptado da referência [77]); (b) $I_{\mathrm{D}}{ }^{1 / 2} v \mathrm{~s}$. $V_{\mathrm{GS}}$ e $\log _{10}\left(I_{\mathrm{D}}\right) v s$. $V_{\mathrm{GS}}$ de um TFT com isolante Mylar $^{\mathrm{TM}}(900 \mathrm{~nm})$ substituindo o substrato (adaptado da referência [78]).

Assim como no caso de TFTs de silício amorfo, não-idealidades tais como histerese (Figura 2.11) e correntes de fuga pelo dielétrico $\left(J_{\text {leakage }}\right)$ afetam negativamente o desempenho do dispositivo [82]. Histerese é uma operação biestável da corrente do transistor e aparece como uma diferença em $I_{D}$ durante varreduras crescente (forward) e decrescente (backward) de tensão. Não é necessariamente uma característica 
indesejável, pois possui aplicação em memórias ferroelétricas a base de transistores de efeito de campo, mas deve ser evitada em circuitos integrados convencionais [83].

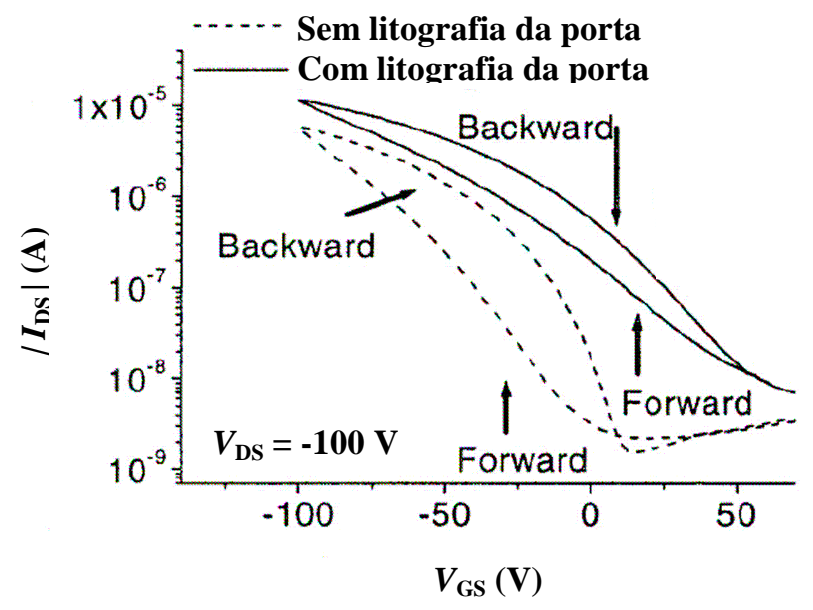

Figura 2.11 - Comparação entre as trans-características $\log _{10}\left(I_{\mathrm{D}}\right) v s$. $V_{\mathrm{GS}}$ de um $T F T$ de MDMO-PPV com porta não litografada (linhas tracejadas) e litografada (linhas sólidas). Adaptado da referência [82].

Diferente dos semicondutores inorgânicos monocristalinos, o transporte elétrico em materiais orgânicos é inerentemente anisotrópico em escala molecular. As cargas se encontram deslocalizadas em suas moléculas (ou ao longo do comprimento de conjugação das cadeias poliméricas), sendo o passo limitante no transporte o salto (comumente conhecido como hopping) intermolecular (ou entre cadeias) dos portadores de carga. Em um transistor orgânico, a mobilidade dos portadores é mais adequadamente assumida dependente da tensão de overdrive (i.e. a diferença entre a tensão de porta $V_{\mathrm{GS}}$ e a tensão de limiar $V_{\mathrm{T}}$ ) através de:

$\mu=k\left(V_{G S}-V_{T}\right)^{\gamma}$

onde $k$ contém informações sobre a morfologia do filme, estando principalmente relacionado com a facilidade de hopping entre sítios, e $\gamma$ está relacionado com a largura de uma distribuição de estados (DOS) exponencial através de $\gamma=2\left(T_{\mathrm{c}} / T-1\right)$. 
Uma explicação possível é dada pelo modelo Variable-Range Hopping proposto por Vissenberg e Matters [84], onde portadores participam do fluxo de corrente somente quando eles são excitados a um nível energético chamado de transporte. Se a concentração de portadores for elevada, a energia média inicial se aproxima da energia de transporte, o que reduz a energia de ativação necessária e, portanto, há um aumento significativo da mobilidade. Alternativamente, segundo o modelo de transporte de Multiple Trapping and Release [85], somente uma fração da carga induzida pela porta contribui ao fluxo de corrente no canal, a parte restante permanecendo aprisionada em uma cauda exponencial de estados localizados. Dado que a razão entre portadores livres e em armadilhas é maior em condições de alta injeção, a mobilidade aumenta com o aumento da tensão de porta. Tais considerações foram demonstradas relevantes no estudo de TFTs de poli(3-hexiltiofeno) (P3HT) [86]. Em ambos os casos, a corrente de dreno $I_{\mathrm{D}}$ em regime linear se torna:

$I_{D}=C_{i} \frac{W}{L} k\left(V_{G S}-V_{T}\right)^{\gamma+1} \cdot V_{D S}$

Em regime de saturação, a corrente passa a ser:

$I_{D}=C_{i} \frac{W}{L} k \frac{1}{\gamma+2}\left(V_{G S}-V_{T}\right)^{\gamma+2}$

A concentração máxima de armadilhas [87], que impactam no desempenho do transistor através da histerese em suas curvas características e de altos valores de inclinação de sublimiar $(S)$, pode ser estimada a partir de:

$N_{\text {trap } \max }=\frac{C_{i}}{q}\left(\frac{q S \log e}{k_{B} T}-1\right)$ 
onde $k_{\mathrm{B}}$ é a constante de Boltzmann, $T$ a temperatura, e $e$ a base do logaritmo natural. A presença de desordem no filme fino semicondutor geralmente implica no aparecimento de fenômenos do tipo Poole-Frenkel, em que a dependência da mobilidade de efeito de campo com o campo elétrico longitudinal pode ser descrita por:

$\mu=\mu_{0} \exp \left\lfloor\eta\left(\sqrt{\mathrm{E}}-\sqrt{\mathrm{E}_{0}}\right)\right\rfloor$

onde $\mu_{0}$ é a mobilidade quando $E=E_{0}, E_{0}$ é o campo elétrico crítico além do qual $\mu$ depende de $E$, e $\eta$ está relacionado à desordem do sistema. A relação entre $\eta$ e $\gamma$ pode ser deduzida a partir das equações (3) e (11) de [86].

Resistências de contato $\left(R_{\mathrm{S}}\right)$ elevadas diminuem a tensão efetiva aplicada ao transistor e, conseqüentemente, o desempenho do dispositivo [88]. Em TFTs de semicondutores de alta mobilidade (e.g. P3HT e pentaceno), o valor de $R_{\mathrm{S}}$ pode ser estimado a partir da resistência do dispositivo em regime linear $\left(R_{\mathrm{ON}}\right.$ ou $\left.R_{\mathrm{TOT}}\right)$ e da resistência do canal em regime linear $\left(\mathrm{R}_{\text {canal }}\right)$ :

$R_{\mathrm{ON}}=\frac{V_{D S}}{I_{D}}=R_{\text {canal }}+R_{S}=\frac{L}{W \mu_{i} C_{i}\left(V_{G S}-V_{T, i}\right)}+R_{S}$

onde $\mu_{\mathrm{i}}$ e $V_{\mathrm{T}, \mathrm{i}}$ são parâmetros intrínsecos do material. A resistência parasitária é normalmente modelada através da soma de uma parcela constante com outra que é função de $V_{\mathrm{GS}}$ :

$R_{S}=\frac{l_{0}}{W \mu_{c} C_{i}\left(V_{G S}-V_{T, c}\right)}+R_{S 0}$

onde $\mu_{\mathrm{c}}$ e $V_{\mathrm{T}, \mathrm{c}}$ representam regiões de menor mobilidade do desempenho, normalmente na interface semicondutor/eletrodos e, por este motivo, independente de $L$ [89]. 
Os principais parâmetros de um TFT são, portanto: mobilidade, modulação de corrente, inclinação de sublimiar, tensão de limiar, histerese e corrente de fuga. Novos materiais semicondutores sendo sintetizados cotidianamente, torna-se claro que a mobilidade dos portadores de carga provavelmente se tornará o fator principal de diferenciação e classificação destes materiais. Embora o objetivo esteja bem definido, conforme será visto a seguir, deve-se levar em conta que a acurácia na mobilidade extraída das curvas de um OTFT pode depender da estrutura empregada, solventes para deposição por fase aquosa, eletrodos, interface dielétrico/semicondutor, concentração de impurezas e condições de processamento dos filmes [90, 91]. Portanto, esta não deve ser considerada simplesmente uma propriedade do material, pois depende das condições de processamento, sendo extremamente sensível à morfologia em escala nanométrica do filme fino semicondutor [92].

\subsubsection{Mobilidade de efeito de campo no FET}

Conforme visto na Seção 1.1, materiais orgânicos podem ter suas propriedades alteradas de condutores a isolantes dependendo do grau de dopagem. Além disso, semicondutores orgânicos possuem mobilidade dependente de sua morfologia, campo elétrico interno e temperatura. A evolução no desempenho destes dispositivos está intrinsecamente relacionada com o estudo detalhado da influência de cada camada e condições de deposição em seu funcionamento. De fato, o primeiro FET orgânico apresentou mobilidades de efeito de campo de somente $10^{-5} \mathrm{~cm}^{2} / \mathrm{Vs}$ [68]. O material utilizado foi o politiofeno depositado por polimerização eletroquímica, técnica geralmente associada à formação de filmes orgânicos desordenados de baixa mobilidade.

No caso específico de poli(3-alquiltiofenos) (P3AT), a regularidade na disposição dos radicais na molécula pode afetar enormemente o transporte de carga no filme. Estes radicais podem ser incorporados à cadeia polimérica em duas regioregularidades diferentes: head to tail (HT) e head to head (HH) (ver Figura 2.12). Um polímero regiorandômico apresenta ambas as configurações em uma mesma cadeia e distribuídas randomicamente, enquanto que um polímero regioregular possui apenas 
uma destas regioregularidades em suas cadeias (i.e. $H H$ ou HT). Além da diferença estrutural entre estas moléculas, polímeros regioregulares tendem a apresentar menor energia de banda proibida, maior ordem e cristalinidade em estado sólido, além de eletrocondutividade aumentada. Bao et al. obtiveram em 1996 resultados notáveis mesmo nos dias de hoje em FETs de P3HT regioregular depositado por casting: $\mu$ $0,015-0,045 \mathrm{~cm}^{2} / \mathrm{Vs}$ e modulação de corrente de aproximadamente $10^{4}$ [71].

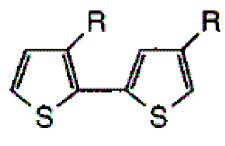

head-to-tail

(HT)

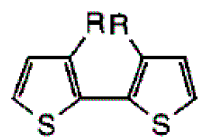

head-to-head

$(\mathrm{HH})$

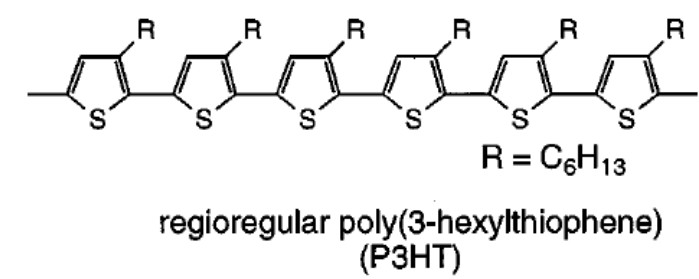

(P3HT)

Figura 2.12 - Regioregularidade em poli(3-hexiltiofenos). Adaptado da referência [71].

A morfologia final de um filme está relacionada com o solvente aplicado. Por exemplo, Bao et al. observaram que o P3HT precipitava durante a evaporação do solvente tetrahidrofurano $(T H F)$, resultando em um filme desuniforme e discontínuo. Microscopia eletrônica revelou a presença de cristais lamelares micrométricos e granulares nanométricos. Utilizando solventes tais como 1,1,2,2-tetracloroetano e clorofórmio, a mobilidade FET aumentou de $6,2 \times 10^{-4}$ a ca. $5 \times 10^{-2} \mathrm{~cm}^{2} / \mathrm{Vs}$ [71].

Filmes monocristalinos ou policristalinos altamente ordenados depositados por sublimação a vácuo apresentam mobilidades de efeito de campo acima de $0,1 \mathrm{~cm}^{2} / \mathrm{Vs}$ [93]. Alternativamente, algumas pequenas moléculas de grande interesse da comunidade científica pelas suas mobilidades elevadas, foram depositadas em fase líquida. Este é o caso de pentaceno $\left(0,1-0,5 \mathrm{~cm}^{2} / \mathrm{Vs}\right)$ [94] e politienileno vinileno $\left(0,22 \mathrm{~cm}^{2} / \mathrm{Vs}\right)$ [95] em que materiais precursores foram sintetizados de forma a converterem-se em polímeros durante o tratamento do filme pós-deposição e fornecerem os compostos desejados [1012]. No entanto, contornos de grão podem assumir um papel determinante na eficiência do componente, agindo como armadilhas para portadores e implicando na dependência da mobilidade com a temperatura [96]. Tendo conhecimento deste fator limitante, Lin e 
colaboradores [78] empregaram dois filmes de pentaceno empilhados depositados a temperaturas de substrato diferentes para obter $\mu=1,5 \mathrm{~cm}^{2} / \mathrm{Vs}$, modulação de corrente maior que $10^{8}, V_{\mathrm{T}} \approx-8 \mathrm{~V}$ e $S<1,6 \mathrm{~V} /$ década. O primeiro filme de $30 \mathrm{~nm}$ evaporado foi depositado no substrato a $90{ }^{\circ} \mathrm{C}$ e foi caracterizado por uma estrutura policristalina de elevada mobilidade interna ao grão. Na evaporação do segundo filme de $20 \mathrm{~nm}$, o substrato se encontra à temperatura ambiente, sendo responsável por preencher os vazios entre os grãos e aumentar a condutividade global.

Em OTFTs, a interface entre dielétrico de porta e semicondutor também desempenha um papel importante no transporte de carga, podendo representar um aumento de até três ordens de grandeza dependendo do dielétrico escolhido [97].

Comparando os dois grupos de materiais orgânicos mais utilizados, os polímeros apresentam a limitação de serem inerentemente mais desordenados que filmes de pequenas moléculas, apesar do fácil processamento a partir de uma solução e de sua utilidade em dispositivos multicamadas flexíveis. De forma geral, apesar da mobilidade inferior a de dispositivos semicondutores inorgânicos, foi descoberto recentemente que oligômeros $\pi$-conjugados altamente empilhados e polímeros como sexitiofeno, antraditiofeno e P3AT regioregular possuem mobilidades de efeito de campo de $10^{-2}-1$ $\mathrm{cm}^{2} / \mathrm{Vs}$, semelhantes às do silício amorfo [71]. Alguns vão além e vêm sendo utilizados como referência ao estudo de novos filmes semicondutores orgânicos $\left(e . g . \mu \sim 6 \mathrm{~cm}^{2} / \mathrm{Vs}\right.$ em TFTs de pentaceno [23] e fulerenos [24] tipo p e n, respectivamente). 


\section{MATERIAL E MÉTODOS}

\subsection{Estudo dos processos de fabricação de dispositivos orgânicos através de células solares de heterojunção}

\subsubsection{Fabricação de células solares orgânicas}

As células solares de bulk heterojunction foram fabricadas em uma estrutura vertical ou "sanduíche" de camadas (ver Figura 3.1.a). Os substratos são de vidro (Corning low alkaline earth boro-aluminosilicate, Delta Tech., $25 \times 25 \times 1,1 \mathrm{~mm}^{3}$ ) coberto por óxido de índio dopado com estanho (ITO, 4-8 $\Omega / \square$ ) ou de polietileno tereftalato (PET, $150 \times 150 \times 0,2 \mathrm{~mm}^{3}$ ) coberto por multicamadas transparentes de $\mathrm{In}_{2} \mathrm{O}_{3} / \mathrm{Au} / \mathrm{Ag}(\leq 10 \Omega / \square)$ ambos fornecidos pela Delta Technologies. Poli(3,4etilenodioxitiofeno) complexado com poli(ácido estireno-sulfônico) (PEDOT:PSS) é a camada transportadora de lacunas e bloqueadora de elétrons entre a camada ativa e o ânodo condutor transparente (CT). O compósito poli(3-hexiltiofeno) regioregular (Rieke Metals) e [6,6]-fenil-C61 butirato de metila (Nano-C), abreviado como rr-P3HT:PCBM, forma a camada ativa do dispositivo (ver Figura 3.1.b). Enfim, um cátodo de alumínio recobre o dispositivo ( $\mathrm{Al}$ ). Fluoreto de lítio $(\mathrm{LiF})$ pode ser usado como camada transportadora de elétrons e bloqueadora de lacunas antes da evaporação de alumínio.

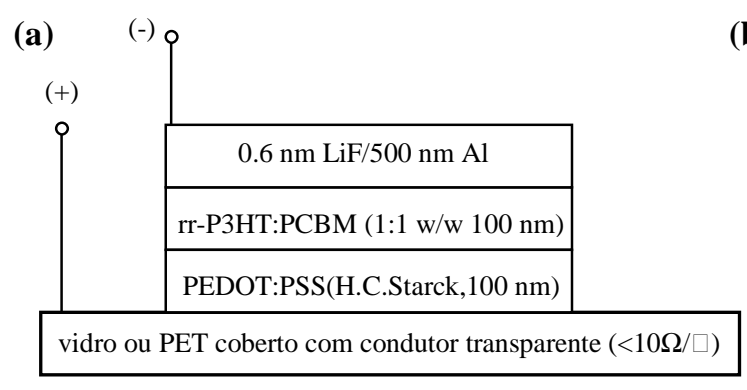

(b)

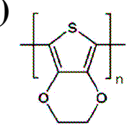

PEDOT
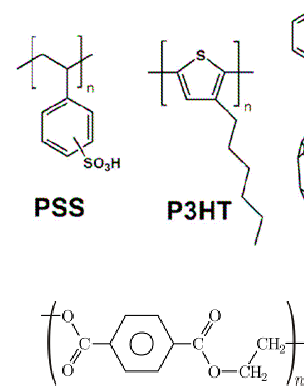

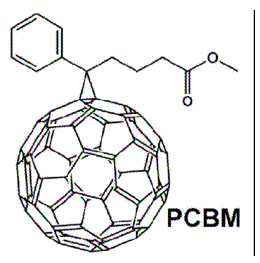

PET

Figura 3.1 - (a) Estrutura da célula solar orgânica de heterojunção. (b) Materiais orgânicos empregados nas células solares fabricadas. 
Os dispositivos fotovoltaicos foram integralmente fabricados na Fondazione Bruno Kessler $(F B K)$, situada no Trentino, província do norte da Itália com estatuto autônomo (Figura 3.2). O processamento foi realizado no Laboratório de Microfabricação (MFLab) em uma sala limpa de classe 10, onde 14 pesquisadores desenvolvem e controlam processos e 15 técnicos trabalham em processos padrão de microeletrônica e manutenção dos equipamentos. Em operação desde 1991, cobrindo uma área total de $500 \mathrm{~m}^{2}$, o laboratório é totalmente equipado para processar lâminas de silício de 4 polegadas com espessura de $200 \mu \mathrm{m}$ a 1,5 mm. Esta parte da atividade foi desenvolvida em colaboração com o grupo Advanced Photonics and Photovoltaics $(A P P)$ criado em 2009 pelo Dr. Georg Pucker.

(a)

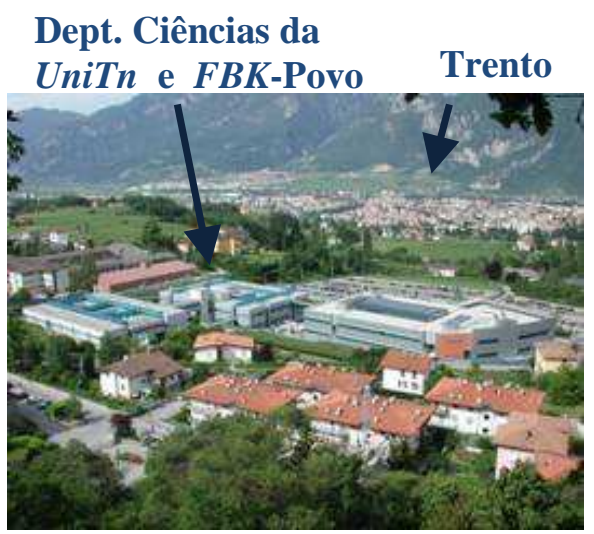

(b)

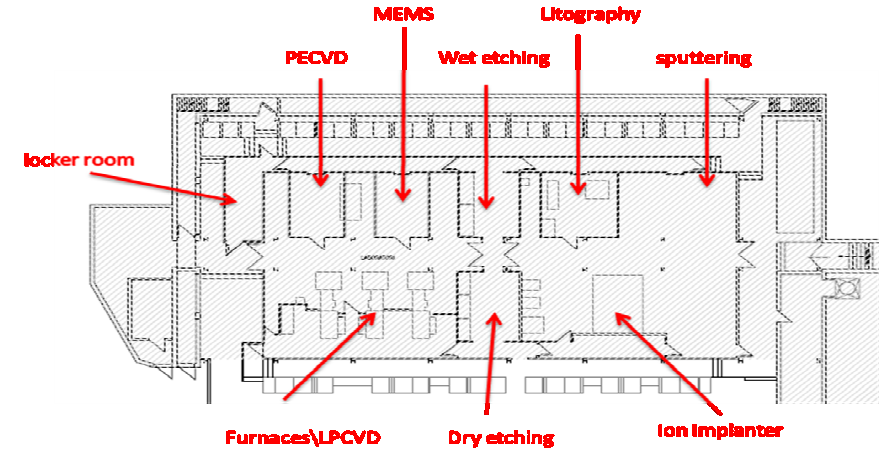

Figura 3.2 - (a) Instalação da FBK em Trento; (b) Planta da sala limpa situada no subsolo.

A fabricação dos dispositivos inicia com a definição e limpeza do ânodo transparente. O mascaramento dos contatos foi realizado com fita isolante e o ataque em solução aquosa dos ácidos clorídrico e nítrico $\left(\mathrm{HCl}: \mathrm{H}_{2} \mathrm{O}: \mathrm{HNO}_{3}\right.$, razão entre volumes 100:100:20). Após corrosão e limpeza em solventes tais como acetona, água e álcool isopropílico, PEDOT:PSS é depositado por spin coating a $5000 \mathrm{rpm}$ por $60 \mathrm{~s}$ e colocado para secar em um hot plate à $120^{\circ} \mathrm{C}$. A camada ativa de rr-P3HT:PCBM é depositada a partir de uma solução 3 wt\% em diclorobenzeno (DCB) em um spinner a baixa rotação (< $1000 \mathrm{rpm})$ durante $60 \mathrm{~s}$ e o solvente é evaporado em um hot plate à $50{ }^{\circ} \mathrm{C}$. As 
amostras são então carregadas em um evaporador térmico para deposição de LiF (6 Å) e $\mathrm{Al}(500 \mathrm{~nm})$. O tratamento térmico ou recozimento final pôde ser realizado em um hot plate ou em uma estufa a vácuo aquecida a $T>100{ }^{\circ} \mathrm{C}$, perto da temperatura de transição vítrea do material polimérico da camada ativa $\left(T_{\mathrm{g}}=110^{\circ} \mathrm{C}\right.$ para o P3HT) [98]. A utilização do solvente diclorobenzeno se deve a publicações de grupos tais como de N. S. Sariciftci na Johannes Kepler University Linz [44] e Y. Yang na University of California Los Angeles [54] que atingiram PCE $4 \%$. Um esquema ilustrativo de cada etapa da fabricação é mostrada na Figura 3.3.

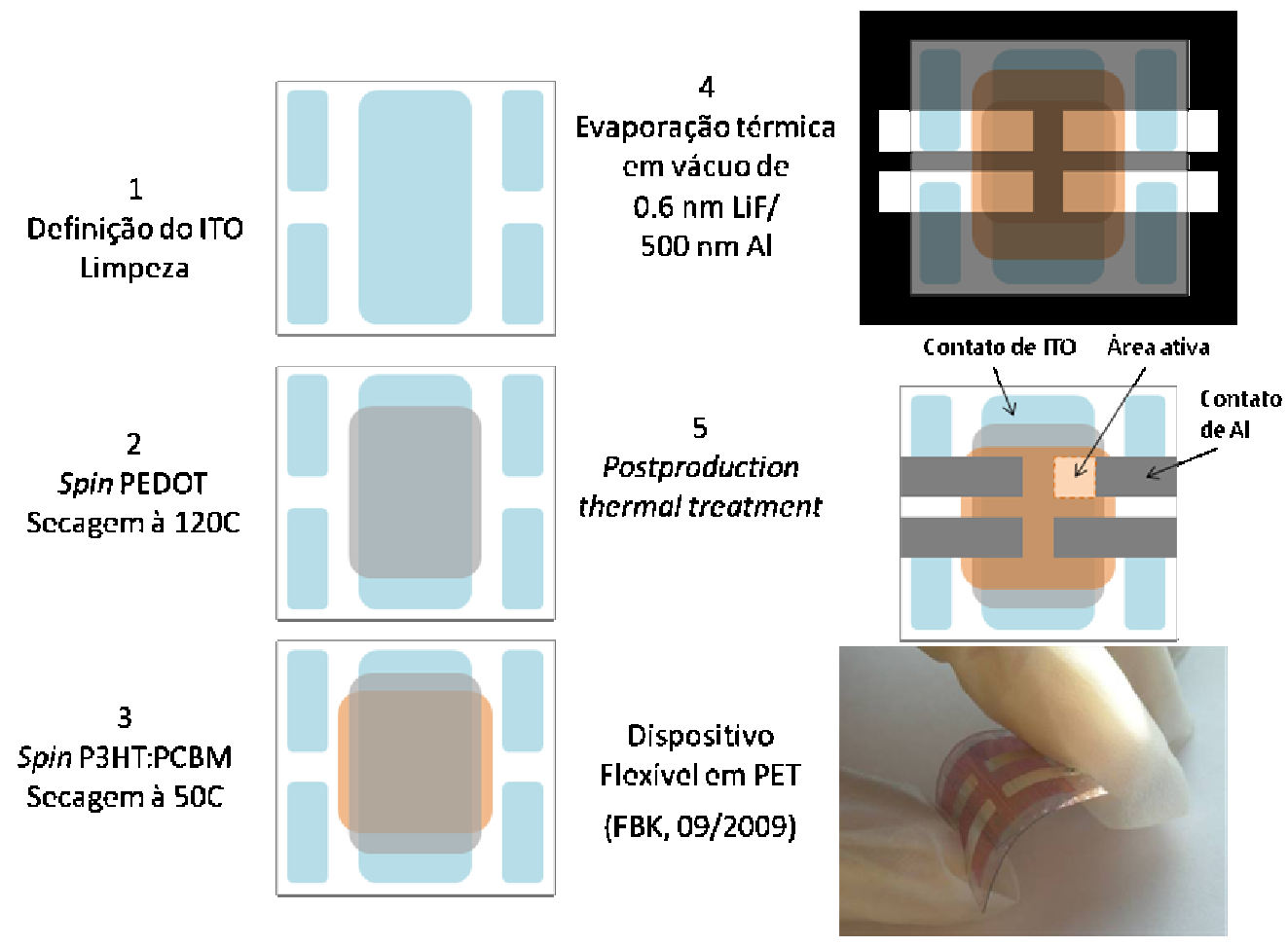

Figura 3.3 - (a) Esquema ilustrativo das diversas etapas de fabricação dos dispositivos fotovoltaicos.

\subsubsection{Caracterização dos dispositivos orgânicos fabricados}

A caracterização dos dispositivos fotovoltaicos foi realizada no Laboratório de Testes (TLab) da FBK através do simulador solar ABET Sun 2000 que fornece uma iluminação equivalente à $1 \mathrm{sol} \mathrm{AM} 1,5 \mathrm{G}\left(100 \mathrm{~mW} / \mathrm{cm}^{2}\right)$ à temperatura ambiente $\left(27^{\circ} \mathrm{C}\right)$. 
Um fotodiodo calibrado foi utilizado para medir a intensidade da luz antes das medições, de forma a identificar possíveis problemas no sistema. Os eletrodos foram contatados através de conectores do tipo "jacaré" conectados por sua vez a um Keithley 2410 HighVoltage SourceMeter. Ambos os instrumentos são controlados por uma estação de trabalho conectados por interface GPIB (Figura 3.4.a).

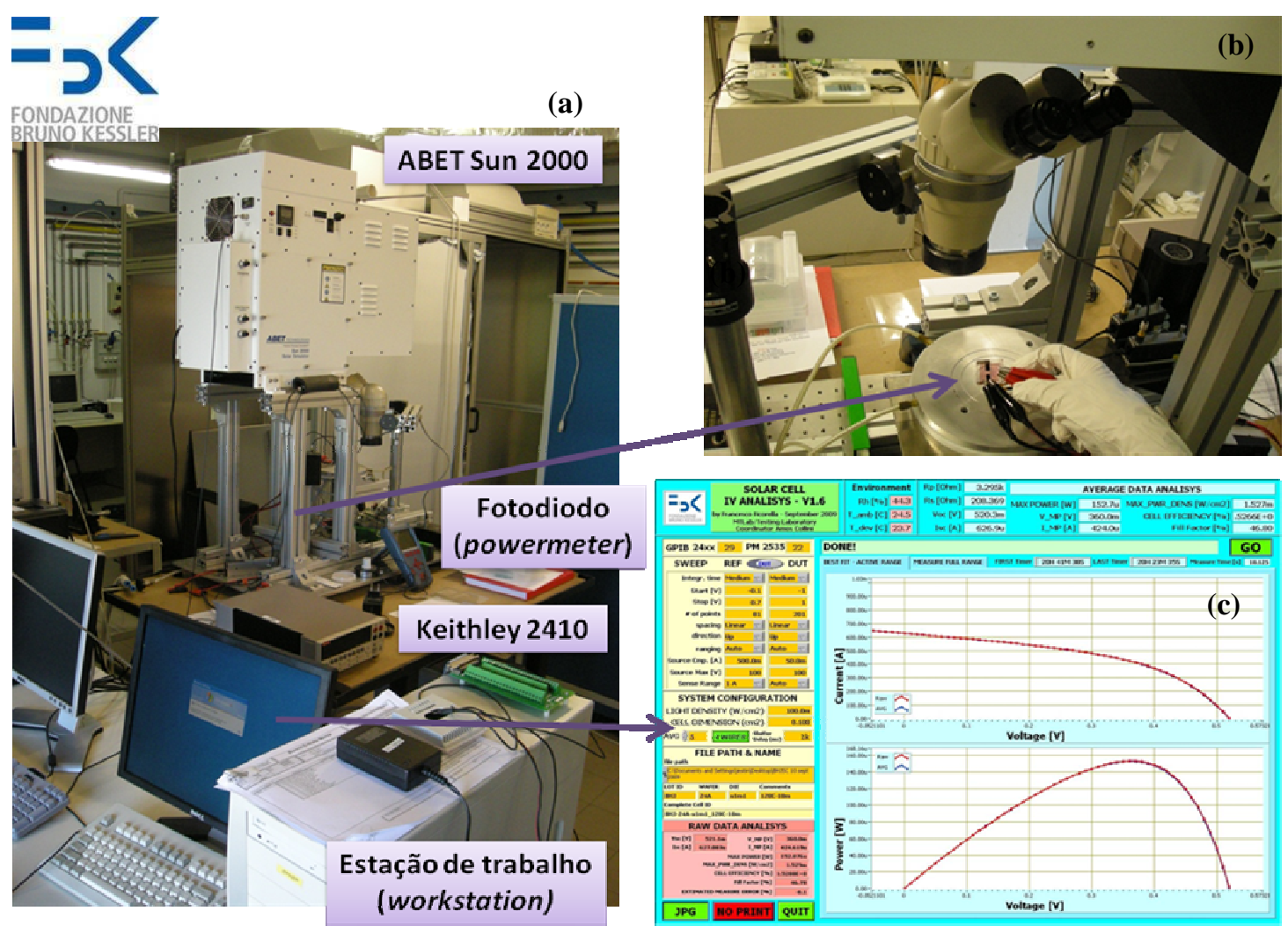

Figura 3.4 - (a) Sistema de caracterização de células solares utilizando o simulador solar ABET Sun 2000. (b) As conexões aos eletrodos foram realizadas através de conectores do tipo "jacaré" em um sistema a quatro pontas. (c) Interface LabVIEW ${ }^{\mathrm{TM}}$ utilizada para medições com o simulador solar do TLab-FBK.

As medidas com estes equipamentos foram sempre realizadas com quatro conectores (i.e. semelhante ao sistema de quatro pontas ou four-point probe measurements, porém neste caso com o objetivo de eliminar resistências elétricas parasitárias), sendo que dois conectores "jacaré" foram conectados ao ânodo (i.e. contato 
positivo) e os dois restantes foram conectados ao cátodo (i.e. contato negativo). Enquanto que um par de conectores positivo e negativo aplica uma tensão e mede a corrente que atravessa o circuito, o segundo par somente mede o potencial exatamente entre o ânodo e o cátodo (Figura 3.4.b). Este tipo de conexão fornece medidas $J x V$ mais precisas, eliminando a resistência série dos contatos e dos cabos.

Um programa baseado em interface LabVIEWTM foi aperfeiçoado pelo TestingLab $(F B K)$ durante este trabalho, tornando-o adequada para células solares orgânicas e estudos de degradação no tempo (Figura 3.4.c). O programa fornecia os dois gráficos necessários para o cálculo dos principais parâmetros de uma célula solar, i.e. corrente $v s$. tensão e potência $v s$. tensão. Os parâmetros extraídos das curvas são vistos no alto da Figura 3.4.c. Os parâmetros de entrada mostrados à esquerda são: área ativa, intensidade luminosa, varredura de tensão e limite de corrente (compliance). Os parâmetros de monitoração são: temperatura ambiente ( $\left.T_{-} \mathrm{amb}\right)$, temperatura do dispositivo ( $T_{-}$dev) e umidade relativa $(R \mathrm{~h})$. Os programas de computador ORIGIN $^{\Theta} \mathrm{e}$ Microsoft $\mathrm{Excel}^{\odot}$ foram utilizados para tratamento e graficação dos dados. O intervalo utilizado para varredura de tensão foi de -1 a $1 \mathrm{~V}$, observando-se uma densidade de corrente menor que $15 \mathrm{~mA} / \mathrm{cm}^{2}$ em módulo.

Um sistema de caracterização alternativo pôde ser utilizado para estudos preliminares, permitindo irradiar as células com diferentes graus de iluminação (Figura 3.5): um micromanipulador dentro de caixa preta com duas micropontas conectadas a um analisador de parâmetros de semicondutores HP 4156C que, por sua vez, era controlado remotamente por uma estação de trabalho. Uma lâmpada de xenônio fornecia luz branca de diferentes intensidades: 2,4, 12, 37,8 e $101 \mathrm{~mW} / \mathrm{cm}^{2}$. Diferentemente da primeira montagem, a caracterização $J x V$ sob iluminação é realizada a duas pontas.

\subsubsection{Extração dos principais parâmetros}

Basicamente, como visto na Seção 2.2.1, os principais parâmetros extraídos das curvas características da célula solar foram: tensão de circuito aberto $\left(V_{\mathrm{OC}}\right)$, densidade corrente de curto-circuito $\left(J_{\mathrm{SC}}\right)$, as coordenadas do ponto de máxima densidade de 
potência elétrica $\left(V_{\mathrm{mp}}, J_{\mathrm{mp}}\right)$, resistência paralela $\left(R_{\mathrm{sh}}\right)$ e resistência série $\left(R_{\mathrm{s}}\right)$ da curva de densidade de corrente $v s$. potencial; ponto de máxima potência $\left(P_{\mathrm{mp}}\right)$ da densidade de potência elétrica vs. potencial. A Figura 3.6 ilustra como extrair todos estes parâmetros.

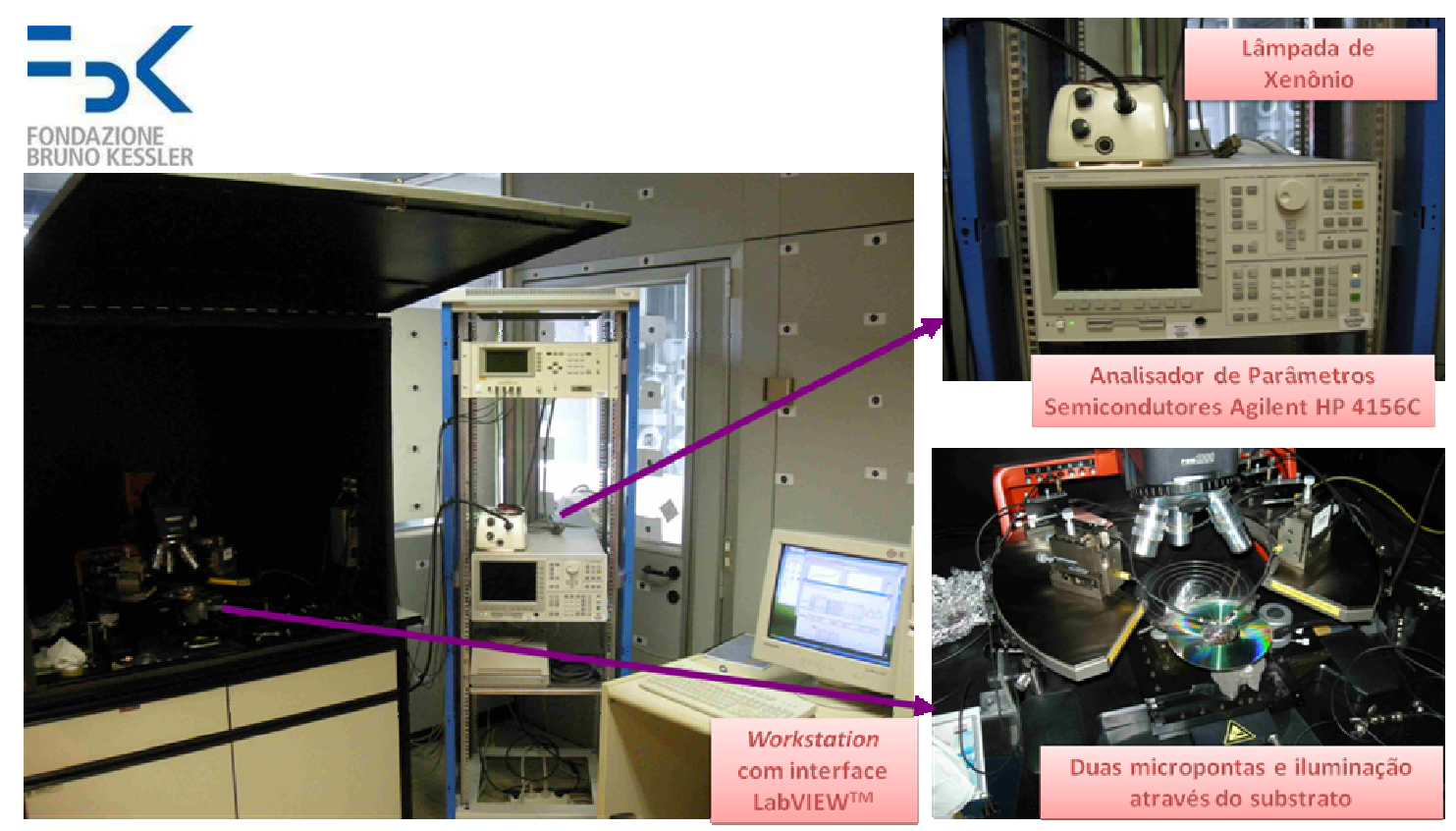

Figura 3.5 - Sistema de caracterização de células solares alternativo para estudos preliminares com um micromanipulador e uma lâmpada de xenônio.

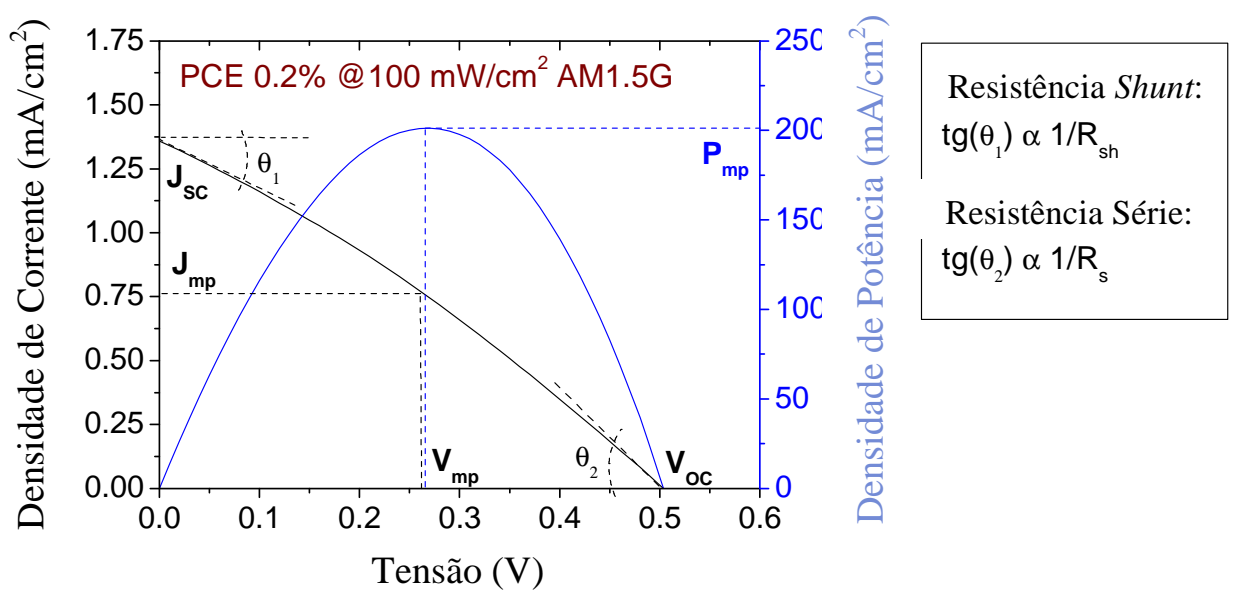

Figura 3.6 - Gráfico ilustrativo de como extrair os principais parâmetros de uma célula solar a partir de suas curvas $J x V$ e $P x V$. 


\subsection{Determinação da mobilidade de portadores em semicondutores orgânicos comerciais}

Inicialmente, foi realizada uma pesquisa dos aspectos teóricos e práticos envolvidos na medição da mobilidade dos portadores de carga em filmes finos

orgânicos. Após esta etapa, foram preparadas as amostras necessárias para obter a mobilidade de cada material. Dependendo do material estudado, foi escolhido um conjunto de técnicas para medição da mobilidade dos portadores. É dada preferência à técnica de Time of Flight (ToF) por ser a forma mais direta de medir mobilidade [99, 100]. A montagem experimental para sua realização é descrita na literatura [100]. Devido a limitações existentes à aplicação desta técnica que requer excitação óptica por laser e espessuras da ordem de micrômetros, foram aplicadas técnicas alternativas que foram apresentadas na Seção 2.1.

As amostras são compostas por um substrato de vidro coberto com óxido de índio dopado com estanho (ITO), o filme a ser estudado e um eletrodo superior. A limpeza inicial do ITO (Delta Tech., não polido, 30-60 $\Omega / \square$ ) foi realizada em banhos ultrassônicos de acetona (20 min) e álcool etílico (10 min), intercalados por lavagem em água ultrapura (> $18 \mathrm{M} \Omega$ ). A secagem foi realizada com jato de gás nitrogênio seco. Os materiais disponíveis em nosso laboratório que foram submetidos a técnicas de caracterização da mobilidade são apresentados na Tabela 3.1. Os eletrodos evaporados utilizados foram ouro (Au), alumínio (Al) e fluoreto de lítio (LiF).

Dentre os materiais estudados nesta etapa estão MDMO-PPV (Merck OLED Materials GmbH, antiga Covion Organic Semiconductors $\mathrm{GmbH}$; peso molecular $\mathrm{Mw}=$ 1.150.000 g/mol e Mn = $170.000 \mathrm{~g} / \mathrm{mol}$ [92]) e MEH-PPV (Sigma-Aldrich, cód. 536512 , 06/2007; peso molecular médio Mn 150000-250000). Estes são depositados em solução de clorofórmio por spin coating após agitação por $24 \mathrm{~h}$ e filtragem a $1 \mu \mathrm{m}$. As amostras são então aquecidas a $55{ }^{\circ} \mathrm{C}$ e 0,4 mbar durante $60 \mathrm{~min}$ para evaporar o solvente. As diferentes espessuras apresentadas são obtidas variando-se a freqüência de rotação do spinner e a concentração da solução. No caso específico do MDMO-PPV, foram 
preparadas soluções de 7 e $20 \mathrm{mg} / \mathrm{ml}$ depositadas à 500, 1000 ou mesmo $3000 \mathrm{rpm}$. Devido à necessidade de obtenção de um contato ôhmico para lacunas visando atingir correntes limitadas pela carga espacial acumulada no volume do material (ver Seção 4.2.3), um filme de $40 \mathrm{~nm}$ de poli(3,4-etilenodioxitiofeno) complexado com poli(ácido estireno-sulfônico) (PEDOT:PSS ou CLEVIOS-P ${ }^{\circledR}$ da H.C. Starck) é depositado entre ânodo e semicondutor. Sua deposição é por spin coating em solução aquosa a 3000 rpm por $30 \mathrm{~s}$ com subseqüente aquecimento a $100^{\circ} \mathrm{C}$ por $10 \mathrm{~min}$ em vácuo.

Tabela 3.1 - Materiais orgânicos cuja mobilidade de seus portadores foi investigada neste trabalho.

\begin{tabular}{|c|l|}
\hline Fabricante & \multicolumn{1}{|c|}{ Material orgânico } \\
\hline Merck & poli(2-metoxi-5-(3',7'-dimetiloctiloxi)-1,4'-fenileno vinileno) (MDMO-PPV) \\
\hline Aldrich & $\begin{array}{l}\text { pentaceno, poli(3-hexiltiofeno) (P3HT) } \\
\text { poli(2-metoxi-5-(2-etil-hexiloxi)-1,4-fenileno vinileno) (MEH-PPV) }\end{array}$ \\
\hline
\end{tabular}

Os equipamentos utilizados (Figura 3.7) foram disponibilizados pelo Prof. Sérgio Mergulhão do Departamento de Física da Universidade Federal de São Carlos (UFSCar). No levantamento de curvas de densidade de corrente por tensão $(J x V)$ foi utilizada uma fonte de tensão programável Keithley 230. Uma fonte de alta tensão Keithley 237, um osciloscópio Tektronix TDS 340A, um gerador de função Agilent 33120A, um gerador de pulsos HP 8013B, e um laser de nitrogênio $(337,1 \pm 0,1 \mathrm{~nm})$ Oriel Instruments 79110 foram utilizados para medições de tempo de vôo. O pulso de laser possuía $5 \mathrm{~ns}$ de duração, $300 \mu \mathrm{J}$ de energia, $60 \mathrm{~kW}$ de pico de potência e 500 ps de jitter do pulso. Um pré-amplificador de baixo ruído Stanford Research Systems SR 570 foi utilizado em substituição à resistência série, porém um porta-amostra incluindo um potenciômetro (100 a $20000 \Omega$ ) foi construído durante a parte inicial desta etapa. O transiente de corrente no circuito foi obtido pela queda de tensão no resistor série dividida pelo valor da resistência série (Lei de Ohm). As medições puderam ser realizadas em vácuo e variando a temperatura através do uso de um Lake Shore 330, um criostato CTI-Cryogenics 350C e uma bomba de vácuo Alcatel Drytel micro HV. 


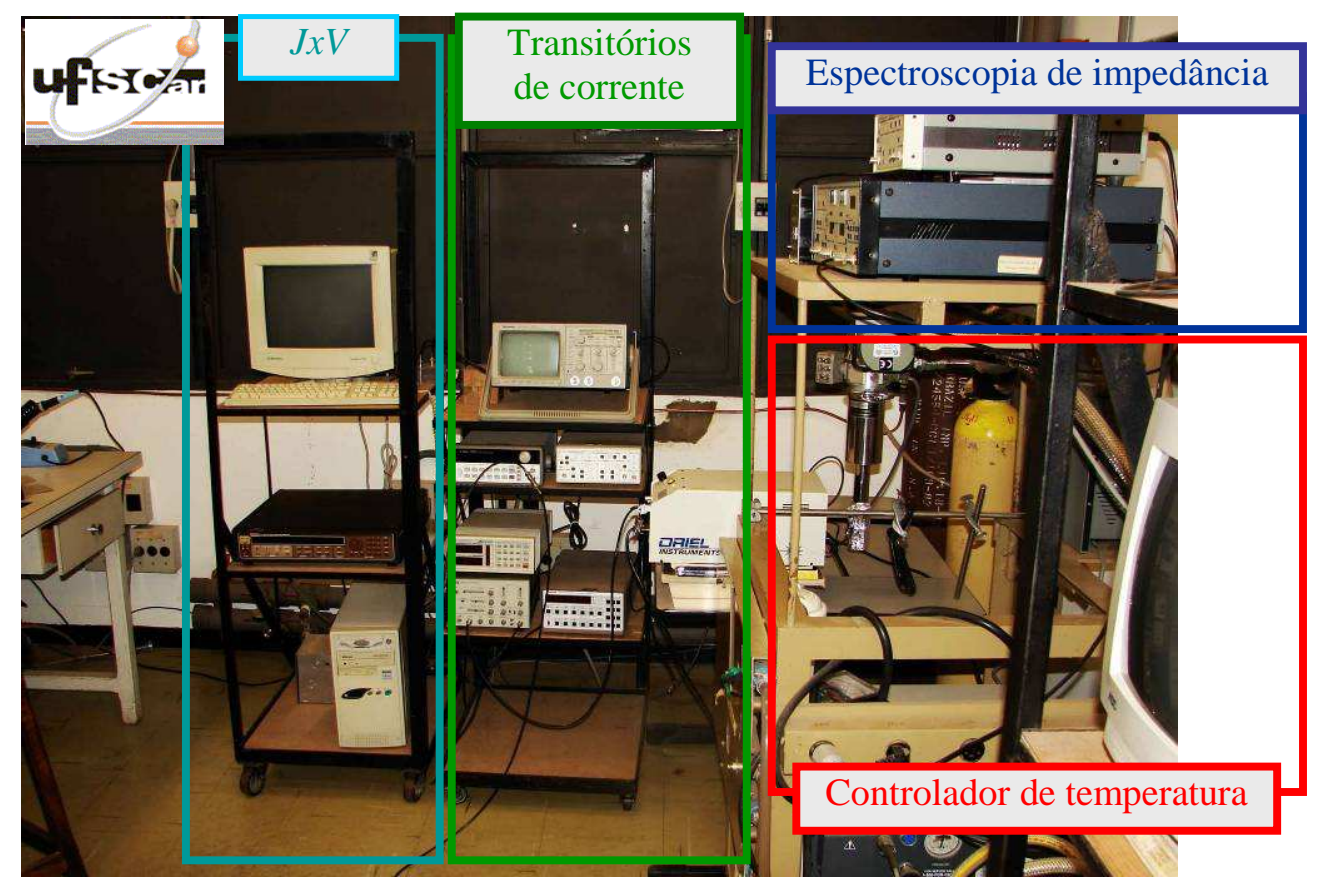

Figura 3.7 - Equipamentos utilizados na UFSCar para caracterização de filmes finos.

O espectro de absorção foi obtido com o espectrofotômetro UV-visível Shimadzu, UV-1650 PC. Sua importância está na extração dos picos de absorção dos materiais empregados e na definição do filtro de cor a ser utilizado com uma fonte luminosa de amplo espectro. A espessura dos filmes foi medida com um Alpha Step 100.

\subsection{Estudo dos processos envolvidos na fabricação de TFTs orgânicos e sua aplicação}

Consiste no desenvolvimento de uma metodologia de fabricação de OTFTs. Foi estudada e caracterizada em detalhes a estrutura FET bottom-gate/bottom-contact com porta comum, conforme indicado na Figura 3.8.

\subsubsection{Fabricação de TFTs orgânicos}


Dispositivos constituídos de substrato de silício monocristalino altamente dopado (camada SUB conforme Figura 3.8), óxido inorgânico (I), semicondutor orgânico (SC) e eletrodos metálicos (S-D). Os substratos utilizados foram lâminas de silício tipo p, espessas $350 \mu \mathrm{m}$, e altamente dopadas $(0,020-0,025 \Omega . \mathrm{cm})$, e vidro coberto por ITO; ambos cortados em amostras de $1 \times 1 \mathrm{pol}^{2}$. O silício foi tratado quimicamente em quatro etapas: (i) limpeza Piranha em $(3: 1) \mathrm{H}_{2} \mathrm{SO}_{4}: \mathrm{H}_{2} \mathrm{O}_{2}\left(105^{\circ} \mathrm{C}\right)$ por 15 min, seguida por uma lavagem em água corrente por 10 min e 5 min de cascatinha; (ii) limpeza RCA 1 em (5:1) $\mathrm{H}_{2} \mathrm{O}: \mathrm{NH}_{4} \mathrm{OH}: \mathrm{H}_{2} \mathrm{O}_{2}: \mathrm{H}_{2} \mathrm{O}$ ultrapura $\left(75^{\circ} \mathrm{C}\right)$ por 15 min, seguida por uma lavagem em água corrente por 10 min e 5 min de cascatinha; (iii) ataque em solução diluída de HF (ou decapante lento de vidro, DLV) por $15 \mathrm{~s}$ em becker de teflon, seguida de uma lavagem em água corrente por 15 min; (iv) limpeza RCA 2 em $(6: 1: 1) \mathrm{H}_{2} \mathrm{O}: \mathrm{H}_{2} \mathrm{O}_{2}: \mathrm{HCl}$ $\left(30^{\circ} \mathrm{C}\right)$ por $15 \mathrm{~min}$, seguida por $10 \mathrm{~min}$ de cascatinha e posterior secagem com $\mathrm{N}_{2}$ seco. A limpeza do ITO foi realizada segundo exposto na Seção 3.2.

Os dielétricos utilizados nesta etapa foram $\mathrm{SiO}_{2}$ por oxidação térmica seca e óxido de nitreto de silício $\left(\mathrm{SiO}_{\mathrm{x}} \mathrm{N}_{\mathrm{y}}\right)$ por deposição química a vapor assistida por plasma (PECVD). Uma espessura de $250 \mathrm{~nm}(450 \mathrm{~nm})$ de $\mathrm{SiO}_{2}$ foi crescida a $1100{ }^{\circ} \mathrm{C}$ por 120 $\min \left(180 \mathrm{~min}\right.$ ) sob fluxo de 774,6 sccm de $\mathrm{O}_{2}$ e 0,032 1/min de tricloroetano (C33), 30 min sob $1500 \mathrm{sccm}$ de $\mathrm{O}_{2}$, e $30 \mathrm{~min}$ sob $1500 \mathrm{sccm}$ de $\mathrm{N}_{2}$. A deposição por PECVD demandou uma mistura gasosa de precursores composta de $3 \mathrm{sccm}$ de silana $\left(\mathrm{SiH}_{4}\right), 150$ sccm de óxido nitroso $\left(\mathrm{N}_{2} \mathrm{O}\right)$ e $200 \mathrm{sccm}$ de hélio $(\mathrm{He})$ a $320{ }^{\circ} \mathrm{C}, 25 \mathrm{~mW} / \mathrm{cm}^{2}$ e 120 mTorr. Estas condições de deposição foram demonstradas ser responsáveis por uma melhor interface com o Si $\left(D_{i t} \sim 4 \times 10^{10} 1 / \mathrm{eV} . \mathrm{cm}\right)$, uma baixa densidade de carga efetivas $\left(N_{s s} \sim 10^{10}\right.$ charges $\left./ \mathrm{cm}^{2}\right)$ e elevada tensão de ruptura $(\sim 10 \mathrm{MV} / \mathrm{cm})$ [103]. A espessura deste dielétrico $\left(x_{i}\right)$ variou de 100 a $500 \mathrm{~nm}$.

Os eletrodos utilizados são de ouro $(100 \mathrm{~nm})$ por deposição física em fase vapor com vaporização por feixe de elétrons (electron beam PVD) e definido por lift-off. A relação largura/comprimento $(W / L)$ de canal varia entre 55 e 220, sendo $L$ igual 5, 10 e $20 \mu \mathrm{m}$. Em alguns dispositivos, foi empregado um filme fino de titânio para aumentar a aderência do ouro sobre o óxido de porta (5-20 nm). 


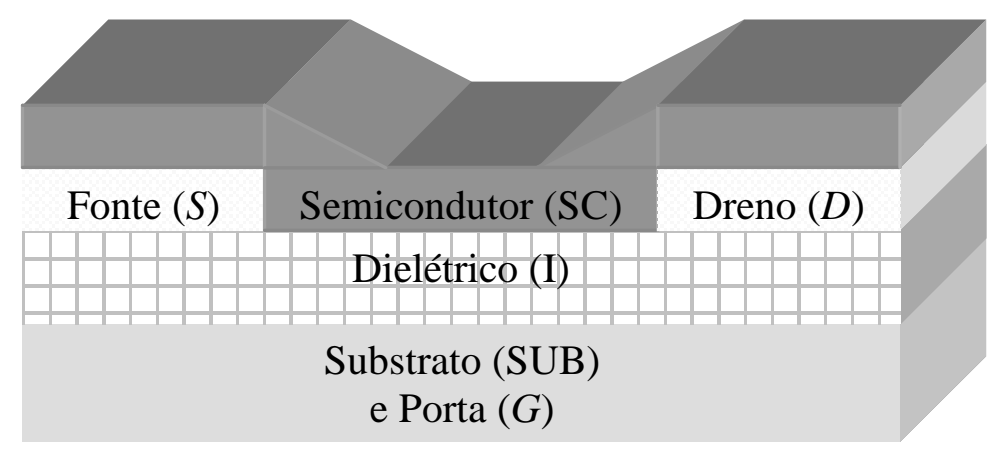

Figura 3.8 - Estrutura modelo para fabricação do OTFT

Os materiais semicondutores empregados foram (i) MDMO-PPV (100 nm), depositado em solução de $7 \mathrm{mg} / \mathrm{ml}$ de clorofórmio ou tolueno por spin coating a 3000 rpm em 60 s, (ii) MEH-PPV (80 nm), depositado em solução de 5 mg/ml de clorofórmio por spin coating a $3000 \mathrm{rpm}$ em 30 s, (iii) P3HT (Sigma-Aldrich, cód. 445703; regioregularidade > 98,5 \%, peso molecular médio Mn 25500, polidispersão PDI 1,48, $100 \mathrm{~nm}$ ), depositado em solução de $5 \mathrm{mg} / \mathrm{ml}$ de clorofórmio por spin coating a $3000 \mathrm{rpm}$ em $90 \mathrm{~s}$, e (iv) pentaceno (densidade de $1 \mathrm{~g} / \mathrm{cm}^{3}, 50 \mathrm{~nm}$ ), evaporado a uma taxa média de $1 \AA$ A s a $10^{-5}-10^{-6}$ mbar. Foram utilizados filtros Millipore de $1 \mu \mathrm{m}$ para remoção de particulados dos derivados de PPV e 0,45 $\mu \mathrm{m}$ para o polímero P3HT. Filmes de PPV foram postos em uma estufa a $55^{\circ} \mathrm{C}$ por $60 \mathrm{~min}$, enquanto que filmes de P3HT foram armazenados em um dessecador a vácuo por 24 horas. A taxa de evaporação do pentaceno não é constante e pode oscilar entre 0,1 a $5 \AA \AA$, dificultando a reprodutibilidade dos resultados em outras amostras. Um controlador de alta precisão foi comprado pelo GEM (EPUSP), porém não foi disponibilizado para este trabalho. A utilização do politiofeno foi resultado de uma colaboração entre o GEM e o Instituto de Física da USP em São Carlos, através do Prof. Dr. Roberto M. Faria e seu estudante de doutorado Alexandre de Castro Maciel [101].

Tratamentos da superfície do $\mathrm{SiO}_{2}$ foram realizados em duas etapas. Inicialmente os substratos são tratados com plasma de oxigênio por 10 min a $100 \mathrm{~W}, 100$ mTorr e 50 sccm. Em seguida, com intervalo menor que 5 minutos, as amostras são posicionadas dentro de uma placa de Petri grande que se encontra dentro de uma estufa a $110{ }^{\circ} \mathrm{C}$. 
Quatro mililitros de hexametildissilazana (HMDS) são pipetados dentro de uma placa de Petri pequena previamente posicionada dentro da grande. A placa de Petri grande e a estufa são fechadas e o sistema posto em vácuo $(0,4$ mbar) por 30 min. Todas as amostras tratadas possuíam $1 \times 1 \mathrm{~cm}^{2}$ de área. Ângulos de contato $(\theta)$ foram estimados através de inspeção visual e fotografias. A gota d'água utilizada possuía menos de 10 microlitros e foi aplicada no centro da amostra. A equação utilizada é apresentada em [102]:

$\theta=2 \tan ^{-1}\left(\frac{h}{a}\right)$

onde $h$ e $a$ estão indicados na Figura 3.9.
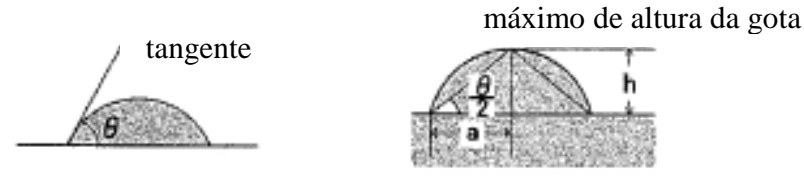

Figura 3.9 - Esquema ilustrativo de como calcular o ângulo de contato $\boldsymbol{\theta}$ de uma gota d'água sobre um dielétrico de porta. Adaptado da referência [102].

Capacitores MOS (Metal/Óxido/Semicondutor) em substratos pouco dopados (1$10 \Omega . c m)$ utilizando os dielétricos citados anteriormente foram fabricados para controlar parâmetros como constante dielétrica $(\kappa)$ e corrente de fuga. Foram utilizados um Keithley model 82-DOS Simultaneous C-V equipment para caracterização elétrica, um elipsômetro Rudolph Research Auto E1 com laser de He-Ne (632,8 nm) para medir espessura e um espectrofotômetro Bio Rad FTS-40 para controlar as ligações químicas presentes no filme. Maiores detalhes sobre a fabricação e a caracterização dos capacitores são encontrados em [103]. A máscara utilizada para definir o eletrodo de porta dos capacitores e o sistema de caracterização são apresentados na Figura 3.10. 

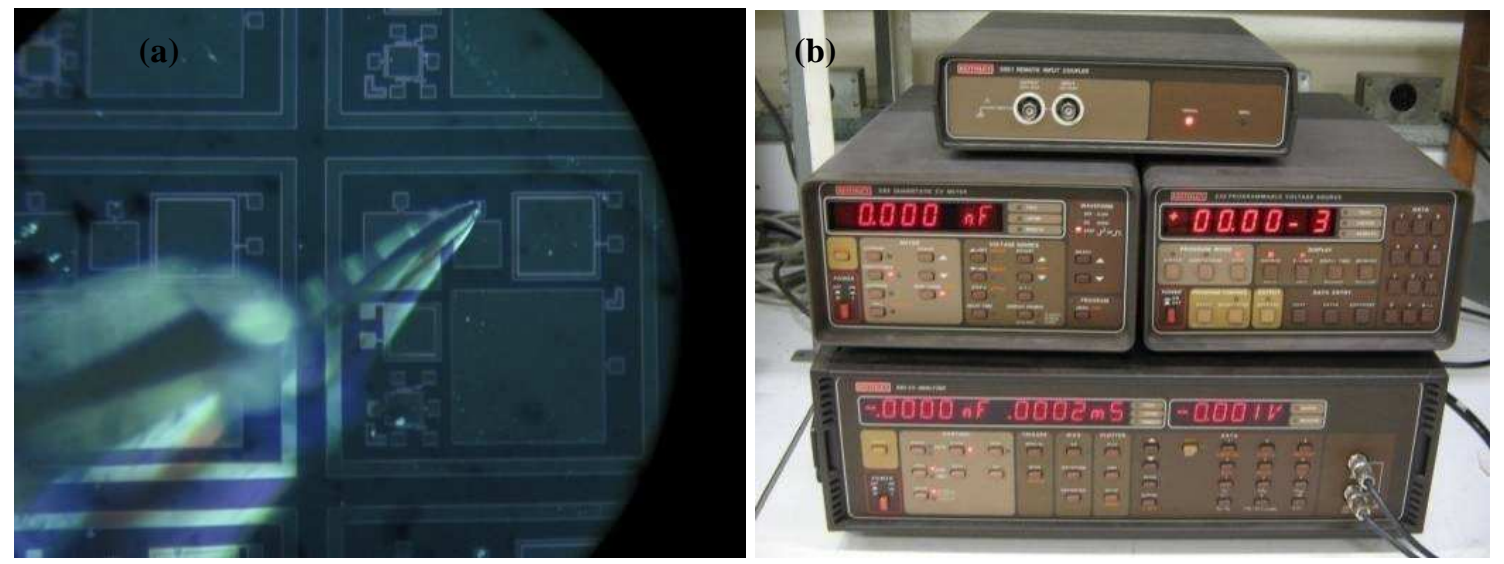

Figura 3.10 - Capacitores MOS: (a) micrografo ótico dos dispositivos; (b) sistema de caracterização.

Em geral, comprimento e largura de canal foram da ordem de 10 a $1000 \mu \mathrm{m}$ (ver Tabela 3.2), respectivamente. Na Figura 3.11, podem ser observados eletrodos de fonte e dreno definidos por fotolitografia. Na ausência de definição do eletrodo de ITO ou empregando-se lâminas de silício, a porta de todos os TFTs estavam curto-circuitadas. O spinner e a evaporadora para deposição de filmes finos orgânicos e eletrodos metálicos se encontram na Glove Box do LME-EPUSP (Projeto FAPESP 03/07454-5). Equipamentos de fotolitografia e electron beam $P V D$, além de fornos de oxidação e reator de PECVD, encontram-se na Sala Limpa do mesmo laboratório.

(a)

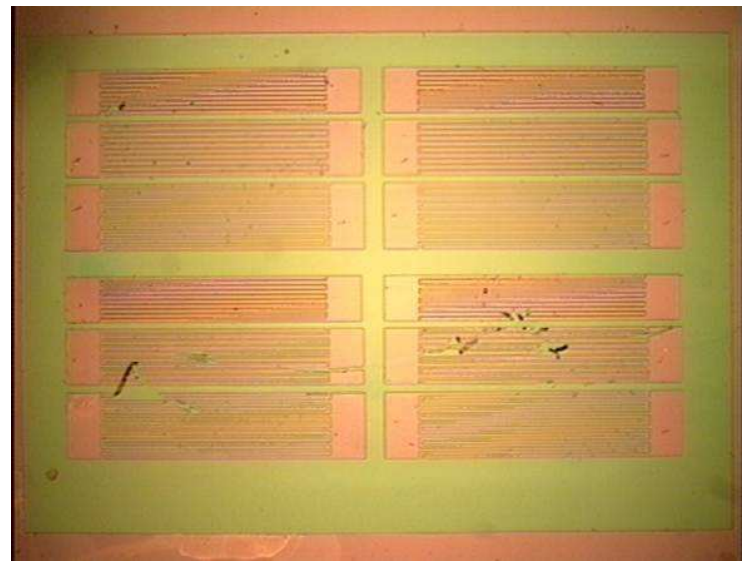

(b)

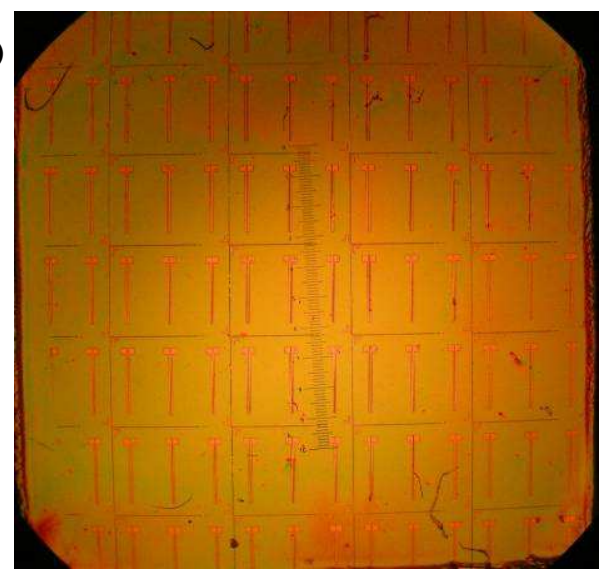

Figura 3.11 - Máscaras utilizadas para definição de eletrodos de fonte e dreno: (a) interdigitados em amostra de $1 \times 1$ pol $^{2}$ de MDMO-PPV sobre $\mathrm{p}+\mathrm{Si}_{-}-\mathrm{SiO}_{\mathrm{x}} \mathrm{N}_{\mathrm{y}}(268 \mathrm{~nm})$; (b) eletrodos paralelos em amostra de $1 \times 1 \mathrm{~cm}^{2}$ de MEH-PPV sobre $\mathrm{p}+\mathrm{Si}-\mathrm{SiO}_{2}(274 \mathrm{~nm})$ tratado com HMDS. 
Tabela 3.2 - Dimensões do canal segundo as máscaras fotolitográficas utilizadas.

\begin{tabular}{|c|c|c|c|c|}
\hline \multirow[b]{2}{*}{ Máscara } & \multicolumn{4}{|c|}{ Dimensões do canal } \\
\hline & $\underset{(\mu \mathrm{m})}{\operatorname{Comprimento}}\left(L_{\mathrm{M}}\right)$ & $\begin{array}{c}\text { Largura }\left(W_{M}\right) \\
(\mu \mathrm{m})\end{array}$ & $W_{\mathrm{M}} / L_{\mathrm{M}}$ & $\begin{array}{c}\text { Área do canal } \\
\left(10^{3}{\left.\mu \mathrm{m}^{2}\right)}^{2}\right.\end{array}$ \\
\hline \multirow{3}{*}{$\begin{array}{c}\text { Eletrodos } \\
\text { interdigitados }\end{array}$} & 10 & 20500 & 2050 & 205 \\
\hline & 20 & 20700 & 1035 & 414 \\
\hline & 30 & 20900 & 697 & 627 \\
\hline \multirow{3}{*}{$\begin{array}{l}\text { Eletrodos } \\
\text { paralelos }\end{array}$} & 5 & \multirow{3}{*}{1100} & 220 & 5,5 \\
\hline & 10 & & 110 & 11,0 \\
\hline & 30 & & 37 & 22,0 \\
\hline
\end{tabular}

\subsubsection{Caracterização dos transistores orgânicos fabricados}

As curvas características do TFT são de $I_{\mathrm{D}}$ em função de $V_{\mathrm{GS}}$ e de $I_{\mathrm{D}}$ em função de $V_{\mathrm{DS}}$. A primeira é traçada para diferentes valores de $V_{\mathrm{GS}}$, enquanto que a segunda requer diferentes valores de $V_{\mathrm{DS}}$. Os equipamentos que compõem o sistema de caracterização são um micromanipulador da MM e um analisador de parâmetros HP 4156A do LME-EPUSP (Figura 3.12). Foram utilizados tempo de integração curta, tempos de retenção ou atraso nulos, sendo a amostra mantida a temperatura ambiente, no escuro e exposta à atmosfera.

(a)

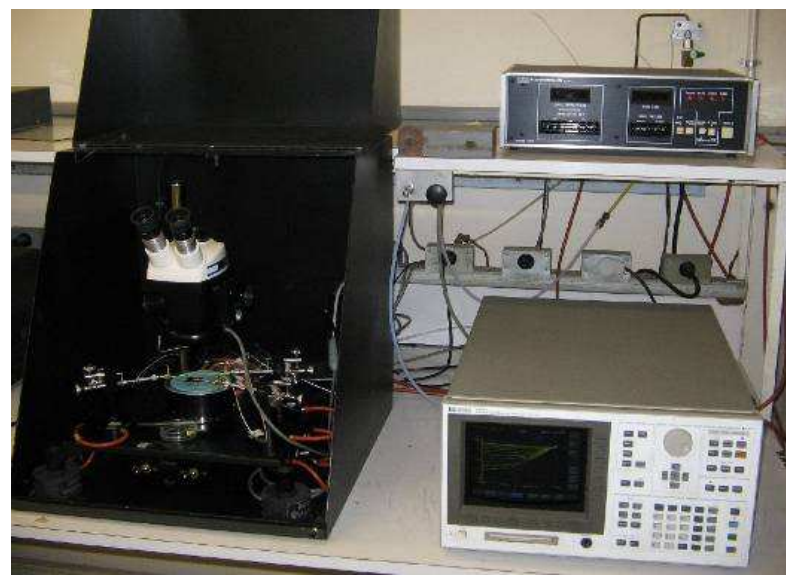

(b)

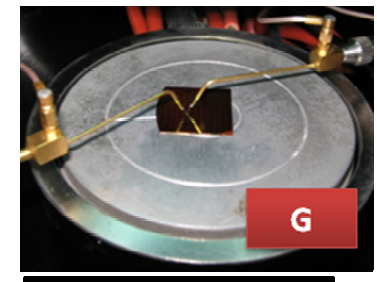

(c)

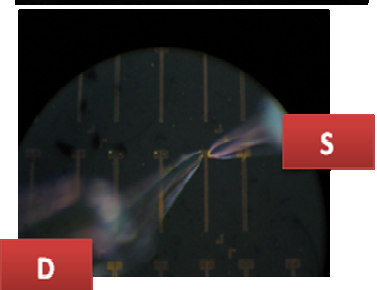

Figura 3.12 - Sistema de caracterização de OTFTs: (a) micromanipulador e analisador de parâmetros; (b) contato de porta $(G)$ através do suporte metálico; (c) contatos de fonte $(S)$ e dreno $(D)$ através de micropontas de ouro. 


\subsubsection{Extração dos principais parâmetros e análise dos resultados}

Os parâmetros a serem identificados após a construção do dispositivo são mobilidade dos portadores, tensão de limiar $\left(V_{T}\right)$, inclinação de sublimiar $(S)$, modulação de corrente $\left(I_{O N / O F F}\right)$, histerese $(H F)$ e corrente de fuga pelo dielétrico $\left(J_{\text {leakage }}\right)$. A geometria do dispositivo, tipo de transistor ( $\mathrm{p}$ ou $\mathrm{n}$ ), além de solventes e eletrodos utilizados, foram identificados por afetarem o desempenho [104, 105].

A mobilidade pode ser extraída a partir da curva $I_{D}$ em função de $V_{G S}$ tanto em regime linear quanto saturado [9, 79]. Assumindo o OTFT operando em regime linear segundo a Equação (18), a transcondutância do canal pode ser definida por:

$g_{m}=\left.\frac{\partial I_{D}}{\partial V_{G S}}\right|_{V_{D S}=c s t e}=\mu C_{i} \frac{W}{L} V_{D S}$

e a mobilidade pode então ser obtida pela aproximação da curva $I_{D} v s$. $V_{G S}$ por uma reta:

$$
\mu=\frac{g_{m}}{C_{i} \frac{W}{L} V_{D S}}
$$

A interseção da reta aproximada com o eixo x $\left(V_{\mathrm{GS} 0}\right)$ é igual a:

$$
V_{G S 0}=V_{T}+\frac{V_{D S}}{2}
$$

permitindo o cálculo da tensão de limiar. Procedimento semelhante e aplicado ao transistor em regime de saturação. Considerando $\left|V_{\mathrm{DS}}\right|>\left|V_{\mathrm{GS}}-V_{\mathrm{T}}\right|$, a mobilidade dos portadores de carga pode ser extraída através da primeira derivada de $I_{\mathrm{D}}{ }^{1 / 2} \mathrm{em}$ relação a $V_{G S}$ obtida a partir da Equação (21): 


$$
\frac{\partial \sqrt{I_{D}}}{\partial V_{G S}}=\sqrt{\frac{1}{2} \mu C_{i} \frac{W}{L}}
$$

A interseção da reta aproximada com o eixo x $\left(V_{\mathrm{GS} 1}\right)$ é igual a $V_{\mathrm{T}}$.

A razão $I_{O N / O F F}$ da corrente de dreno é obtida por sua vez conforme descrito na literatura [106]. Cabe destacar que, no caso deste trabalho, a corrente $I_{\mathrm{ON}}$ é sempre estimada na máxima tensão de operação disponível, i.e. $V_{\mathrm{DS}}=V_{\mathrm{GS}}=-40 \mathrm{~V}$. Uma ilustração da aplicação destas técnicas pode ser vista na Figura 3.13. O procedimento para cálculo do fator de histerese $(H F)$ a partir das curvas $I_{\mathrm{D}} v s$. $V_{\mathrm{GS}}$ é apresentado em [107]. Os dois modelos utilizados para cálculo de resistência série são o diferencial de Natali et al. [88] e transmission line exposto por Zaumseil et al. [89]. Há disponível no LME-EPUSP o simulador de circuitos PSpice e os softwares LabVIEW ${ }^{\text {TM }}$, MATLAB ${ }^{\circledR}$, ORIGIN $^{\odot}$ e Microsoft Office ${ }^{\odot}$ para aquisição, tratamento e análise de dados. Modelos que utilizem mobilidade dependente da tensão de porta ou resistências de contato foram aplicados às curvas características através da ferramenta de nonlinear fitting (i.e. aproximação não-linear) do ORIGIN $^{\circledR}$ (Versão 7.5).

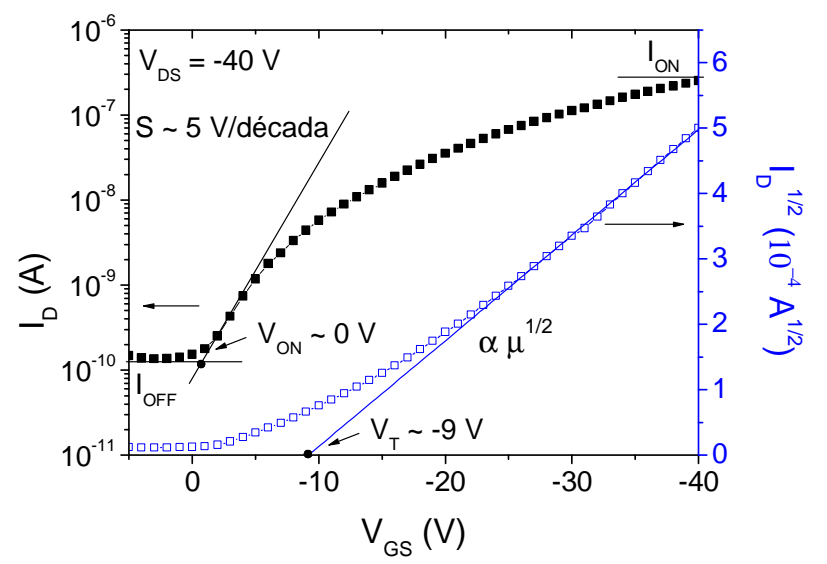

Figura 3.13 - Gráfico ilustrativo do método empregado para calcular a mobilidade $\left(\mu_{h}\right)$ na saturação, a tensão de limiar $\left(V_{T}\right)$, a inclinação de sublimiar $(S)$ e a modulação de corrente $\left(I_{O N / O F F}\right)$. Curva extraída para TFT de MDMO-PPV em substrato de $\mathrm{p}+-\mathrm{Si} / \mathrm{SiO}_{\mathrm{x}} \mathrm{N}_{\mathrm{y}}(279 \mathrm{~nm})$. 


\section{RESULTADOS}

\subsection{Células Solares Orgânicas}

\subsubsection{Definição dos eletrodos}

O principal problema observado nas etapas iniciais de desenvolvimento deste dispositivo eletrônico foi a realização do contato elétrico entre as micropontas de ouro e o eletrodo superior de alumínio (sistema de caracterização mostrado na Figura 3.5). A máscara mecânica disponível para evaporação de Al requeria que a microponta contatasse o eletrodo sem perfurar as camadas restantes abaixo. Mesmo aproximando-se com cuidado da superfície do cátodo de alumínio para não perfurar o dispositivo, outras fontes de "ruído" podiam perturbar a medição:

- qualquer oscilação da microponta pode inserir ruído na corrente medida;

- visto que eram utilizadas somente duas pontas, uma elevada resistência série poderia afetar profundamente as curvas características e o rendimento;

- devido às baixas correntes, as medições deviam ser lentas (e.g. maior tempo de integração em um analisador de parâmetros) para a obtenção de curvas de corrente estacionária. Na Figura 4.1.a, é mostrado que uma tensão $V_{\mathrm{OC}}$ de 1,3V foi obtida em condições inadequadas de caracterização (o valor esperado varia de 0,5 a $0,6 \mathrm{~V}$ ). Este efeito pode ser observado em medidas no escuro em que o gráfico de $\mathrm{J} v s$. $\mathrm{V}$ da célula não atravessa o ponto $(0 ; 0)$.

- um efeito secundário de uma elevada resistência série está na redução do fator de preenchimento $(F F)$ calculado, podendo ser até menor que $25 \%$, acarretando a perda da forma de diodo da curva $J x V$ sob iluminação.

A maior parte destas observações podem ser vistas na Figura 4.1.a. No caso de substratos flexíveis, a situação é ainda pior devido à deformação do PET, sendo que um contato ideal só pôde ser realizado com conectores do tipo "jacaré" no sistema de 
caracterização da Figura 3.4 (como será visto a seguir). Utilizando uma máscara mecânica improvisada com uma folha de alumínio e mudando de um formato circular para retangular, o rendimento $(P C E)$ aumentou 280 vezes. A diferença principal está na presença de uma região dedicada nos bordos do substrato onde é possível contatar o $\mathrm{Al}$ sem danificar as camadas orgânicas e curto-circuitar o dispositivo (Figura 4.1.b).
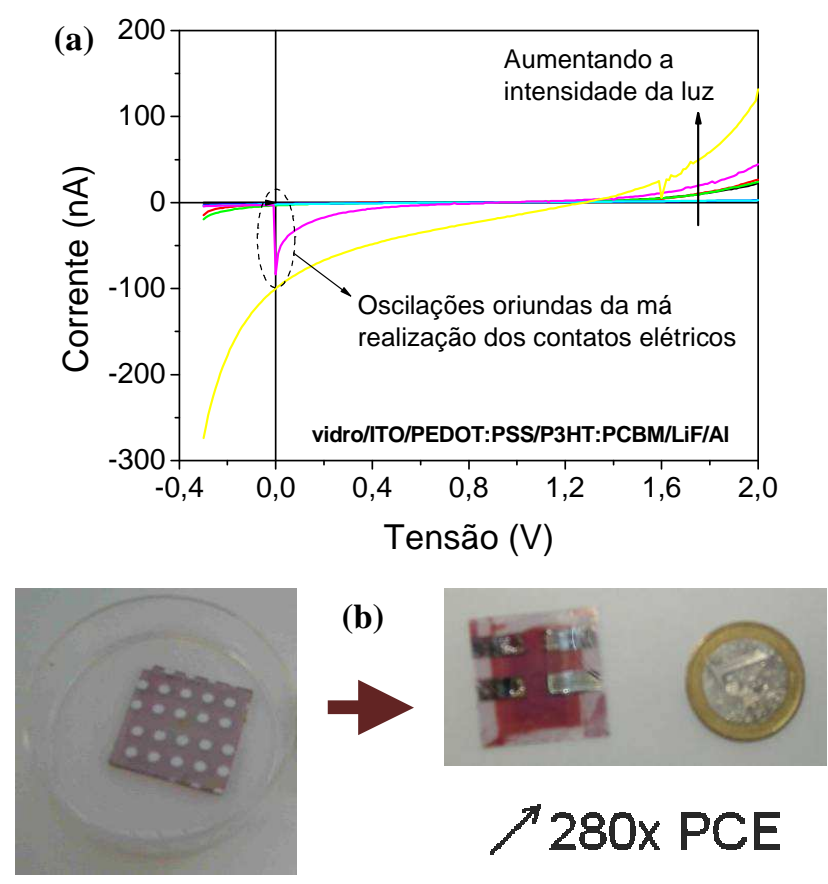

Figura 4.1 - (a) Curva da corrente vs. tensão elétrica de CSO em vidro com contato circular de Al; (b) Substituindo a máscara mecânica do cátodo por outra de formato retangular, o $P C E$ foi aumentado 280 vezes (dimensões da amostra comparáveis às de uma moeda de 1€).

Após a validação desta configuração, uma máscara mecânica (ver Figura 4.2) foi preparada no Laboratório de Integração de Microsistemas (MILab-FBK). Fluoreto de lítio e alumínio foram depositados em substratos flexíveis pela primeira vez neste trabalho, porém alguns estudos intermediários se fizeram necessários. Um espaçador de vidro foi utilizado inicialmente para fixar os substratos contra a máscara, pois as amostras se moviam com o carrossel do evaporador. Danos mecânicos e a obtenção de células curto-circuitadas levaram finalmente à utilização de uma fita adesiva de carbono no lugar do vidro para fixar as amostras. Este tipo de fita é adequado para sistemas de 
vácuo e fixação de amostras em MEV com espectroscopia por dispersão de energia de raios-X e microscopia de varredura por tunelamento (STM, do inglês Scanning Tunneling Microscopy). O diâmetro externo da máscara fabricada é de quatro polegadas, deixando espaço para cinco amostras de 2,5 ×2,5 $\mathrm{cm}^{2}$, contendo quatro células solares cada $\left(\sim 10 \mathrm{~mm}^{2}\right.$ de área).

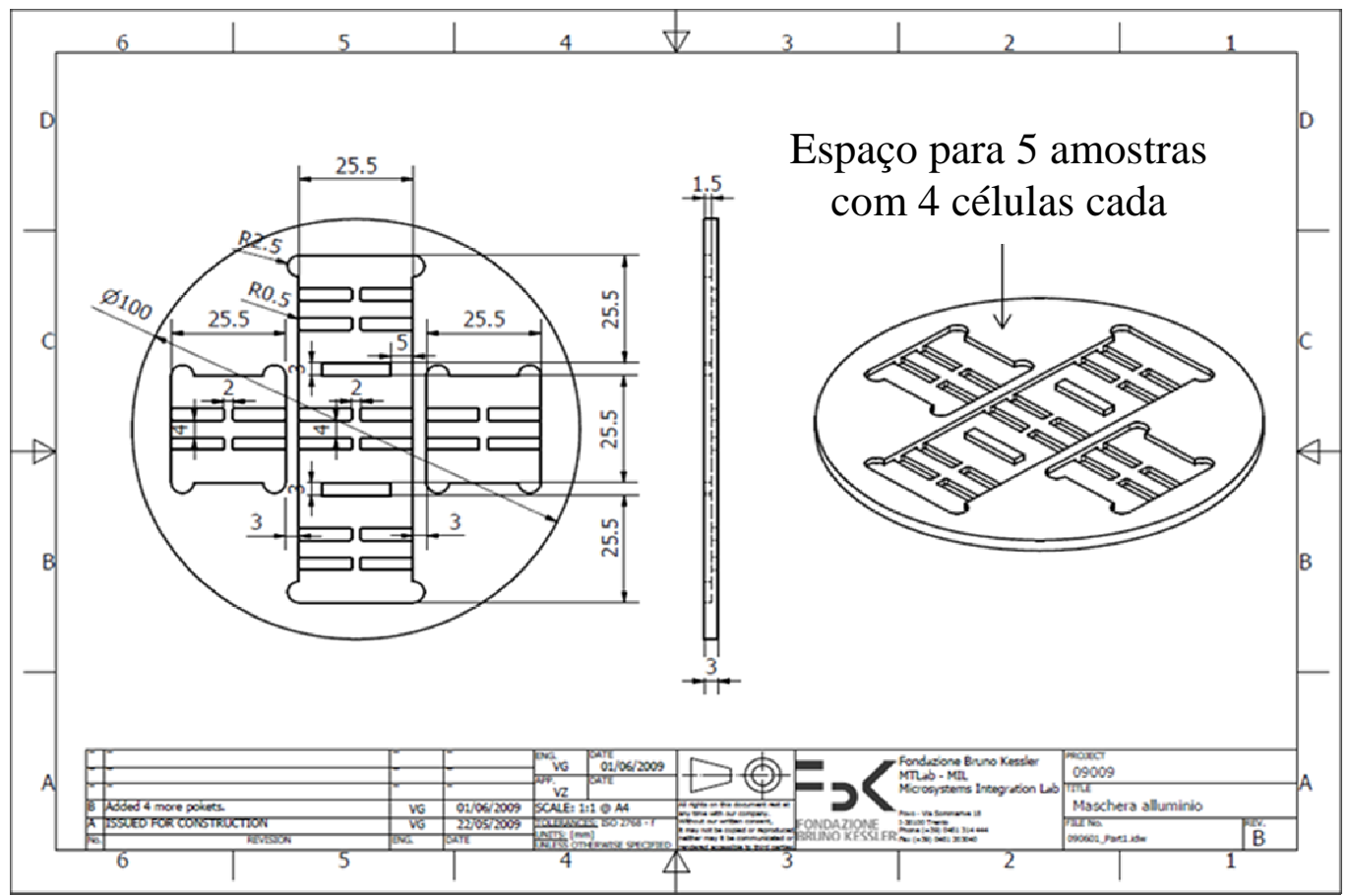

Figura 4.2 - Máscara mecânica desenvolvida com o Laboratório de Integração de Microsistemas (MILab-FBK) para deposição do cátodo.

\subsubsection{Tempo de secagem do PEDOT:PSS}

Pontos brilhantes na superfície do alumínio em substratos de vidro apareciam após o recozimento final em uma estufa a vácuo a $140{ }^{\circ} \mathrm{C}$ por $15 \mathrm{~min}$ (Figura 4.3). Visto que estes pontos se concentravam na área ativa e perto a borda do cátodo, acreditava-se que estes eram devidos a bolhas de solvente remanescentes nos filmes orgânicos, conseqüência da evaporação parcial dos solventes. Ao aumentar o tempo de secagem do filme de PEDOT:PSS a $120{ }^{\circ} \mathrm{C}$ de 5 a 15 min em um hot plate e mantendo o tempo de 
secagem da camada ativa inalterado, resultou no desaparecimento total destes pontos da superfície do Al. Além disso, um aumento de 9 vezes do $P C E$ foi obtido.
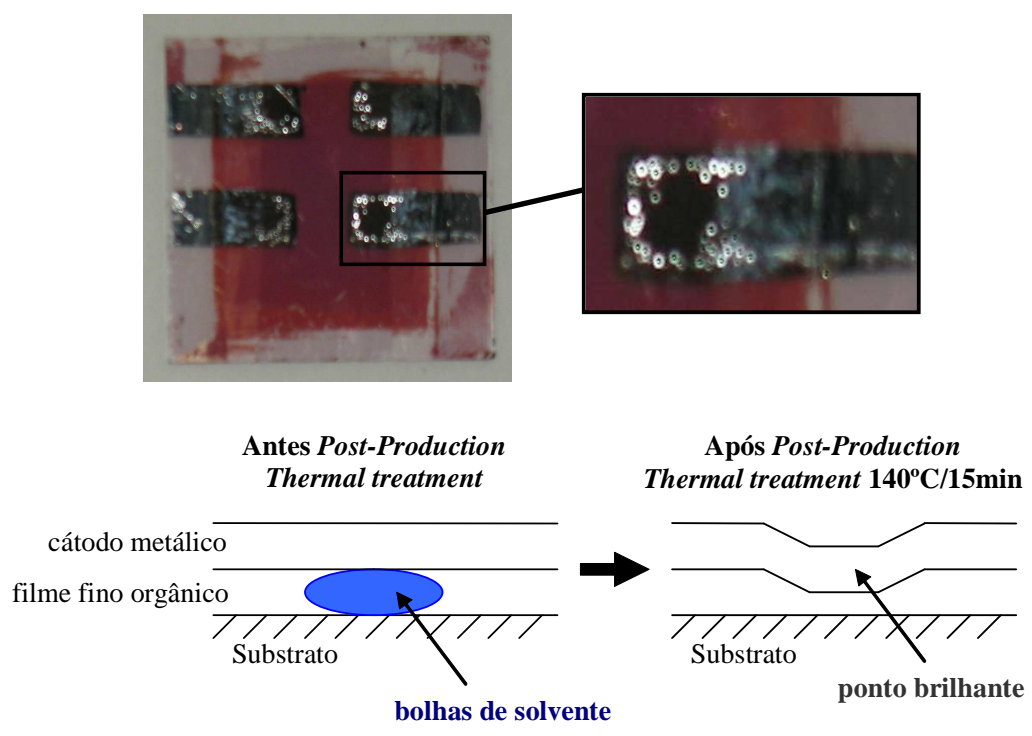

Figura 4.3 - Pontos claros na superfície do Al observados após o tratamento térmico final de amostras em vidro. Acredita-se que estas regiões brilhantes eram devidas a bolhas de solvente remanescentes de uma secagem incompleta.

É importante também destacar que a qualidade do filme de PEDOT:PSS pode aumentar se a dispersão for devidamente armazenada. Sem agitação e armazenada em refrigerador, a dispersão CLEVIOS $^{\mathrm{TM}} \mathrm{P}$ se torna mais viscosa com o tempo (período de estudo de menos de seis meses) e de difícil manuseio para deposição por spin coating. Constatou-se a aparição de aglomerados sólidos na dispersão e, conseqüentemente, rastros em forma de cometa no filme formado, mesmo filtrando a solução com filtros de $0,45 \mu \mathrm{m}$ antes da deposição. Após agitação da solução a $280 \mathrm{rpm}$ e $40{ }^{\circ} \mathrm{C}$ por $24 \mathrm{~h}$ antes da deposição, inspeção óptica dos filmes comprovou uma melhora na homogeneidade em espessura e ausência de cometas no filme.

\subsubsection{Primeiros estudos em substratos flexíveis: corrosão, limpeza e tempos de secagem}


Estudos realizados em substratos flexíveis foram realizados após a fabricação de células solares em vidro e obtenção de $P C E$ aceitáveis (ca. 0,1\%). Alguns parâmetros de processamento dos dispositivos tiveram que ser adequados às limitações impostas pelo PET e do condutor multicamada transparente $\left(\operatorname{In}_{2} \mathrm{O}_{3} / \mathrm{Au} / \mathrm{Ag}\right)$. $\mathrm{O}$ tempo de corrosão do ITO sobre vidro sem um catalisador como pó de zinco é de uma hora e meia em um banho de $\mathrm{HCl}: \mathrm{H}_{2} \mathrm{O}: \mathrm{HNO}_{3}$ (razão entre volumes 100:100:20). Foi verificado que, provavelmente devido à rápida oxidação da prata e do destaque do respectivo óxido, 50 segundos são mais do que suficientes para definição do eletrodo em substratos flexíveis mascarados com fita adesiva. Se deixado por mais tempo, há underetching do ânodo, como mostrado na Figura 4.4 em um dispositivo finalizado. Pó de zinco foi utilizado somente em amostras em vidro para estudo da mobilidade dos portadores de carga, processadas no LME-EPUSP. O tempo de corrosão é tão curto, sendo necessário apenas esfregar um cotonete no pó, mergulhar em uma solução de $\mathrm{HCl}$ e esfregá-lo contra o ITO. Este processo dura menos de um minuto.

Outro fator importante no processamento de dispositivos orgânicos em substratos flexíveis foi a limpeza inicial: sabendo-se que o condutor multicamada transparente é inorgânico e rígido, muito cuidado deve ser tomado ao manusear as amostras para evitar a ruptura do filme transparente (cracking). Por exemplo, esfregar os substratos para remoção de restos de cola de fita adesiva e outras partículas de sujeira é indesejável. Além disso, o banho de acetona foi removido do procedimento padrão de limpeza para evitar possíveis danos à superfície do substrato polimérico de PET [108].

O último fator importante foi o tempo de secagem do solvente após a deposição de um filme orgânico. Problemas tais como "bolhas" na superfície do cátodo após o recozimento final não foram observados em substratos flexíveis. Provavelmente devido ao substrato ser de menor espessura (0,2 mm comparados a $1,1 \mathrm{~mm}$ de vidro) e interagir de forma diferente com os solventes, tempos mais breves são eficientes para evaporação de cada solvente em filmes sobre PET após spin coating. As altas temperaturas usadas para este tratamento térmico eram suspeitas de serem responsáveis por danificar o substrato e o condutor transparente (CT). Maiores detalhes na Seção 4.1.4. 


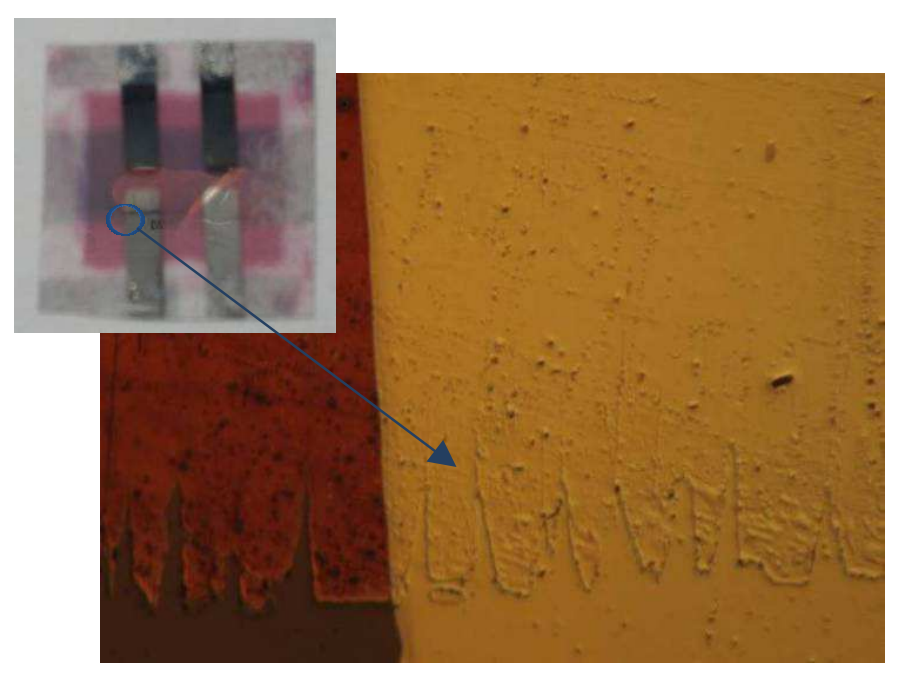

Figura 4.4 - Underetching do eletrodo de $\operatorname{In}_{2} \mathrm{O}_{3} / \mathrm{Au} / \mathrm{Ag}$ em substrato flexível de PET.

\subsubsection{Efeitos de tratamentos térmicos ao substrato de PET-CT}

Dispositivos flexíveis apresentaram rendimento inferior a células solares em vidro durante todo o trabalho e, inicialmente, um decréscimo de PCE de 1000 vezes após tratamento térmico final foi observado. Um estudo detalhado de degradação do eletrodo em função da temperatura foi realizado para esclarecer se a piora no desempenho estava relacionado à temperatura de $140{ }^{\circ} \mathrm{C}$ de tratamento pós-fabricação. Muitas dúvidas se encontravam nas propriedades físicas do condutor transparente, pois diferentemente dos substratos de vidro, não se trata de ITO mas de um multicamada de óxido de índio, ouro e prata. Testes preliminares em estufa a vácuo e sobre hot plate a $90^{\circ}$ e $140{ }^{\circ} \mathrm{C}$ mostraram até uma redução na resistência de folha após períodos de 30 min. Logo, uma análise mais detalhada foi feita para confirmar estes resultados e observar a partir de que ponto a resistência aumenta. Para tal, quatro resistores quadrados do condutor transparente em substratos de PET (Delta Tech. PF-65IN) foram definidos e contatados separadamente com tinta prata e um multímetro. A tinta prata serviu para delimitar a área dos resistores. A temperatura foi variada de 20 a $200{ }^{\circ} \mathrm{C} \mathrm{em}$ 120 minutos e a resistência foi medida para diferentes patamares de temperatura. Os resultados estão na Figura 4.5. A resistência de folha monitorada em um hot plate 
aumenta quando a uma temperatura de $150{ }^{\circ} \mathrm{C}$, alcançando o limite após $180{ }^{\circ} \mathrm{C}$. Diversos fenômenos atuam tal como degradação das propriedades elétricas, encolhimento, flexão (observável a partir de $90{ }^{\circ} \mathrm{C}$ ) e fusão (visível entre 180 e $200{ }^{\circ} \mathrm{C}$ ).

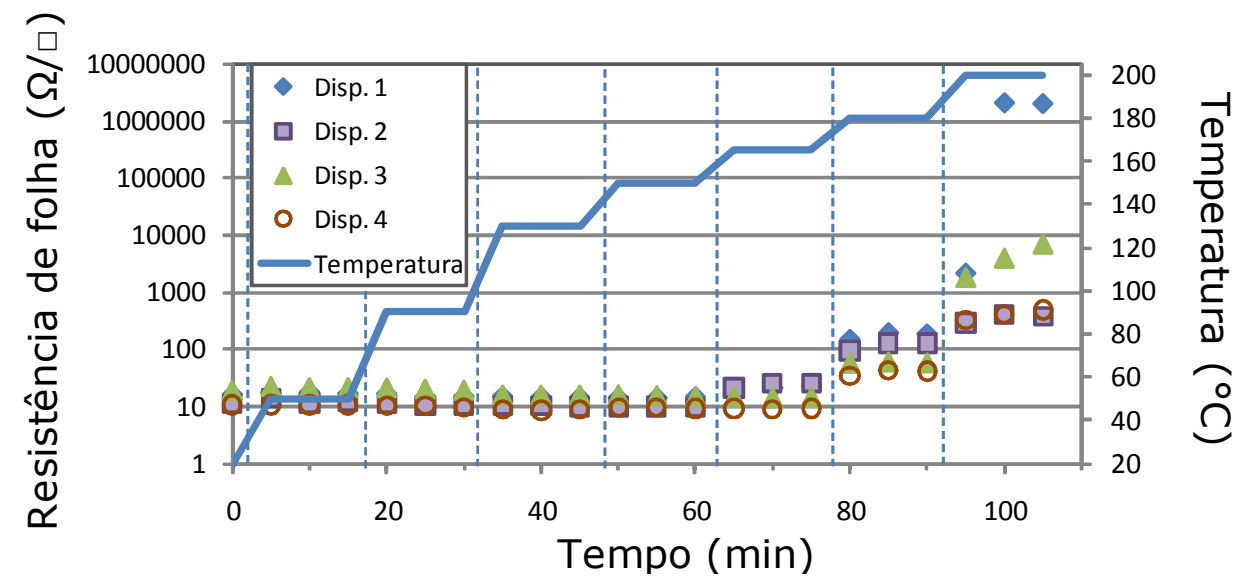

Figura 4.5 - Resistência de folha monitorada no tempo para quatro resistores diferentes em um mesmo substrato de PET para diferentes patamares de temperatura (intervalo: da temperatura ambiente até $\left.200^{\circ} \mathrm{C}\right) . \mathrm{O}$ material condutor é um multicamada $\mathrm{In}_{2} \mathrm{O}_{3} / \mathrm{Au} / \mathrm{Ag}$ da Delta Tech.

\subsubsection{Recozimento final (Post-Production Thermal Treatment)}

Enquanto que o recozimento final após deposição do cátodo é realizado em torno de $140-150{ }^{\circ} \mathrm{C}$ por 15 min para células solares em substratos de vidro [52], após o estudo apresentado na Seção 4.1.4, dispositivos em substratos flexíveis passaram a ser tratados a $120^{\circ} \mathrm{C}$ por $10 \mathrm{~min}$. Como visto na Seção 4.1 .4 , uma temperatura de $150^{\circ} \mathrm{C}$ já é capaz de danificar o ânodo transparente. De qualquer modo, uma melhora póstratamento em PET foi observada somente ao se tratar as células solares no mesmo dia de deposição de $\mathrm{LiF}$ e $\mathrm{Al}($ ca. 0,4 \%). Devido à degradação do dispositivo em substrato flexível, nenhuma melhora era observada um dia após a deposição do cátodo, mesmo após o tratamento térmico final.

Estudos de degradação dos principais parâmetros para células solares armazenadas no escuro a temperatura ambiente, em circuito aberto e expostas a umidade e oxigênio, revelaram que dispositivos sobre vidro apresentavam um tempo de vida além 
de $450 \mathrm{~h}$, ou seja, superior a resultados significativos presentes na literatura [109]. A degradação do $P C E$ está principalmente relacionada ao decréscimo de $J_{\mathrm{SC}}$ e $F F$ no tempo, enquanto que $V_{\mathrm{OC}}$ permanece praticamente constante (ver Figura 4.6.a). Dispositivos em substrato flexível sob as mesmas condições demonstram uma degradação acelerada de $F F$ e $V_{\mathrm{OC}}$, implicando no descarte da célula solar em menos de 24 h (ver Figura 4.6.b). Esta degradação acelerada foi inicialmente observada em filmes semicondutores preparados a partir de uma solução de dois meses ( $c a .12 \mathrm{~h}$ de tempo de vida). Após a preparação de uma nova solução 3 wt\% 1:1 w/w P3HT:PCBM em DCB, que forneceu $P C E$ tão alto quanto o obtido em substrato de vidro (exceto pelo pior $F F$ ), a célula solar resultante era duas vezes mais estável, porém ainda degradava em menos de $24 \mathrm{~h}$. A maior estabilidade está provavelmente relacionada a maior eficiência oriunda de uma nanomorfologia otimizada. Visto que o tempo de transporte do exciton até uma interface tende a ser menor (pois maior contato entre os materiais), assim como o transporte de carga até os eletrodos (pois menor concentração de armadilhas), fica assim dificultada uma possível reação dos materiais da camada ativa com oxigênio ou vapor d'água. O conhecimento do tempo de vida e da velocidade de degradação para estes dispositivos influenciou seu cronograma de processamento e permitiu assim a obtenção de eficiências em PET semelhantes às obtidas em vidro.
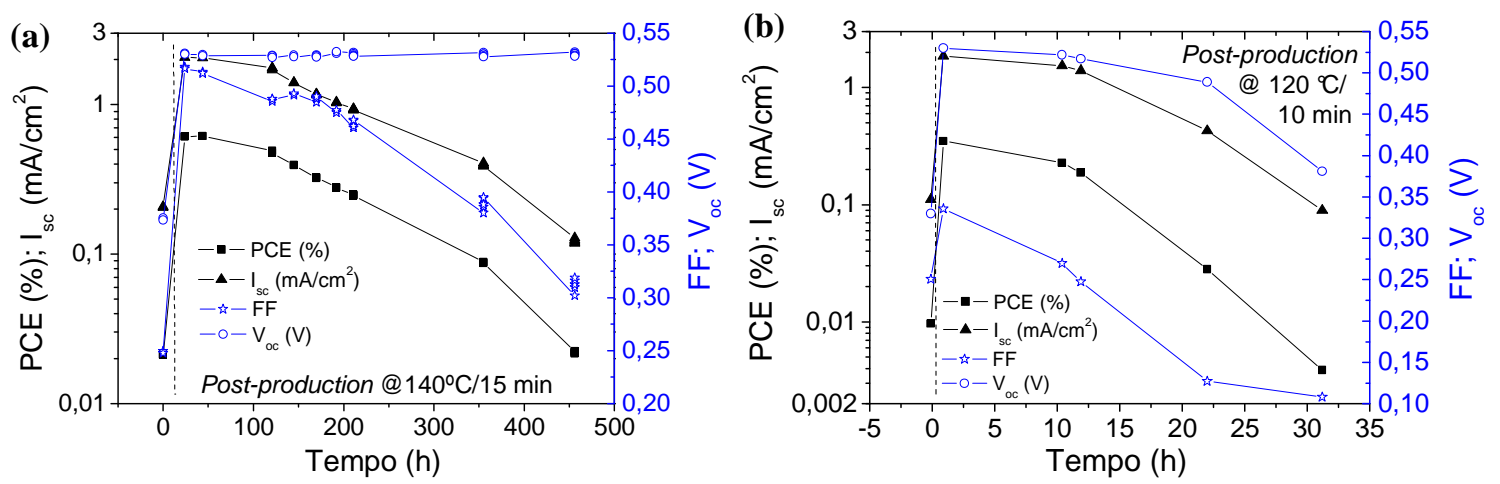

Figura 4.6 - Degradação no tempo de células solares de heterojunção de rr-P3HT:PCBM em substratos de (a) vidro e (b) PET. 
Um avanço significativo foi alcançado tratando os dispositivos flexíveis e aplicando simultaneamente uma tensão positiva de 1,5 V. Como mostrado na Figura 4.7, comparando-se os melhores resultados obtidos em uma mesma amostra com e sem tratamento, pode-se concluir que $R_{\mathrm{SH}}$ aumenta de 2,87 a $4,53 \mathrm{k} \Omega, R_{\mathrm{S}}$ diminui de 3,38 a $1,3 \mathrm{k} \Omega, F F$ aumenta de 27,1 a $30,8 \%$, e $P C E$ aumenta de 0,39 a $0,44 \%$. Em uma série de quatro amostras, os melhores $F F$ e $P C E$ em cada amostra foram obtidos tratando-se com 1,5 V. Calculando-se a razão entre $P C E$ depois e antes do recozimento final, observa-se que um aumento de $c a$. 350 contra 200 vezes sem a tensão.
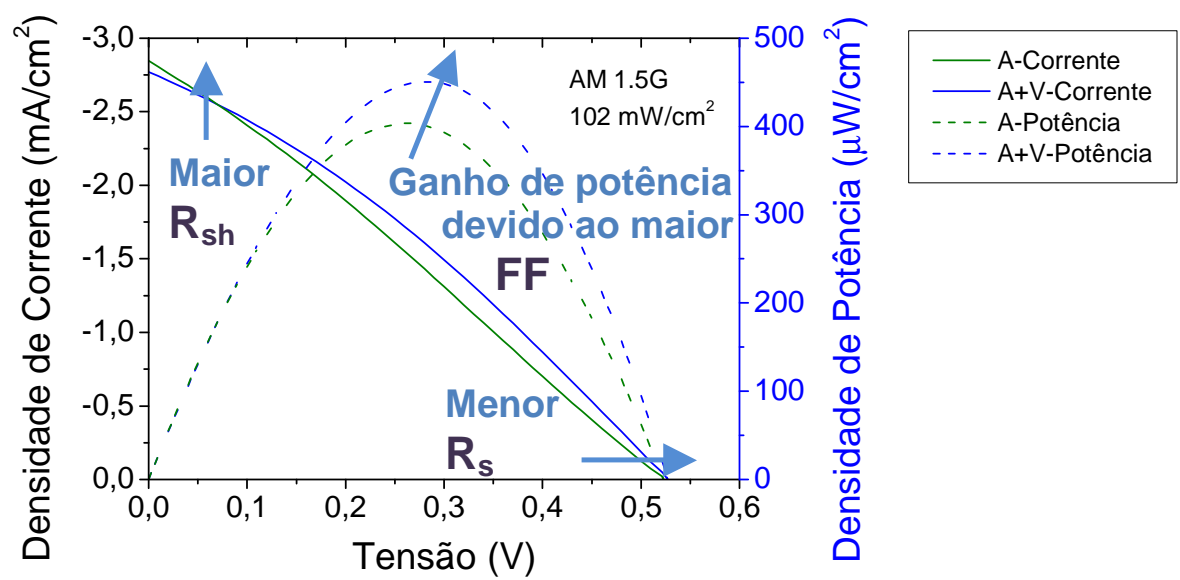

Figura 4.7 - Comparação entre células solares na mesma amostra tratadas diferentemente após a deposição do cátodo: $120{ }^{\circ} \mathrm{C}$ por 10 min com (legenda $\mathrm{A}+\mathrm{V}$ ) e sem (A) a aplicação de uma tensão de $1,5 \mathrm{~V}$ entre os eletrodos das células.

\subsubsection{Preparação da solução de P3HT:PCBM em diclorobenzeno}

Inicialmente, cada solução de P3HT:PCBM era preparada pela mistura direta dos materiais em uma razão mássica 1:1 (w/w) dentro de um recipiente de vidro, com adição direta de diclorobenzeno (DCB) à garrafa. A agitação era realizada por uma hora antes da deposição a $280 \mathrm{rpm}$ e $40{ }^{\circ} \mathrm{C}$. Conseqüentemente, rastros em forma de cometa apareciam no filme semicondutor formado. O responsável pela má formação do filme não era então conhecido pois ambos os materiais eram dissolvidos ao mesmo tempo em DCB. Uma sutil melhora na qualidade do filme foi obtida adicionando-se primeiro o 
politiofeno, agitando-se por $24 \mathrm{~h}$ a $40{ }^{\circ} \mathrm{C}$ e somente então adicionando o derivado de fulereno. A solução final foi agitada por $24 \mathrm{~h}$ antes da deposição por spin coating. Evidenciou-se por inspeção visual que o polímero P3HT é dissolvido em menos de dez minutos e não deve ser o responsável pela má formação do filme. Visto que este filme ainda apresentava cometas, acredita-se que estes se devam a um excesso de PCBM e conseqüente formação de aglomerados. Cometas e manchas visíveis a olho nu se faziam presente mesmo quando os semicondutores eram depositados sobre um filme de PEDOT:PSS de alta qualidade.

\subsubsection{Panorama geral da evolução na eficiência de conversão de potência $(P C E)$}

Os melhores desempenhos atingidos em condições AM1,5G com CSOs em substrato de vidro ocorreu para solução 3 wt\% 1:0,8 w/w P3HT:PCBM em DCB agitada por $1 \mathrm{~h}$ a $50{ }^{\circ} \mathrm{C}$ antes da deposição, com dissolução separada de cada semicondutor orgânico (ver Tabela 4.1). O rendimento superior a 1,7\% foi conseqüência do tempo de secagem lento pós-spin coating do compósito semicondutor (slow drying de $24 \mathrm{~h}$ a pressão atmosférica e temperatura ambiente) e da ausência de um recozimento térmico final. O recozimento levou à degradação do $P C E$ em quase uma ordem de grandeza. Resultados semelhantes para dispositivos flexíveis $(P C E \approx 1 \%)$ foram alcançados somente com solução 3 wt\% 1:1 w/w em DCB agitada do mesmo modo e com dissolução gradual de cada material. Não foi realizada secagem lenta em amostras flexíveis. Os principais parâmetros destas células são apresentados na Tabela 4.1.

Um resumo da evolução no tempo da eficiência das células fabricadas se encontra em forma de gráfico na Figura 4.8. Cada ponto corresponde a uma CSO diferente, sendo que foram apresentados somente resultados que representassem uma melhora em relação aos anteriores. A presença deste gráfico é justificada por este trabalho ter sido realizado exatamente após a criação de uma linha de pesquisa em células solares orgânicas na $F B K$ em Trento, refletindo assim o aprendizado do grupo de 
pesquisa no tempo. As curvas $J x V$ do dispositivo flexível mais eficiente são mostradas na Figura 4.9.

Tabela 4.1 - Melhores resultados em cada tipo de substrato a 1 sol AM1,5G com ABET Sun 2000.

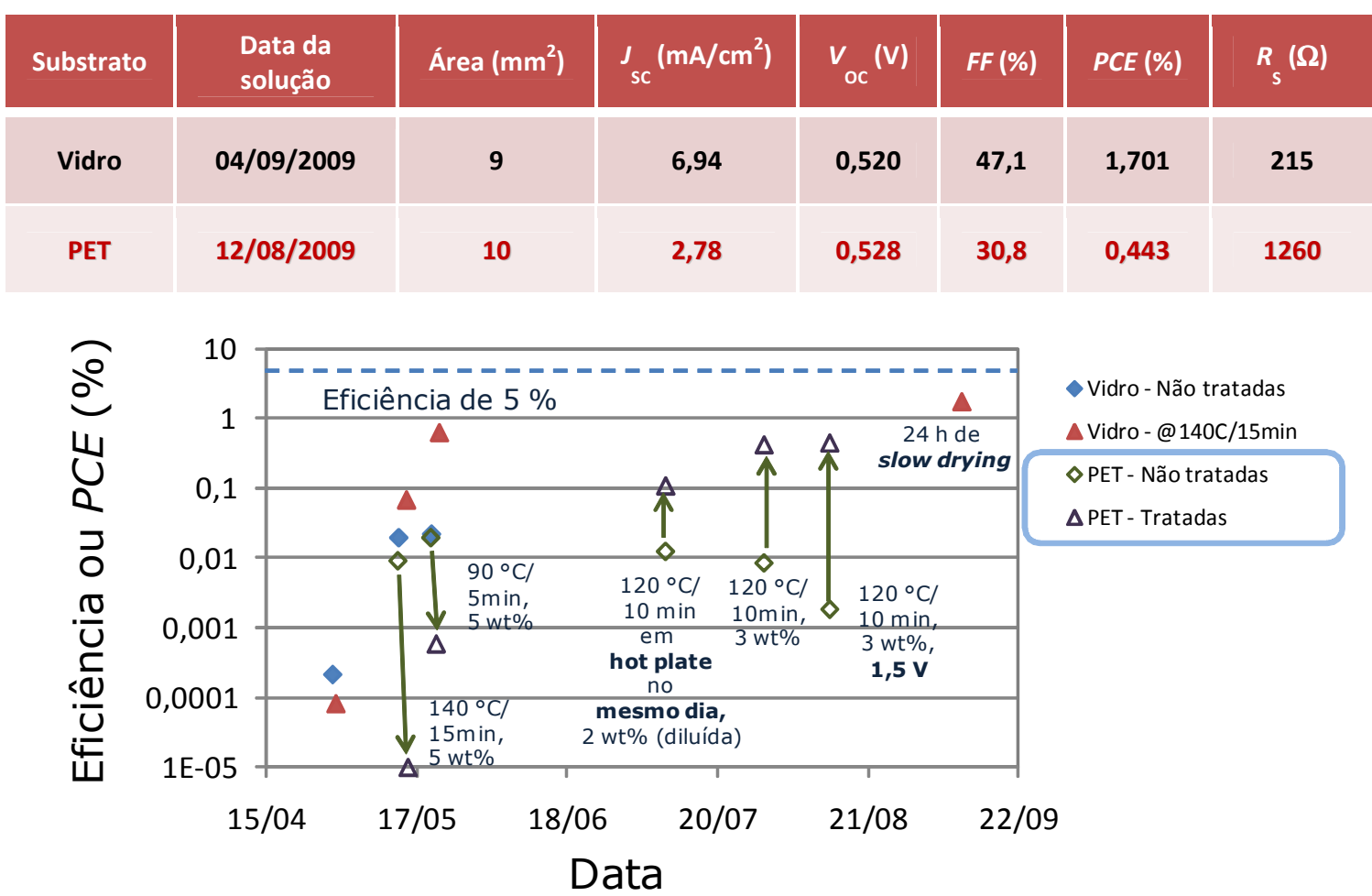

Figura 4.8 - Evolução de PCE no tempo de CSOs de P3HT:PCBM em substratos de vidro (símbolos fechados) e PET (símbolos abertos). Os dados são apresentados antes (diamantes) e após (pirâmides) o recozimento final.
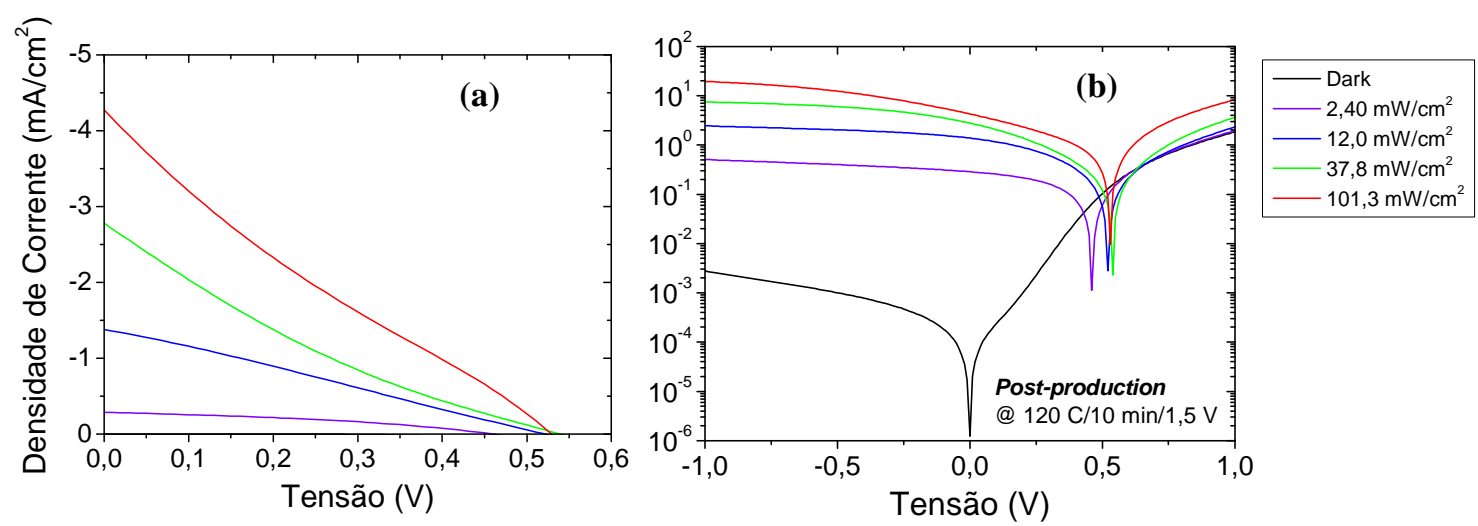

Figura 4.9 - Densidade de corrente versus potencial para uma célula solar flexível e de alta eficiência no escuro até sob iluminação de $101,3 \mathrm{~mW} / \mathrm{cm}^{2}$ de luz branca: (a) região fotovoltaica; (b) varredura completa de -1 a $1 \mathrm{~V}$ do logaritmo da densidade de corrente. 


\subsection{As diferentes técnicas para caracterização da mobilidade e aplicação em semicondutores comerciais}

Nesta Seção, foram utilizados majoritariamente derivados de poli(para-fenileno vinileno) (PPV) por apresentarem vantagens tais como processamento em solução e aplicação em eletrônica de grande superfície a baixo custo. Sua versatilidade resulta em sua utilização em células fotovoltaicas [50], LEDs [110], TFTs [111] e transistores eletroluminescentes [112].

\subsubsection{Tempo de Vôo com excitação óptica (Time of Flight, ToF)}

A excitação utilizada em $337,1 \mathrm{~nm}$ é justificada pelo espectro da densidade ótica $(O D)$ mostrado na Figura 4.10.a. Observa-se que o máximo global para derivados de PPV ocorre para $\lambda \approx 500 \mathrm{~nm}$. A transmitância dos filmes mostrada na Figura 4.10.b foi calculada segundo a Equação (14). O coeficiente de atenuação foi obtido segundo a Equação (3) em [113]: $\alpha=(O D / x) \ln (10)$. Pode-se notar que, para 186 e $240 \mathrm{~nm}$ de filme de MDMO-PPV, a transmitância é superior a $50 \%$ e que, para todos os filmes estudados, é superior a $10 \%$. O coeficiente de atenuação para $\lambda=500 \mathrm{~nm}$ é igual a 0,0179 e 0,0177 1/nm em filmes de MDMO-PPV e MEH-PPV, respectivamente. No caso do comprimento de onda do laser utilizado, $\alpha=0,0031$ e 0,0027 1/nm em filmes de MDMO-PPV e MEH-PPV, respectivamente. Os valores apresentados estão de acordo com os resultados de Quist et al. [113] para células solares de heterojunção de MDMOPPV:PCBM.

Se considerarmos somente a absorção do eletrodo transparente de ITO, a transmissão do pulso a 337,1 nm é de cerca $57,1 \%$. Os portadores gerados, caso fossem injetados no semicondutor devido à presença de um campo elétrico constante no filme $\mathrm{e}$ ao alinhamento dos níveis de energia, permitiriam a medida do tempo de vôo principalmente das lacunas. No caso de irradiação através do eletrodo de $\mathrm{Al}$, uma atenuação ainda maior seria esperada, porém a injeção tenderia a não ser significativa 
devido aos níveis energéticos envolvidos. Os resultados apresentados neste trabalho são principalmente por iluminação do eletrodo transparente.
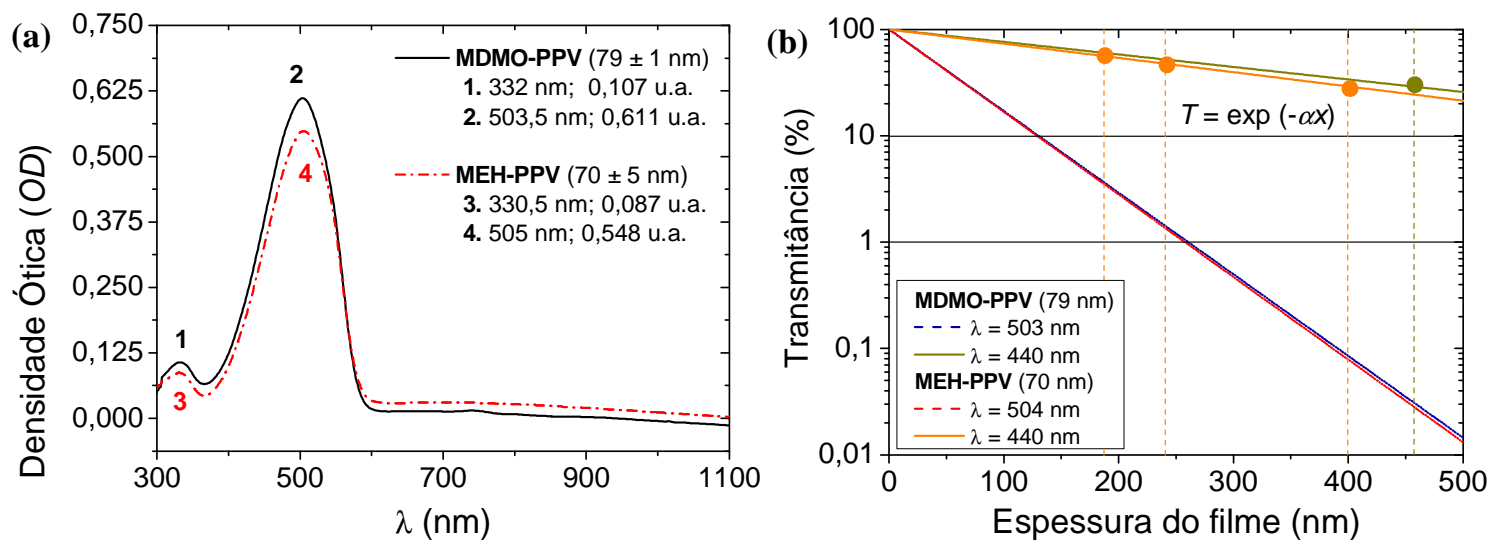

Figura 4.10 - Espectrofotometria de filmes finos de derivados de PPV: (a) espectro de absorção; (b) transmitância calculada a partir do coeficiente de atenuação $(\alpha)$ obtido da curva de $O D$ vs. $\lambda$.

Típicos transientes de corrente obtidos para MDMO-PPV são mostrados na Figura 4.11. A corrente no resistor série é calculada a partir da lei de Ohm, através da razão entre a queda de tensão entre seus terminais e sua resistência. Caso a duração do pulso do laser (5 ns) fosse maior que o tempo de trânsito $\left(t_{\mathrm{tr}}>1 \mu \mathrm{s}\right)$, a forma do transiente de corrente seria a própria forma do pulso de luz, i.e. a amostra se comportaria como um detetor de radiação. Isto não ocorre para as amostras utilizadas e não será mais discutido neste trabalho. O caráter dispersivo dos transitórios da Figura 4.11 foi observado para todas as espessuras estudadas. Por este motivo, o tempo de trânsito $\left(t_{\text {tr }}\right)$ só pôde ser extraído a partir do gráfico di-log (ou log-log) da corrente vs. tempo. O cálculo de $\mu$ é apresentado em detalhes na Figura 4.11 para uma tensão constante de $6 \mathrm{~V}$.

A mobilidade de elétrons e lacunas para o MDMO-PPV calculada através da Equação (1) e a partir dos valores medidos de $t_{\text {tr }}$ é apresentada na Figura 4.12. Foram caracterizadas amostras de diferentes espessuras (186-400 nm), com mobilidade variando de $10^{-8}$ a $10^{-5} \mathrm{~cm}^{2} / V s$. 


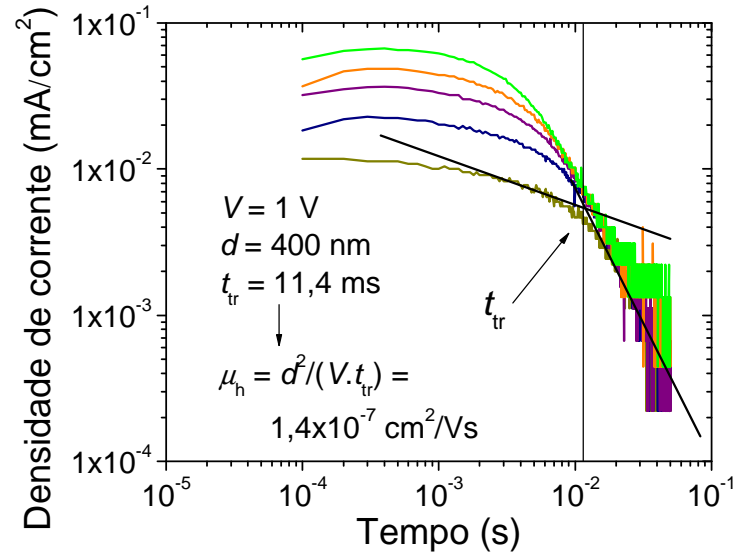

Figura 4.11 - Transientes de corrente ToF dispersivos em amostra de MDMO-PPV extraídos à partir da tensão em um resistor série.
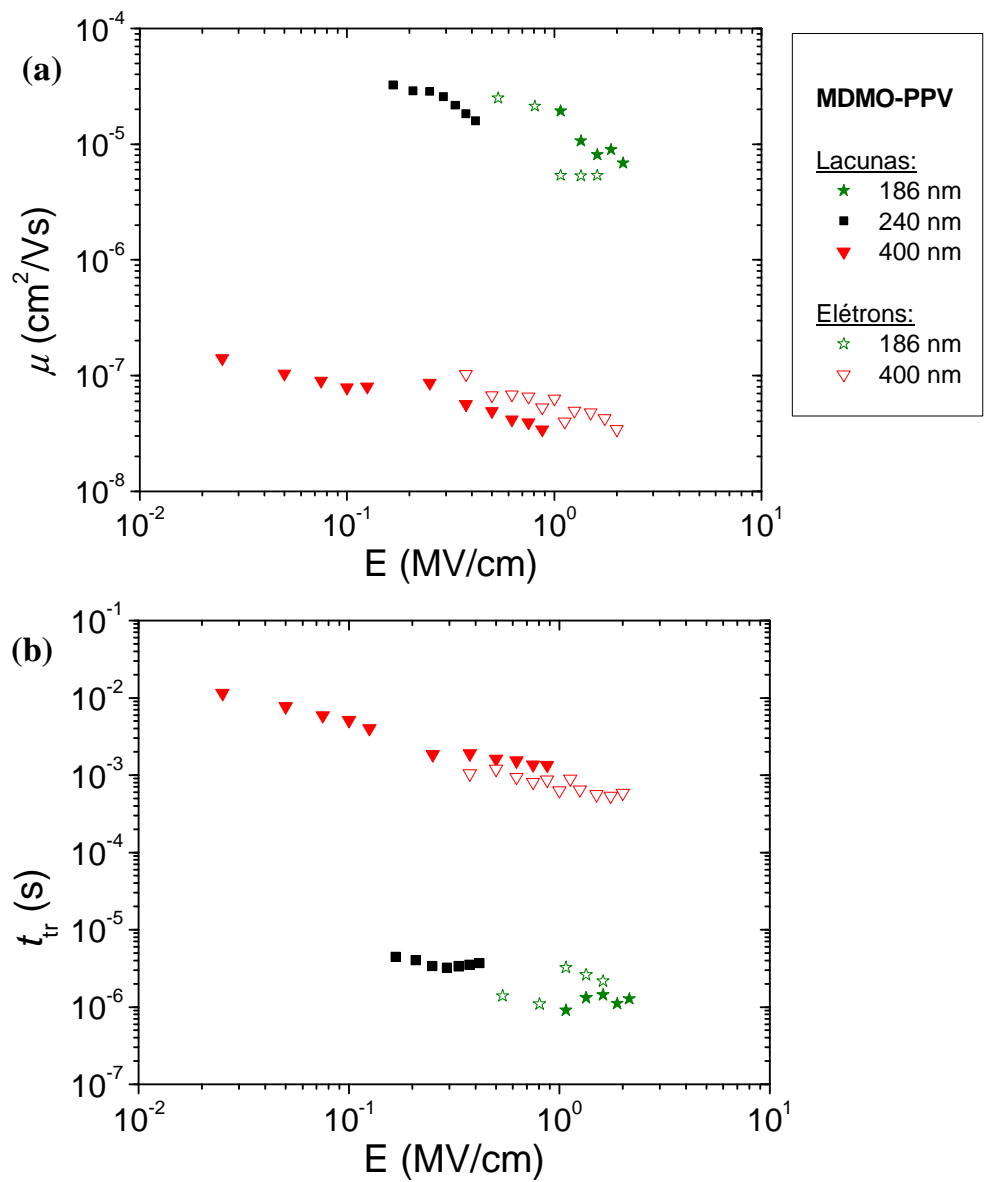

Figura 4.12 - Gráficos da (a) tempo de trânsito $\left(t_{\text {tr }}\right)$ e (b) mobilidade $(\mu)$ de elétrons e lacunas obtidos para diversas espessuras do polímero MDMO-PPV em amostras de ITO/MDMO-PPV/AI. 
No caso do MEH-PPV, espesso $460 \mathrm{~nm}$, foram calculadas mobilidades da ordem de $10^{-6} \mathrm{~cm}^{2} / \mathrm{Vs}$ (ver Figura 4.13.a), com pouca variação de acordo com o campo aplicado. A mobilidade eletrônica para derivados de PPV é conhecida por ser duas ordens de grandeza inferior a de lacunas $[114,115]$. Os resultados indicam que o fato da amostra absorver fótons em todo o seu volume implica no "mascaramento" do transiente do portador de menor mobilidade pelo de maior mobilidade. Portanto, as mobilidades apresentadas aparentemente pertencem às lacunas somente. Na Figura 4.13.b, é mostrado um diagrama de energia com as estruturas empregadas para aplicação do ToF. Um filme de PEDOT:PSS entre o cátodo e o semicondutor foi utilizado somente para amostras de MEH-PPV.
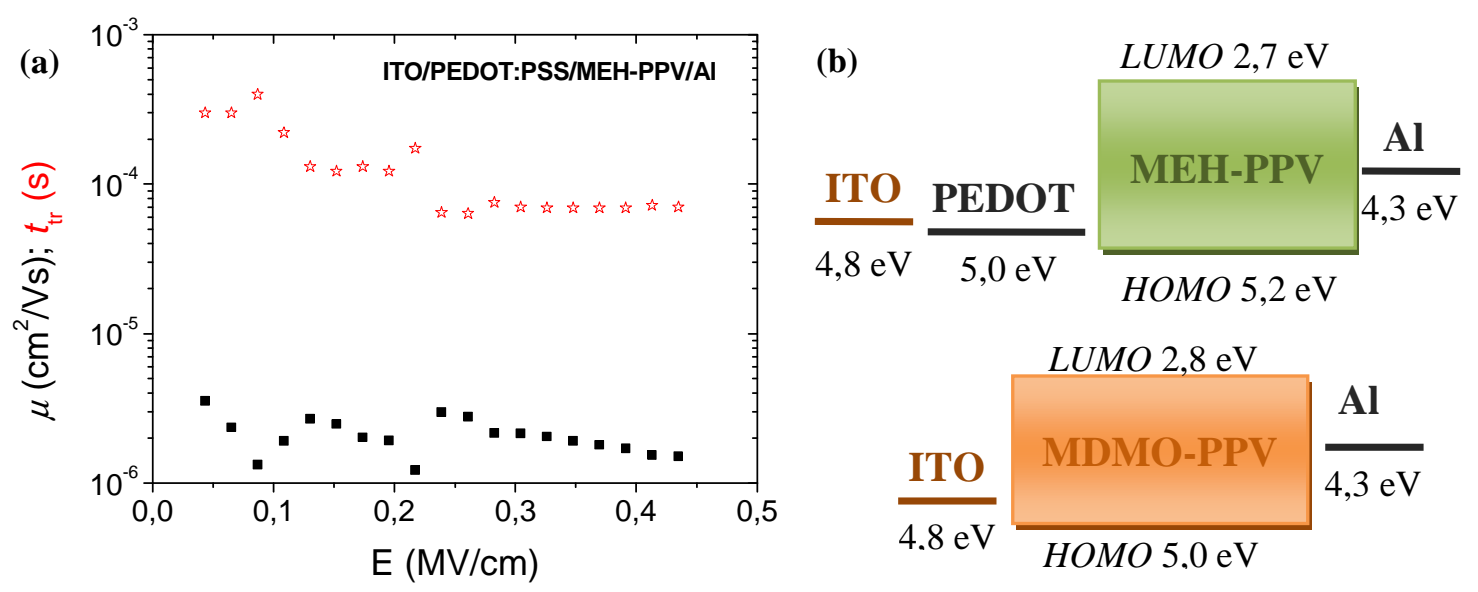

Figura 4.13 - (a) Mobilidade $(\mu)$ e tempo de trânsito $\left(t_{\text {tr }}\right)$ de lacunas obtidos para $460 \mathrm{~nm}$ de MEHPPV. (b) Diagrama de energia das estruturas empregadas para estudo da mobilidade por ToF.

\subsubsection{Charge Extraction in Linearly Increasing Voltage (CELIV)}

Típicos transientes de corrente photo-CELIV obtidos para derivados de PPV são mostrados na Figura 4.14. As amostras foram iluminadas com o laser Oriel através do eletrodo de alumínio $\sim 1 \mathrm{~s}$ antes da aplicação da rampa. As curvas de $J x t$ se aproximam da teórica [30] ao aplicar a rampa de tensão ao eletrodo de alumínio por ser extremamente bloqueante para ambos os tipos de portadores de carga. 

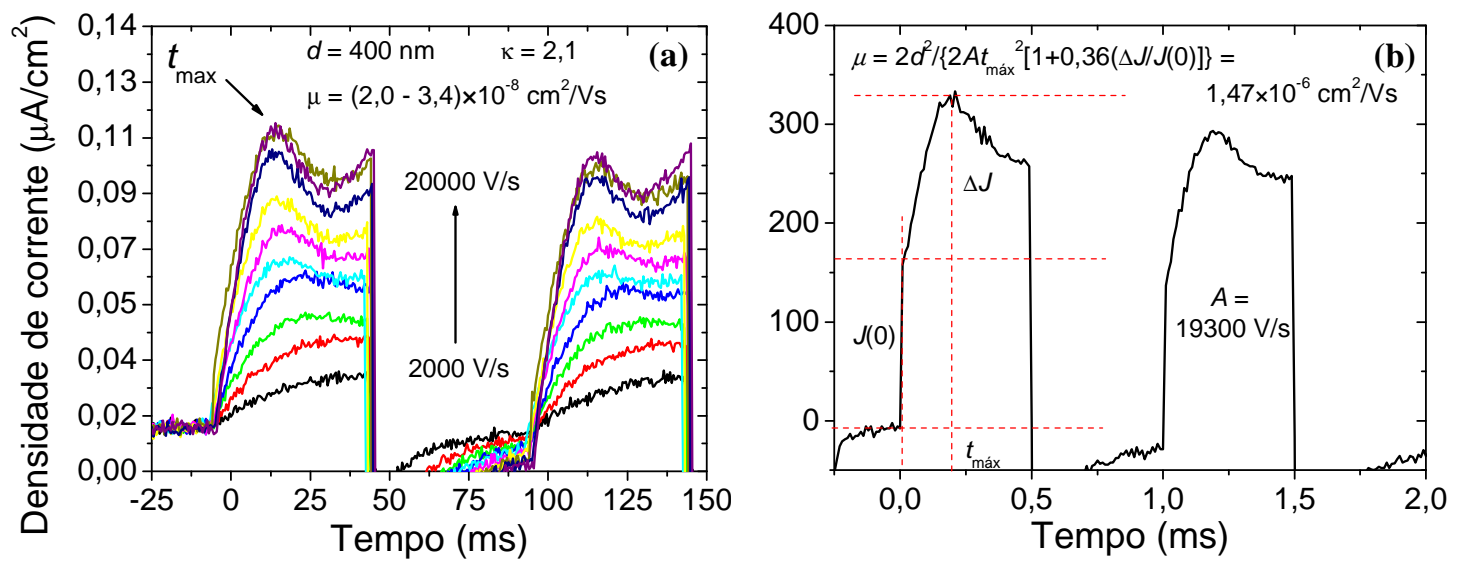

Figura 4.14 - Transientes de corrente photo-CELIV em amostras de (a) MDMO-PPV e (b) MEHPPV extraídos à partir da tensão em um resistor série.

A mobilidade das lacunas e a condutividade dos filmes estudados são mostradas na Figura 4.15. A constante dielétrica relativa ( $\kappa$ ) utilizada em (3) foi 2,1 para o MDMO-PPV [22] e 3,0 para o MEH-PPV [116, 117, 118]. Em ambos os casos, a mobilidade aparentemente não varia com o campo elétrico de baixa intensidade aplicado, sendo aproximadamente constante e igual a $3 \times 10^{-8}$ e $2 \times 10^{-6} \mathrm{~cm}^{2} / \mathrm{Vs}$ para MDMO-PPV e MEH-PPV, respectivamente. Por sua vez, a condutividade é aproximadamente igual a $1 \times 10^{-11}$ e $1 \times 10^{-9} \mathrm{~S} / \mathrm{cm}$ para MDMO-PPV e MEH-PPV, respectivamente. O tempo de relaxação $-t_{\sigma}=\kappa \varepsilon_{0} / \sigma[30]-$ varia de $1,0 \times 10^{-2}$ a $1,9 \times 10^{-1} \mathrm{~s}$ para MDMO-PPV e de $1,7 \times 10^{-4}$ a $2,5 \times 10^{-4}$ s para MEH-PPV.
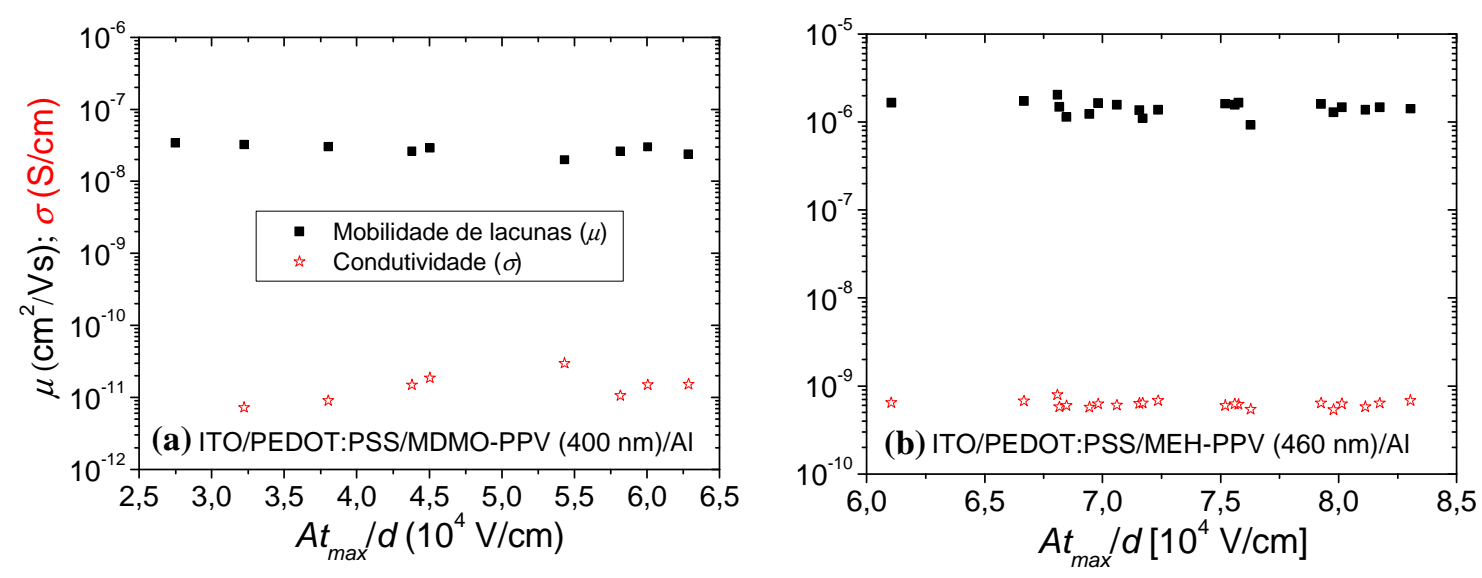

Figura 4.15 - Mobilidade de lacunas $(\mu)$ e condutividade $(\sigma)$ calculadas considerando o material polimérico com distribuição exponencial de armadilhas. 


\subsubsection{Curvas de densidade de corrente por tensão (JxV)}

Diversos regimes de regime de corrente limitada por carga espacial (SCLC) foram observados variando as condições de deposição e a concentração da solução. Regimes $S C L C$ com armadilhas rasas e preenchidas foram observados para uma amostra de $108 \mathrm{~nm}$ de MDMO-PPV (ver Figura 4.16). A mobilidade das lacunas calculada através da Equação (5) para altas e baixas tensões é igual a $2,70 \times 10^{-7}$ e $3,87 \times 10^{-11}$ $\mathrm{cm}^{2} / \mathrm{Vs}$, respectivamente. O fator de modulação $\theta$ é igual a $9,47 \times 10^{-6}$ para uma concentração de armadilhas $H$ de $1,71 \times 10^{16} \mathrm{~cm}^{-3}$ calculada a partir da Equação (6). Como explicado nas Seções precedentes, o filme fino de PEDOT:PSS é necessário à obtenção de contatos ôhmicos assim como na melhora da interface com o semicondutor.

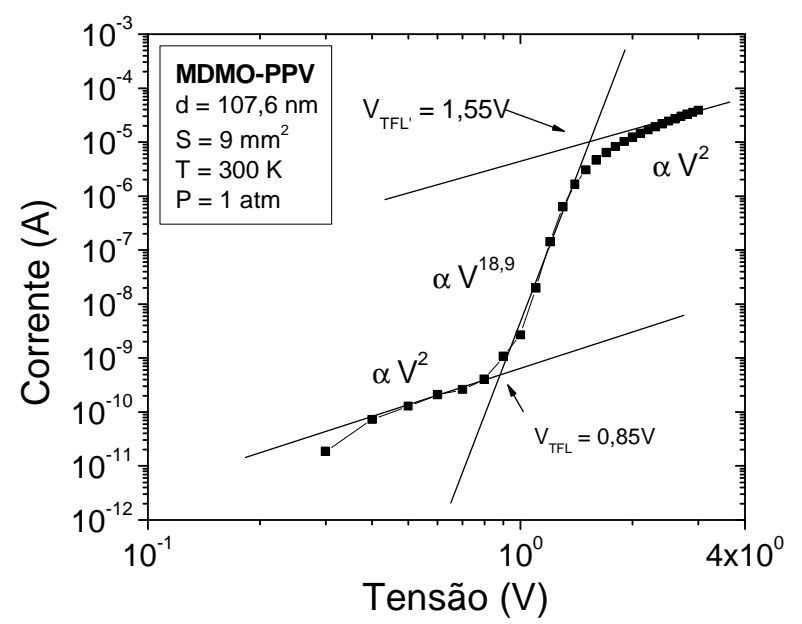

Figura 4.16 - Condução SCLC com um nível energético de armadilhas rasas para MDMO-PPV.

Um regime SCLC com armadilhas profundas foi observado em amostras de MDMO-PPV espesso $190 \mathrm{~nm}$ (ver Figura 4.17). A condução SCLC com armadilhas preenchidas para altas tensões é caracterizada por uma mobilidade de lacunas igual à $2,30 \times 10^{-8} \mathrm{~cm}^{2} / V s$. Na região linear da curva (i.e. $J \alpha V$ ), utilizando a Equação (4) e substituindo a mobilidade calculada, é possível extrair $p_{0}: 1,03 \times 10^{13} \mathrm{~cm}^{-3}$. Aplicando as Equações (7) à (9) no regime $J \alpha V^{4.8}$, obtém-se $l=3,81, T_{c}=1144 \mathrm{~K}, p_{0}=8,66 \times 10^{12}$ $\mathrm{cm}^{-3}, H=1,13 \times 10^{17} \mathrm{~cm}^{-3}$ e $\mu=2.79 \times 10^{-8} \mathrm{~cm}^{2} / V s$. A mobilidade das lacunas e a 
concentração de portadores termicamente gerados calculadas através deste último modelo está de acordo com o cálculo segundo as Equações (4) e (5).

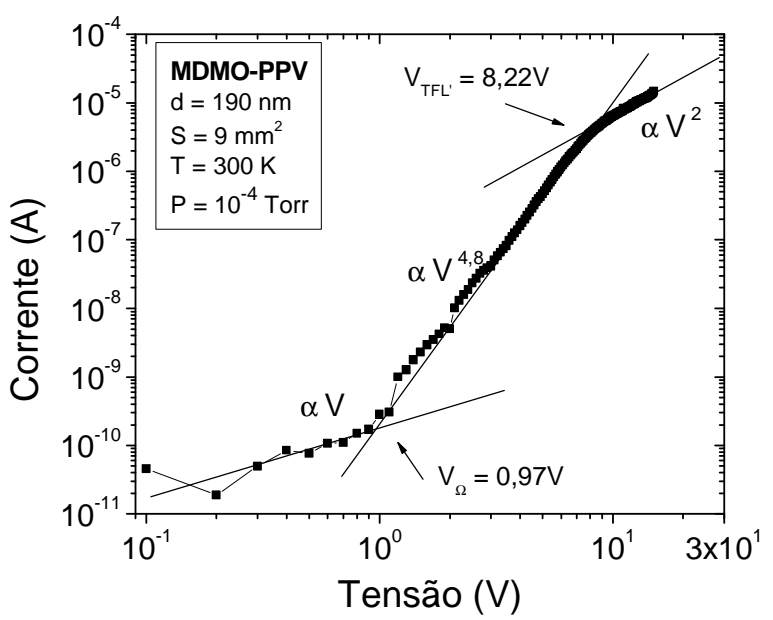

Figura 4.17 - Condução SCLC com distribuição exponencial de armadilhas profundas para MDMO-PPV.

As curvas $J x V$ para filmes de MEH-PPV (Figura 4.18) foram analisadas em colaboração com o estudante de mestrado do Prof. S. Mergulhão, Cleber A. de Amorim, que dedicou parte de seu trabalho ao estudo da técnica CELIV e sua aplicação a materiais poliméricos conjugados para OLEDs. No caso deste material, o transporte de carga se apresentou limitado por injeção, sendo que modelos como Richardson-Schottky e Fowler-Nordheim se adaptaram melhor aos resultados. Tais modelos em geral não permitem o cálculo da mobilidade e por este motivo não são reportados aqui. No entanto, a aplicação de um modelo $S C L C$ livre de armadilhas na presença do fenômeno Poole-Frenkel proposto por Martin et al. [119] aponta para uma barreira de injeção de ca. $3 \mathrm{eV}$ e uma mobilidade de lacunas $\mu_{\mathrm{E}=0}(300 \mathrm{~K})$ da ordem de $10^{-10} \mathrm{~cm}^{2} / V s$. O leitor mais curioso é convidado a ler a dissertação de mestrado do estudante ${ }^{1}$.

\footnotetext{
${ }^{1} \mathrm{O}$ texto está em fase de preparação e deverá estar finalizado após abril de 2010.
} 


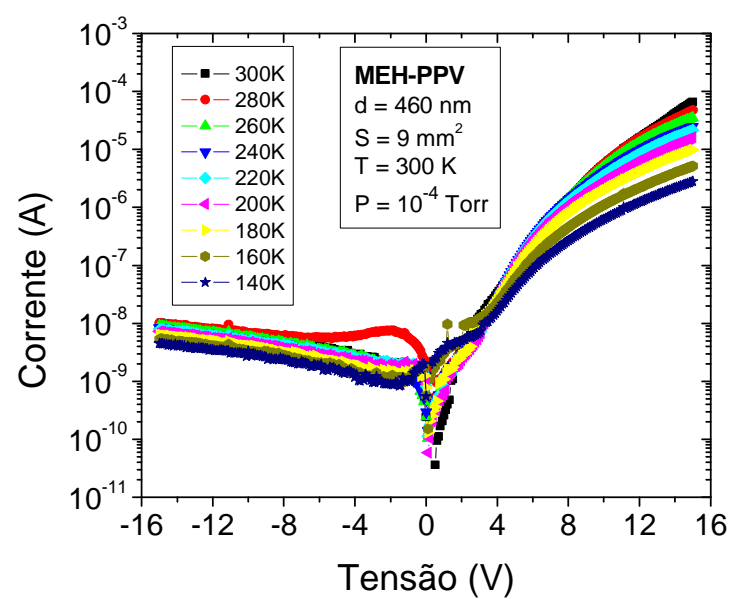

Figura 4.18 - Gráfico de corrente por tensão para ITO/PEDOT:PSS/MEH-PPV/AI.

\subsection{Transistores de Filmes Finos de MDMO-PPV}

A principal técnica utilizada para extração de uma mobilidade constante através das curvas características do OTFT é apresentada em detalhes na Seção 3.3.3. No entanto, um modelo mais elaborado que considerasse mobilidade variável e a presença de resistências de contato foi estudado em conjunto com o Prof. Dr. Marco Sampietro (Politecnico de Milano, Milão, Itália) e aplicado em algumas curvas com o intuito de desenvolver uma metodologia de seleção de novos materiais (ver Seção 5.3). Esta Seção do trabalho se divide em duas partes: (1) Dielétricos e substratos estudados através de mobilidade constante; e (2) Mobilidade dependente da tensão de porta $-\mu=f\left(V_{G S}\right)$.

\subsubsection{Dielétricos e substratos estudados através de mobilidade constante}

A importância desta etapa se deve à intensa busca por dielétricos inorgânicos alternativos e substratos alternativos ao desenvolvimento de OTFTs. A fabricação sobre substrato de silício é utilizada somente em um estágio inicial de desenvolvimento, devido ao alto nível de desempenho atingido com esta tecnologia, porém contradiz o real 
objetivo de utilização de substratos transparentes e até mesmo flexíveis. Por este motivo, foram utilizados dois substratos (i.e. silício altamente dopado e vidro recoberto por ITO) e dois dielétricos (i.e. $\mathrm{SiO}_{2}$ e $\mathrm{SiO}_{\mathrm{x}} \mathrm{N}_{\mathrm{y}}$ ), assim como três máscaras de fonte e dreno (i.e. interdigitados fotogravados e paralelos por máscara mecânica e fotogravação) e quatro semicondutores (i.e. MDMO-PPV, MEH-PPV, P3HT e pentaceno). Finalmente, foi testada a aplicação de uma camada de adesão de titânio para eletrodos de ouro. Contatos interdigitados foram abandonados inicialmente, devido a problemas de adesão pós-liftoff e por fornecerem poucos dispositivos por amostra. Porém, poderão ser retomados em outros trabalhos caso não seja verificada uma degradação no desempenho do TFT. A utilização de máscara mecânica ${ }^{2}$ para definição do canal permitiria a deposição dos eletrodos de fonte e dreno sobre dielétricos orgânicos e até a fabricação de estruturas top gate. No entanto, resultados obtidos para MDMO-PPV depositado sobre $\mathrm{SiO}_{2}(279 \mathrm{~nm})$ com e sem tratamento por HMDS apontam para ruptura do dielétrico devido à dimensão macroscópica dos contatos. Um curto entre semicondutor e porta pode ocorrer por eletromigração do metal devido à grande área ocupada e à possível presença de contaminação durante o processamento. Resultados significativos poderiam ser obtidos com espessuras de $467 \mathrm{~nm}$ (ver discussão na Seção 5.2). Além disso, TFTs bottom gate top contact talvez apresentassem resistência maior a ruptura.

$\mathrm{O}$ dielétrico obtido por PECVD apresentou resultados semelhantes ao $\mathrm{SiO}_{2}$ crescido termicamente, seja através de espectroscopia FTIR (Figura 4.19) que através do estudo de capacitores MOS (Tabela 4.2).

Tabela 4.2 - Principais parâmetros extraídos de capacitores $\mathrm{MOS}$ empregando $\mathrm{SiO}_{2} \mathrm{e} \mathrm{SiO}_{\mathrm{x}} \mathrm{N}_{\mathrm{y}}$.

\begin{tabular}{|c|c|c|c|c|c|}
\hline Dielétrico & $\kappa$ & $\begin{array}{c}N_{s s} \\
\left(10^{11} 1 / \mathrm{cm}^{2}\right)\end{array}$ & $\begin{array}{c}N_{i t} \\
\left(10^{11} \mathrm{eV}^{-1} \cdot \mathrm{cm}^{-2}\right)\end{array}$ & $\begin{array}{c}J_{\text {leakage }} \\
\left(10^{-7} \mathrm{~A} / \mathrm{cm}^{2}\right)\end{array}$ & $\begin{array}{c}E_{b d} \\
(\mathrm{MV} / \mathrm{cm})\end{array}$ \\
\hline $\mathrm{SiO}_{2}$ & 3,9 & $4,7 \pm 1,1$ & 1,9 & $16 \pm 12$ & $9,3 \pm 1,3$ \\
\hline $\mathrm{SiO}_{\mathrm{x}} \mathrm{N}_{\mathrm{y}}$ & 4,5 & $4,9 \pm 0,4$ & 1,5 & $1,5 \pm 1,3$ & $3,3 \pm 0,3$ \\
\hline
\end{tabular}

O espectro FTIR aponta para uma grande semelhança estrutural e química entre os dois dielétricos. Os resultados apresentados na Tabela 4.2 demonstram uma

\footnotetext{
${ }^{2}$ Desenvolvidas em conjunto com o Prof. R. M. Faria (IFSC-USP) e fabricadas em São Carlos na USP.
} 
superioridade elétrica dos capacitores de oxinitreto de silício, pois possuem maior constante dielétrica $(\kappa=4,5>3,9)$ e menor corrente de fuga $\left(J_{\text {leakage }}=(1,5 \pm 1,3) \times 10^{-7}<\right.$ $\left.(1,6 \pm 1,2) \times 10^{-6} \mathrm{~A} / \mathrm{cm}^{2}\right)$. Os movimentos vibracionais apresentados na Figura 4.19 são detalhados em [120].

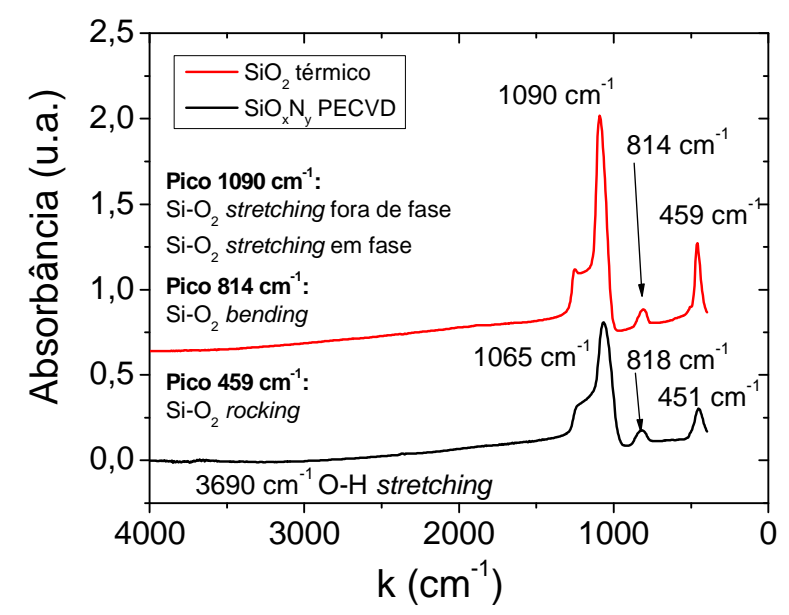

Figura 4.19 - Espectroscopia FTIR para filmes de $\mathrm{SiO}_{2}$ térmico e $\mathrm{SiO}_{\mathrm{x}} \mathrm{N}_{\mathrm{y}}$ por $P E C V D$.

Curvas características típicas de OTFTs fabricados utilizando substratos de Si e vidro-ITO são mostradas na Figura 4.20. Cada amostra continha em média 300 transistores, dos quais foram caracterizados aleatoriamente 10 OTFTs para cada valor de comprimento de canal. Um resumo dos principais parâmetros extraídos a partir das curvas $I_{D} v s$. $V_{G S}$ para as diversas estruturas é mostrado na Tabela 4.3. A espessura é de cerca $300 \mathrm{~nm}$ para todos os dielétricos relacionados, permitindo assim um estudo comparativo (densidade de cargas acumuladas semelhante para todas as estruturas). Observa-se que a estrutura $\mathrm{p}+-\mathrm{Si} / \mathrm{SiO}_{\mathrm{x}} \mathrm{N}_{\mathrm{y}}$ forneceu os melhores resultados, tais como maiores mobilidade $\left(\mu_{h}=1,1 \times 10^{-4} \mathrm{~cm}^{2} / \mathrm{Vs}\right)$ e modulação de corrente (1800), além de uma menor inclinação de sublimiar (5 V/déc).

A Tabela 4.4 mostra que TFTs de MDMO-PPV dissolvidos em tolueno são comparáveis a dispositivos a partir de clorofórmio. Embora a maior mobilidade tenha sido atingida dissolvendo em tolueno e depositando sobre $\mathrm{SiO}_{\mathrm{x}} \mathrm{N}_{\mathrm{y}}$, é dado maior destaque neste trabalho a MDMO-PPV dissolvido em clorofórmio. 
Tabela 4.3 - Principais parâmetros extraídos a partir de $I_{\mathrm{D}} v s$. $V_{\mathrm{GS}}$ em regime de saturação para MDMO-PPV dissolvido em clorofórmio e depositado em ambos os dielétricos e substratos. As dimensões do canal são $W_{\mathrm{M}}=1,1 \mathrm{~mm}$ e $L_{\mathrm{M}}=5 \mu \mathrm{m}$.

\begin{tabular}{|c|c|c|c|c|c|c|c|}
\hline Substr./Isol. & $\begin{array}{c}x_{\mathrm{i}} \\
(\mathrm{nm})\end{array}$ & $\begin{array}{c}n_{\mathrm{Q}} \\
\left(10^{12} 1 / \mathrm{cm}^{2}\right)\end{array}$ & $\begin{array}{c}\mu_{\mathrm{h}} \\
\left(10^{-5} \mathrm{~cm}^{2} / \mathrm{Vs}\right)\end{array}$ & $\begin{array}{c}V_{\mathrm{T}} \\
(\mathrm{V})\end{array}$ & $\begin{array}{c}S \\
(\mathrm{~V} / \mathrm{dec} .)\end{array}$ & $I_{\mathrm{ON} / \mathrm{OFF}}$ & $\begin{array}{c}H F \\
(\%)\end{array}$ \\
\hline $\mathrm{p}+-\mathrm{Si} / \mathrm{SiO}_{2}$ & $296 \pm 12$ & $2,9 \pm 0,1$ & $5,0 \pm 0,5$ & $-6,9 \pm 3,2$ & $8 \pm 1$ & 300 & $14,4 \pm 2,2$ \\
\hline $\mathrm{p}+-\mathrm{Si} / \mathrm{SiO}_{\mathrm{x}} \mathrm{N}_{\mathrm{y}}$ & $279 \pm 20$ & $3,6 \pm 0,8$ & $11,0 \pm 2,6$ & $-8,7 \pm 1,0$ & $5 \pm 1$ & 1800 & $22,7 \pm 3,5$ \\
\hline $\mathrm{ITO} / \mathrm{SiO}_{\mathrm{x}} \mathrm{N}_{\mathrm{y}}$ & $301 \pm 18$ & $3,3 \pm 0,2$ & $5,5 \pm 2,0$ & $-5,5 \pm 0,9$ & $9 \pm 1$ & 500 & $15,4 \pm 1,0$ \\
\hline
\end{tabular}
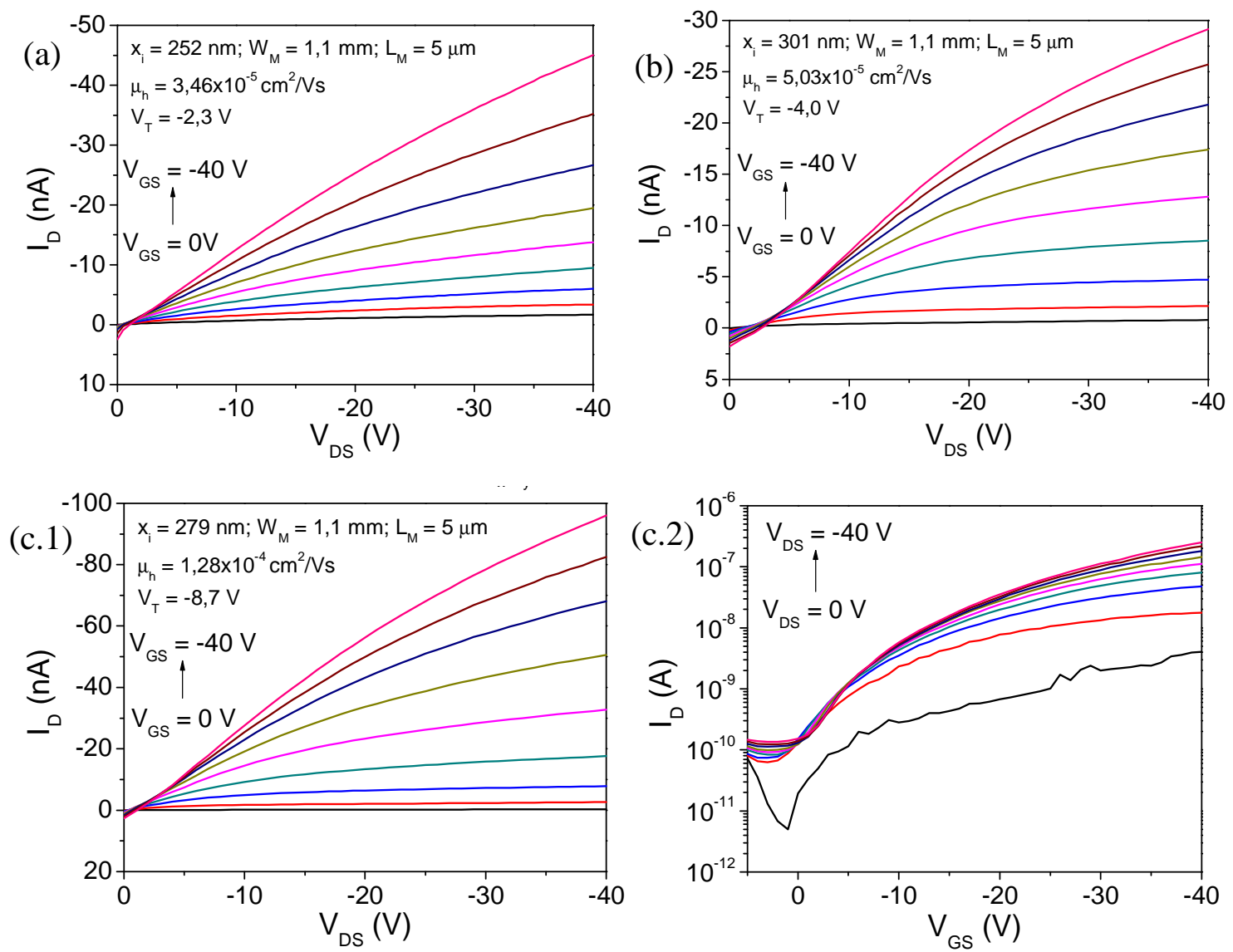

Figura 4.20 - $I_{\mathrm{D}}$ vs. $V_{\mathrm{DS}}$ e $I_{\mathrm{D}}$ vs. $V_{\mathrm{GS}}$ para TFTs de MDMO-PPV sobre (a) $\mathrm{p}+-\mathrm{Si} / \mathrm{SiO}_{2}$, (b) vidro$\mathrm{ITO} / \mathrm{SiO}_{\mathrm{x}} \mathrm{N}_{\mathrm{y}},(\mathrm{c}) \mathrm{p}+-\mathrm{Si} / \mathrm{SiO}_{\mathrm{x}} \mathrm{N}_{\mathrm{y}}$. 
Tabela 4.4 - Principais parâmetros extraídos a partir de $I_{\mathrm{D}} v s$. $V_{\mathrm{GS}}$ em regime de saturação para MDMO-PPV depositado a partir de clorofórmio e tolueno em ambos os dielétricos. As dimensões do canal são $W_{\mathrm{M}}=1,1 \mathrm{~mm}$ e $L_{\mathrm{M}}=5 \mu \mathrm{m}$. A carga acumulada é $(3,4 \pm 0,1)$ sobre $\mathrm{SiO}_{2}$ e $(10,3 \pm 1,4) \times 10^{12}$ $\operatorname{cargas} / \mathrm{cm}^{2} \operatorname{com} \mathrm{SiO}_{\mathrm{x}} \mathrm{N}_{\mathrm{y}}$.

\begin{tabular}{|c|c|c|c|c|c|c|c|}
\hline Solvente & $\begin{array}{c}\text { Substr./ } \\
\text { Isol. }\end{array}$ & $\begin{array}{c}x_{\mathrm{i}} \\
(\mathrm{nm})\end{array}$ & $\begin{array}{c}\mu_{h} \\
\left(10^{-5} \mathrm{~cm}^{2} / \mathrm{Vs}\right)\end{array}$ & $\begin{array}{l}V_{\mathrm{T}} \\
(\mathrm{V})\end{array}$ & $\begin{array}{c}S \\
\text { (V/déc.) }\end{array}$ & $I_{\mathrm{ON} / \mathrm{OFF}}$ & $\begin{array}{l}H F \\
(\%)\end{array}$ \\
\hline clorofórmio & \multirow{2}{*}{$\begin{array}{c}\mathrm{p}+-\mathrm{Si} / \\
\mathrm{SiO}_{2}\end{array}$} & \multirow{2}{*}{$252 \pm 10$} & $2,5 \pm 0,2$ & $-5,2 \pm 1,9$ & $8 \pm 1$ & 1500 & $19,6 \pm 3,0$ \\
\hline tolueno & & & $2,2 \pm 0,3$ & $-9,1 \pm 1,4$ & $14 \pm 1$ & 100 & $9,4 \pm 1,4$ \\
\hline clorofórmio & \multirow{2}{*}{$\begin{array}{l}\mathrm{p}+-\mathrm{Si} / \\
\mathrm{SiO}_{\mathrm{x}} \mathrm{N}_{\mathrm{y}}\end{array}$} & \multirow{2}{*}{$94 \pm 12$} & $3,3 \pm 0,4$ & $-21,0 \pm 3,8$ & $4 \pm 1$ & 1500 & $26,6 \pm 5,2$ \\
\hline tolueno & & & $4,3 \pm 0,4$ & $-19,1 \pm 1,0$ & $5 \pm 1$ & 5500 & $43,9 \pm 1,2$ \\
\hline
\end{tabular}

No caso de dispositivos em que o lift-off não funcionou corretamente e comprimentos de canal próximos a $1 \mu \mathrm{m}$ foram obtidos, efeitos de canal curto surgiram nas curvas características do transistor. Na Figura 4.21, tem-se uma curva de $I_{\mathrm{D}} v s$. $V_{\mathrm{DS}}$ para um OTFT de MDMO-PPV em vidro com $L \sim 1,5 \mu \mathrm{m}$. A corrente de dreno atinge 1 $\mu \mathrm{A}$ e $I_{\mathrm{ON} / \mathrm{OFF}}>10^{4}$, porém a região de saturação desaparece completamente.

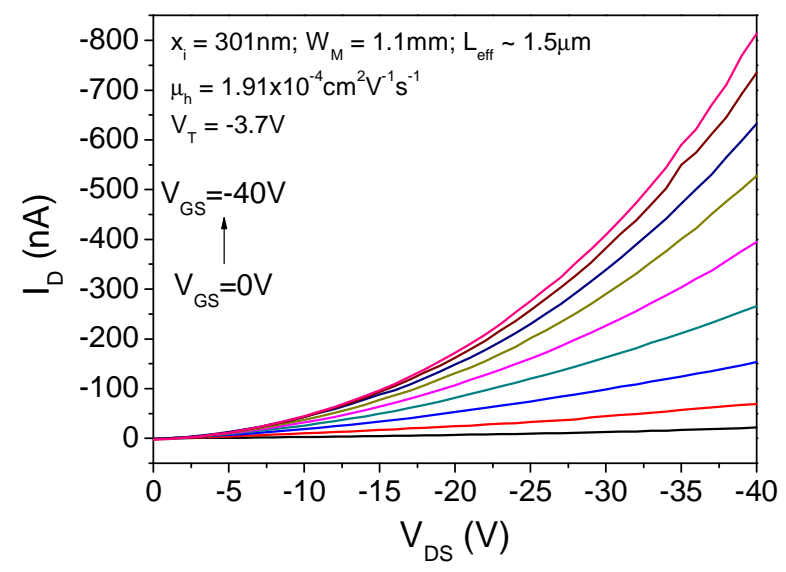

Figura 4.21 - Ausência de saturação em OTFTs de MDMO-PPV em vidro-ITO/SiO $\mathrm{S}_{\mathrm{y}}$.

A mobilidade dos portadores de carga em TFTs de MDMO-PPV foi estudada variando a espessura do dielétrico (ver Figura 4.22) e o comprimento do canal (ver Figura 4.23). No caso de semicondutores de baixa mobilidade, pode-se observar que espessuras próximas a $100 \mathrm{~nm}$ podem implicar no comprometimento do funcionamento 
do dispositivo. De fato, o desempenho dos dispositivos é pior para maiores comprimentos de canal $(L \sim 20 \mu \mathrm{m})$, o que pode ser devido a correntes de operação comparáveis às parasitárias. Além disso, como mostrado na Figura 4.24, um aumento do canal implica em uma maior inclinação de sublimiar $(S)$. A análise dos resultados apresentados na Figura 4.23 segundo um comportamento Poole-Frenkel de $\mu_{h}$ em relação ao campo elétrico longitudinal é apresentada na Seção 4.3.2.

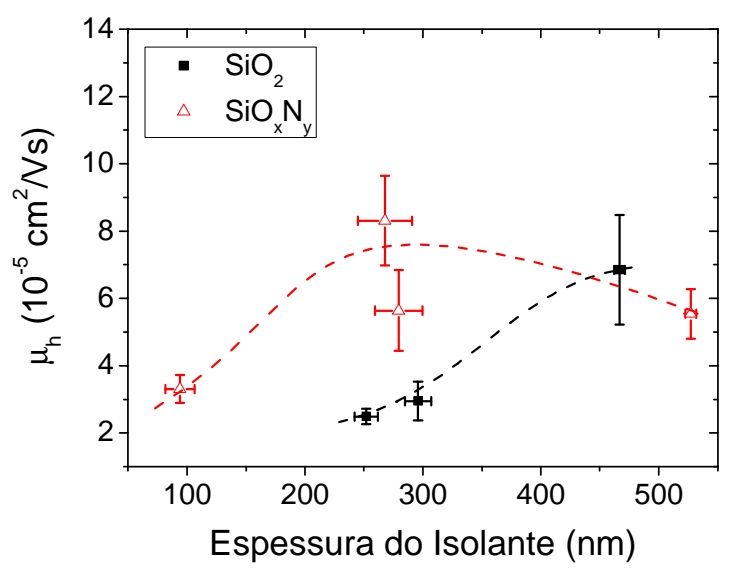

Figura 4.22 - Variação de $\mu_{\mathrm{h}}$ com a espessura de $\mathrm{SiO}_{2}$ e $\mathrm{SiO}_{\mathrm{x}} \mathrm{N}_{\mathrm{y}}$ (Dimensões do canal: $\left.\mathrm{W}_{M}=1.1 \mathrm{~mm} \mathrm{e} \mathrm{L}_{M}=10 \mu \mathrm{m}\right)$.
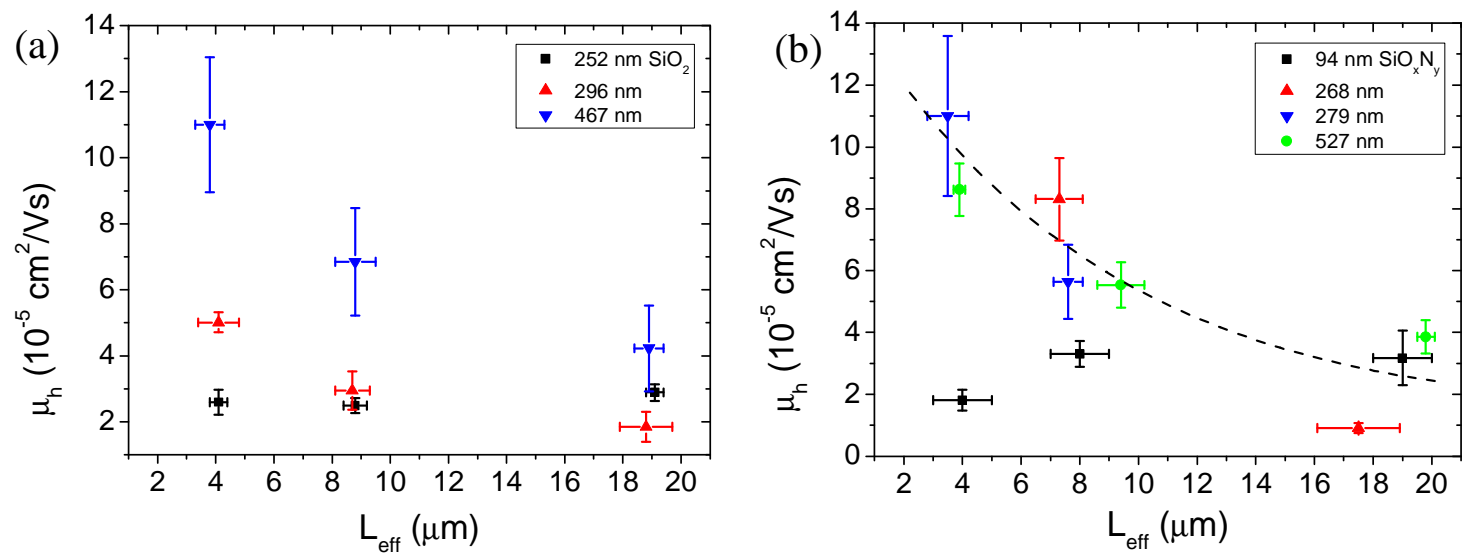

Figura 4.23 - Variação de $\mu_{\mathrm{h}}$ com o comprimento do canal para OTFTs de MDMO-PPV com (a) $\mathrm{SiO}_{2}$ e (b) $\mathrm{SiO}_{\mathrm{x}} \mathrm{N}_{\mathrm{y}}$ em substrato de p+-Si. 


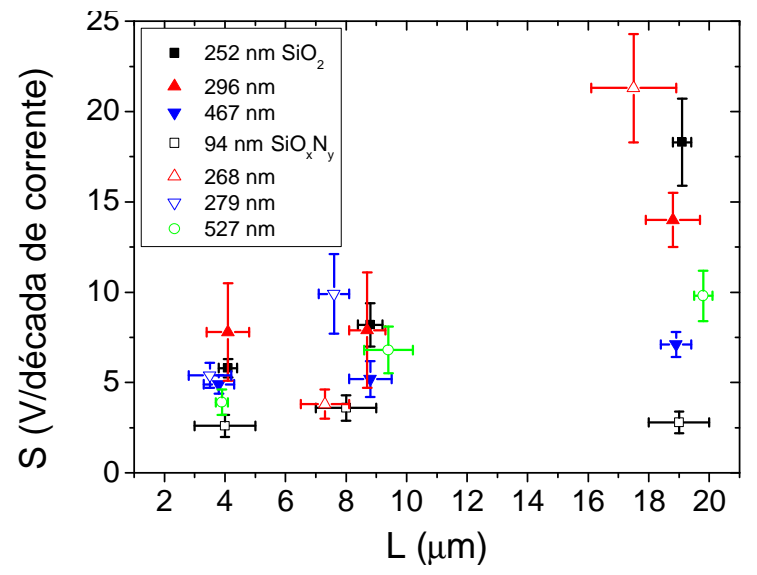

Figura 4.24 - Inclinação de sublimiar versus comprimento do canal para OTFTs de MDMO-PPV com $\mathrm{SiO}_{2}$ e $\mathrm{SiO}_{\mathrm{x}} \mathrm{N}_{\mathrm{y}}$ em substrato de p+-Si.

Transistores com $L_{\mathrm{M}}=20 \mu \mathrm{m}$ incluindo $20 \mathrm{~nm}$ de titânio para promover maior adesão do ouro sobre óxidos inorgânicos apresentaram $\mu_{h}$ comparável sobre $\mathrm{SiO}_{2}$ e quase quatro vezes inferior sobre $\mathrm{SiO}_{\mathrm{x}} \mathrm{N}_{\mathrm{y}}$ em relação a dispositivos sem a camada de adesão (ver Tabela 4.5). Os outros parâmetros não apresentaram nenhuma tendência que permitisse uma comparação. TFTs com $L_{\mathrm{M}}=5$ ou $10 \mu \mathrm{m}$ demonstram um desempenho uma ordem de grandeza inferior sobre $\mathrm{SiO}_{\mathrm{x}} \mathrm{N}_{\mathrm{y}}$ e cerca de três vezes pior sobre $\mathrm{SiO}_{2}$, provavelmente devido a resistências de contato significativas. Devido às baixas correntes nestes dispositivos, não foi possível calcular $R_{\mathrm{S}}$ através do método diferencial ou por linha de transmissão. No entanto, ao utilizar apenas $5 \mathrm{~nm}$ de titânio e tratar a superfície do dielétrico com HMDS, a resistência série pareceu ser irrelevante. Resultados preliminares para TFTs de MDMO-PPV depositado em $\mathrm{SiO}_{2}(274 \mathrm{~nm})$ tratado com vapor de HMDS apresentam um aumento em $\mu_{h}$ de 3 a $11 \times 10^{-5} \mathrm{~cm}^{2} / \mathrm{Vs}$ para $L_{M}=10 \mu \mathrm{m}$ e $n_{Q}=3,2 \times 10^{12} \mathrm{~cm}^{-2}$. TFTs com $L_{M}=20 \mu \mathrm{m}$ melhoram de 2 a $7 \times 10^{-5}$ $\mathrm{cm}^{2} / V s$. Mesmo se uma menor dispersão dos parâmetros por amostra foi observada, $H F$ $=11 \%$ e $S=9 \mathrm{~V} /$ década são comparáveis a TFTs com $\mathrm{SiO}_{2}$ sem tratamento. Os ângulos de contato medidos variam de $41,4^{\circ}$ após limpeza em solventes orgânicos a 3,1 $1^{\circ}$ após plasma de $\mathrm{O}_{2}$, até enfim $73,4^{\circ}$ após tratamento com HMDS. Tratamento por HMDS líquido pode ser realizado por spin coating em duas etapas: (a) amostra parada por $30 \mathrm{~s}$ após pipetar HMDS; (b) deposição a 3000 rpm por 2 min. Ângulos de contato medidos 
para um volume de água menor que 10 microlitros após $30 \mathrm{~min}$ de estufa foram 76,3․ Nenhum dispositivo foi fabricado integrando este processo, porém este resultado é um indicativo de que o tratamento de superfície também pode ser feita em fase líquida de forma eficaz.

Tabela 4.5 - Principais parâmetros extraídos a partir de $I_{\mathrm{D}} v s$. $V_{\mathrm{GS}}$ em regime de saturação para MDMO-PPV dissolvido em clorofórmio e depositado sobre eletrodos com e sem filme de titânio (20 nm). As dimensões do canal são $W_{M}=1,1 \mathrm{~mm}$ e $L_{\mathrm{M}}=20 \mu \mathrm{m}$.

\begin{tabular}{|c|c|c|c|c|c|c|c|c|}
\hline $\begin{array}{c}\text { Substr./ } \\
\text { Isol. }\end{array}$ & $\mathrm{S} / \mathrm{D}^{*}$ & $\begin{array}{c}x_{\mathrm{i}} \\
(\mathrm{nm})\end{array}$ & $\begin{array}{c}n_{\mathrm{Q}} \\
\left(10^{12} 1 / \mathrm{cm}^{2}\right)\end{array}$ & $\begin{array}{c}\mu_{h} \\
\left(10^{-5} \mathrm{~cm}^{2} / \mathrm{Vs}\right)\end{array}$ & $\begin{array}{c}V_{\mathrm{T}} \\
(\mathrm{V})\end{array}$ & $\begin{array}{c}S \\
(\mathrm{~V} / \text { déc. })\end{array}$ & $I_{\mathrm{ON} / \mathrm{OFF}}$ & $\begin{array}{c}H F \\
(\%)\end{array}$ \\
\hline $\begin{array}{c}\mathrm{p}+-\mathrm{Si} / \\
\mathrm{SiO}\end{array}$ & $\mathrm{Au}$ & $467 \pm 5$ & $1,9 \pm 0,1$ & $4,2 \pm 1,3$ & $-2,0 \pm 3,5$ & $7 \pm 1$ & 600 & $11,5 \pm 2,8$ \\
\cline { 2 - 10 } & $\mathrm{Ti} / \mathrm{Au}$ & $431 \pm 18$ & $2,0 \pm 0,1$ & $3,8 \pm 0,7$ & $-5,7 \pm 2,3$ & $6 \pm 1$ & 350 & $23,6 \pm 2,7$ \\
\hline $\begin{array}{c}\mathrm{p}+-\mathrm{Si} / \\
\mathrm{SiO}_{\mathrm{x}} \mathrm{N}_{\mathrm{y}}\end{array}$ & $\mathrm{Au}$ & $527 \pm 35$ & $2,1 \pm 0,2$ & $3,9 \pm 0,5$ & $-2,6 \pm 2,4$ & $10 \pm 1$ & 500 & $14,3 \pm 2,4$ \\
\cline { 2 - 9 } & $\mathrm{Ti} / \mathrm{Au}$ & $542 \pm 22$ & $1,9 \pm 0,1$ & $1,0 \pm 0,1$ & $-0,7 \pm 0,5$ & $11 \pm 1$ & 550 & $21,2 \pm 2,0$ \\
\hline
\end{tabular}

* S/D: eletrodos metálicos de fonte e dreno.

(a)

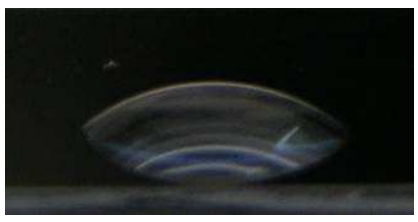

(b)

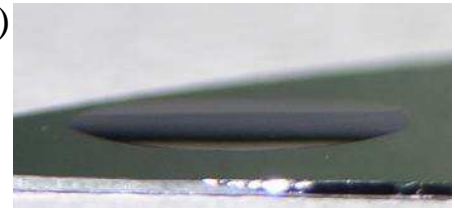

(c)

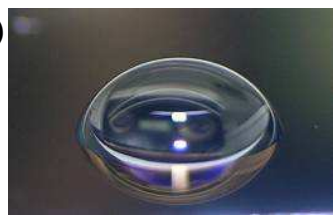

Figura 4.25 - Imagens das gotas d'água sobre $\mathrm{SiO}_{2}$ após diferentes tratamentos: (a) limpeza em solventes orgânicos; (b) 10 min de plasma de $\mathrm{O}_{2}$; e (c) 30 min de exposição ao vapor de HMDS.

\subsubsection{Mobilidade dependente da tensão de porta $-\mu=f\left(V_{\mathrm{GS}}\right)$}

Aplicando a metodologia de extração de parâmetros a partir da curva $I_{\mathrm{D}} v s . V_{\mathrm{GS}}$ de TFTs operando em regime de saturação e sem resistências de contato apresentada em [88] (ver Seção 2.3.2) foram obtidos os resultados expostos na Tabela 4.6. Em semicondutores de alta mobilidade $\left(\mu>0,1 \mathrm{~cm}^{2} / \mathrm{Vs}\right)$, a resistência do canal pode ser de mesma ordem ou menor que a resistência de contato, logo o leitor interessado pode recorrer a um modelo incluindo efeitos de resistência série na referência [88]. As mesmas medidas utilizadas para preencher a Tabela 4.3 foram estudadas aplicando $\mu=$ 
$f\left(V_{G S}\right)$. Mobilidades calculadas a $V_{\mathrm{DS}}=V_{\mathrm{GS}}=-40 \mathrm{~V}$ para $L_{\mathrm{M}}=5 \mu \mathrm{m}$ estão de acordo com os valores apresentados na Tabela 4.3, permanecendo dentro do intervalo de erro. Aparentemente, o pior desempenho em substrato de vidro-ITO não está relacionado a uma maior concentração de armadilhas, visto que $\gamma$ é menor em substratos de vidro. Em segundo lugar, $V_{\mathrm{T}}$ calculada através deste modelo tende para valores mais positivos, aproximando-se de zero.

Tabela 4.6 - Parâmetros extraídos de TFTs para $\mu=f\left(V_{\mathrm{GS}}\right)$ em regime de saturação de MDMO-PPV dissolvido em clorofórmio e depositado em ambos os dielétricos e substratos. As dimensões do canal são $W_{M}=1,1 \mathrm{~mm}$ e $L_{M}=5 \mu \mathrm{m}$.

\begin{tabular}{|c|c|c|c|c|c|c|}
\hline $\begin{array}{c}\text { Substr./Isol. } \\
\left(x_{\mathrm{i}}(\mathrm{nm})\right)\end{array}$ & $\begin{array}{c}n_{\mathrm{Q}} \\
\left(10^{12} 1 / \mathrm{cm}^{2}\right)\end{array}$ & $\begin{array}{c}k \\
\left(10^{-6} \mathrm{~cm}^{2} / \mathrm{V}^{1-\gamma} \mathrm{s}\right)\end{array}$ & $\gamma$ & $\begin{array}{c}T_{\mathrm{c}} \\
(\mathrm{K})\end{array}$ & $\begin{array}{c}\mu_{h_{h}^{*}}{ }^{-2} \\
\left(10^{-5} \mathrm{~cm}^{2} / \mathrm{Vs}\right)\end{array}$ & $\begin{array}{c}V_{\mathrm{T}} \\
(\mathrm{V})\end{array}$ \\
\hline $\begin{array}{c}\mathrm{p}+-\mathrm{Si} / \mathrm{SiO} \mathrm{O}_{2} \\
(296 \pm 12) \dagger\end{array}$ & $2,9 \pm 0,1$ & $2,0 \pm 1,2$ & $0,8 \pm 0,1$ & $415 \pm 47$ & 3,8 & $1,3 \pm 0,9$ \\
\hline $\begin{array}{c}\mathrm{p}+-\mathrm{Si}_{\mathrm{SiO}} \mathrm{N}_{\mathrm{y}} \\
(279 \pm 20)\end{array}$ & $3,6 \pm 0,8$ & $4,0 \pm 2,0$ & $0,9 \pm 0,1$ & $423 \pm 10$ & $9,5 \pm 2,6$ & $0,8 \pm 1,1$ \\
\hline $\begin{array}{c}\mathrm{ITO} / \mathrm{SiO}_{\mathrm{x}} \mathrm{N}_{\mathrm{y}} \\
(301 \pm 18)\end{array}$ & $3,3 \pm 0,2$ & $13,4 \pm 7,2$ & $0,4 \pm 0,2$ & $351 \pm 25$ & $5,2 \pm 1,9$ & $-0,9 \pm 0,8$ \\
\hline
\end{tabular}

* Valores calculados a $V_{\mathrm{DS}}=V_{\mathrm{GS}}=-40 \mathrm{~V}$

† Aproximação com erro significativo e, para muitos dispositivos, divergente. Resultados são para apenas um transistor.

Ambos os métodos de fitting aplicados a um transistor saturado junto com seus dados experimentais são mostrados na Figura 4.26.a. O método de aproximação 1 utiliza $\mu$ constante $\left(\mu_{h}=1,28 \times 10^{-4} \mathrm{~cm}^{2} / \mathrm{Vs}, V_{\mathrm{T}}=-8,7 \mathrm{~V}\right)$, enquanto que o método 2 considera a mobilidade dependente da tensão de porta $\left(\gamma=0,83, V_{\mathrm{T}}=0 \mathrm{~V}, k=5,39 \times 10^{-6} \mathrm{~cm}^{2} / \mathrm{V}^{1-\gamma} \mathrm{s}\right.$, $\left.\mu_{h}=1,14 \times 10^{-4} \mathrm{~cm}^{2} / \mathrm{Vs}\right)$. O gráfico da mobilidade em função da tensão de porta ( $\left.V_{\mathrm{GS}}\right)$ é mostrado na Figura 4.26.b. Para baixas tensões de porta e conseqüentemente baixas concentrações de carga no canal, uma semelhança maior com os valores obtidos através de outras técnicas é observado (e.g. ToF, CELIV e $J x V$ ). As temperaturas características calculadas $\left(T_{\mathrm{c}}\right)$, no entanto, diferem do que foi obtido a partir dos estudos de transporte de carga. 
(a)

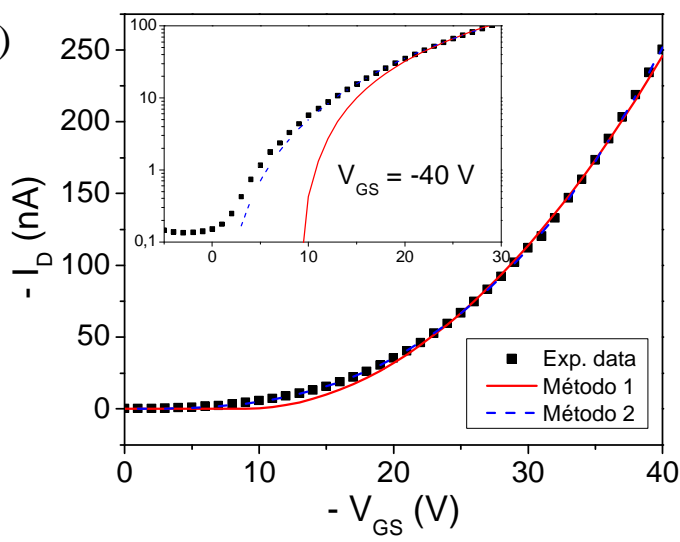

(b)

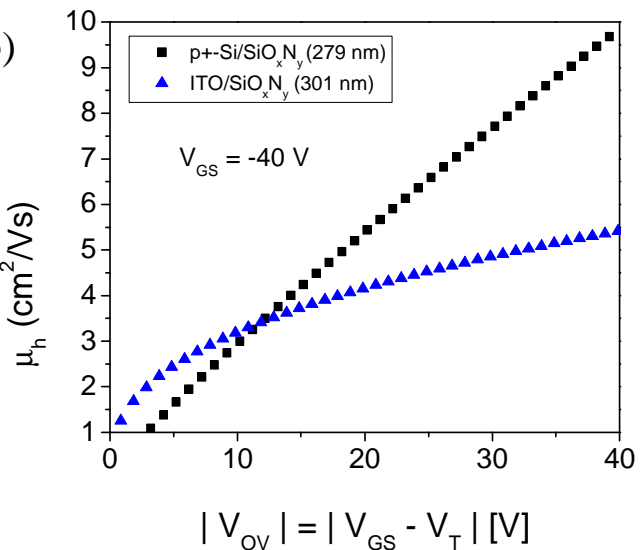

Figura 4.26 - Resultados obtidos para TFTs de MDMO-PPV em SiO $\mathrm{N}_{\mathrm{y}} \operatorname{com} W_{\mathrm{M}}=1,1 \mathrm{~mm}$ e $L_{\mathrm{M}}=$ $10 \mu \mathrm{m}$ operando em regime de saturação $\left(V_{\mathrm{DS}}=-40 \mathrm{~V}\right)$ : (a) dados experimentais de $I_{\mathrm{D}} v s$. $V_{\mathrm{GS}}$ para p+-Si/SiO $\mathrm{X}_{\mathrm{y}}(279 \mathrm{~nm})$ e aproximação por dois métodos diferentes. (b) Dependência da mobilidade com $V_{\text {Ov }}$ para dispositivos em p+-Si (quadrados), e ITO (pirâmides). Parâmetros da Tabela 4.6.

A relação entre a desordem no filme fino de MDMO-PPV e a variação da mobilidade de efeito de campo pode ser representada através da Equação (26). A mobilidade para TFTs de MDMO-PPV sobre $\mathrm{p}+-\mathrm{Si} / \mathrm{SiO}_{2}$ (ver $x_{\mathrm{i}}=467 \mathrm{~nm}$ na Figura 4.23.a) e p+-Si/SiO $\mathrm{S}_{\mathrm{y}}\left(\right.$ ver $x_{\mathrm{i}}=279 \mathrm{~nm}$ na Figura 4.23.b) em função do campo elétrico longitudinal médio $\left(E_{/ /}\right)$é mostrada na Figura 4.29. Em regime linear, $E_{/ /}=V_{\mathrm{DS}} / L$, enquanto que saturado, $\mathrm{E}_{/ /} \sim\left(V_{\mathrm{GS}}-V_{\mathrm{T}}\right) / L$. Os dados utilizados são dos TFTs que apresentaram melhor desempenho em ambos os dielétricos. Os resultados oriundos da aplicação de um modelo de mobilidade constante em regime linear não foram apresentados na Seção anterior, no entanto, são necessários ao estudo por Poole-Frenkel. A aproximação dos dados experimentais foi realizada integrando todos os comprimentos de canal disponíveis e os resultados obtidos se encontram na Tabela 4.7. $E_{0}$ foi variado de zero a $5,6 \mathrm{kV} / \mathrm{cm}$, porém seu valor não afeta o cálculo de $\eta$. Considerando uma DOS gaussiana, $\sigma k_{\mathrm{B}} T$ foi calculado a partir da Equação (11) em [86]. Substituindo o resultado obtido na Equação (3) em [86], obteve-se $\gamma=2 \beta$. Há concordância com os valores obtidos através do método diferencial (ver Tabela 4.6), observando-se novamente maior desordem sobre $\mathrm{p}+-\mathrm{Si} / \mathrm{SiO}_{\mathrm{x}} \mathrm{N}_{\mathrm{y}}$. Na Tabela 4.7, são apresentados também resultados para OTFTs cujo dielétrico foi tratado por vapor de HMDS. Observa- 
se que o comportamento Poole-Frenkel observado, além de depender do dielétrico de porta utilizado, varia de acordo com o tratamento de superfície aplicado ao dielétrico.

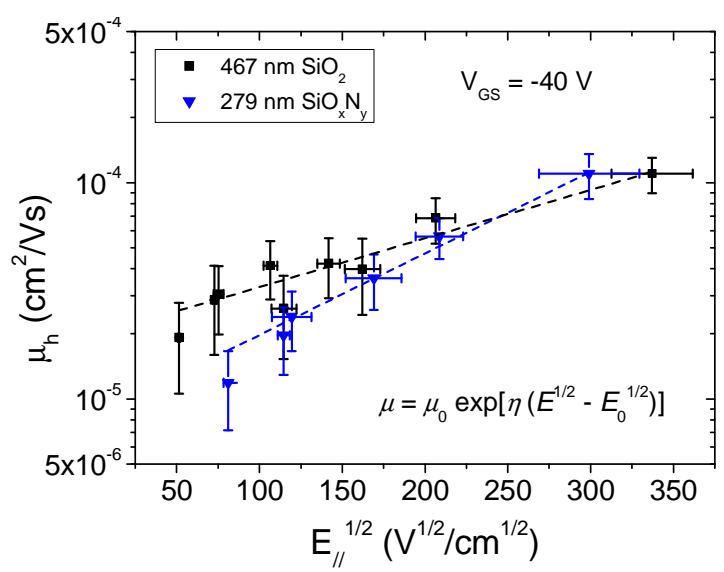

Figura 4.27 - Mobilidade de lacunas em função do campo elétrico longitudinal médio em TFTs de MDMO-PPV sobre ambos os dielétricos. A linha tracejada são aproximações segundo a Equação (26).

Tabela 4.7 - Dependência Poole-Frenkel da mobilidade com o campo elétrico longitudinal em TFTs de MDMO-PPV depositado sobre ambos os dielétricos.

\begin{tabular}{|c|c|c|c|c|c|c|}
\hline Substr./Isol. & $\begin{array}{c}x_{\mathrm{i}} \\
(\mathrm{nm})\end{array}$ & $\begin{array}{c}E_{0} \\
\left(10^{3} \mathrm{~V} / \mathrm{cm}\right)\end{array}$ & $\begin{array}{c}\mu_{0} \\
\left(10^{-5} \mathrm{~cm}^{2} / \mathrm{Vs}\right)\end{array}$ & $\begin{array}{c}\eta \\
\left(10^{-3} \mathrm{~cm}^{1 / 2} / \mathrm{V}^{1 / 2}\right)\end{array}$ & $\sigma / k_{\mathrm{B}} T$ & $\gamma$ \\
\hline $\mathrm{p}+-\mathrm{Si} / \mathrm{SiO}_{2}$ & $467 \pm 5$ & \multirow{2}{*}{$0-5,6$} & $2,0-3,0$ & $5,2 \pm 0,4$ & $4,5 \pm 0,4$ & 0,77 \\
\hline $\mathrm{p}+-\mathrm{Si} / \mathrm{SiO}_{\mathrm{x}} \mathrm{N}_{\mathrm{y}}$ & $279 \pm 62$ & & $0,8-2,0$ & $8,7 \pm 0,5$ & $5,7 \pm 0,3$ & 1,03 \\
\hline $\mathrm{p}+-\mathrm{Si} / \mathrm{SiO}_{2} \dagger$ & $275 \pm 4$ & 0 & $0,58 \pm 0,08$ & $17,2 \pm 0,8$ & $7,8 \pm 0,4$ & 1,30 \\
\hline
\end{tabular}

$\dagger$ Dielétrico tratado com vapor de HMDS. Resultados para $L=8 \mu \mathrm{m}$.

\subsection{TFTs de MEH-PPV}

Transistores bottom gate bottom contact de poli(2-metoxi-5-(2-etil-hexiloxi)-1,4fenileno vinileno) (MEH-PPV) sobre silício altamente dopado e $\mathrm{SiO}_{2}$ térmico $\left(x_{\mathrm{i}}=274 \pm\right.$ $4 \mathrm{~nm}$ ) tratado com HMDS apresentaram desempenho superior aos de MDMO-PPV fabricados nessas mesmas condições: $1 \times 10^{-4} \mathrm{~cm}^{2} / \mathrm{Vs}$ para $V_{\mathrm{GS}}=-40 \mathrm{~V}$ e $n_{\mathrm{Q}}=$ $(3,5 \pm 0,1) \times 10^{12}$ cargas $/ \mathrm{cm}^{2}$ (Figura 4.28). Assim como apresentado na Seção 4.3.1, foram 
utilizados eletrodos de Ti $(5 \mathrm{~nm})$ e $\mathrm{Au}(95 \mathrm{~nm})$. Resultados obtidos para canais de 5, 10 e $20 \mu \mathrm{m}$ em regime linear são apresentados na Tabela 4.8 e, em saturação, na Tabela 4.9. Foram utilizados dados somente de um TFT para cada comprimento de canal e todos pertencentes à mesma amostra. Foi utilizada aproximação linear com mobilidade constante para $V_{\mathrm{DS}}=-5$ e $-10 \mathrm{~V}$ no regime linear, além de $-40 \mathrm{~V}$ em regime de saturação. Há um aumento gradual de $\mu_{h}$ em relação a um aumento de $V_{\mathrm{DS}}$ e a uma diminuição de L. A histerese de 10-20\% e inclinação de sublimiar > 5 V/déc., apesar de comparáveis aos valores obtidos com MDMO-PPV, indicam a presença de armadilhas e, portanto, a aplicação de um modelo de $\mu$ constante é inadequada. Resultados semelhantes foram obtidos para outros transistores da amostra e em outra amostra fabricada paralelamente.
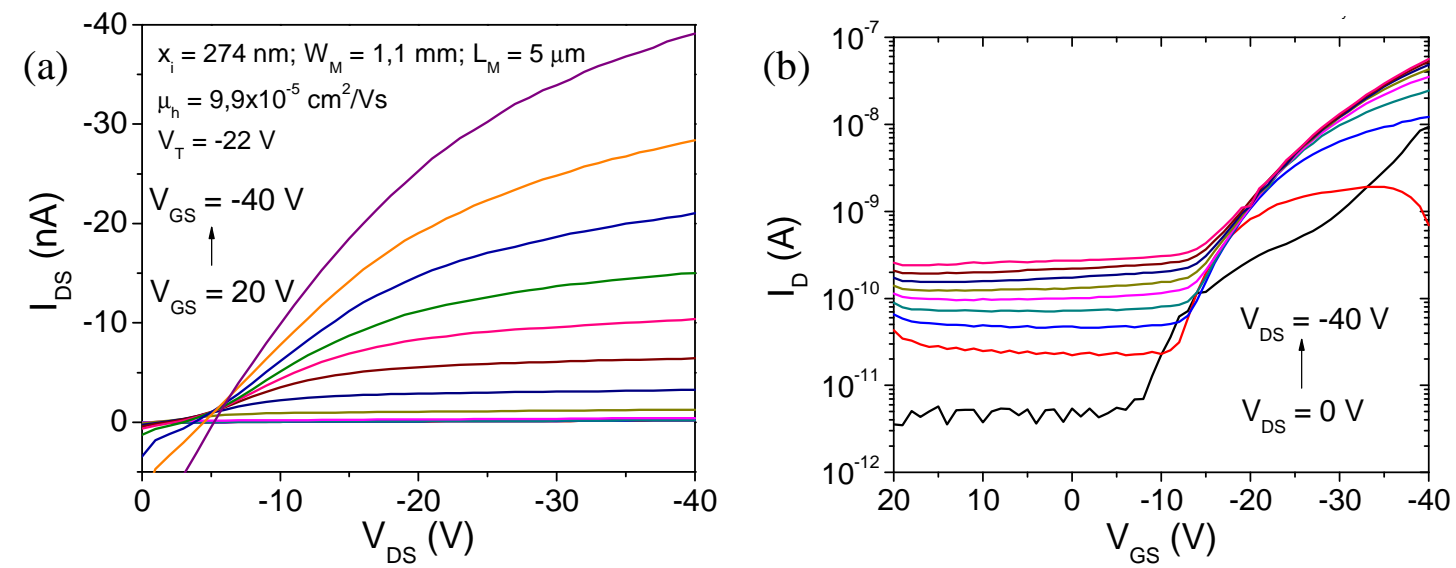

Figura 4.28 - Curvas características de um TFT de MEH-PPV sobre p+-Si/SiO ${ }_{2}$.

Tabela 4.8 - Principais parâmetros extraídos a partir de $I_{D} v s . V_{G S}$ em regime linear para MEH-PPV depositado sobre p+-Si/SiO ${ }_{2}$. A largura do canal $\left(W_{M}\right)$ é $1,1 \mathrm{~mm}$.

\begin{tabular}{|c|c|c|c|c|c|c|}
\hline $\begin{array}{c}L \\
(\mu \mathrm{m})\end{array}$ & $\begin{array}{l}V_{\mathrm{DS}} \\
(\mathrm{V})\end{array}$ & $\left(10^{-5} \stackrel{\mu_{h}}{\left.\mathrm{~cm}^{2} / \mathrm{Vs}\right)}\right.$ & $\begin{array}{l}V_{\mathrm{T}} \\
(\mathrm{V})\end{array}$ & $\begin{array}{l}V_{\mathrm{DS}} \\
(\mathrm{V})\end{array}$ & $\begin{array}{c}\mu_{h} \\
\left(10^{-5} \mathrm{~cm}^{2} / \mathrm{Vs}\right)\end{array}$ & $\begin{array}{l}V_{\mathrm{T}} \\
(\mathrm{V})\end{array}$ \\
\hline $4 \pm 1$ & \multirow{3}{*}{-5} & $0,7 \pm 0,2$ & $-11,1 \pm 0,5$ & \multirow{3}{*}{-10} & $1,7 \pm 0,4$ & $-14,4 \pm 0,8$ \\
\hline $10 \pm 1$ & & $1,6 \pm 0,2$ & $-13,3 \pm 0,5$ & & $3,7 \pm 0,4$ & $-17,1 \pm 0,5$ \\
\hline $19 \pm 1$ & & $1,3 \pm 0,1$ & $-13,8 \pm 3,6$ & & $3,5 \pm 0,2$ & $-18,1 \pm 0,5$ \\
\hline
\end{tabular}


Tabela 4.9 - Principais parâmetros extraídos a partir de $I_{\mathrm{D}} v s$. $V_{\mathrm{GS}}$ em regime de saturação para MEH-PPV depositado sobre p+-Si/SiO . A largura do canal $\left(W_{M}\right)$ é 1,1 mm.

\begin{tabular}{|c|c|c|c|c|c|c|}
\hline $\begin{array}{c}L \\
(\mu \mathrm{m})\end{array}$ & $\begin{array}{l}V_{\mathrm{DS}} \\
(\mathrm{V})\end{array}$ & $\begin{array}{c}\mu_{h} \\
\left(10^{-5} \mathrm{~cm}^{2} / \mathrm{Vs}\right)\end{array}$ & $\begin{array}{l}V_{\mathrm{T}} \\
(\mathrm{V})\end{array}$ & $\begin{array}{c}S \\
\text { (V/déc.) }\end{array}$ & $I_{\mathrm{ON} / \mathrm{OFF}}$ & $\begin{array}{l}H F \\
(\%)\end{array}$ \\
\hline $4 \pm 1$ & \multirow{3}{*}{-40} & $9,9 \pm 0,7$ & $-21,9 \pm 1,1$ & 3,9 & 250 & 16,5 \\
\hline $10 \pm 1$ & & $11,7 \pm 0,8$ & $-22,7 \pm 0,5$ & 4,0 & 150 & 15,0 \\
\hline $19 \pm 1$ & & $7,9 \pm 0,5$ & $-21,7 \pm 0,6$ & 4,2 & 100 & 11,1 \\
\hline
\end{tabular}

A relação entre a desordem no filme fino de MEH-PPV e a variação da mobilidade de efeito de campo, assim como para o MDMO-PPV, foi estudada segundo a Equação (26). A mobilidade apresentada nas duas Tabelas anteriores é mostrada na Figura 4.29 em função do campo elétrico longitudinal médio $\left(E_{/ /}\right)$. Em regime linear, $E_{/ /}$ $=V_{\mathrm{DS}} / L$, enquanto que saturado, $\mathrm{E}_{/ /} \approx\left(V_{\mathrm{GS}}-V_{\mathrm{T}}\right) / L$. A aproximação dos dados experimentais foi realizada para cada comprimento de canal e os resultados se encontram na Tabela 4.10. De forma geral, $E_{0}$ foi considerado nulo e obteve-se $\mu_{0} \sim$ $2,5 \times 10^{-6} \mathrm{~cm}^{2} / \mathrm{Vs}$ e $\eta \sim 3,5 \times 10^{-2}(\mathrm{~V} / \mathrm{cm})^{-1 / 2}$. Semelhante ao estudo realizado para o MDMO-PPV, a partir da Equação (11) em [86] e considerando uma DOS gaussiana, obteve-se $\sigma k_{\mathrm{B}} T \sim 11$. Substituindo o resultado obtido na Equação (3) em [86], concluiu-se que $\gamma=2 \beta \sim 1,4$.

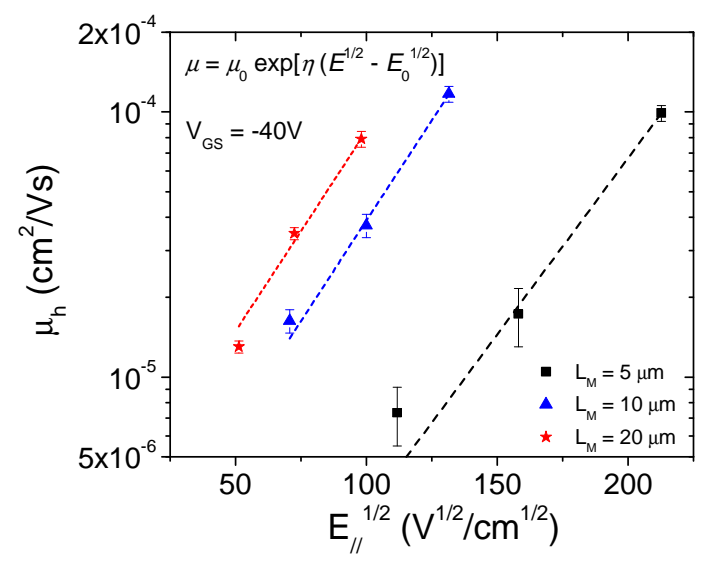

Figura 4.29 - Mobilidade de lacunas em função do campo elétrico longitudinal médio em TFTs de MEH-PPV sobre $\mathrm{p}+-\mathrm{Si}_{/} \mathrm{SiO}_{2}$. A linha tracejada é a curva aproximada segundo a Equação (26). 
Tabela 4.10 - Dependência Poole-Frenkel da mobilidade com o campo elétrico longitudinal em TFTs de MEH-PPV depositado sobre p+-Si/SiO ${ }_{2}$. A largura do canal $\left(W_{\mathrm{M}}\right)$ é $1,1 \mathrm{~mm}$.

\begin{tabular}{|c|c|c|c|c|}
\hline $\begin{array}{c}L \\
(\mu \mathrm{m})\end{array}$ & $\begin{array}{c}\mu_{0} \\
\left(10^{-6} \mathrm{~cm}^{2} / \mathrm{Vs}\right)\end{array}$ & $\begin{array}{c}\eta \\
\left(10^{-2} \mathrm{~cm}^{1 / 2} / \mathrm{V}^{1 / 2}\right)\end{array}$ & $\sigma / k_{\mathrm{B}} T$ & $\gamma$ \\
\hline $4 \pm 1$ & $0,15 \pm 0,09$ & $3,1 \pm 0,3$ & $10,4 \pm 0,9$ & 1,42 \\
\hline $10 \pm 1$ & $1,19 \pm 0,30$ & $3,5 \pm 0,2$ & $11,1 \pm 0,6$ & 1,43 \\
\hline $19 \pm 1$ & $2,61 \pm 0,82$ & $3,5 \pm 0,3$ & $11,1 \pm 1,1$ & 1,43 \\
\hline
\end{tabular}

As curvas $I_{\mathrm{D}}$ vs. $V_{\mathrm{GS}}$ estudadas segundo um modelo de mobilidade variável forneceram os resultados apresentados na Tabela 4.11. Observa-se uma grande concordância entre os valores obtidos para os diversos comprimentos de canal $(L)$. A tensão de limiar $V_{\mathrm{T}} \sim-11 \mathrm{~V}$ indica que os valores obtidos pelos métodos anteriores são geralmente mais negativos e imprecisos. Além disso, os valores de mobilidade calculados são válidos somente para tensões máximas de $V_{\mathrm{GS}}$. A dependência da mobilidade em relação a tensão de overdrive $\left(V_{\mathrm{OV}}=V_{\mathrm{GS}}-V_{\mathrm{T}}\right)$ é mostrada na Figura 4.30. $\mathrm{O}$ valor de $\gamma$ está de acordo com o obtido pelo estudo da mobilidade por Poole-Frenkel, indicando a presença de uma distribuição gaussiana em vez de exponencial (representada por $T_{\mathrm{c}}$ na Tabela 4.11 ).

Tabela 4.11 - Parâmetros extraídos de TFTs para $\mu=f\left(V_{\mathrm{GS}}\right)$ em regime de saturação de MEH-PPV depositado sobre p+-Si/SiO $\mathrm{S}_{2}$ A largura do canal $\left(W_{\mathrm{M}}\right)$ é 1,1 mm.

\begin{tabular}{|c|c|c|c|c|c|}
\hline $\begin{array}{c}L \\
(\mu \mathrm{m})\end{array}$ & $\begin{array}{c}k \\
\left(10^{-6} \mathrm{~cm}^{2} / \mathrm{V}^{1-\gamma} \mathrm{s}\right)\end{array}$ & $\gamma$ & $\begin{array}{c}T_{\mathrm{c}} \\
(\mathrm{K})\end{array}$ & $\begin{array}{c}\mu_{h^{*}} \\
\left(10^{-5} \mathrm{~cm}^{2} / \mathrm{Vs}\right)\end{array}$ & $\begin{array}{c}V_{\mathrm{T}} \\
(\mathrm{V})\end{array}$ \\
\hline $4 \pm 1$ & $0,21 \pm 0,09$ & $1,7 \pm 0,1$ & $541 \pm 27$ & 6,35 & $-9,3 \pm 0,6$ \\
\hline $10 \pm 1$ & $0,40 \pm 0,10$ & $1,6 \pm 0,1$ & $525 \pm 20$ & 7,50 & $-11,2 \pm 0,4$ \\
\hline $19 \pm 1$ & $0,69 \pm 0,23$ & $1,3 \pm 0,1$ & $488 \pm 33$ & 5,52 & $-11,7 \pm 0,6$ \\
\hline
\end{tabular}

* Valores calculados a $V_{\mathrm{DS}}=V_{\mathrm{GS}}=-40 \mathrm{~V}$ 


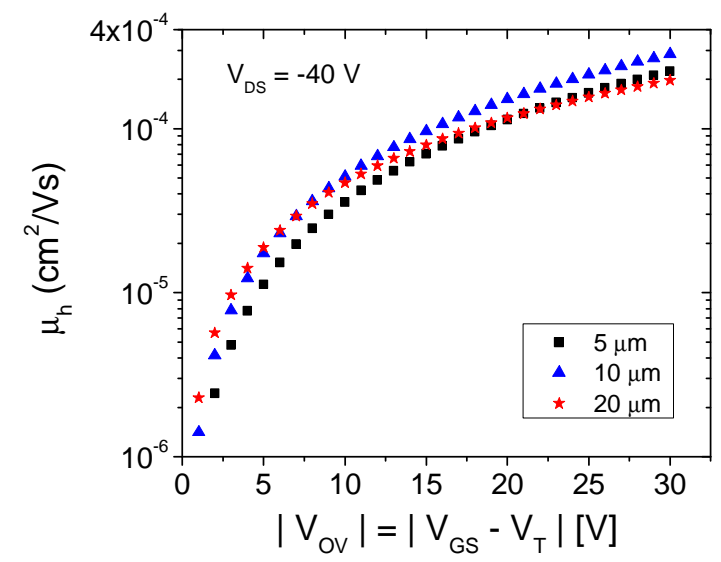

Figura 4.30 - Dependência da mobilidade com a tensão de overdrive para TFTs de MEH-PPV sobre p+-Si/SiO ${ }_{2}$ em saturação (parâmetros extraídos da Tabela 4.11).

\subsection{TFTs de P3HT}

Transistores bottom gate bottom contact de poli(3-hexiltiofeno) (P3HT) sobre silício altamente dopado e óxido de silício térmico $\left(x_{\mathrm{i}}=252 \pm 10 \mathrm{~nm}\right)$ apresentaram mobilidades acima de $2 \times 10^{-3} \mathrm{~cm}^{2} / \mathrm{Vs}$ para $V_{\mathrm{GS}}=-40 \mathrm{~V}$ e $n_{\mathrm{Q}}=(3,4 \pm 0,1) \times 10^{12} \mathrm{cargas} / \mathrm{cm}^{2}$ (ver Figura 4.31). A saturação tende a desaparecer para $V_{\mathrm{GS}}>20 \mathrm{~V}$ e o canal ainda existe para $V_{\mathrm{GS}}=25 \mathrm{~V}$. Assim como apresentado na Seção 4.4, TFTs com canais de 5, 10 e $20 \mu \mathrm{m}$ foram estudados em regime linear (ver Tabela 4.12) e em saturação (ver Tabela 4.13). Foram utilizados dados somente de um TFT para cada comprimento de canal e todos pertencentes à mesma amostra. Observa-se novamente um aumento gradual de $\mu_{h}$ em relação a um aumento de $V_{\mathrm{DS}}$ e a uma diminuição do comprimento de canal $(L)$. No entanto, o desligamento do transistor não aparece $\left(V_{\mathrm{ON}}<25 \mathrm{~V}\right)$ e a tensão de limiar varia de 34 a $46 \mathrm{~V}$. Por este motivo, os valores de $S$ apresentam grande erro e são apresentados na Tabela 4.13 somente para ilustrar este fenômeno. Seu cálculo fica comprometido devido à modulação $I_{\mathrm{ON} / \mathrm{OFF}}<30$. Resultados semelhantes foram obtidos para outros transistores da mesma amostra e para outra amostra fabricada paralelamente. Os dispositivos foram caracterizados expostos à atmosfera, porém no escuro. 

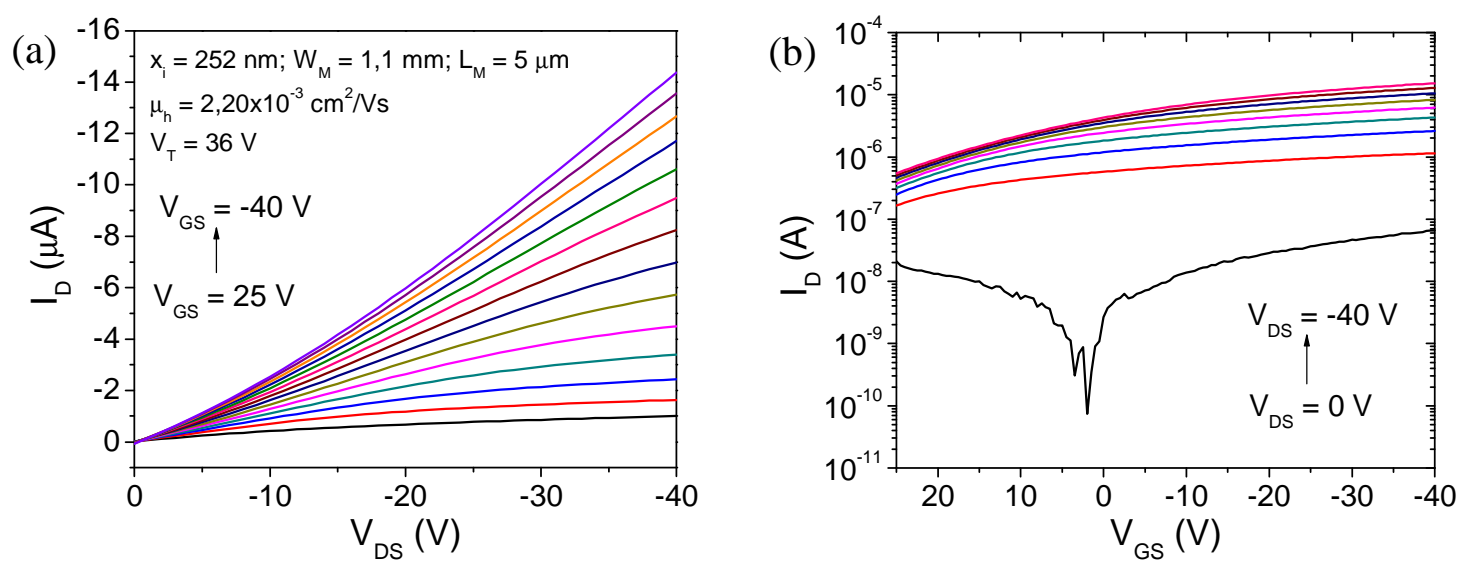

Figura 4.31 - Curvas características de um TFT de P3HT sobre p+-Si/SiO ${ }_{2}$.

Tabela 4.12 - Principais parâmetros extraídos a partir de $I_{\mathrm{D}} v s$. $V_{\mathrm{GS}}$ em regime linear para P3HT depositado sobre p+-Si/SiO $O_{2}$ A largura do canal $\left(W_{\mathrm{M}}\right)$ é 1,1 mm.

\begin{tabular}{|c|c|c|c|c|c|c|}
\hline $\begin{array}{c}L \\
(\mu \mathrm{m})\end{array}$ & $\begin{array}{l}V_{\mathrm{DS}} \\
(\mathrm{V})\end{array}$ & $\begin{array}{c}\mu_{h} \\
\left(10^{-5} \mathrm{~cm}^{2} / \mathrm{Vs}\right)\end{array}$ & $\begin{array}{l}V_{\mathrm{T}} \\
(\mathrm{V})\end{array}$ & $\begin{array}{l}V_{\mathrm{DS}} \\
(\mathrm{V})\end{array}$ & $\begin{array}{c}\mu_{h} \\
\left(10^{-5} \mathrm{~cm}^{2} / \mathrm{Vs}\right)\end{array}$ & $\begin{array}{l}V_{\mathrm{T}} \\
(\mathrm{V})\end{array}$ \\
\hline $5 \pm 1$ & \multirow{3}{*}{-5} & $9,5 \pm 1,9$ & $43,3 \pm 0,1$ & \multirow{3}{*}{-10} & $11,8 \pm 2,4$ & $38,2 \pm 0,1$ \\
\hline $10 \pm 1$ & & $8,1 \pm 0,9$ & $46,7 \pm 0,4$ & & $10,7 \pm 1,2$ & $34,3 \pm 0,2$ \\
\hline $20 \pm 1$ & & $8,0 \pm 0,5$ & $41,2 \pm 0,3$ & & $8,1 \pm 0,5$ & $36,5 \pm 0,1$ \\
\hline
\end{tabular}

Tabela 4.13 - Principais parâmetros extraídos a partir de $I_{\mathrm{D}} v s$. $V_{\mathrm{GS}}$ em regime de saturação para P3HT depositado sobre p+-Si/SiO ${ }_{2}$. A largura do canal $\left(W_{M}\right)$ é 1,1 mm.

\begin{tabular}{|c|c|c|c|c|c|c|}
\hline $\begin{array}{c}L \\
(\mu \mathrm{m})\end{array}$ & $\begin{array}{l}V_{\mathrm{DS}} \\
(\mathrm{V})\end{array}$ & $\begin{array}{c}\mu_{h} \\
\left(10^{-4} \mathrm{~cm}^{2} / \mathrm{Vs}\right)\end{array}$ & $\begin{array}{l}V_{\mathrm{T}} \\
(\mathrm{V})\end{array}$ & $\begin{array}{c}S \\
\text { (V/déc.) }\end{array}$ & $I_{\mathrm{ON} / \mathrm{OFF}}$ & $\begin{array}{l}H F \\
(\%)\end{array}$ \\
\hline $5 \pm 1$ & \multirow{3}{*}{-40} & $22,0 \pm 4,5$ & $36,0 \pm 0,1$ & 20 & 30 & 6,5 \\
\hline $10 \pm 1$ & & $14,9 \pm 1,6$ & $34,3 \pm 0,1$ & 23 & 10 & 4,5 \\
\hline $20 \pm 1$ & & $11,7 \pm 0,7$ & $34,1 \pm 0,1$ & 24 & 10 & 1,1 \\
\hline
\end{tabular}

A relação entre a desordem no filme fino polimérico e a variação da mobilidade de efeito de campo foi estudada da mesma forma que em filmes de derivados de PPV e é apresentada na Figura 4.32. Variando $E_{0}$ de 0 a $2,5 \times 10^{4} \mathrm{~V} / \mathrm{cm}$, obtiveram-se os seguintes valores: $\mu_{0}=(6,3-7,8) \times 10^{-4} \mathrm{~cm}^{2} / \mathrm{Vs}$ e $\eta=4,13 \times 10^{-3}(\mathrm{~V} / \mathrm{cm})^{-1 / 2}$. A partir da Equação (11) em [86], obteve-se $\sigma k_{\mathrm{B}} T=4,1$. Substituindo o resultado obtido na Equação (3) do mesmo trabalho, concluiu-se que $\beta=\gamma / 2=0,32$. Tal comportamento não pôde ser verificado nas curvas de $I_{\mathrm{D}} v s$. $V_{\mathrm{GS}}$ devido ao erro elevado na aproximação de $\mu=f\left(V_{\mathrm{GS}}\right)$. 
A resistência de contato não pôde ser extraída através dos métodos de Natali et al. [88] e, tampouco através do método conhecido como transmission line method $(T L M)$ [89]. Isto é uma indicação de que a resistência do canal ainda é muito superior à resistência série.

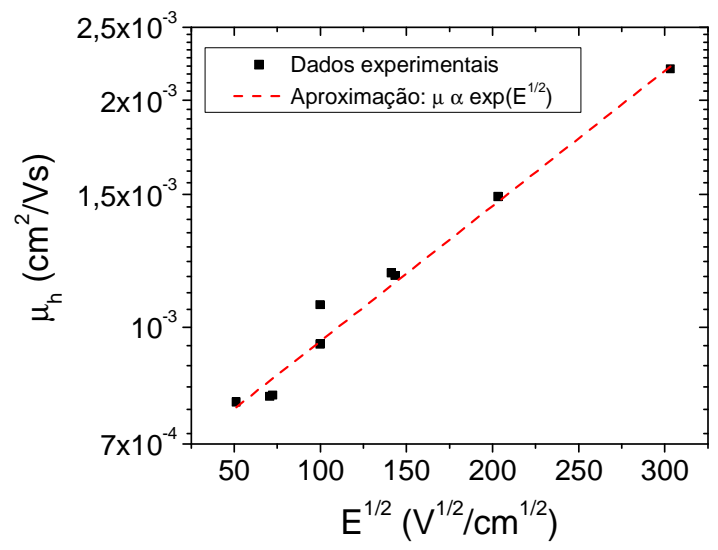

Figura 4.32 - Mobilidade de lacunas em função do campo elétrico longitudinal médio em TFTs de P3HT sobre $\mathrm{p}+-\mathrm{Si} / \mathrm{SiO}_{2}$. A linha tracejada é a curva aproximada segundo a Equação (26).

\subsection{TFTs de pentaceno}

Transistores bottom gate bottom contact de pentaceno sobre $\mathrm{p}+-\mathrm{Si} / \mathrm{SiO}_{2}\left(x_{\mathrm{i}}=296\right.$ $\pm 11 \mathrm{~nm}$ ) com eletrodos de fonte e dreno paralelos apresentaram melhor desempenho: $\mu_{h}$ $>1 \times 10^{-2} \mathrm{~cm}^{2} / \mathrm{Vs}$ para $V_{\mathrm{GS}}=-40 \mathrm{~V}$ e $n_{\mathrm{Q}}=(2,9 \pm 0,1) \times 10^{12}$ cargas $/ \mathrm{cm}^{2}$ (ver Figura 4.33). Assim como apresentado na Seção 4.4, TFTs com comprimento de canal igual a 5, 10 e $20 \mu \mathrm{m}$ foram estudados em regime linear (ver Tabela 4.14) e em saturação (ver Tabela 4.15). Os resultados reportados para p+-Si/SiO 2 são de somente um TFT para cada $L$ que apresentou o melhor desempenho em uma mesma amostra. Foram omitidos os resultados para $L=10 \mu \mathrm{m}$ por apresentarem desempenho inferior aos outros e, assim como será visto na seqüência, não serem úteis ao cálculo da resistência série. De forma geral, TFTs em p+-Si/SiO $2, \mathrm{p}+-\mathrm{Si} / \mathrm{SiO}_{\mathrm{x}} \mathrm{N}_{\mathrm{y}}$ e até mesmo sobre vidro-ITO/ $\mathrm{SiO}_{\mathrm{x}} \mathrm{N}_{\mathrm{y}}$ 
apresentaram mobilidade de lacunas entre $10^{-4}$ e $10^{-2} \mathrm{~cm}^{2} / V s$. Os piores resultados foram obtidos para TFTs sobre vidro-ITO/SiO $\mathrm{N}_{\mathrm{y}}\left(x_{\mathrm{i}}=301 \pm 18 \mathrm{~nm}\right)$, enquanto que desempenho intermediário foi observado sobre $\mathrm{p}+-\mathrm{Si}_{\mathrm{S}} \mathrm{SiO}_{\mathrm{x}} \mathrm{N}_{\mathrm{y}}(301 \pm 18$ e $268 \pm 23 \mathrm{~nm})$. TFTs com eletrodos interdigitados sobre $\mathrm{p}+-\mathrm{Si} / \mathrm{SiO}_{2}\left(x_{\mathrm{i}}=296 \pm 11 \mathrm{~nm}\right)$ e $\mathrm{p}+-\mathrm{Si} / \mathrm{SiO} \mathrm{x}_{\mathrm{y}}$ $\left(x_{\mathrm{i}}=268 \pm 23 \mathrm{~nm}\right)$ apresentaram $\mu_{\mathrm{h}} \sim 10^{-3} \mathrm{~cm}^{2} / V s$. O melhor desempenho sobre $\mathrm{SiO}_{\mathrm{x}} \mathrm{N}_{\mathrm{y}}$ em saturação $\left(n_{\mathrm{Q}}=(3,7 \pm 0,3) \times 10^{12} \mathrm{cargas} / \mathrm{cm}^{2}\right)$ e sem correção de resistência série foi obtido para eletrodos interdigitados sobre silício altamente dopado. Os resultados são mostrados na Tabela 4.15 e pertencem à mesma série de amostras cujos resultados são apresentados na Tabela 4.14. Devido à ausência de controle automático da taxa de evaporação, houve grande dispersão de uma série a outra de amostras, mas também de um transistor a outro em uma mesma amostra, dificultando comparações.
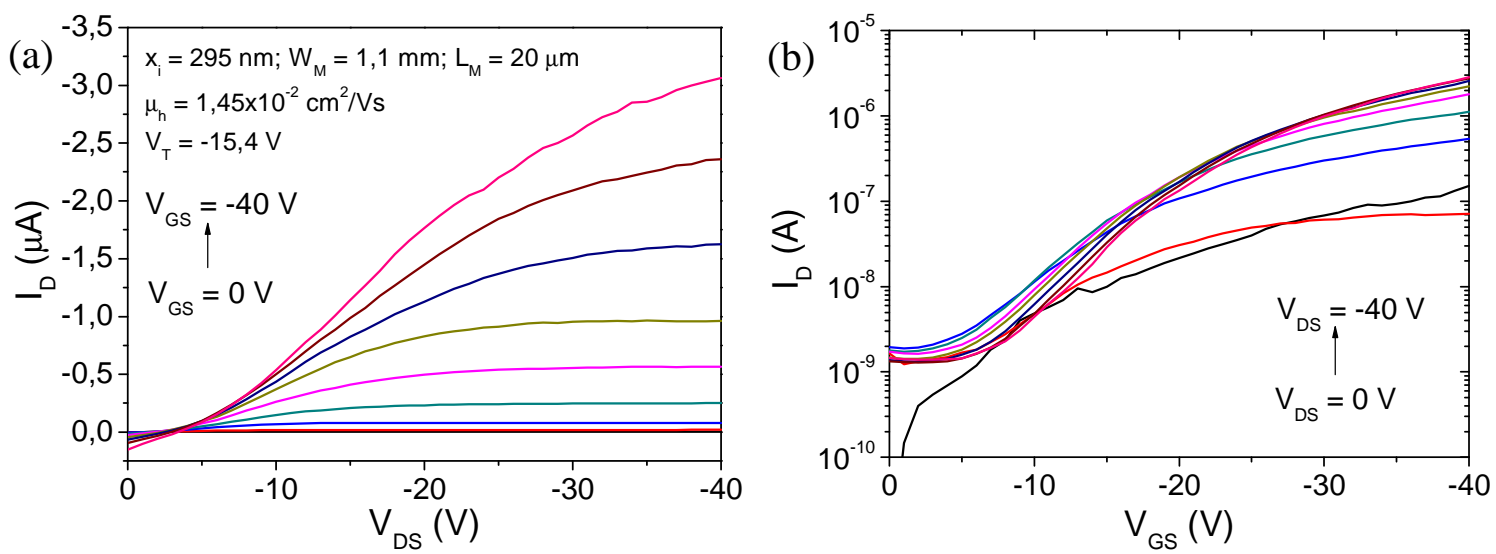

Figura 4.33 - Curvas características de um TFT de pentaceno sobre $\mathrm{p}+-\mathrm{Si} / \mathrm{SiO}_{2}$.

Tabela 4.14 - Principais parâmetros extraídos a partir de $I_{\mathrm{D}} v s$. $V_{\mathrm{GS}}$ em regime linear para pentaceno evaporado sobre $\mathrm{p}+-\mathrm{Si} / \mathrm{SiO}_{2}$. A largura do canal $\left(W_{\mathrm{M}}\right)$ é $1,1 \mathrm{~mm}$.

\begin{tabular}{|c|c|c|c|c|c|c|}
\hline $\begin{array}{c}L \\
(\mu \mathrm{m})\end{array}$ & $\begin{array}{l}V_{\mathrm{DS}} \\
(\mathrm{V})\end{array}$ & $\begin{array}{l}\mu_{h} \\
\left(10^{-3} \mathrm{~cm}^{2} / \mathrm{Vs}\right)\end{array}$ & $\begin{array}{l}V_{\mathrm{T}} \\
(\mathrm{V})\end{array}$ & $\begin{array}{l}V_{\mathrm{DS}} \\
(\mathrm{V})\end{array}$ & $\begin{array}{c}\mu_{h} \\
\left(10^{-3} \mathrm{~cm}^{2} / \mathrm{Vs}\right)\end{array}$ & $\begin{array}{l}V_{\mathrm{T}} \\
(\mathrm{V})\end{array}$ \\
\hline $5 \pm 1$ & \multirow{2}{*}{-5} & $0,43 \pm 0,09$ & $-9,0 \pm 0,2$ & \multirow{2}{*}{-10} & $1,72 \pm 0,35$ & $-14,0 \pm 0,4$ \\
\hline $20 \pm 1$ & & $1,01 \pm 0,07$ & $-7,9 \pm 0,3$ & & $3,65 \pm 0,23$ & $-12,2 \pm 0,3$ \\
\hline
\end{tabular}


Tabela 4.15 - Principais parâmetros extraídos a partir de $I_{\mathrm{D}} v s . V_{\mathrm{GS}}$ em regime de saturação para pentaceno evaporado sobre $\mathrm{p}+-\mathrm{Si}_{/} \mathrm{SiO}_{2}$. A largura do canal $\left(W_{\mathrm{M}}\right)$ é $1,1 \mathrm{~mm}$ em eletrodos paralelos e $20,9 \mathrm{~mm}$ em eletrodos interdigitados.

\begin{tabular}{|c|c|c|c|c|c|c|c|}
\hline Dispositivos & $\begin{array}{c}L \\
(\mu \mathrm{m})\end{array}$ & $\begin{array}{l}V_{\mathrm{DS}} \\
(\mathrm{V})\end{array}$ & $\left(10^{-3} \stackrel{\mu_{h}}{\left.\mathrm{~cm}^{2} / \mathrm{Vs}\right)}\right.$ & $\begin{array}{l}V_{\mathrm{T}} \\
(\mathrm{V})\end{array}$ & $\begin{array}{c}S \\
\text { (V/dec.) }\end{array}$ & $I_{\mathrm{ON} / \mathrm{OFF}}$ & $\begin{array}{l}H F \\
(\%)\end{array}$ \\
\hline \multirow{2}{*}{$\begin{array}{c}\mathrm{p}+-\mathrm{Si} / \mathrm{SiO}_{2} \\
S \text { e } D \text { paralelos }\end{array}$} & $5 \pm 1$ & \multirow{3}{*}{-40} & $6,84 \pm 1,40$ & $-16,2 \pm 0,4$ & 6,2 & 1000 & 28,8 \\
\hline & $20 \pm 1$ & & $14,5 \pm 0,9$ & $-15,4 \pm 0,2$ & 6,0 & 1500 & 27,7 \\
\hline $\begin{array}{c}\text { p+-Si/SiO } \mathrm{SiN}_{\mathrm{y}} \\
S \text { e } D \text { interdigit. }\end{array}$ & $30 \pm 1$ & & $3,84 \pm 0,37$ & $-5,7 \pm 0,3$ & 2,4 & 17000 & 14,0 \\
\hline
\end{tabular}

De acordo com a Figura 4.34.a, observa-se um aumento gradual de $\mu_{h}$ ao aumentar $V_{\mathrm{DS}}$ e $L$. Os dados mostram que a mobilidade em regime de saturação depende tanto de L quanto em regime linear. O fato de diminuir com o comprimento de canal é uma indicação da presença de efeitos de resistência série $\left(R_{\mathrm{S}}\right)$. Além disso, demonstra que mesmo para o transistor saturado, efeitos de interface com o contato ainda se sobrepõe a efeitos no canal. Uma queda de tensão na interface eletrodo/semicondutor diminui a tensão efetiva através do canal e, portanto, a corrente utilizada para calcular a mobilidade dos portadores. Em regime de saturação, seria esperado que o seu efeito fosse mínimo, pois a corrente de dreno deveria ser independente da tensão $V_{\mathrm{DS}}$. No entanto, como observado na Figura 4.33, há um aumento significativo da corrente em relação a $V_{\mathrm{DS}}$ para o transistor saturado.

Comparando-se $V_{\mathrm{T}}$ obtido para diferentes regimes, observa-se que há um deslocamento para tensões mais negativas ao passar do regime linear à saturação. Além disso, $I_{\mathrm{D}}$ satura para tensões mais negativas em TFTs de canal curto, o que é consistente com um aumento da importância de resistências parasitárias em relação à resistência do canal, diminuindo a queda de tensão efetiva no canal.

O método de linha de transmissão (transmission line method ou scaling rule) para cálculo da resistência série aplicado aos TFTs apresentados na Tabela 4.14 pode ser visto na Figura 4.34. A resistência $R_{\mathrm{ON}}$ foi calculada em regime linear a partir da curva $I_{\mathrm{D}} \times V_{\mathrm{DS}}$ e de acordo com a Equação (27). O coeficiente angular da reta que aproxima os resultados de $R_{\mathrm{ON}} W$ vs. $L$ (ver Figura 4.34.b) fornece a condutância de folha do canal $\left(g_{\text {d,folha }}\right)$ para diferentes $V_{\mathrm{GS}}$, que deve ser independente do comprimento do 
canal. A partir da curva $g_{\text {d,folha }} v s$. $V_{\mathrm{GS}}$ (ver Figura 4.34.c), obtém-se uma mobilidade de lacunas intrínseca $\mu_{\mathrm{i}}=(5,1 \pm 0,3) \times 10^{-3} \mathrm{~cm}^{2} /$ Vs e tensão de limiar do canal $V_{\mathrm{T}, \mathrm{i}}=-6,8 \pm$ $1,6 \mathrm{~V}$.
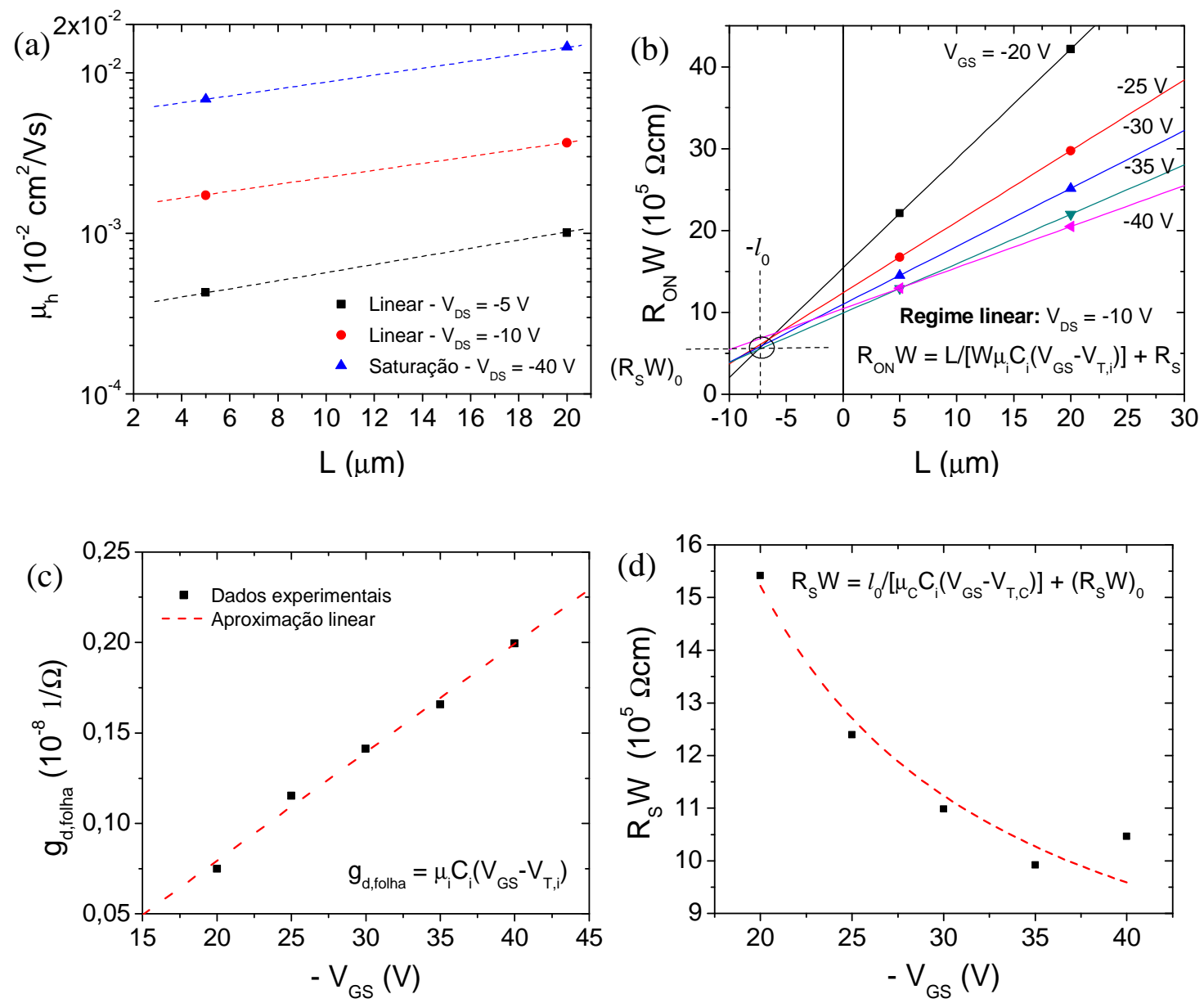

Figura 4.34 - Estudo por linha de transmissão da resistência série $\left(R_{S}\right)$ em TFTs de pentaceno sobre p+-Si/SiO ${ }_{2}$ : (a) mobilidade de lacunas $\left(\mu_{h}\right)$ sem considerar efeitos de resistência séries vs. comprimento de canal $(L)$; (b) resistência total em regime linear multiplicada pela largura do canal $\left(R_{\mathrm{ON}} W\right) v s . L ;(c)$ condutância de folha do canal $\left(g_{\mathrm{d}, \text { folha }}\right) v s$. a tensão de porta $\left(V_{\mathrm{GS}}\right) ;(\mathrm{d}) R_{\mathrm{S}} W v s . V_{\mathrm{GS}}$.

A resistência parasitária corresponde ao intercepto das linhas de tendência na Figura 4.34.b com o eixo y $\left(R_{\mathrm{S}}=R_{\mathrm{ON}} W\right.$ para $\left.L=0\right)$. Pode-se observar que $R_{\mathrm{S}} W$ depende não-linearmente de $V_{\mathrm{GS}}$, tendendo a um valor constante para elevadas tensões de porta (ver Figura 4.34.c). Estudos empíricos aplicados a TFTs de silício amorfo apontam que a 
resistência série varia de acordo com a Equação (28) [89]. Representa-se a dependência de $\mathrm{R}_{\mathrm{S}}$ com $V_{\mathrm{GS}}$ pela existência de uma extensão de $L$ igual a $l_{0}$ em que a mobilidade é reduzida $\left(\mu_{\mathrm{c}}\right)$. Soma-se a parcela variável de $R_{\mathrm{S}}$ um valor constante $\left(R_{\mathrm{S}}\right)_{0}$. A partir do encontro das linhas de tendência na Figura 4.34.b, pôde-se obter $l_{0}=7,2 \mu \mathrm{m}$ e $\left(R_{\mathrm{S}}\right)_{0}=$ 5,1 M $\Omega$. Substituindo em (28) e através de aproximação não-linear na Figura 4.34.d, obteve-se $\mu_{\mathrm{c}}=(4,5 \pm 0,7) \times 10^{-3} \mathrm{~cm}^{2} / \mathrm{Vs}$ e $V_{\mathrm{T}, \mathrm{c}}=-5,9 \pm 2,7 \mathrm{~V}$.

A aplicação do método diferencial [88] para mobilidade variável e resistência de contato constante em regime linear confirmou que, de fato, a resistência de contato não é constante e não atinge um mínimo para as tensões utilizadas $\left(\left|V_{\mathrm{DS}}\right|,\left|V_{\mathrm{GS}}\right|<40 \mathrm{~V}\right)$. Os resultados são apresentados nas duas primeiras linhas da Tabela 4.16. Observa-se que o valor de $V_{\mathrm{T}}$ é aceitável (próximo a $-7 \mathrm{~V}$ ), porém a mobilidade possui forte dependência com $V_{\mathrm{GS}}(\gamma \sim 1,0)$. Além disso, essa dependência não é função de $L$, de acordo com o que foi estipulado para $R_{\mathrm{S}}$. Natali et al. alertam que se a resistência de contato depender de $V_{\mathrm{GS}}$ de forma semelhante à mobilidade, então o método diferencial não pode ser aplicado, sendo necessário recorrer ao método de linha de transmissão. A relação entre $I_{\mathrm{D}}$ e $V_{\mathrm{GS}}$ não é alterada devido à presença de resistência de contato, porém os valores de $\gamma$ e $k$ calculados considerando $R_{\mathrm{S}}$ constante seriam incorretos. Caso fossem aplicadas tensões elevadas e a resistência se tornasse aproximadamente constante, o modelo poderia ser aplicado com sucesso, porém somente para este intervalo específico de tensão elétrica.

Tabela 4.16 - Parâmetros extraídos de TFTs para $\mu=f\left(V_{\mathrm{GS}}\right)$ em regime de saturação de pentaceno depositado sobre p+-Si/SiO . A largura do canal $\left(W_{M}\right)$ é $1,1 \mathrm{~mm}$.

\begin{tabular}{|c|c|c|c|c|c|c|}
\hline $\begin{array}{c}\text { Método } \\
\text { diferencial }\end{array}$ & $\begin{array}{c}L \\
(\mu \mathrm{m})\end{array}$ & $\gamma$ & $\begin{array}{c}V_{\mathrm{T}} \\
(\mathrm{V})\end{array}$ & $\begin{array}{c}k \\
\left(10^{-3} \mathrm{~cm}^{2} / \mathrm{V}^{1-\gamma} \mathrm{s}\right)\end{array}$ & $\begin{array}{c}R_{\mathrm{S} 0} \\
(\mathrm{M} \Omega)\end{array}$ & $\begin{array}{c}\alpha \\
\left(10^{6} \Omega \mathrm{Vm}\right)\end{array}$ \\
\hline $\mathrm{R}_{\mathrm{S}}=\mathrm{R}_{\mathrm{S} 0}$ & $5 \pm 1$ & $1,01 \pm 0,01$ & $-7,7 \pm 0,2$ & $0,040 \pm 0,008$ & $40-80$ & - \\
\cline { 2 - 7 } & $20 \pm 1$ & $1,01 \pm 0,02$ & $-5,8 \pm 0,6$ & $0,087 \pm 0,005$ & $60-120$ & - \\
\hline \multirow{2}{*}{$R_{\mathrm{S}}=f\left(V_{\mathrm{GS}}\right)$} & $20 \pm 1$ & $\begin{array}{c}0,0020 \pm 0,0001 \\
* 0,75 \pm 0,12\end{array}$ & $-7,9 \pm 1,7$ & $3,2 \pm 0,7$ & - & - \\
& & $*-5,0 \pm 0,7$ & - & $33,9 \pm 2,3$ & $* 13,8 \pm 5,3$ \\
\hline
\end{tabular}

* Valores obtidos para as regiões de contato através da equação (26) em [88]. 
Considerando agora um modelo de resistência variável arbitraria (ver Seção V e Equação 25 em [88]), porém independente de $L$, obteve-se os resultados apresentados na última linha da Tabela 4.16. O método é semelhante ao diferencial, porém utiliza somente dois comprimentos de canal e considera a mobilidade variável com $V_{\mathrm{GS}}$. A mobilidade obtida é praticamente constante $(\gamma \sim 0)$ e duas ordens de grandeza superior à obtida considerando $R_{\mathrm{S}}$ constante. A aplicação do método aos canais de $L=5$ e $20 \mu \mathrm{m}$ é mostrada na Figura 4.35. A resistência de contato calculada a partir da Equação (27) para ambos os canais não atinge um patamar, diminuindo de 200 a $50 \mathrm{M} \Omega$ com o aumento de $V_{\mathrm{GS}}$ (ver Figura 4.35.c). Fazendo uma aproximação não-linear da Equação (26) na Seção V.A em [88], obtiveram-se os valores marcados com asterisco na Tabela 4.16. A elevada dependência em relação a $V_{\mathrm{GS}}(\gamma=0,75)$ e o valor de $\mathrm{V}_{\mathrm{T}} \sim-5 \mathrm{~V}$ indicam que os contatos tendem a incluir em sua modelagem uma resistência série constante e uma região de baixa mobilidade fortemente dependente de $V_{\mathrm{GS}}$. Pode-se concluir que $R_{\mathrm{S}}$ tende a um valor de 33,9 M $\Omega$ para altas tensões elétricas.

A aplicação de outros métodos diferenciais apresentados em [88] para TFTs em regime linear e de saturação não forneceram resultados por necessitarem de mais valores de $L$ (para este material, têm-se resultados somente para dois comprimentos de canal, i.e. 5 e $20 \mu \mathrm{m}$ ) e de tensões mais elevadas de tal forma que $R_{\mathrm{S}}$ atinja um patamar. 

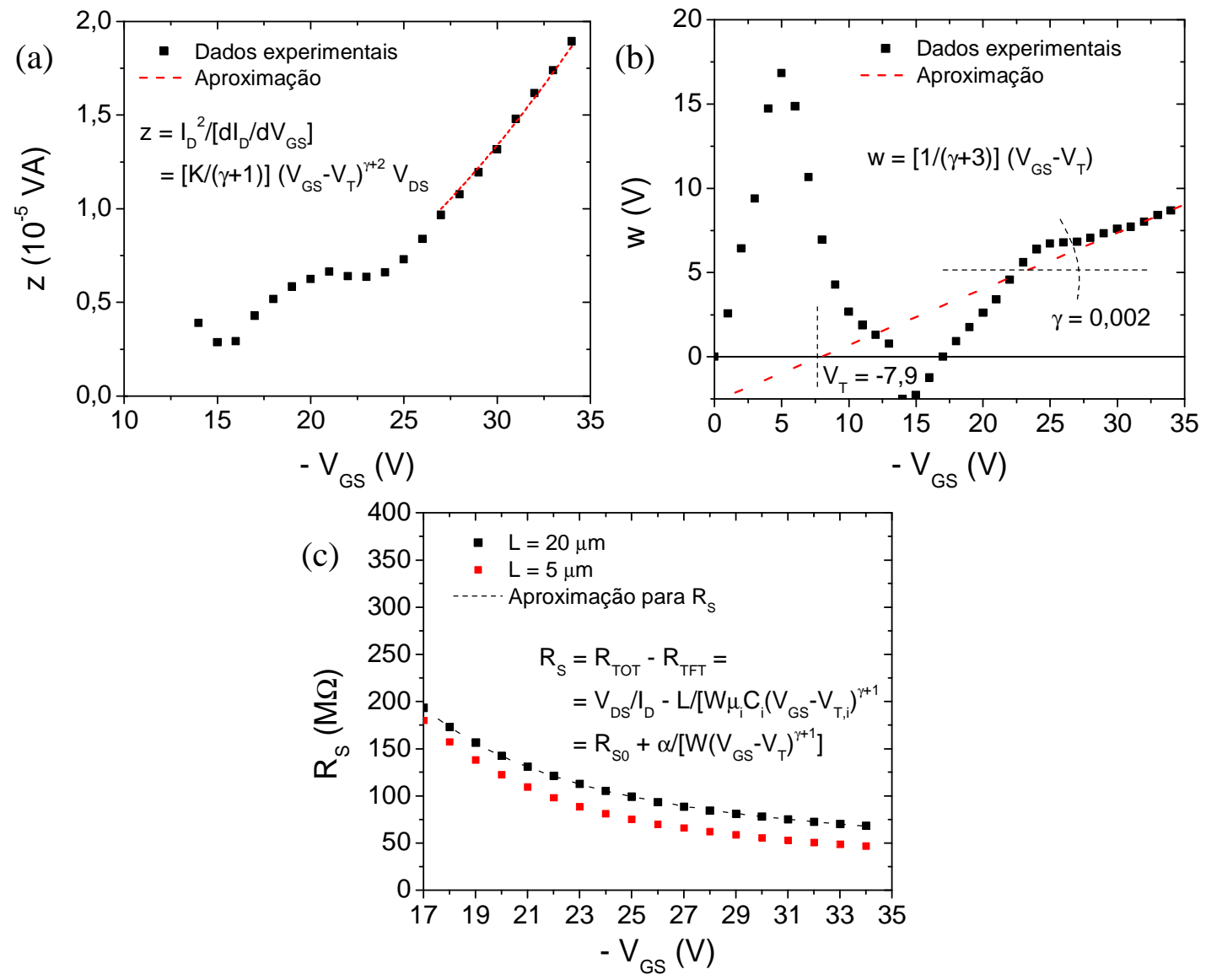

Figura 4.35 - Aplicação do método diferencial considerando $R_{S}$ constante em TFTs de pentaceno sobre $\mathrm{p}+-\mathrm{Si}_{\mathrm{SiO}}$ : (a) $z$ vs. $V_{\mathrm{GS}}$; (b) $w$ vs. $V_{\mathrm{GS}}$; (c) $R_{\mathrm{S}} v s$. $V_{\mathrm{GS}}$. 


\section{DISCUSSÃo}

\subsection{Estudo da fabricação de dispositivos orgânicos através de células solares}

O conhecimento adquirido em processamento de células solares orgânicas (CSO) de heterojunção de rr-P3HT:PCBM, i.e. corrosão e definição do ânodo, limpeza dos substratos, preparação de solução de materiais orgânicos, spin coating, tempo de secagem após deposição, definição do cátodo e máscara mecânica, recozimento final, permitiu atingir cerca de $1 \%$ de eficiência na conversão de potência $(P C E)$ tanto em substratos de vidro quanto em PET sob 1 sol. Isto foi alcançado através da otimização dos parâmetros de processamento, inspeção freqüente dos filmes por microscopia óptica e caracterização do dispositivo final em um simulador solar. A evolução no tempo da eficiência se encontra na Figura 4.8. Os principais passos desta evolução em ambos os tipos de substratos foram: a produção de uma nova máscara mecânica, o aumento do tempo de secagem do filme de PEDOT:PSS e o estudo da solubilidade do compósito orgânico em DCB.

Principal problema observado nas etapas iniciais de fabricação de CSOs, o contato entre as micropontas e o eletrodo superior de alumínio não era possível de ser realizado sem danificar as camadas subjacentes (Figura 4.1.a). O fator determinante para aumentar a eficiência em três ordens de grandeza foi a presença de uma região dedicada nos bordos do substrato para contatar o $\mathrm{Al}$ (Figura 4.1.b). Por sua vez, pontos brilhantes na superfície do alumínio em substratos de vidro (Figura 4.3) desapareceram somente após aumentar o tempo de secagem do filme de PEDOT:PSS a $120{ }^{\circ} \mathrm{C}$ de 5 a $15 \mathrm{~min}$ em

um hot plate. Considerando que estas regiões brilhantes não colaborassem com o funcionamento do dispositivo, então seria fácil entender o aumento de 9 vezes de $P C E$. $\mathrm{O}$ melhor desempenho foi atingido para spin coating a $5000 \mathrm{rpm}$ por $60 \mathrm{~s}$ e annealing a $120{ }^{\circ} \mathrm{C}$ por 20 min. A melhora na formação da camada ativa, no entanto, demandou um 
estudo da preparação da solução. O desaparecimento de "cometas" no filme semicondutor formado foi condicionado pela adição e agitação separada do politiofeno por $24 \mathrm{~h}$ a $40^{\circ} \mathrm{C}$ para somente então adicionar o derivado de fulereno. Foi necessário variar a concentração relativa de PCBM, o tempo de agitação e os parâmetros de deposição por spin coating até obter um filme de qualidade. Os melhores resultados foram obtidos com uma solução $3 \mathrm{wt} \%$ (1:0,8 w/w) de P3HT:PCBM em DCB agitada por $24 \mathrm{~h}$ após adição de cada soluto e por $1 \mathrm{~h}$ a $50{ }^{\circ} \mathrm{C}$ antes da deposição. A solução foi processada por spin coating a $700 \mathrm{rpm}$ por $60 \mathrm{~s}$ com posterior annealing a $50^{\circ} \mathrm{C} / 15 \mathrm{~min}$ e tratamento térmico final em hot plate a $120^{\circ} \mathrm{C}$ por $10 \mathrm{~min}$.

Passos importantes somente em substratos flexíveis foram: (i) a realização do recozimento final no mesmo dia de deposição do cátodo a 120 em vez de $140{ }^{\circ} \mathrm{C}$, e (ii) a aplicação simultânea de uma tensão positiva de 1,5 V durante o tratamento térmico pósdeposição do cátodo. Dispositivos flexíveis apresentaram rendimento inferior a células solares em vidro durante todo o trabalho e, inicialmente, um decréscimo de PCE de 1000 vezes após recozimento era observado. O estudo detalhado da degradação do eletrodo em função da temperatura (Figura 4.5) esclareceu que a resistência de folha aumentava entre 150 e $165{ }^{\circ} \mathrm{C}$ e explodia entre 180 e $200{ }^{\circ} \mathrm{C}$. Logo, dispositivos em substratos flexíveis passaram a ser tratados a $120^{\circ} \mathrm{C}$ por $10 \mathrm{~min}$. Além disso, cerca de $0,4 \%$ de $P C E$ só foi atingido ao se tratar as células solares no mesmo dia de deposição de $\mathrm{LiF}$ e Al. Os responsáveis pela degradação acelerada da célula eram o fator de preenchimento $(F F)$ e a tensão de circuito aberto $\left(V_{\mathrm{OC}}\right)$, provavelmente conseqüência da degradação dos eletrodos e não somente pelo fotobranqueamento da camada ativa (photobleaching). Visto que células idênticas sobre vidro-ITO duram três semanas a mais, o decaimento está provavelmente relacionado ao cracking do ânodo e destruição do dispositivo pela propagação das rachaduras da camada mais interna à mais externa. $\mathrm{O}$ passo adiante foi tratar os dispositivos flexíveis aplicando simultaneamente uma tensão positiva de 1,5 V (ver Figura 4.7). Pôde-se concluir que a resistência paralela aumenta, a resistência série diminui, e o fator de preenchimento aumenta, levando ao aumento da eficiência global. 
Existem outras diferenças de processamento entre dispositivos fabricados em vidro e em PET. O ânodo multicamada transparente em PET é corroído em menos de um minuto ( $40 \mathrm{~s}$ ) contra mais de uma hora necessária para corroer ITO sobre vidro. $\mathrm{O}$ banho em acetona foi evitado para substratos flexíveis e um cuidado extra foi tomado durante seu manuseio para evitar danos ao eletrodo e à superfície do substrato. Além disso, uma técnica alternativa tal como tratamento pós-spinning em atmosfera de solventes (solvent annealing) é desejável para redução do estresse causado nos filmes finos pelos tratamentos de secagem e térmico sobre substrato flexível.

As melhores curvas $J x V$ obtidas para dispositivos em PET (ver Figura 4.9) demonstram que, aumentando-se a intensidade da luz irradiada, $F F$ decresce junto com $R_{\mathrm{SH}}$. Enquanto que $F F$ pode variar de 20 a $40 \%$ de intensidades altas a baixas, $P C E$ pode aumentar 2 ou 3 vezes (de 0,5 a $1 \%$ ). Sabe-se que em células solares nem todas as cargas fotogeradas responsáveis por uma densidade de cargas dependente da intensidade irradiada contribuem à fotocorrente [38]. Porém a existência das mesmas e sua mobilidade contribuem à condutividade da camada semicondutora. Portanto a geração de portadores de carga reduz a resistência do volume do material por efeito de uma

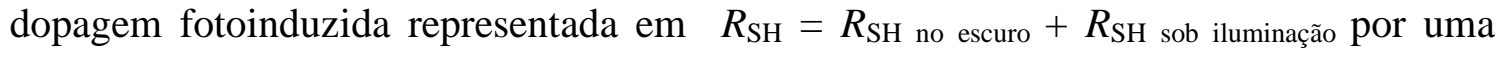
resistência paralela e dependente da intensidade de luz incidente na célula. Uma tática para aumentar a eficiência destes dispositivos é otimizar a morfologia do filme fino orgânico (e.g. separação de fase e cristalinidade do P3HT conseqüência de uma solução e tratamento térmico pós-produção otimizados), e assim a mobilidade dos portadores de carga e o fator de preenchimento, implicando em maiores (e dominantes se comparadas à de difusão) correntes de deriva e tempo de vida dos portadores. Desta maneira, um fator de preenchimento praticamente independente da intensidade luminosa deveria ser obtido, aumentando também a reprodutibilidade destes dispositivos orgânicos. Acreditase que parte da dificuldade na obtenção de uma nanomorfologia otimizada esteja na própria escolha do solvente. Grupos de pesquisa tais como de A. J. Heeger na University of California Santa Barbara [52] e D. L. Carroll na Wake Forest University [121] passaram a utilizar monoclorobenzeno $(\mathrm{CB})$ nos últimos anos e obtiveram $P C E \geq 5 \%$. A temperatura de ebulição elevada do $\operatorname{DCB}\left(178>132^{\circ} \mathrm{C}\right)$ pode ocasionar uma retenção 
excessiva do líquido no filme após spin coating e demandar tempos extremamente longos de tratamento térmico (ou annealing), estressando filmes e substratos.

Nas CSOs estudadas, a tensão de circuito-aberto $\left(V_{\mathrm{OC}}\right)$ aumenta com o aumento da intensidade luminosa. De acordo com o circuito da Figura 2.1.c e a Equação (2) em [46], é esperada uma dependência logarítmica com a corrente fotogerada $\left(J_{\mathrm{ph}}\right)$, i.e. $V_{\mathrm{OC}} \approx$ $n k_{\mathrm{B}} T / e \ln \left\{1+J_{\mathrm{ph}} / J_{0}\right\}$. Tal comportamento é comumente observado em células solares à base de materiais inorgânicos (e.g. silício monocristalino). Segundo este mesmo modelo, a corrente de curto-circuito $\left(J_{\mathrm{SC}}\right)$ deve ser aproximadamente igual a $-J_{\mathrm{ph}}$. Uma divergência destas equações indica a presença de resistências série alta e paralela baixa, provavelmente função da intensidade luminosa.

Correntes reversas elevadas são outro fator de degradação de $F F$ (ver corrente no escuro na Figura 4.9.b). Esta densidade de corrente reversa provavelmente é formada por portadores de carga deslocalizados, causados por dopagem por íons ou oxigênio, que por sua vez contribuem à corrente causada por portadores de carga minoritários que atravessam a barreira dos eletrodos retificantes [38, 122]. Uma melhora sucessiva de PCE poderia ser observada fabricando os dispositivos dentro de uma glove box em atmosfera inerte (e.g. argônio, nitrogênio) devido a uma redução no aprisionamento dos portadores e maior comportamento retificador dos eletrodos ${ }^{3}$.

O fato de alcançarem $1 \%$ de PCE e poderem ser produzidas em substratos flexíveis demonstra que estas células têm potencial para serem de baixo custo, leves, flexíveis, coloridas ou translúcidas, podendo cobrir grandes superfícies, e alimentando dispositivos eletrônicos para propósitos militares e turísticos, principalmente em ambientes desabitados, distantes ou desérticos. Geralmente eficientes sob baixa intensidade (<0,5 sol) e pequeno ângulo de incidência, podem ser integrados em roupas e coberturas, abrindo seu espaço no novo campo da Eletrônica Têxtil. Rumo a sua comercialização, é necessário direcionar esforços à fabricação destes dispositivos em sistemas multi-rolos (roll-to-roll) visando diminuir os custos em até quatro vezes.

\footnotetext{
${ }^{3}$ Equipamento indisponível na $F B K$ (Trento, Itália) durante a realização deste trabalho.
} 


\subsection{Aplicação de oxinitreto de silício $\left(\mathrm{SiO}_{x} \mathrm{~N}_{y}\right)$ e eletrodos de ITO em transistores de filmes finos orgânicos}

Os resultados apresentados na Seção 4.3.1 demonstram que $\mathrm{SiO}_{\mathrm{x}} \mathrm{N}_{\mathrm{y}}$ depositado por PECVD pode substituir $\mathrm{SiO}_{2}$ térmico em OTFTs bottom gate bottom contact e podem mesmo ser utilizados sobre vidro coberto por ITO. O fato de $\mu_{h}$ ser pelo menos 2 vezes maior sobre $\mathrm{p}+-\mathrm{Si} / \mathrm{SiO}_{\mathrm{x}} \mathrm{N}_{\mathrm{y}}$ em relação às demais está provavelmente relacionado à elevada constante dielétrica do $\mathrm{SiO}_{\mathrm{x}} \mathrm{N}_{\mathrm{y}}(\kappa=4.5)$ e, portanto, à maior concentração de portadores $\left(n_{Q}\right)$ no canal. Yoon et al. [80] realizaram um estudo comparativo semelhante de bicamadas dielétricas, porém calcularam $\mu$ em um intervalo específico de densidade de cargas acumuladas, i.e. $(4-5) \times 10^{12} \mathrm{~cm}^{-2}$. A carga acumulada é ligeiramente para dispositivos em $\mathrm{SiO}_{\mathrm{x}} \mathrm{N}_{\mathrm{y}}$, o quê poderia explicar o desempenho superior (ver Tabela 4.3). Apesar de maiores $\kappa$ e $n_{Q}$, TFTs sobre ITO apresentam desempenho apenas equiparável ao obtido com $\mathrm{SiO}_{2}$ térmico. Estes resultados estão de acordo com o apresentado por Todescato et al. para limpeza úmida de $\mathrm{SiO}_{2}$ sem $\mathrm{HF}$ [123], onde $\mu_{h}=2.5 \times 10^{-5} \mathrm{~cm}^{2} / \mathrm{Vs}$, $V_{T}=-8.7 \mathrm{~V}, I_{O N / O F F}=130$. Em seu trabalho, MDMO-PPV foi depositado a partir de uma solução de clorobenzeno em uma estrutura bottom gate top contact com $L>100 \mu \mathrm{m}$, sendo que os dispositivos também apresentaram elevada histerese. Bonfiglio et al. [82] demonstraram que este fenômeno se deve em parte à utilização de um eletrodo comum de porta, no entanto Todescato et al. defendem que a funcionalização da interface dielétrico/semicondutor é fundamental e pode resolver o problema se realizada adequadamente. De forma geral, os resultados obtidos com $\mathrm{SiO}_{\mathrm{x}} \mathrm{N}_{\mathrm{y}}$ são superiores aos apresentados por Geens et al. para OTFTs de MDMO-PPV obtidos a partir de soluções de tolueno e clorobenzeno [124]. A Tabela 4.4 confirma a superioridade dos TFTs em $\mathrm{SiO}_{\mathrm{x}} \mathrm{N}_{\mathrm{y}}$, demonstrando que esta independe do solvente. Além disso, os resultados para soluções de MDMO-PPV em tolueno são comparáveis aos obtidos com clorofórmio.

$H F$ é maior em OTFTs sobre p+- $\mathrm{Si} / \mathrm{SiO}_{\mathrm{x}} \mathrm{N}_{\mathrm{y}}$, mas comparável para $\mathrm{p}+-\mathrm{Si} / \mathrm{SiO}_{2} \mathrm{e}$ $\mathrm{SiO}_{\mathrm{x}} \mathrm{N}_{\mathrm{y}}$ depositado sobre vidro-ITO. Observam-se correntes menores para tensões decrescentes em todos os dispositivos. Este comportamento é freqüentemente atribuído a 
armadilhas aos portadores de carga próximas do canal e a íons móveis no dielétrico, atestando a qualidade dos dielétricos apresentada na Tabela 4.2. Visto que $H F$ é maior que $10 \%$ para quase todos os transistores neste trabalho, esta é uma indicação clara de que tratamentos de superfície poderiam proporcionar um aumento do desempenho dos TFTs através de sua freqüência de chaveamento. O desempenho geral poderia ser aumento através da redução de estados superficiais, tais como defeitos ou impurezas na interface que podem ser carregados ou descarregados. Uma definição alternativa de histerese é a mudança em $V_{T}$ entre as varreduras crescente e decrescente de tensão. Portanto, deseja-se reduzir (i) a densidade de armadilhas aos portadores de carga livres, e (ii) a injeção de carga da porta para o dielétrico. Chua et al. [125] verificaram um aumento da corrente de dreno de $10^{4}$ em n-OTFTs de F8BT, ao tratar o $\mathrm{SiO}_{2}$ com octadecil triclorosilano (OTS), responsável por passivar grupos $\mathrm{SiOH}$ presentes na sílica e reduzir o aprisionamento de elétrons.

A baixa modulação on-off é provavelmente devido à corrente de fuga através do dielétrico e concentração residual de portadores no canal quando o transistor está cortado. A resistência do canal pode ser minimizada em princípio pela execução de projetos gananciosos visando por exemplo atingir um elevado W/L. No entanto, a utilização de pequenos comprimentos de canal pode implicar em não-idealidades em seu comportamento tais como efeito de canal curto (short-channel effect) [105]. Na Figura 4.21 , tem-se uma curva de $I_{D} x V_{D S}$ para um OTFT de MDMO-PPV em que a região de saturação desaparece completamente. Este fenômeno é freqüente em dispositivos de canal submicrométrico e foi observado por Austin e Chou em TFTs de P3HT com contatos de fonte e dreno obtidos por nanoimprint lithography [126]. A saturação começa a desaparecer ao encurtar o canal de 1000 a $200 \mathrm{~nm}$, até desaparecer completamente quando os eletrodos de ouro ficam distantes apenas $70 \mathrm{~nm}$. As curvas apresentadas possuem grande semelhança com a da Figura 4.21, porém o dielétrico de porta $\left(\mathrm{SiO}_{2}\right.$ térmico) era espesso apenas $5 \mathrm{~nm}$. Correntes limitadas por carga espacial devido aos campos elevados entre fonte e dreno são os responsáveis por este efeito. Em um estudo recente, Fujimori et al. [127] demonstram em TFTs de pentaceno que a saturação poderá reaparecer caso a espessura do dielétrico seja diminuída e que 
resistências parasitárias podem implicar na diminuição do campo elétrico interno e desaparecimento de efeitos de canal curto.

Efeitos de resistência série podem de fato se tornar relevantes se o canal entrar em escala nanométrica, devido à menor resistência do canal e tensões de operação. Tal efeito parasitário pode ser resolvido pela aplicação de um adequado tratamento de superfície ao eletrodo com conseqüente melhor alinhamento entre a função trabalho do metal e o HOMO do polímero [128]. Resultados obtidos para TFTs de MDMO-PPV sobre p+-Si/SiO $\mathrm{S}_{\mathrm{y}}$ empregando $20 \mathrm{~nm}$ de $\mathrm{Ti}$ e $90 \mathrm{~nm}$ de $\mathrm{Au}$ são quase quatro vezes inferiores em relação ao mesmo dispositivo empregando unicamente ouro (ver Tabela 4.5). Santato et al. demonstram que a deposição de $\mathrm{Cr}$ entre $\mathrm{Au}$ e $\mathrm{SiO}_{2}$ implica em menores mobilidades e maiores resistências série [129]. Resistências de contato podem depender da geometria dos contatos também. Através da configuração staggered (ver Figura 2.7) em TFTs de MDMO-PPV, Chua et al. [125] obtiveram $\mu_{h} \sim 5 \times 10^{-4} \mathrm{~cm}^{2} / \mathrm{Vs}$ depositada a partir de uma mistura de xilenos em divinyltetramethylsiloxanebis(benzocyclobutene) (BCB). A área de contato com o semicondutor é maior e as linhas de campo elétrico favorecem uma maior injeção se comparada à estrutura coplanar [130]. Kayashima et al. obtiveram $\mu_{h}=3,2 \times 10^{-4} \mathrm{~cm}^{2} / \mathrm{Vs}$ em filmes finos de PPV depositados à partir de um precursor em solução aquosa por drop casting sob condições de elevada gravidade em substrato de $\mathrm{p}+-\mathrm{Si} / \mathrm{SiO}_{2}$ tratado com OTS [131]. No entanto, os autores aplicaram tensões de polarização elevadas: $V_{D S}=-100 \mathrm{~V}$ e $V_{G S} \sim-80 \mathrm{~V}$.

Uma solução alternativa para aumentar o desempenho dos dispositivos é diminuir a espessura do dielétrico. Porém, pode ser observado na Figura 4.22 que espessuras próximas a $100 \mathrm{~nm}$, no caso de semicondutores de baixa mobilidade, podem implicar no comprometimento do funcionamento do dispositivo. A presença de defeitos no dielétrico tais como defeitos estruturais em seu volume e na interface $\mathrm{Si} / \mathrm{SiO}_{2}$, pinholes (ou furos passantes), contaminação por água (possivelmente, criando defeitos) e íons em seu volume tendem a diminuir a rigidez dielétrica $\left(E_{b d}\right)$ e aumentar a densidade de corrente de fuga (Jleakage) [132]. Por outro lado, de acordo com (16), dielétricos espessos acarretam uma menor acumulação de carga no canal prejudicando o desempenho do TFT. A redução de $n_{Q}$ implica no aumento da energia de ativação 
necessária para transporte e, portanto, uma diminuição dos estados de transporte [84]. Logo, pode-se concluir que o ponto ótimo deve ser próximo a $279 \mathrm{~nm}$ para $\mathrm{SiO}_{\mathrm{x}} \mathrm{N}_{\mathrm{y}} \mathrm{e}$ maior que $467 \mathrm{~nm}$ para $\mathrm{SiO}_{2}$ térmico. Linhas de tendência desenhadas na Figura 4.22 indicam de forma aproximada a posição dos máximos. Obviamente, o limite inferior é determinado pela qualidade da sala limpa e das condições de deposição do dielétrico.

$\mathrm{Na}$ Figura 4.23, observa-se que o desempenho dos dispositivos é pior para maiores comprimentos de canal $(L \sim 20 \mu \mathrm{m})$ em $\mathrm{p}+-\mathrm{Si}$, o que pode ser devido ao menor campo elétrico longitudinal $\left(\mathrm{E}_{/ /}=V_{D S} / L\right)$, mas também correntes comparáveis às parasitárias. Um comportamento do tipo Poole-Frenkel é observado para quase todas as espessuras e uma linha de tendência foi desenhada para TFTs em p+-Si/SiO $\mathrm{N}_{\mathrm{y}}$ na Figura 4.23.b. É um indicativo da presença de armadilhas geralmente localizadas na interface dielétrico/semicondutor ou em contornos de grãos de semicondutores policristalinos [133]. O campo elétrico é maior para canais curtos, reduzindo a barreira energética da armadilha e, conseqüentemente, o tempo de aprisionamento. Uma dependência menor em relação à $L$ é observada para $x_{i}=252 \mathrm{~nm}\left(\mathrm{p}+-\mathrm{Si} / \mathrm{SiO}_{2}\right)$ e $94 \mathrm{~nm}$ $\left(\mathrm{p}+-\mathrm{Si} / \mathrm{SiO}_{\mathrm{x}} \mathrm{N}_{\mathrm{y}}\right)$, provavelmente devido a uma maior acumulação de cargas no canal, preenchendo todas as armadilhas para altas tensões. A baixa mobilidade deve estar relacionada a correntes de fuga afetando a precisão do cálculo. A observação deste tipo de comportamento indica que a resistência série é desprezível para os TFTs de MDMOPPV estudados. De acordo com a Figura 10 em [88], Natali et al. demonstram que a mobilidade normalmente decresce ordens de grandeza com uma diminuição do canal sob efeitos de resistência série.

Como mostrado na Figura 4.24, um aumento do canal implica em uma maior inclinação de sublimiar $(S)$. Considerando dispositivos sobre $268 \mathrm{~nm}$ de $\mathrm{SiO}_{\mathrm{x}} \mathrm{N}_{\mathrm{y}}, N_{\text {trapmax }}$ varia de $(33,2 \pm 9,9)$ a $(5,9 \pm 1,3) \times 10^{12} \mathrm{~cm}^{-2}$ quando $L$ passa de 17,5 a $7,3 \mu \mathrm{m}$. $N_{\text {trapmax }}$ é cerca $(1-1,5) \times 10^{12} \mathrm{~cm}^{-2}$ em filmes de $94 \mathrm{~nm}$, decrescendo de $(8,7 \pm 1,2)$ a $(3,4 \pm$ $0,6) \times 10^{12} \mathrm{~cm}^{-2}$ quando $L$ varia de 19,8 a $3,9 \mu \mathrm{m}$ e $x_{i}=527 \mathrm{~nm}$. Um intervalo de valores semelhantes, i.e. $(1-10) \times 10^{12} \mathrm{~cm}^{-2}$, foi observado por Yoon e colaboradores para semicondutores orgânicos do tipo $\mathrm{p}$ de alta mobilidade, tais como pentaceno e $\alpha, \varpi$ dihexylcarbonyl-quaterthiophene (DHCO-4T) [27]. Em seu estudo, o dielétrico 
bicamada era composto por $300 \mathrm{~nm}$ de $\mathrm{SiO}_{2}$ térmico de alta qualidade e um filme fino orgânico. Levando-se em conta a discussão anterior para a Figura 4.23, pode-se concluir que o decréscimo em $S$ em relação a $L$ está provavelmente relacionado a um efeito tipo Poole-Frenkel, visto que a máxima densidade de armadilhas é menor para $\mathrm{L} \sim 5 \mu \mathrm{m}$. Além disso, a tendência observada na Figura 4.22 também é observada em $S v s$. $L$, visto que os menores valores de $S$ são observados para $467 \mathrm{~nm}$ de $\mathrm{SiO}_{2}$ e $279 \mathrm{~nm}$ oxinitreto de silício (excluindo os valores para $94 \mathrm{~nm}$ ). Dispositivos com $94 \mathrm{~nm}$ de $\mathrm{SiO}_{\mathrm{x}} \mathrm{N}_{\mathrm{y}}$ apresentam a menor $N_{\text {trapmax }}$, de acordo com a invariância de $\mu_{h}$ em relação a $L$ (ver Figura 4.23.b).

$\mathrm{Na}$ Figura 4.20, pode-se observar que correntes de fuga e o comportamento ambipolar do MDMO-PPV parecem ser os responsáveis por desvios nas curvas características em relação ao MOSFET ideal. Freqüentemente presentes em TFTs poliméricos, correntes de fuga induzidas por $V_{G S}$ e off-set de $I_{D}$ (i.e. deslocamento vertical da corrente em relação ao valor ideal) são discutidos em [134, 135]. Bonfiglio et $a l$. demonstraram diferenças de uma ordem de magnitude em $I_{D}$ entre transistores de MDMO-PPV com porta comum - assim como neste trabalho - e dispositivos com porta litografada [82]. Segundo Huang [136], a opção por uma estrutura de porta comum pode diminuir a relação sinal-ruído durante caracterização e dificultar a extração dos parâmetros do TFT. Diversos autores sustentam que a utilização de um filme nanométrico de alumínio sob a lâmina de silício aumenta o acoplamento elétrico entre o suporte do sistema de caracterização e o substrato de silício, reduzindo assim efeitos de resistência e capacitância parasitárias [137]. Outra fonte de erro em relação ao transistor ideal é o comportamento ambipolar já estudado em TFTs de MDMO-PPV [112, 138]. FETs do tipo acumulação, Goetz et al. demonstrou que sensores a base de p-TFTs de P3HT apresentam $V_{T}$ positiva de $\sim 5 \mathrm{~V}$. De forma similar aos dispositivos aqui apresentados, um canal condutor já está claramente formado para $V_{G S}=0 \mathrm{~V}$ [135]. Apesar de todas estas não-idealidades, este estudo comparativo é válido por comparar TFTs saturados operando a tensões superiores em módulo a $40 \mathrm{~V}$, utilizando-se sempre da mesma estrutura, semicondutor e eletrodos. 
Finalmente, uma monocamada automontada $(S A M)$ ou um filme fino polimérico dielétrico pode ser aplicada antes da deposição do semicondutor orgânico. Todescato $e t$ al. demonstraram que é possível atingir mobilidades de lacunas de $1,0 \times 10^{-3} \mathrm{~cm}^{2} / \mathrm{Vs}$ em OTFTs de MDMO-PPV sem nenhuma histerese com superfícies tratadas por hexametildissilazana (HMDS) ou polimetilmetacrilato (PMMA) [123]. Resultados preliminares para MDMO-PPV depositado sobre $\mathrm{SiO}_{2}(274 \mathrm{~nm})$ tratado com HMDS apresentam um aumento em de 3,7 para $L_{M}=10 \mu \mathrm{m}$ e 3,5 para $20 \mu \mathrm{m}$. De acordo com o que foi apresentado neste texto, melhores resultados poderiam ser obtidos para $L_{M}=5$ $\mu \mathrm{m}$ e $x_{i}=467 \mathrm{~nm}$. Visto que $\mu_{h}>1,0 \times 10^{-4} \mathrm{~cm}^{2} / \mathrm{Vs}$, provavelmente seria obtido o maior valor de mobilidade deste trabalho. Resultados comparáveis aos de Todescato e colaboradores requerem $\theta>90^{\circ}$ e, provavelmente, a utilização de $\mathrm{SiO}_{\mathrm{x}} \mathrm{N}_{\mathrm{y}}$. Apesar da histerese não ter diminuído, vale lembrar que as armadilhas não são oriundas apenas de estados interfaciais, mas também do caráter intrinsecamente amorfo dos semicondutores poliméricos. Materiais que apresentem transporte por bandas tais como em semicondutores mono- e policristalinos poderiam apresentar aprisionamento reduzido de portadores majoritários [83]. Além disso, foram utilizados $5 \mathrm{~nm}$ de titânio para maior aderência dos eletrodos de fonte e dreno de ouro. Portanto, até o momento, não se pode afirmar se há um efeito de resistência série reduzindo o desempenho destes TFTs.

Tratamentos de superfície poderiam ainda ser utilizados na produção de nOTFTs, visto que a condução de elétrons em PPVs é amplamente reduzida por armadilhas [148, 139]. Investigações sobre a dependência da mobilidade com a temperatura em transistores de tipo n mostram que o transporte de carga é enormemente limitado por armadilhas de origem pouco conhecida [140]. A escolha por um tratamento adequado pode levar à fabricação de inversores e CMOS orgânicos [112]. Uma última alternativa para aumentar a razão $I_{O N / O F F}$ de TFTs é o patterning ou definição da camada ativa semicondutora, reduzindo as correntes indesejáveis entre dielétrico e semicondutor além de efeitos de borda [134]. 


\subsection{Definição de uma metodologia de seleção de novos semicondutores para aplicação em Eletrônica Orgânica}

\subsubsection{Tempo de Vôo com excitação óptica (Time of Flight, ToF)}

Os resultados obtidos para o polímero MDMO-PPV apresentam grande dispersão com mobilidades variando de $10^{-8}$ a $10^{-5} \mathrm{~cm}^{2} / \mathrm{Vs}$ (Figura 4.12). Provavelmente, isto decorre da pouca espessura dos filmes semicondutores empregados. No caso de amostras de filmes espessos $~ 200 \mathrm{~nm}$, a mobilidade é 100 vezes maior que de espessos aproximadamente $400 \mathrm{~nm}$. A diferença poderia ser explicada pelo fato que as armadilhas no filme semicondutor se encontram em baixa concentração e totalmente preenchidas, sendo o transporte de carga independente do campo elétrico sob campos elétricos intensos ( 1 MV/cm). Outra hipótese é o fato de filmes finos gerarem pares elétronlacuna ao longo de todo o volume da amostra, e fornecerem assim um valor de mobilidade superestimado. Visto que os portadores devem ser gerados o mais próximo possível da interface eletrodo/semicondutor ( $<10 \%$ de profundidade), o comprimento de onda da excitação utilizado $(337,1 \mathrm{~nm})$ foi o mais próximo possível do máximo de absorção do filme orgânico ( $500 \mathrm{~nm})$. No entanto, apesar disso, o tempo de trânsito medido em filmes de 186 e $240 \mathrm{~nm}$ (ver Figura 4.12.a) parece não variar com o campo elétrico, o que pode ser devido aos campos elevados $(0,5 \mathrm{MV} / \mathrm{cm})$ e à saturação da velocidade no filme, como também ao fato da maior parte dos portadores estarem sendo gerados em profundidade no material, divergindo da Equação (1). Considerando a última hipótese apresentada como sendo a correta, i.e. o tempo de trânsito variando de forma anômala com o campo elétrico, implica que a mobilidade também variará de forma inesperada. Deste modo, mesmo se a mobilidade efetiva é constante, um decréscimo aparente com o aumento do campo é esperado, como mostrado na Figura 4.12.b. A primeira hipótese em conjunto com a segunda hipótese poderiam explicar os resultados.

Analisando a transmitância $(T)$ calculada a partir do coeficiente de atenuação $(\alpha)$, observa-se que filmes de MDMO-PPV espessos 186 e $240 \mathrm{~nm}$ possuem $T>50 \%$ (ver 
Figura 4.10.b). Além disso, filmes espessos $~ 500 \mathrm{~nm}$ de ambos os PPVs possuem $T>$ $10 \%$. Isto justificaria comportamentos anômalos observados até mesmo nos filmes mais espessos. Seriam necessárias espessuras superiores a 5,0 $\mu \mathrm{m}$ para que $10 \%$ de atenuação fossem observados em $10 \%$ de profundidade do filme. Além disso, a absorção de fótons por todo o volume do filme semicondutor pode levar a um aparente comportamento dispersivo do transiente $J x t$ medido.

A presença de um coeficiente Poole-Frenkel negativo da mobilidade em função da raiz do campo elétrico é apresentada na literatura para poli(alquiltiofenos) regioregulares [141]. Apesar de aparente não ser o caso neste trabalho, Bässler et al. explicaram que uma dependência negativa da mobilidade com o campo pode aparecer ao inserir um parâmetro de desordem espacial $(\Sigma)$ à desordem energética $(\sigma)$ [142]. Em seu modelo original, constava somente a desordem energética, implicando obrigatoriamente em um aumento da mobilidade com o campo elétrico. Em semicondutores policristalinos com transporte de carga espacial anisotrópico, pode-se observar um ponto de mínimo e, para campos elevados, o aumento esperado de $\mu$ com $E$. O parâmetro de desordem espacial pode ser entendido como o grau de desvio em relação à direção imposta pelo campo elétrico durante o percurso dos portadores entre os eletrodos. Comportamento semelhante foi observado para outras moléculas semicondutoras orgânicas [25, 143].

Diferenças entre amostras finas e espessas podem ser explicadas também pelas diferentes rotações de spinner e concentrações de solução utilizadas para obter diversas espessuras da camada semicondutora. Amplamente observado na literatura, a preparação da solução e as condições de deposição estão intrinsecamente relacionadas com a morfologia final do filme formado [92, 144]. Outra condição à aplicabilidade do ToF é que o tempo de relaxação do dielétrico deve ser mais lento quando comparado ao tempo de trânsito, i.e. $t_{\sigma}>t_{\mathrm{tr}}>10^{-3} \mathrm{~s}$. Se esta condição não for preenchida, então a concentração dos portadores de carga em equilíbrio $\left(p_{0}\right)$ pode ser suficiente para redistribuir o campo elétrico dentro da amostra durante um intervalo de tempo menor que o tempo de deriva das cargas fotogeradas através da amostra. Consequientemente, a mobilidade aparente dos portadores de carga estimada pelo ToF aumenta com uma diminuição do campo 
elétrico, enquanto que na realidade não aumenta. Este parece ser o caso em nossas amostras e será discutido em mais detalhes na Seção 4.2.2.

Resultados anteriores apresentados por Tuladhar et al. [25] para espessuras de $610 \mathrm{~nm}$ à $1,7 \mu \mathrm{m}$ mostram transientes dispersivos, mobilidades com comportamento Poole-Frenkel e da ordem de $10^{-6} \mathrm{~cm}^{2} / V s$. Nossos transientes também foram dispersivos (i.e. estimados na intersecção de duas assíntotas em curvas de $\log J$ versus $\log t$ e apresentados na Figura 4.11), porém a observação de uma dependência Poole-Frenkel da mobilidade das lacunas com o campo elétrico está provavelmente relacionado à espessura maior das amostras em seu experimento. Mozer et al., por sua vez, não observaram nenhuma mudança na mobilidade variando-se a espessura do polímero, porém esta variou de 0,32 à $2,3 \mu \mathrm{m}$ e os parâmetros de deposição foram sempre os mesmos (i.e. utilizaram-se da concentração da solução para obter espessuras diferentes) [145]. Conforme será apresentado nas seções seguintes, uma mobilidade entre $10^{-8}-10^{-7}$ $\mathrm{cm}^{2} / \mathrm{Vs}$ seria esperada para o MDMO-PPV, semelhante à obtida para filmes espessos $400 \mathrm{~nm}$.

No caso do MEH-PPV (ver Figura 4.13.a), há pouca variação de acordo com o campo aplicado $\left(\mu \sim 10^{-6} \mathrm{~cm}^{2} / \mathrm{Vs}\right)$. Tal comportamento vem reforçar o que foi explicado para o MDMO-PPV, i.e. a presença de campos elevados e utilização de espessuras no limite de aplicabilidade da técnica de tempo de vôo. Neste caso, devido ao fato do HOMO do MEH-PPV ser superior ao do MDMO-PPV (5,3 versus 5,1 eV), a utilização do filme de PEDOT:PSS não auxiliou na obtenção de um contato ôhmico e transientes típicos de ToF foram obtidos para o MEH-PPV.

\subsubsection{Charge Extraction in Linearly Increasing Voltage (CELIV)}

Uma das limitações do ToF é que o tempo de relaxação $\left(t_{\sigma}\right)$ do material deve ser maior do que o tempo de atraso entre a aplicação tensão e do pulso de luz. Segunda limitação do $T o F$, como explicado na Seção 5.3.1, $t_{\sigma}$ deve ser maior de que $t_{\text {tr }}$. Caso isto não ocorra, o número de portadores em equilíbrio térmico é suficiente para redistribuição do campo elétrico dentro de um tempo menor que $t_{\text {tr }}$, afetando o resultado. 
A mobilidade das lacunas e a condutividade dos filmes derivados do PPV aparentemente não variam com o campo elétrico de baixa intensidade aplicado (ver Figura 4.15).

A condição $t_{\sigma}>t_{\text {tr }}$ parece ser então a responsável pelo aparente decréscimo da mobilidade $T o F$ com o aumento do campo. Juška et al. explicaram e demonstraram este comportamento em detalhes para o polímero regioregular poli(3-octiltiofeno) (rr-P3OT) [146]. Tal condição não é preenchida principalmente para filmes de MDMO-PPV de 186 e $240 \mathrm{~nm}$. Dennler et al. usaram uma variante desta técnica, conhecida como photoCELIV, para estudar células solares de heterojunção de MDMO-PPV:PCBM [147]. A espessura utilizada da camada ativa foi de 150 a $250 \mathrm{~nm}$ e a área ativa de 4 a $6 \mathrm{~mm}^{2}$, resultando em mobilidades de $\sim 2 \times 10^{-6} \mathrm{~cm}^{2} / \mathrm{Vs}$ em filmes com unicamente MDMOPPV. A discrepância com estes resultados anteriores é provavelmente conseqüência das diferentes condições de processamentos, dos materiais utilizados (diferentes fabricantes) e da degradação ao transportar as amostras da Universidade de São Paulo à Universidade Federal de São Carlos. A deposição dos filmes orgânicos dentro da glovebox da EPUSP, seguidos da deposição dos eletrodos em alto vácuo e encapsulamento em atmosfera inerte, poderia reduzir os efeitos da degradação.

\subsubsection{Curvas de densidade de corrente por tensão ( $J x V)$}

Um regime de corrente limitada por carga espacial com armadilhas rasas e preenchidas foi observado para uma amostra de MDMO-PPV espessa $108 \mathrm{~nm}$ (ver Figura 4.16). Blom et al. observaram condução SCLC de lacunas em OLEDs de MDMO-PPV com mobilidades à baixo campo de $5 \times 10^{-7} \mathrm{~cm}^{2} /$ Vs [148]. Filmes de MDMO-PPV de 130, 300 e $700 \mathrm{~nm}$ entre eletrodos de ITO e Au foram estudados segundo a Equação (5), assumindo $\varepsilon_{r}=3$. Para intensidades de campo elétrico superiores à $3 \times 10^{5} \mathrm{~V} / \mathrm{cm}$, foi observado um desvio gradual da Equação (5) com crescimento exponencial da mobilidade $\left(\alpha \exp \left[g(E)^{1 / 2}\right]\right)$.

Amostras de MDMO-PPV espesso $190 \mathrm{~nm}$ apresentaram regime SCLC com armadilhas profundas (ver Figura 4.17). Semelhante ao que foi proposto na Seção 5.3.1, dependendo da espessura do semicondutor, diferentes comportamentos são esperados 
nas curvas $J x V$. A presença de armadilhas no semicondutor em níveis energéticos rasos ou profundos impacta na repetibilidade das curvas e pode dificultar o estudo das propriedades elétricas no caso de novos semicondutores orgânicos sintetizados. Nestes cristais de van der Waals, a nanomorfologia final depende de parâmetros envolvidos na preparação do filme tais como polaridade do solvente, tempo de secagem, temperatura do substrato e método de deposição $[149,150]$. Exposição ao oxigênio ambiente durante o processamento e a caracterização podem afetar nos regimes de transporte de carga observados [151]. O panorama mais favorável seria estudar a mobilidade em filmes com condições de deposição semelhantes às do transistor. Isto não é normalmente observado em técnicas de transiente de corrente, visto que espessuras maiores que $500 \mathrm{~nm}$ são utilizadas. Considerando como uma aproximação o campo elétrico constante e igual à $V / d$, o tempo de trânsito teórico obtido através da Equação (1) é $2,76 \times 10^{-4}$ e $1,91 \times 10^{-3} \mathrm{~s}$ para filmes de 108 e 190 nm, respectivamente. Estes valores estão de acordo com os apresentados para o tempo de vôo (ver Figura 4.12.a), sendo uma ordem de grandeza inferiores aos resultados obtidos com espessura de $400 \mathrm{~nm}$ e três ordens de grandeza superiores se comparados aos resultados com espessuras de 186 e $240 \mathrm{~nm}$.

A obtenção de resultados positivos à aplicação de CELIV com a mesma estrutura empregada no estudo de curvas de $J x V$ indica que uma pequena barreira energética à injeção ( 0,1-0,2 eV) não necessariamente impede o aparecimento de correntes limitadas por carga espacial sob campo elétrico elevado $\left(>10^{5} \mathrm{~V} / \mathrm{cm}\right)$.

\subsubsection{Transistores de Filmes Finos Orgânicos}

O conhecimento obtido estudando o transporte de carga varia de acordo com a técnica adotada. Time of Flight (ToF) requer filmes espessos pelo menos uma ordem de grandeza maior que nos dispositivos, porém é a forma mais direta de estudo da mobilidade. Charge Extraction in a Linearly Increasing Voltage (CELIV) não necessita de lasers para excitação óptica como no caso do $T o F$ e já foi demonstrada com sucesso em filmes finos ( $100 \mathrm{~nm}$ ), evitando desperdício desnecessário de material. No entanto, são necessárias amostras com eletrodos diferentes para estudar tanto o transporte de 
lacunas (normalmente, portadores majoritários) quanto de elétrons (minoritários). Curvas de corrente por tensão estacionárias $(J x V)$ oferecem informações detalhadas sobre a dependência da mobilidade com o campo elétrico e a distribuição de estados das armadilhas, porém assim como no caso do CELIV demanda contatos ôhmicos para atingir correntes limitadas por carga espacial no volume do semicondutor. Se comparada às duas técnicas precedentes, mesmo obtendo correntes $S C L C$, devido à grande quantidade de modelos disponíveis, o estudo pode se tornar lento e custoso. No caso dos OTFTs, a escolha de uma estrutura conhecida (benchmark ou de referência) para estudar semicondutores orgânicos é importante em estágios iniciais de desenvolvimento. Por este motivo, transistores de filmes finos em substratos de silício altamente dopado coberto por óxidos de alta qualidade foram utilizados nesta Seção.

Considerando o modelo com mobilidade constante calculada a partir de $\mathrm{d} I_{\mathrm{D}}{ }^{1 / 2} / \mathrm{d} V_{\mathrm{GS}}$ (ver $\mu$ na Tabela 4.3 e fórmula na Seção 3.3.3), observa-se que o valor obtido é aproximadamente igual ao apresentado na Tabela 4.6 quando $V_{\mathrm{GS}}=-40 \mathrm{~V}$, não fornecendo informações sobre a dependência da mobilidade com a tensão de porta. A tensão de limiar $\left(V_{T}\right)$ se aproxima de zero em ambos os substratos, atestando assim a pouca concentração de defeitos na interface polímero-óxido (i.e. oriundos de defeitos localizados na superfície do óxido ou do polímero tais como ligações incompletas) e no volume destes materiais (e.g. contaminação por íons de sódio e potássio). $V_{T}$ apresentado na Tabela 4.3 é geralmente incorreto, tendendo a valores mais negativos caso a mobilidade dependa de $V_{\text {GS. }}$ De fato, na Figura 4.26.a, pode-se observar que uma mobilidade variável aproxima muito melhor os dados para tensões mais baixas. Assim como destacado por Shaked et al. [152], no caso de tensões próximas de zero, existem três fonte de erro: correntes de fuga através do dielétrico (neste trabalho, menor que 1 $\mathrm{nA}$ ), concentração residual de portadores no canal quando o dispositivo é desligado e filmes compostos de duas ou mais fases com diferentes DOS (e.g. policristalinos).

$\mathrm{Na}$ Figura 4.26.b, no caso específico do oxinitreto de silício, observa-se que mobilidade ainda superiores poderiam ser atingidas se os TFTs fossem polarizados a tensões maiores que $40 \mathrm{~V}$. Para baixas tensões de porta e, conseqüentemente, baixas concentrações de carga no canal, é observada uma semelhança maior com os valores 
obtidos através de outras técnicas (e.g. ToF, CELIV e $J x V$ ). Tanase e colaboradores [111] demonstraram que diferenças de três ordens de magnitude na mobilidade são esperadas entre OTFTs e OLEDs do mesmo semicondutor. Tal fenômeno é consequiência da elevada densidade de portadores na interface semicondutor/dielétrico, implicando na redução da energia de ativação, e do transporte de carga paralelo ao substrato (principalmente em semicondutores anisotrópicos). De acordo com o modelo Variable-Range Hopping de Vissenberg e Matters [84], lacunas (elétrons) se movem em uma distribuição de estados no nível HOMO (LUMO) e contribuem com a corrente somente quando excitados ao chamado nível de transporte.

As temperaturas características calculadas $\left(T_{c}\right)$ também diferem do que foi obtido a partir dos estudos de transporte de carga. Esta diferença está parcialmente relacionada às condições diferentes de deposição para obtenção dos 100 nm de MDMO-PPV usados em TFTs. A análise da variação de $\mu_{h}$ em relação ao campo elétrico longitudinal ( $\left.\mathrm{E}_{/ /}\right)$no canal indica que a $D O S$ é gaussiana em transistores e que o transporte de carga está sujeito então ao fenômeno Poole-Frenkel (ver Figura 4.27). Este comportamento foi observado em TFTs de MEH-PPV (ver Figura 4.29), assim como a concordância no valor obtido para $\gamma$ entre os métodos diferencial e Poole-Frenkel. No entanto, deve-se levar em conta que o transporte de carga ocorre principalmente através do canal do transistor, sujeito assim às armadilhas presentes na interface dielétrico/semicondutor. Conforme mostrado na Tabela 4.7, os parâmetros de transporte variam de acordo com o dielétrico e o tratamento de superfície aplicado. Além disso, em TFTs de semicondutores poliméricos amorfos e policristalinos, observa-se grande semelhança entre os resultados obtidos para um mesmo isolante: este é o caso para P3HT e MDMO-PPV depositados sobre $\mathrm{SiO}_{2}$, e para MEH-PPV e MDMO-PPV sobre $\mathrm{SiO}_{2}$ tratado com HMDS. Portanto, visto que $\mu$ depende fortemente de $V_{O V}$ e da interface dielétrico/semicondutor, o material dielétrico escolhido para comparar diferentes materiais deve ser o mesmo. Ter-se-ão assim acumulação de cargas $\left(n_{\mathrm{Q}}\right)$ no canal e concentração de armadilhas de interface $\left(N_{\text {it }}\right)$ semelhantes.

Comparando tudo o que foi exposto nesta Seção com as técnicas utilizadas para estudo de transporte de cargas (e.g. ToF, CELIV e $J x V$ ), observa-se que todas as outras 
têm em comum: i) mobilidade duas ou três ordens de grandeza inferior que em um $T F T$ do mesmo semicondutor orgânico; ii), transporte de carga perpendicular ao substrato; iii) densidades de cargas ordens de grandeza inferior. Logo, se o interesse comum é aplicar o filme em circuitos transistorizados orgânicos, a melhor solução é ter uma estrutura benchmark de TFT (e.g. substrato, dielétrico, tratamento de superfície) e condições standard de caracterização (e.g. tensões aplicadas, temperatura, luz e umidade). Este trabalho considera um substrato de silício coberto com $\mathrm{SiO}_{2}$ térmico e eletrodos de $\mathrm{Au}$ como a melhor estrutura de TFT para estudar derivados do PPV, dado que tais estruturas ainda não têm previsão de substituição. No entanto, tal como demonstrado na Seção 4.3.1, resultados semelhantes podem ser obtidos em vidro coberto por ITO.

Ao se estudar um novo material sintetizado, mesmo utilizando-se de uma estrutura TFT conhecida, um alinhamento adequado do nível de Fermi dos eletrodos metálicos (i.e. fonte e dreno) e do HOMO (LUMO) de um semicondutor tipo p (n) é necessário (barreira preferencialmente menor que 0,3 eV). Um estudo inicial dos níveis de energia HOMO/LUMO pode ser realizado com voltametria cíclica e espectroscopia de absorção UV-visível [153]. Um estudo prévio de solubilidade e de morfologia do filme fino é necessário ao controle da espessura, rugosidade e wettability (i.e. hidrofobicidade ou hidrofilicidade).

A metodologia descrita acima foi aplicada a dispositivos de alta mobilidade tais como uma pequena molécula orgânica - pentaceno - e um polímero - P3HT. Um estudo prévio dos níveis energéticos do material e das condições de deposição não foi necessário, devido à grande quantidade de publicações empregando estes materiais em TFTs. A estrutura empregada para estudo foi a bottom gate bottom contact sobre silício altamente dopado e $\mathrm{SiO}_{2}$ térmico (250-300 nm) empregando eletrodos de ouro. Não foi utilizada a espessura de $\sim 500 \mathrm{~nm}$ recomendada, porém, como será discutido a seguir, os resultados estão de acordo com a literatura. Os métodos diferencial [88] e linha de transmissão [89] foram utilizados na extração da resistência série para correta caracterização do dispositivo. No entanto, resultados obtidos para P3HT regioregular apontam para algumas limitações relacionadas à aplicação do modelo diferencial (ver Figura 4.32). No caso deste polímero, uma dependência clara da mobilidade foi 
observada somente em relação à $V_{\mathrm{DS}}$. Apesar da mobilidade superior a $10^{-3} \mathrm{~cm}^{2} / \mathrm{Vs}$, a resistência do canal está na ordem de 1-10 M $\Omega$, superior aos $10-500 \mathrm{k} \Omega\left(\mu_{h} \sim 0,5-1 \times 10^{-}\right.$ $2 \mathrm{~cm}^{2} / \mathrm{Vs}$ ) utilizados em [88] para desenvolver o método. $\sigma / \mathrm{kT}$ obtido a partir da Equação (11) em [86] coincide com os resultados de Fumagalli et al. para Mw $=33 \mathrm{kDa}$. O valor de $\eta \sim 10^{-3}-10^{-2}(\mathrm{~V} / \mathrm{cm})^{-1 / 2}$ está de acordo com o valor obtido para os TFTs de P3HT [86]. O expoente $\beta$ obtido a partir da Equação (3) em [86] coincide com o apresentado para $33 \mathrm{kDa}$, apesar de que no caso deles o parâmetro foi extraído de curvas $I_{\mathrm{D}}$ vs. $V_{\mathrm{GS}}$. A mobilidade máxima atingida para este peso molecular foi de $2,0 \times 10^{-3}$ $\mathrm{cm}^{2} / V s$. Algumas diferenças em relação a este trabalho estão na utilização de eletrodos de fonte e dreno de platina, aplicação de tratamento com dimetildiclorosilano (DDS), e caracterização em vácuo de $10^{-6}$ mbar. Este último, necessário para evitar contaminação da camada ativa por oxigênio e umidade, deve ser levado em conta ao se comparar diversos semicondutores. Em [122], Ferrari et al. demonstraram que a modulação de corrente $\left(I_{\mathrm{ON} / \mathrm{OFF}}\right)$ em TFTs de P3HT pode variar de $10^{6}$ a apenas 10 ao expor os dispositivos a atmosfera. Além disso, a forma da curva se altera, dificultando uma aproximação por mobilidade variável (dados não mostrados neste texto para fitting nãolinear segundo [86]). Poderia ser fixado no padrão IEEE de caracterização de OTFTs [154], no capítulo 3.5 Environmental control and Standards, a presença de encapsulamento ou pressão $<10^{-6}$ mbar. Segundo estudo de Chen, Wu e Rieke [155], o poli(alquiltiofeno) estudado possui $\mathrm{Mw}=37,7 \mathrm{kDa}$ e dispersão tal que $\mathrm{Mn}=25,5 \pm 17,7$ kDa (desvio padrão calculado a partir da polidispersão). Tal fato pode também levar a uma maior desordem, além da dificuldade em modelar o transporte de carga na presença de tantos pesos moleculares misturados. Assim como visto na Seção 4.1.5 para células solares de P3HT:PCBM, o tratamento térmico pós-deposição poderia aumentar a cristalinidade do filme e, portanto, a mobilidade dos portadores de carga. Neste caso, provavelmente, efeitos de resistência série não poderiam ser desprezados. Além do que foi exposto acima, a tendência de obtenção de uma DOS gaussiana em TFTs poliméricos foi confirmada para este material também.

TFTs de pentaceno apresentaram a maior mobilidade em saturação $\left(\sim 10^{-2}\right.$ $\mathrm{cm}^{2} / \mathrm{Vs}$ ) e, por este motivo, foram observados para estes dispositivos efeitos de 
resistência série. Métodos que consideram $\mu_{h}$ constante foram utilizados inicialmente para atestar a presença de $R_{\mathrm{S}}$ comparável à resistência do canal $\left(R_{\mathrm{ON}}\right)$. Este efeito apareceu na aparente diminuição da mobilidade com a diminuição do comprimento do canal, mas também com a diminuição de $V_{\mathrm{DS}}$ (ver Figura 4.34.a). Este último, normalmente atribuído ao efeito Poole-Frenkel, também ocorre se $R_{\mathrm{S}}$ for elevado e comparável a $R_{\mathrm{ON}}$ em dispositivos com $W / L$ elevados. Mobilidades em regime linear corrigidas pela presença de $R_{\mathrm{S}}$ foram de $\sim 5 \times 10^{-3} \mathrm{~cm}^{2} / \mathrm{Vs}$ e pouco variaram de um modelo a outro. Ambos os modelos consideram que a região dos contatos pode ser modelada por uma resistência constante e uma região de baixa mobilidade cujo valor seja independente de $L$ e varie somente com $V_{\mathrm{GS}}$. Tal fato é comum em materiais policristalinos evaporados sobre eletrodos de fonte e dreno e já foi amplamente demonstrado por P. V. Necliudov $[130,156]$. Especificamente, a aplicação do método diferencial requer mais valores de comprimento de canal e tensões elétricas elevadas o suficiente para que a resistência série atinja um patamar. Tais considerações enfatizam a necessidade por um standard IEEE de caracterização de OTFTs que leve em conta o projeto de uma máscara litográfica com diversos valores de $L$ (ou $W$ ), além de tensões elevadas o suficiente para simplificar a caracterização e a escolha do modelo de tratamento de dados. Normalmente, TFTs orgânicos são caracterizados em tensões de até $100 \mathrm{~V}$, facilmente obtidas com a utilização adequada dos Source/Monitor Units (SMUs) e interlock de um analisador de parâmetros [157]. Valores maiores de $L$ são desejáveis à obtenção de TFTs de alta mobilidade com $R_{\mathrm{S}}$ desprezível em relação a $R_{\mathrm{ON}}$. $R_{\mathrm{S}}$ tende a $30 \mathrm{M} \Omega$ para $V_{\mathrm{GS}}>-40 \mathrm{~V}$ em transistores de pentaceno, um valor ordens de grandeza superior ao esperado em dispositivos poliméricos. No caso especifico do pentaceno, amostras sobre $\mathrm{p}+-\mathrm{Si} / \mathrm{SiO}_{\mathrm{x}} \mathrm{N}_{\mathrm{y}}$ com eletrodos interdigitados da mesma série de amostras que forneceu os melhores resultados demonstram a aplicabilidade deste dielétrico também em TFTs de pequenas moléculas orgânicas (ver Tabela 4.15). Comparado aos dispositivos poliméricos, a qualidade da interface dielétrico/semicondutor (e.g. armadilhas, rugosidade) nestes dispositivos é determinante para uma cristalização adequada do filme durante a formação das primeiras monocamadas [80]. Assim como esperado, maior modulação de corrente $\left(\sim 2 \times 10^{4}\right)$ e correntes mais elevadas $(\sim 40 \mu \mathrm{A})$ 
foram obtidas para o pentaceno, material reconhecido por seu desempenho excepcional, validando desta forma a metodologia descrita. 


\section{CONCLUSÕES}

O conhecimento adquirido em processamento de células solares orgânicas (CSO) de heterojunção de rr-P3HT:PCBM permitiu atingir cerca de $1 \%$ de eficiência na conversão de potência ( $P C E$ ) tanto em substratos de vidro quanto em PET sob 1 sol. Isto foi alcançado através do estudo da influência de cada parâmetro de processamento, inspeção freqüente dos filmes por microscopia óptica e caracterização do dispositivo final em um simulador solar. A estrada percorrida para obter este rendimento em substrato flexível foi maior devido à degradação acelerada da célula. Além disso, foi necessário levar em conta diferenças de processamento entre dispositivos em vidro e em PET. O ânodo multicamada transparente em PET é corroído em 40 s contra mais de $1 \mathrm{~h}$ necessária para corroer ITO sobre vidro. O banho em acetona foi evitado e um cuidado maior foi tomado durante seu manuseio para evitar danos mecânicos. Enfim, enquanto que as melhores células fotovoltaicas de P3HT:PCBM são tratadas a temperaturas superiores a $140{ }^{\circ} \mathrm{C}$, o substrato flexível sofre os efeitos do aquecimento já a $100{ }^{\circ} \mathrm{C}$.

O aprendizado das técnicas de fabricação de CSOs e a familiaridade com a estrutura vertical utilizada também em $O L E D s$ e em técnicas para extrair a mobilidade dos portadores de carga foram fundamentais na realização deste trabalho. Foi demonstrado que substratos alternativos aos de silício monocristalino (e.g. vidro recoberto com óxido de índio-estanho - ITO) e dielétricos alternativos ao amplamente utilizado óxido de silício térmico (e.g. oxinitreto de silício - $\mathrm{SiO}_{\mathrm{x}} \mathrm{N}_{\mathrm{y}}$ ) podem ser utilizados em OTFTs. Este estudo pôde ser utilizado na compreensão da influência dos principais parâmetros de fabricação no desempenho final do dispositivo, tais como a correlação entre a constante dielétrica do dielétrico e a densidade de portadores no canal, além da necessidade de tratamentos de superfície na redução da histerese observada nas curvas características. OTFTs de MDMO-PPV fabricados podem integrar LEDs em mostradores de informação de matriz ativa (AMOLEDs), além de circuitos digitais devido ao comportamento ambipolar este polímero. Independente do semicondutor 
escolhido, a degradação dos parâmetros do OTFT com o tempo, temperatura e campo elétrico devem ser investigados. As propriedades de TFTs usados em eletrônica digital deve ser previsível e repetitiva. São necessários semicondutores que demandem menores tensões de polarização para atingir correntes elevadas para aplicação em AMOLEDs.

Mais do que definir uma metodologia de fabricação de TFTs orgânicos, foi desenvolvida uma metodologia de seleção de materiais para aplicações em circuitos transistorizados orgânicos, passo importante no estudo destes dispositivos e criação de uma classificação com os materiais semicondutores aplicáveis a este setor da eletrônica através da mobilidade dos portadores. A solução mais conveniente é a utilização de uma estrutura conhecida (benchmark) bottom gate e condições standard de caracterização (e.g. tensões aplicadas, pressão, temperatura, luz, umidade, valores de comprimento ou largura de canal) com escolha de um dielétrico que forneça tensão de limiar aproximadamente zero e interface semicondutor/dielétrico de baixa densidade de armadilhas $\left(<10^{16} \mathrm{~cm}^{-3}\right)$. Caso uma estimativa rápida da mobilidade dos portadores majoritários seja necessária, Charge Extraction in a Linearly Increasing Voltage (CELIV) pode fornecer resultados a baixo custo e de forma simples. Deve-se levar em conta que a mobilidade obtida através de técnicas alternativas que não empregam a estrutura de TFT é em geral ordens de grandeza inferior. 


\section{CONTINUIDADE DO TRABALHO}

Pode-se dar continuidade a realização experimental de TFTs através da substituição do óxido inorgânico de porta por um dielétrico orgânico. Além disso, podese dar início ao estudo de estruturas que incorporem condutores poliméricos.

Fabricação de OTFTs em substrato flexível, aproveitando-se do conhecimento adquirido com a fabricação de células solares sobre PET.

Aplicação da metodologia desenvolvida para estudo de novos materiais inteiramente nos laboratórios da EPUSP. Diversos materiais, que não apresentam um estudo profundo da mobilidade de seus portadores, vêm sendo empregados recentemente em dispositivos orgânicos. Estes podem ser fornecidos pela Dra. Leni Campos Akcelrud da Universidade Federal do Paraná (e.g. complexos de terras raras) ou pela Profa. Dra. Neyde Y. M. Iha do Instituto de Química da Universidade de São Paulo (e.g. complexos de metais de transição) para serem estudados na Escola Politécnica. Equipamentos necessários à aplicação da técnica $C E L I V$, por exemplo, encontram-se disponíveis no laboratório de microeletrônica da EPUSP.

O trabalho realizado em células solares orgânicas de heterojunção será

prosseguido em Trento pela $F B K$ e financiado pela companhia Diatec visando a fabricação em substrato flexível transparente e por processos rolo-a-rolo. O grupo APP comandado por Dr. Georg Pucker ficará encarregado desta atividade. 


\section{PUBLICAÇÕES RELACIONADAS}

Trabalhos completos submetidos a periódicos:

1. CAVAllari, M. R. ; AlBerTin, K. F. ; SANTOS, G. ; RAMOS, C. A. S. ; PEREYRA, I. ; FONSECA, F. J. ; ANDRADE, A. M. PECVD Silicon Oxynitride as Insulator for MDMO-PPV Thin-Film Transistors. Submitted to Journal of Integrated Circuits and Systems. January of 2010.

Trabalhos completos publicados em anais de congressos:

1. CAVAllari, M. R. ; AlBERTIN, K. F. ; SANTOS, G. ; RAMOS, C. A. S. ; PEREYRA, I. ; FONSECA, F. J. ; ANDRADE, A. M. . Comparative Study of MDMO-PPV Thin-Film Transistors Using Thermal $\mathrm{SiO}_{2}$ and PECVD Silicon Oxynitride as Insulator. In: 24th Symposium on Microelectronics Technology and Devices, 2009, Natal (Rio Grande do Norte). Microelectronics Technology and Devices - SBMicro 2009, 2009. v. 23. p. 113-120.

Resumos publicados em anais de congressos:

1. CAVAllari, M. R.; CUPPOLETTI, C. M.; PUCKER, G.; FONSECA, F. J.; ANDRADE, A. M.; CARTURAN, S.; MAGGIONI, G.; QUARANTA, A.; BUFFA, M.; TONEZZER, M. Degradation studies of rigid and flexible rr-P3HT:PCBM bulk heterojunction solar cells encapsulated with a parylene polymeric coating. In: 11th International Conference on Advanced Materials - VIII Encontro SBPMat, 2009, Rio de Janeiro, Brazil. Abstracts of the 11th International Conference on Advanced Materials VIII Encontro SBPMat, 2009.

2. AMORIM, C. A.; SOUSA, F. B.; CAVALLARI, M. R.; SANTOS, G.; FONSECA, F. J.; ANDRADE, A. M.; MERGULHAO, S. Determination of Carrier Mobility in MEH-PPV by Time-of-Flight, Dark Injection SCLC and Charge Extraction in a Linearly Increasing Voltage (CELIV) techniques. In: 11th International Conference 
on Advanced Materials - VIII Encontro SBPMat, 2009, Rio de Janeiro, Brazil. Abstracts of the 11th International Conference on Advanced Materials - VIII Encontro SBPMat, 2009.

3. AMORIM, C. A.; CAVALLARI, M. R.; SANTOS, G.; FONSECA, F. J.; ANDRADE, A. M.; MERGULHAO, S. MEH-PPV Polymer Light-Emitting Diode Charge Transport and Degradation Studies Based in CELIV Measurements. In: XXXII Brazilian Meeting on Condensed Matter Physics, 2009, Águas de Lindóia. Livro de Resumos, 2009. v. 32.

4. CAVAllari, M. R.; AMORIM, C. A.; SANTOS, G.; MERGULHAO, S.; FONSECA, F. J.; ANDRADE, A. M. Methodology of material selection for organic thin-film transistors based on charge carrier mobility characterization. In: VII Encontro da Sociedade Brasileira de Pesquisa em Materiais, 2008, Guarujá. Abstracts do VI Encontro SBPMat, 2008. v. 1.

5. CAVAllari, M. R.; ALBERTIN, K. F.; SANTOS, G.; RAMOS, C. A. S.; PEREYRA, I.; FONSECA, F. J.; ANDRADE, A. M. Comparative study of MDMOPPV in Organic Thin-Film Transistors using $\mathrm{SiO}_{2}$ and silicon oxynitride as insulators. In: 29th International Conference on the Physics of Semiconductors, 2008, Rio de Janeiro. 29th International Conference on the Physics of Semiconductors, Abstracts, 2008. p. 589-590.

6. CAVALLARI, M. R.; ALBERTIN, K. F.; SANTOS, G.; PEREYRA, I.; FONSECA, F. J.; ANDRADE, A. M. MDMO-PPV in Organic Thin-Film Transistors using different insulators and substrates: comparative study. In: IV Seminatec Workshop on Semiconductors and Micro \& Nano Technology, 2008, São Paulo. Iv Seminatec Workshop on Semiconductors and Micro \& Nano Technology, 2008. p. 28-28.

7. CAVAllaRI, M. R.; FONSECA, F. J.; ANDRADE, A. M. Development of a manufacturing methodology for organic thin-film transistors. In: VII Workshop do projeto Instituto Multidiciplinar de Materiais Poliméricos - IMMP, 2008, Atibaia. VII IMMP Poster Presentation Abstracts, 2008., 2008. p. 22-22. 


\section{REFERÊNCIAS BIBLIOGRÁFICAS}

[1] SAMPIETRO, M. Curso de ELETTRONICA A SEMICONDUTTORI ORGANICI: Principi, dispositivi ed applicazioni. Aula ASPETTI BASE dei SEMICONDUTTORI ORGANICI, Politecnico di Milano, Milão, Itália. Maio 2009. Disponível em: <http://home.dei.polimi.it/sampietr/ESO/index.html>. Acesso em: 30 de maio de 2009.

[2] SHIRAKAWA, H. et al. Synthesis of electrically conducting organic polymers: halogen derivatives of polyacetylene, (CH)x. J. Chem. Soc. Chem. Commun. 578,1977.

[3] SKOTHEIM, T.A. Handbook of Conducting Polymers, vol. 1\&2, New York: Marcel Dekker, 1986.

[4] SRINIVASAN, K.S.V. Macromolecules: New Frontiers, vol. 1\&2, New Delhi: Allied Publishers, 1998.

[5] GENOUD, F. et al. ESR study of electrochemical doping in the conducting polymer polypyrrole Phys. Rev. Lett. 55:118-121, 1985.

[6] CROSS, M.G. et al. A voltammetric survey of steric and $\beta$-linkage effects in the electropolymerisation of some substituted pyrroles J. Electroanal. Chem. 189:389-396,1985.

[7] LIDZEY, D.G. et al. Electroluminescence in polymer films Nature 386,135-135, 1997.

[8] KAO, K.C.; HWANG, W. Electrical Transport in Solids, Pergamon Press, Oxford, 1981.

[9] SZE, S. M. Physics of Semiconductor Devices, second ed. New York: John Wiley \& Sons, 1981. 880p.

[10] REINEKE, S. et al. White organic light-emitting diodes with fluorescent tube efficiency. Nature 459: 234-238, 2009.

[11] PARK, S.H. et al. Bulk heterojunction solar cells with internal quantum efficiency approaching $100 \%$. Nat. Photon. 3: 297-302, 2009.

[12] YAN, H. et al. A high-mobility electron-transporting polymer for printed transistors. Nature 457: 679-686, 2009.

[13] STALlingA, P. Electrical Characterization of Organic Electronic Materials and Devices. In: 1. General Concepts. John Wiley and Sons Ltd., 2009. p. 1-38.

[14] JEONG, S.H.; SONG, C.K. \& YI, M. Capacitance enhancement in the accumulation region of C-V characteristics in metal-insulator-semiconductor capacitors consisting of pentacene and poly(4-vinylphenol). Appl. Phys. Lett. 94: 183302, 2009.

[15] MYNY, K. et al. An integrated double half-wave organic Schottky diode rectifier on foil operating at $13.56 \mathrm{MHz}$. Appl. Phys. Lett. 93: 093305, 2008.

[16] MA, L. et al. Nanometer-scale recording on an organic-complex thin film with a scanning tunneling microscope. Appl. Phys. Lett. 69: 3762, 1996.

[17] TONIOLO, R.; LEPIENSKI, C. \& HÜMMELGEN, I.. Organic electronic pulse generator. Electron. Lett. 40: 566-567, 2004.

[18] ZHANG, C. et al. Alkali metal crystalline polymer electrolytes. Nat. Mater. 8: 580-584, 2009.

[19] OTERO, T.F.; BROSCHART, M. Polypyrrole artificial muscles: a new rhombic element. Construction and electrochemomechanical characterization. J. Appl. Electrochem. 36(2): 205-214, 2006.

[20] SOKOLOV, A.N.; ROBERTS, M.E. \& BAO, Z. Fabrication of low-cost electronic biosensors. Mater. Today 12(9): 12-20, 2009

[21] INOUE, Y. et al. Low-Voltage Organic Thin-Film Transistors on Flexible Plastic Substrates. Mat. Res. Soc. Symp. Proc. 736: D4.2.1, 2003.

[22] YOKOYAMA, O. Active-matrix full color organic electroluminescent displays fabricated by ink-jet printing. Optronics 254: 119, 2003. 
[23] KELleY, T.W. et al. High performance organic thin film transistors. Mater. Res. Soc. Symp. Proc. 771 : L6.5.1,2003.

[24] SINGH, T.H.B. et al. Enhanced mobility of organic field-effect transistors with epitaxially grown C60 film by insitu heat treatment of the organic dielectric. Mater. Res. Soc. Symp. Proc. 871E, 2005.

[25] TULADHAR, S.M. et al. Ambipolar charge transport in meth'anofullerene and poly(phenylenevinylene)/ methanofullerene blends. Adv. Funct. Mater. 15: 1171-1182, 2005.

[26] TSANG, S.W. et al. PEDOT:PSS polymeric conducting anode for admittance spectroscopy. Org. Electron. 7 : 474-479, 2006.

[27] KITAMURA, M. et al. Time-of-flight measurement of lateral carrier mobility in organic thin films. Jpn J. Appl. Phys. 43: 2326, 2000.

[28] MEYER, H. et al. Chemical structure of PPV and DPOP-PPV Phys. Rev. B 52: 2587, 1995

[29] SCHER, H.; MONTROLL, E.W. Anomalous transit-time dispersion in amorphous solids. Phys. Rev. B 12: 2455,1975 .

[30] JUŠKA, G. et al. New method of drift mobility evaluation in $\mu \mathrm{c}-\mathrm{Si}: \mathrm{H}$, basic idea and comparison with time-offlight. J. Non-Crystal. Sol. 266-269: 331-335, 2000.

[31] JUŠKA, G. et al. Charge transport in $\pi$-conjugated polymers from extraction current transients. Phys. Rev. B 62(24): R16 235, 2000.

[32] ARKHIPOV, V.I. et al. Charge injection into Light-Emitting Diodes: Theory and experiment. J. Appl. Phys. 84(2): 848-856, 1998.

[33] DAVIDS, P.S.; CAMPBELL, I.H. \& SMITH, D.L. Device model for single carrier organic diodes. J. Appl. Phys. 82: 6319, 1997.

[34] BRAUN, D. Electronic Injection and Conduction Processes for Polymer Devices. J. Pol. Sci. Part B: Pol. Phys. 41(21): 2622-2629, 2003

[35] LAMPERT, M. Simplified theory of space-charge-current in an insulator with traps. Phys. Rev. 103: 1648-1656, 1956.

[36] BECQUEREL, E. Mémoire sur les effets électriques produits sous l'influence des rayons solaires. Comptes Rendus des Séances Hebdomadaires 9: 561-567, 1839.

[37] MOLITON, A. et al. How to model the behavior of organic photovoltaic cells. Polym. Int. 55: 583-600, 2006.

[38] WALDAUF, C. et al. Material and device concepts for organic photovoltaics: towards competitive efficiencies. Thin Solid Films 451-452: 503-507, 2004.

[39] CHAPIN, D. M.; FUlLER, C. S. \& PEARSON, G. L. A New Silicon p-n Junction Photocell for Converting Solar Radiation into Electrical Power. J. Appl. Phys. 25: 676-677, 1954.

[40] YAMAGUCHI, M. et al. Present status and future of crystalline silicon solar cells in Japan. Solar Energy 80: 104-110, 2006

[41] PAGliarO, M.; CIRIMINNA, R.; PALMISANO, G. Flexible Solar Cells. ChemSusChem 1: 880-891, 2008; KREBS, F.C. Polymer solar cell modules prepared using roll-to-roll methods: Knife-over-edge coating, slot-die coating and screen printing. Solar Energy Materials \& Solar Cells 93: 465-475, 2009.

[42] YU, G. et al. Polymer Photovoltaic Cells: Enhanced Efficiencies via a Network of Internal Donor-Acceptor Heterojunctions. Science 270: 1789-1791, 1995.

[43] SARICIFTCI, N.S. et al. Photoinduced Electron Transfer from a Conducting Polymer to Buckminsterfullerene. Science 258: 1474-1476, 1992; SARICIFTCI, N.S.; HEEGER, A. J. Reversible, Metastable, Ultrafast Photoinduced Electron Transfer from Semiconducting Polymers to Buckminsterfullerene and in the Corresponding Donor/Acceptor Heterojunctions. Intern. J. Mod. Phys. B 8: 237-274, 1994.

[44] PADINGER, F.; RITTBERGER, R.S. \& SARICIFTCI, N.S. Effects of Postproduction Treatment on Plastic Solar Cells. Adv. Funct. Mater. 13: 85-88, 2003. 
[45] KROON, R et al. Small Bandgap Polymers for Organic Solar Cells (Polymer Material Development in the Last 5 Years). Polym. Rev., 48: 531-582, 2008.

[46] KIPPELEN, B.; BREDAS, J.-L. Organic photovoltaics. Energy Environ. Sci. 2: 251-261, 2009.

[47] DHANABALAN, A. et al. Synthesis and Characterization of a Low Bandgap Conjugated Polymer for Bulk Heterojunction Photovoltaic Cells. Adv. Funct. Mater. 11: 255-262, 2001.

[48] BUNDGAARD, E.; KREBS, F.C. Low band gap polymers for organic photovoltaics. Solar Energy Materials \& Solar Cells 91: 954-985, 2007.

[49] VALENTE, G.M. da S. Célula solar orgânica de heterojunção de poli[2-metoxi-5-[(3,7-dimetiloctoxi) fenileno vinileno]] e nanotubos de carbono. Campinas, 2008. V234c. Tese (Mestrado) - Faculdade de Engenharia Elétrica e de Computação, Universidade Estadual de Campinas, 2008.

[50] PIVRIKAS, A. et al. A Review of Charge Transport and Recombination in Polymer/Fullerene Organic Solar Cells. Prog. Photovolt: Res. Appl. 15: 677-696, 2007.

[51] DENNLER, G.; SCHARBER, M.C. \& BRABEC, C.J. Polymer-Fullerene Bulk-Heterojunction Solar Cells. Adv. Mater. 21: 1323-1338, 2009; PEET, J. et al. Efficiency enhancement in low-bandgap polymer solar cells by processing with alkane dithiol. Nat. Mater. 6: 497-500, 2007; WANG, E. et al. High-performance polymer heterojunction solar cells of a polysilafluorene derivative. Appl. Phys. Lett. 92: 033307, 2008; WONG, W.Y. et al. Metallated conjugated polymers as a new avenue towards high-efficiency polymer solar cells. Nat. Mater. 6: 521-527, 2007; PEET, J. et al. Small molecule sensitizers for near-infrared absorption in polymer bulk heterojunction solar cells. Appl. Phys. Lett. 93: 163306, 2008.

[52] MA, W. et al. Thermally Stable, Efficient Polymer Solar Cells with Nanoscale Control of the Interpenetrating Network Morphology. Adv. Funct. Mater. 15: 1617-1622, 2005.

[53] REYES-REYES, M.; KIM, K. \& CARROLL, D. L. High-efficiency photovoltaic devices based on annealed poly(3-hexylthiophene) and 1-(3-methoxycarbonyl)-propyl-1-phenyl-(6,6)C61 blends. Appl. Phys. Lett. 87: 083506, 2005; CHEN, F.C.; TSENG, H.C. \& KO, C.J. Solvent mixtures for improving device efficiency of polymer photovoltaic devices. Appl. Phys. Lett. 92: 103316, 2008.

[54] LI, G. et al. High-efficiency solution processable polymer photovoltaic cells by self-organization of polymer blends. Nat. Mater. 4: 864-868, 2005;

[55] KIM, J.Y. et al. New Architecture for High-Efficiency Polymer Photovoltaic Cells Using Solution-Based Titanium Oxide as an Optical Spacer. Adv. Mater. 18: 572-576, 2006.

[56] KIM, J.Y. et al. Efficient Tandem Polymer Solar Cells Fabricated by All-Solution Processing. Science 317: 222 $225,2007$.

[57] LILIENFELD, J.E. Methods and apparatus for controlling electric current. US Patent 1745 175. Requerida em 8 out. 1926, outorgada em 18 jan. 1930.

[58] KAHNG, D.; ATAlla, M.M. IRE Solid-State Devices Research Conference, Carnegie Institute of Technology, Pittsburgh, PA 1960.

[59] MOORE, G. Cramming more components onto integrated circuits. Electronics Magazine, 1965.

[60] VOSS, D. Cheap and cheerful circuits. Nature 407: 442-444, 2000.

[61] MABROOK, M.F. et al. A pentacene-based organic thin film memory transistor. Appl. Phys. Lett. 94: 173302, 2009.

[62] MACCIONI, M. et al. Towards the textile transistor: Assembly and characterization of an organic field effect transistor with a cylindrical geometry. Appl. Phys. Lett. 89: 143515, 2006.

[63] MABECK, J.; MALLIARAS, G. Chemical and biological sensors based on organic thin-film transistors. Anal. Bioanal. Chem. 384: 343-353, 2005

[64] BARTIC, C.; BORGHS, G. Organic thin-film transistors as transducers for (bio) analytical applications. Anal. Bioanal. Chem. 384: 354-365, 2006.

[65] SINGH, T.B.; SARICIFTCI, N.S. Progress In Plastic Electronics Devices. Annu. Rev. Mater. Res. 36: 199-230, 2006. 
[66] KAUK, H. et al. Pentacene Organic Transistors and Ring Oscillators on Glass and on Flexible Polymeric Substrates. Appl. Phys. Lett. 82: 4175, 2003.

[67] LEE, J. et al. Flexible semitransparent pentacene thin-film transistors with polymer dielectric layers and $\mathrm{NiOx}$ electrodes. Appl. Phys. Lett. 87: 023504, 2005.

[68] TSUMURA, A.; KOEZUKA, H. \& ANDO, T. Macromolecular electronic device: Field-effect transistor with a polythiophene thin film. Appl. Phys. Lett. 49: 1210, 1986.

[69] KOEZUKA, H.; TSUMURA, A. \& ANDO, T. Field-effect transistor with polythiophene thin film. Synth. Met. 18: 699-704, 1987.

[70] LAWRENCE, C.J. The mechanics of spin coating of polymer films. Phys. Fluids, 31: 2786-2795, 1988.

[71] BAO, Z.; DODABALAPUR, A. \& LOVINGER, A.J. Soluble and processable regioregular poly(3hexylthiophene) for thin film field-effect transistor applications with high mobility. Appl. Phys. Lett. 69: 41084110, 1996.

[72] KITAMURA, M.; IMADA, T. \& ARAKAWA, Y. Organic light-emitting diodes driven by pentacene-based thinfilm transistors Appl. Phys. Lett. 83: 3410, 2003.

[73] DECHER, G.; HONG, J.-D. Buildup of ultrathin multilayer films by a self-assembly process: I. consecutive adsorption of anionic and cationic bipolar amphiphiles. Makromolekulare Chemie-Macromolecular Symposia 46: 321-327, 1991.

[74] BAO, Z. et al. High-performance plastic transistors fabricated by printing techniques. Chem. Mater. 9: 12991301, 1997.

[75] ROGERS, J.A. et al. Printing process suitable for reel-toreel production of high-performance organic transistors and circuits. Adv. Mater. 11: 741-745,1999.

[76] XIA, Y.; WHITESIDES, G.M. Soft lithography. Angew. Chem. Int. Ed. 37: 550, 1998

[77] DIMITRAKOPOULOS, C.D. et al. Low-Voltage Organic Transistors on Plastic Comprising High-Dielectric Constant Gate Insulators. Science 283: 822-824, 1999.

[78] LIN, Y.-Y. et al. Stacked Pentacene Layer Organic Thin-Film Transistors with Improved Characteristics. IEEE Electron Dev. Lett. 18(12): 606-608, 1997.

[79] MARTINO, J. A.; PAVANELlO, M. A. \& VERDONCK, P. B. Transistor MOS. ln: Caracterização elétrica de tecnologia e dispositivos MOS. São Paulo: Pioneira Thomson Learning, 2003. p. 75-106.

[80] YOON, M.-H. et al. Gate Dielectric Chemical Structure-Organic Field-Effect Transistor Performance Correlations for Electron, Hole, and Ambipolar Organic Semiconductors. J. Am. Chem. Soc. 128: 12851-12869, 2006

[81] OHNUKI, H. et al. Effects of interfacial modification on the performance of an organic transistor based on TCNQ LB films. Thin Solid Films 516: 2747-2752, 2008.

[82] BONFIGLIO, A.; MAMELI, F. \& SANNA, O. A completely flexible organic transistor obtained by a one-mask photolithographic process. Appl. Phys. Lett. 82(20): 3550-3552, 2003.

[83] EGGINGER M. et al. Current versus gate voltage hysteresis in organic field effect transistors. Monatsh Chem. 140: 735-750, 2009.

[84] VISSENBERG, M.C.J.M.; MATTERS, M. Theory of the field-effect mobility in amorphous organic transistors. Phys. Rev. B 57: 12964-12967, 1999.

[85] HOROWITZ, G.; HAJlAOUI, M.E. \& HAJlAOUI, R. Temperature and gate voltage dependence of hole mobility in polycrystalline oligothiophene thin film transistors. J. Appl. Phys. 87: 4456, 2000.

[86] FUMAGALLI, L. et al. Dependence of the mobility on charge carrier density and electric field in poly(3hexylthiophene) based thin film transistors: Effect of the molecular weight. J. Appl. Phys. 104: 084513, 2008.

[87] MCDOWELL, M. et al. Improved organic thin-film transistor performance using novel self-assembled monolayers. Appl. Phys. Lett. 88: 073505, 2006. 
[88] NATALI, D.; FUMAGALLI, L. \& SAMPIETRO, M. Modeling of organic thin film transistors: Effect of contact resistances. J. Appl. Phys. 101: 014501, 2007.

[89] ZAUMSEIL, J.; BALDWIN, K.W. \& ROGERS, J.A. Contact resistance in organic transistors that use source and drain electrodes formed by soft contact lamination. J. Appl. Phys. 93:6117-6124, 2003.

[90] BOLOGNESI, A.; DI CARLO, A. \& LUGLI, P. Influence of carrier mobility and contact barrier height on the electrical characteristics of organic transistors. Appl. Phys. Lett. 81: 4646-4648, 2002.

[91] BAO, Z. et al. Silsesquioxane Resins as High-Performance Solution Processible Dielectric Materials for Organic Transistor Applications. Adv. Funct. Mater. 12(8): 526-531, 2002.

[92] HOPPE, H. et al. Nanoscale Morphology of Conjugated Polymer/Fullerene-Based Bulk- Heterojunction Solar Cells. Adv. Funct. Mater. 14: 1005-1011, 2004

[93] LAQUINDANUM, J.G.; KATZ, H.E. \& LOVINGER, A.J. Synthesis, Morphology, and Field-Effect Mobility of Anthradithiophenes Am. Chem. Soc. 120: 664-672, 1998.

[94] SAUDARI, S.R.; FRAIL, P.R. \& KAGAN, C.R. Ambipolar transport in solution-deposited pentacene transistors enhanced by molecular engineering of device contacts. Appl. Phys. Lett. 95: 023301, 2009.

[95] FUCHIGAMI, H.; TSUMURA, A. \& KOEZUKA, H. Polythienylenevinylene thin-film transistor with high carrier mobility. Appl. Phys. Lett. 63: 1372, 1993.

[96] SCHON, J.H.; BATLOGG, B. Modeling of the temperature dependence of the field-effect mobility in thin film devices of conjugated oligomers. Appl. Phys. Lett. 74(2): 260-262, 1999.

[97] SALANECK, W.R.; STAFSTRÖM, S. \& BRÉDAS, J.L. Conjugated polymer surfaces and interfaces. Cambridge University Press, Cambridge, 1996. cap 4 e 5, p. 50-71.

[98] KIM, Y. et al. Device annealing effect in organic solar cells with blends of regioregular poly(3-hexylthiophene) and soluble fullerene. Appl. Phys. Lett. 86: 063502, 2005.

[99] LeSsmanN, R. Medidas de Mobilidade de Portadores de Carga em Materiais Semicondutores Orgânicos por Tempo de Vôo (TOF). Paraná, 2005. Tese (Mestrado) - Departamento de Física, Universidade Federal do Paraná, 2005.

[100] DENG, Z. et al. Carrier transport in thin films of organic electroluminescent materials. Synth. Met. 107: 107109, 1999.

[101] MACIEL, A. de C. Fabricação e Estudo das Propriedades de Transporte de Transistores de Filmes Finos Orgânicos. Primeiro relatório anual da FAPESP (Programa de Doutorado Direto), Processo No: 2007/07251-8 Instituto de Física de São Carlos da Universidade de São Paulo, 2009.

[102] IWAMA, Y. et al. Electroluminescence Properties of Organic Light-Emitting Diodes Using ITO with Different Surface Treatments. Proc. 7th. Int. Conf. Properties and Applications of Dielectric Materials, 718-721, 2003.

[103] FRANKLIN, K. Estudo de camadas dielétricas para aplicação em capacitores MOS. São Paulo, 2007. Tese (Doutorado) - Escola Politécnica, Universidade de São Paulo, 2007.

[104] LODHA, A.; SINGH, R. Prospects of Manufacturing Organic Semiconductor-Based Integrated Circuits IEEE Trans. on Semic. Manuf. 14: 281-296, 2001.

[105] CHABINYC M.L.; SALLEO, A. Materials Requirements and Fabrication of Active Matrix Arrays of Organic Thin-Film Transistors for Displays. Chem. Mater. 16: 4509-4521, 2004.

[106] CHIACCHIO, R.S. Montagem e caracterização de um dispositivo eletrônico usando polímero condutor. Campinas, 2004. C43e. Tese (Mestrado) - Instituto de Química, Universidade Estadual de Campinas, 2004.

[107] FUMAGALLI, L. et al. $\mathrm{Al}_{2} \mathrm{O}_{3}$ as gate dielectric for organic transistors: Charge transport phenomena in poly-(3hexylthiophene) based devices. Org. Electron. 9: 198-208, 2008

[108] KREBS, F.C. et al. Lifetimes of organic photovoltaics: photochemistry, atmosphere effects and barrier layers in ITO-MEHPPV:PCBM-aluminium devices. Solar Energy Materials \& Solar Cells 86: 499-516, 2005; INOUE, K. et al. Temperature and Time Dependence of Heat Treatment of RR-P3HT/PCBM Solar Cell. Synth. Met. 154: 41-44, 2005. 
[109] LEE, K. et al. Air-Stable Polymer Electronic Devices. Adv. Mater. 19, 2445-2449, 2007.

[110] ALVAREZ, A.L. et al. Analytical Evaluation of the Ratio Between Injection and Space-Charge Limited Currents in Single Carrier Organic Diodes. IEEE Trans. Elect. Dev. 55: 674-680, 2008.

[111] TANASE, C. et al. Unification of the Hole Transport in Polymeric Field-Effect Transistors and Light-Emitting Diodes. Phys. Rev. Lett. 91(21): 216601, 2003.

[112] MUCCINI, M. A bright future for organic field-effect transistors Nat. Mater. 5: 605-613, 2006.

[113] QUIST, P.A.C. et al. Photo-induced charge separation and electron diffusion in MDMO-PPV:PCBM bulk heterojunctions. Solar Energy Materials \& Solar Cells 90: 362-378, 2006.

[114] BOZANO, L. et al. Temperature- and field-dependent electron and hole mobilities in polymer light-emitting diodes. Appl. Phys. Lett. 74: 1132-1134, 1999.

[115] MARTENS, H.C.F.; HUIBERTS, J.N. \& BLOM, P.W.M. Simultaneous measurement of electron and hole mobilities in polymer light-emitting diodes. Appl. Phys. Lett. 77 : 1852-1854, 2000.

[116] BLOM, P.W.M.; DE JONG, M.J.M. \& VAN MUSTER, M.G. Electric-field and temperature dependence of the hole mobility in poly(p-phenylene vinylene). Phys. Rev. B 55: R656, 1997.

[117] ROICHMAN, Y.; PREEZANT, Y. \& TESSLER, N. Analysis and modeling of organic devices. Phys. Stat. Sol. (a) 201: 1246-1262, 2004.

[118] KUMAR, P. et al. Effect of CoFe magnetic nanoparticles on the hole transport in poly(2-methoxy, 5-(2ethylhexiloxy) 1,4-phenylenevinylene). J. Phys. D: Appl. Phys. 41: 185104, 2008.

[119] MARTIN, S.J. et al. Modelling temperature-dependent current-voltage characteristics of an MEH-PPV organic light emitting device. J. Phys.: Condens. Matter 14 : 9925-9933, 2002.

[120] CHÁVEZ, M.I.A. Deposição e caracterização de filmes de $\mathrm{SiO}_{2}$ crescidos pela técnica de PECVD a baixa temperatura. São Paulo, 1996. Tese (Mestrado) - Escola Politécnica, Universidade de São Paulo, 1996. p. 3.63.11 .

[121] KIM K. et al. Roles of donor and acceptor nanodomains in $6 \%$ efficient thermally annealed polymer photovoltaics. Appl. Phys. Lett. 90: 163511, 2007.

[122] FERRARI, S. et al. Atomic layer deposited $\mathrm{Al}_{2} \mathrm{O}_{3}$ as a capping layer for polymer based transistors. Org. Electron. 8: 407-414, 2007.

[123] TODESCATO, F. et al. Correlation between Dielectric/Organic Interface Properties and Key Electrical Parameters in PPV-based OFETs. J. Phys. Chem. B 112: 10130-10136, 2008.

[124] GEENS, W. et al. Dependence of field-effect hole mobility of PPV-based polymer films on the spin-casting solvent. Org. Electron. 3: 105-110, 2002.

[125] CHUA, L.-L. et al. General observation of n-type field-effect behaviour in organic semiconductors. Nature $434:$ 194-199, 2005.

[126] AUSTIN, M.D. \& CHOU, S.Y. Fabrication of $70 \mathrm{~nm}$ channel length polymer organic thin-film transistors using nanoimprint lithography. Appl. Phys. Lett. 81(23): 4431-4433, 2002.

[127] FUJIMORI, F. et al. Current transport in short channel top-contact pentacene field-effect transistors investigated with the selective molecular doping technique. Appl. Phys. Lett. 90: 193507, 2007.

[128] YUN, D.-J. et al. Contact resistance between pentacene and indium-tin oxide (ITO) electrode with surface treatment. Org. Electron. 8: 690-694, 2007.

[129] SANTATO, C. et al. Organic light-emitting transistors using concentric source/drain electrodes on a molecular adhesion layer. Appl. Phys. Lett. 88: 163511, 2006.

[130] NECLIUdOV, P.V. et al. Modeling of organic thin film transistors of different designs. J. Appl. Phys. 88: $6594,2000$. 
[131] KAYASHIMA, H. et al. Fabrication of $\mathrm{p}$ - and n-Type Field-Effect Transistors Using Poly( pphenylenevinylene) via Water-Soluble Precursor under High-Gravity Condition. Jpn. J. Appl. Phys. 46: L177L179, 2007.

[132] SINGH, R. Growth of Thin Thermal $\mathrm{SiO}_{2}$ Films. Microelectronics Journal 23: 273-281, 1992.

[133] NEWMAN, C.R. et al. Introduction to Organic Thin Film Transistors and Design of n-Channel Organic Semiconductors. Chem. Mater. 16: 4436-4451, 2004.

[134] JIA, H. et al. Gate induced leakage and drain current offset in organic thin film transistors. Org. Electron. 7: 16-21, 2006.

[135] GOETZ, S.M. et al. Organic field-effect transistors for biosensing applications. Org. Electron. 10: 573-580, 2009.

[136] HUANG, A. Fabrication and Test Characterization of Organic Poly (3,3"'dialkylquarterthiophene) (PQT-12) Transistors. 24th Annual Microelectronic Engineering Conference, 2006. p. 20-24.

[137] PESAVENTO, P.V. et al. Gated four-probe measurements on pentacene thin-film transistors: Contact resistance as a function of gate voltage and temperature. J. Appl. Phys. 96: 7312, 2004. INOUE, Y. et al. Organic ThinFilm Transistors with High Electron Mobility Based on Perfluoropentacene. Jpn. J. Appl. Phys. 44: 3663, 2005. LIU, P.-T.; CHOU, Y.-T. \& KAO, Y.-Y. Improvement of Electron-Gun Evaporated Aluminum Oxide for Pentacene Thin-Film Transistor. Electrochem. Solid-State Lett. 12: H11-H13, 2009.

[138] CICOIRA, F.; SANTATO, C. Organic Light Emitting Field Effect Transistors: Advances and Perspectives. Adv. Funct. Mater. 17: 3421-3434, 2007.

[139] ANTONIADIS, H.; ABKOWITZ, M.A. \& HSIEH, B.R. Carrier deep-trapping mobility-lifetime products in poly(p-phenylene vinylene). Appl. Phys. Lett. 65: 2030-2032, 1994.

[140] CHESTERFIELD, R.J. et al. Organic Thin Film Transistors Based on N-Alkyl Perylene Diimides: Charge Transport Kinetics as a Function of Gate Voltage and Temperature. J. Phys. Chem. B 108: 19281-19292, 2004.

[141] MOZER, A.J. et al. Charge carrier mobility in regioregular poly(3-hexylthiophene) probed by transient conductivity techniques: A comparative study. Phys. Rev. B 71: 035214, 2005.

[142] BORSENBERGER, P.M.; RICHERT, R. \& BÄSSLER, H. Dispersive and nondispersive charge transport in a molecularly doped polymer with superimposed energetic and positional disorder. Phys. Rev. B 47: 4289-4295, 1993.

[143] GAILBERGER, M. \& BÄSSLER, H. dc and transient photoconductivity of poly(2-phenyl-1,4phenylenevinylene). Phys. Rev. B 44: 8643-8651, 1991; HERTEL, D. et al. Charge carrier transport in conjugated polymers. J. Chem. Phys. 110: 9214-9222, 1999; SO, S.K.; TSE, S.C. \& TONG, K.L. Charge Transport and Injection to Phenylamine-Based Hole Transporters for OLEDs Applications. J. Display Tech. 3: 225-232, 2007.

[144] HOPPE, H.; SARICIFTCI, N.S. Morphology of polymer/fullerene bulk heterojunction solar cells. J. Mater. Chem. 16: 45-61, 2006.

[145] MOZER, A.J.et al. Novel Regiospecific MDMO-PPV Copolymer with Improved Charge Transport for Bulk Heterojunction Solar Cells. J. Phys. Chem. B 108: 5235-5242, 2004.

[146] JUŠKA, G. et al. Charge transport at low electric fields in $\pi$-conjugated polymers. Phys. Rev. B 65: 233208, 2002.

[147] DENNLER, G. et al. Charge carrier mobility and lifetime versus composition of conjugated polymer/fullerene bulk-heterojunction solar cells. Org. Electron. 7: 229, 2006.

[148] BLOM, P.W.M.; DE JONG, M.J.M. Electrical characterization of polymer light-emitting diodes. IEEE J. Sel. Top. Quantum Electron. 4: 105-112, 1998.

[149] ARIAS, A.C. et al. Photovoltaic Performance and Morphology of Polyfluorene Blends: A Combined Microscopic and Photovoltaic Investigation. Macromolecules 34: 6005-6013, 2001.

[150] GADISA, A. et al. Correlation between oxidation potential and open-circuit voltage of composite solar cells based on blends of polythiophenes/ fullerene derivative. Appl. Phys. Lett. 84: 1609, 2004. 
[151] MALliARAS, G.G. et al. Nondispersive electron transport in Alq 3 . Appl. Phys. Lett. 79: 2582, 2001.

[152] SHAKED, S. et al. Charge Density and Film Morphology Dependence of Charge Mobility in Polymer FieldEffect Transistors. Adv. Mater. 15: 913-916, 2003.

[153] CHIRVASE, D. et al. Electrical and optical design and characterisation of regioregular poly(3-hexylthiophene2,5diyl)/fullerene-based heterojunction polymer solar cells. Synth. Met. 138: 299-304, 2003.

[154] IEEE Standard Test Methods for the Characterization of Organic Transistors and Materials. IEEE Standards 1620: $1-13,2004$

[155] CHEN, T.-A.; WU, X. \& RIEKE, R.D. Regiocontrolled Synthesis of Poly(3-alkylthiophenes) Mediated by Rieke Zinc: Their Characterization and Solid-state Properties. J. Am. Chem. Soc. 117: 233-244, 1995

[156] NECLIUDOV, P.V. et al. Contact resistance extraction in pentacene thin film transistors. Solid-State Electron. 47: 259-262, 2003.

[157] Chapter 2: Installation. In: Semiconductor Parameter Analyzer. User's Task Guide. Hewlett-Packard Company (Agilent). Third Edition, 1995. p. 2-24-2-34. 